\title{
Long-acting inhaled therapy (beta-agonists, anticholinergics and steroids) for COPD: a network meta-analysis (Review)
}

Kew KM, Dias S, Cates CJ

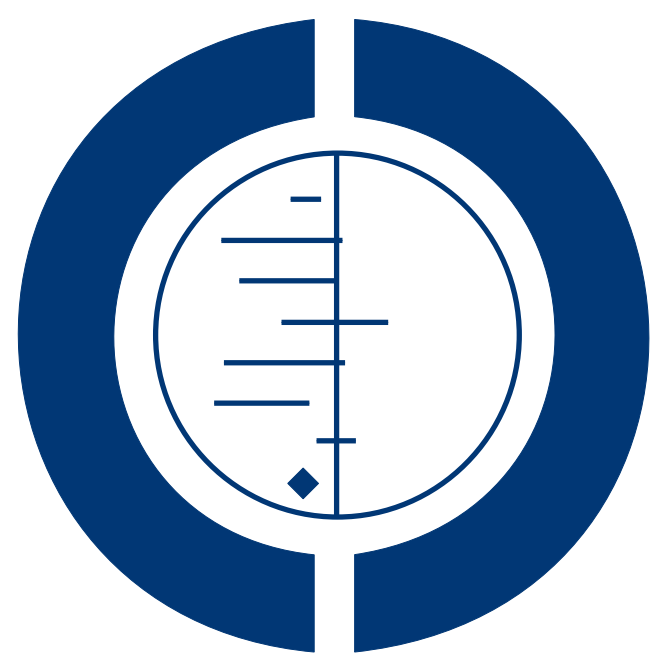

THE COCHRANE

COLLABORATION $^{\circledR}$

This is a reprint of a Cochrane review, prepared and maintained by The Cochrane Collaboration and published in The Cochrane Library 2014, Issue 3

http://www.thecochranelibrary.com

\section{WILEY}

Long-acting inhaled therapy (beta-agonists, anticholinergics and steroids) for COPD: a network meta-analysis (Review)

Copyright $\odot 2014$ The Cochrane Collaboration. Published by John Wiley \& Sons, Ltd. 
TABLE OF CONTENTS

HEADER . . . . . . . . . . . . . . . . . . . . . . . . . . . . . . . . . . . . . . . 1

ABSTRACT . . . . . . . . . . . . . . . . . . . . . . . . . . . . . . . . . . . . . . . 1

PLAIN LANGUAGE SUMMARY . . . . . . . . . . . . . . . . . . . . . . . . . . . . . . . . . . . . . . . . . .

BACKGROUND . . . . . . . . . . . . . . . . . . . . . . . . . . . . . . . . . . . . . . . . 44

OBJECTIVES . . . . . . . . . . . . . . . . . . . . . . . . . . . . . . . . . . . . . . . . . . . . .

METHODS . . . . . . . . . . . . . . . . . . . . . . . . . . . . . . . . . . . . . . 5

RESULTS . . . . . . . . . . . . . . . . . . . . . . . . . . . . . . . . . . . . . . . 8

Figure 1. . . . . . . . . . . . . . . . . . . . . . . . . . . . . . . 9

Figure 2. . . . . . . . . . . . . . . . . . . . . . . . . . . . . . . . . . . . . 13

Figure 3. . . . . . . . . . . . . . . . . . . . . . . . . . . . . . . . . . . . . . 15

Figure 4. . . . . . . . . . . . . . . . . . . . . . . . . . . . . . . . . . . . . . 17

Figure 5. . . . . . . . . . . . . . . . . . . . . . . . . . . . . . . . . . . . . . 18

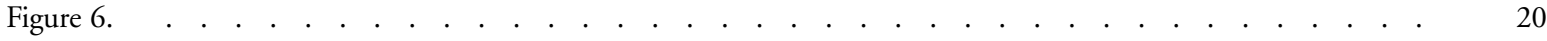

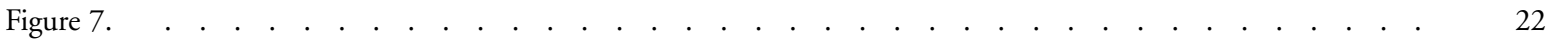

DISCUSSION . . . . . . . . . . . . . . . . . . . . . . . . . . . . . . . . . . 23

AUTHORS' CONCLUSIONS . . . . . . . . . . . . . . . . . . . . . . . . . . . . . . . . . . 25

ACKNOWLEDGEMENTS . . . . . . . . . . . . . . . . . . . . . . . . . . . . . . . . . . . . . . . . .

REFERENCES . . . . . . . . . . . . . . . . . . . . . . . . . . . . . . . . . . . . . . . . . . . .

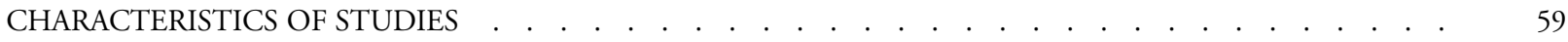

DATA AND ANALYSES . . . . . . . . . . . . . . . . . . . . . . . . . . . . . . . . . . . . . . . . . . . . . . . . . . . .

ADDITIONAL TABLES . . . . . . . . . . . . . . . . . . . . . . . . . . . . . . . . . . . . . . . . . . 168

APPENDICES . . . . . . . . . . . . . . . . . . . . . . . . . . . . . . . . . . . . . 182

CONTRIBUTIONS OF AUTHORS . . . . . . . . . . . . . . . . . . . . . . . . . . . . . . . . . . . 189

DECLARATIONS OF INTEREST . . . . . . . . . . . . . . . . . . . . . . . . . . . . . . . . . . . . . . . . . . . 189

SOURCES OF SUPPORT . . . . . . . . . . . . . . . . . . . . . . . . . . . . . . . . . . . . . . . . 189

DIFFERENCES BETWEEN PROTOCOL AND REVIEW . . . . . . . . . . . . . . . . . . . . . . . . . . . 190

INDEX TERMS . . . . . . . . . . . . . . . . . . . . . . . . . . . . . . . . . . . . . 190 


\title{
[Intervention Review]
}

\section{Long-acting inhaled therapy (beta-agonists, anticholinergics and steroids) for COPD: a network meta-analysis}

\author{
Kayleigh M Kew ${ }^{1}$, Sofia Dias ${ }^{2}$, Christopher J Cates ${ }^{1}$ \\ ${ }^{1}$ Population Health Research Institute, St George's, University of London, London, UK. ${ }^{2}$ School of Social and Community Medicine, \\ University of Bristol, Bristol, UK \\ Contact address: Kayleigh M Kew, Population Health Research Institute, St George’s, University of London, Cranmer Terrace, London, \\ SW17 0RE, UK. kkew@sgul.ac.uk. \\ Editorial group: Cochrane Airways Group. \\ Publication status and date: New, published in Issue 3, 2014. \\ Review content assessed as up-to-date: 5 September 2013.
}

Citation: Kew KM, Dias S, Cates CJ. Long-acting inhaled therapy (beta-agonists, anticholinergics and steroids) for COPD: a network meta-analysis. Cochrane Database of Systematic Reviews 2014, Issue 3. Art. No.: CD010844. DOI: 10.1002/14651858.CD010844.pub2.

Copyright (C) 2014 The Cochrane Collaboration. Published by John Wiley \& Sons, Ltd.

\begin{abstract}
A B S T R A C T
Background

Pharmacological therapy for chronic obstructive pulmonary disease (COPD) is aimed at relieving symptoms, improving quality of life and preventing or treating exacerbations.

Treatment tends to begin with one inhaler, and additional therapies are introduced as necessary. For persistent or worsening symptoms, long-acting inhaled therapies taken once or twice daily are preferred over short-acting inhalers. Several Cochrane reviews have looked at the risks and benefits of specific long-acting inhaled therapies compared with placebo or other treatments. However for patients and clinicians, it is important to understand the merits of these treatments relative to each other, and whether a particular class of inhaled therapies is more beneficial than the others.
\end{abstract}

\section{Objectives}

To assess the efficacy of treatment options for patients whose chronic obstructive pulmonary disease cannot be controlled by shortacting therapies alone. The review will not look at combination therapies usually considered later in the course of the disease.

As part of this network meta-analysis, we will address the following issues.

1. How does long-term efficacy compare between different pharmacological treatments for COPD?

2. Are there limitations in the current evidence base that may compromise the conclusions drawn by this network meta-analysis? If so, what are the implications for future research?

\section{Search methods}

We identified randomised controlled trials (RCTs) in existing Cochrane reviews by searching the Cochrane Database of Systematic Reviews (CDSR). In addition, we ran a comprehensive citation search on the Cochrane Airways Group Register of trials (CAGR) and checked manufacturer websites and reference lists of other reviews. The most recent searches were conducted in September 2013.

Long-acting inhaled therapy (beta-agonists, anticholinergics and steroids) for COPD: a network meta-analysis (Review)

Copyright @ 2014 The Cochrane Collaboration. Published by John Wiley \& Sons, Ltd. 


\section{Selection criteria}

We included parallel-group RCTs of at least 6 months' duration recruiting people with COPD. Studies were included if they compared any of the following treatments versus any other: long-acting beta 2 -agonists (LABAs; formoterol, indacaterol, salmeterol); long-acting muscarinic antagonists (LAMAs; aclidinium, glycopyrronium, tiotropium); inhaled corticosteroids (ICSs; budesonide, fluticasone, mometasone); combination long-acting beta 2 -agonist (LABA) and inhaled corticosteroid (LABA/ICS) (formoterol/budesonide, formoterol/mometasone, salmeterol/fluticasone); and placebo.

\section{Data collection and analysis}

We conducted a network meta-analysis using Markov chain Monte Carlo methods for two efficacy outcomes: St George's Respiratory Questionnaire (SGRQ) total score and trough forced expiratory volume in one second $\left(\mathrm{FEV}_{1}\right)$. We modelled the relative effectiveness of any two treatments as a function of each treatment relative to the reference treatment (placebo). We assumed that treatment effects were similar within treatment classes (LAMA, LABA, ICS, LABA/ICS). We present estimates of class effects, variability between treatments within each class and individual treatment effects compared with every other.

To justify the analyses, we assessed the trials for clinical and methodological transitivity across comparisons. We tested the robustness of our analyses by performing sensitivity analyses for lack of blinding and by considering six- and 12-month data separately.

\section{Main results}

We identified 71 RCTs randomly assigning 73,062 people with COPD to 184 treatment arms of interest. Trials were similar with regards to methodology, inclusion and exclusion criteria and key baseline characteristics. Participants were more often male, aged in their mid sixties, with $\mathrm{FEV}_{1}$ predicted normal between $40 \%$ and $50 \%$ and with substantial smoking histories (40+ pack-years). The risk of bias was generally low, although missing information made it hard to judge risk of selection bias and selective outcome reporting. Fixed effects were used for SGRQ analyses, and random effects for Trough FEV 1 analyses, based on model fit statistics and deviance information criteria (DIC).

\section{SGRQ}

SGRQ data were available in 42 studies ( $\mathrm{n}=54,613)$. At six months, 39 pairwise comparisons were made between 18 treatments in 25 studies $(\mathrm{n}=27,024)$. Combination LABA/ICS was the highest ranked intervention, with a mean improvement over placebo of -3.89 units at six months $(95 \%$ credible interval $(\mathrm{CrI})-4.70$ to -2.97$)$ and -3.60 at 12 months $(95 \% \mathrm{CrI}-4.63$ to -2.34$)$. LAMAs and LABAs were ranked second and third at six months, with mean differences of -2.63 (95\% CrI -3.53 to -1.97$)$ and -2.29 (95\% CrI -3.18 to 1.53), respectively. Inhaled corticosteroids were ranked fourth (MD -2.00, 95\% CrI -3.06 to -0.87). Class differences between LABA, LAMA and ICS were less prominent at 12 months. Indacaterol and aclidinium were ranked somewhat higher than other members of their classes, and formoterol $12 \mathrm{mcg}$, budesonide $400 \mathrm{mcg}$ and formoterol/mometasone combination were ranked lower within their classes. There was considerable overlap in credible intervals and rankings for both classes and individual treatments.

\section{Trough FEV $_{1}$}

Trough $\mathrm{FEV}_{1}$ data were available in 46 studies $(\mathrm{n}=47,409)$. At six months, 41 pairwise comparisons were made between 20 treatments in 31 studies $(n=29,271)$. As for SGRQ, combination LABA/ICS was the highest ranked class, with a mean improvement over placebo of $133.3 \mathrm{~mL}$ at six months (95\% CrI 100.6 to 164.0) and slightly less at 12 months (mean difference (MD) $100,95 \%$ CrI 55.5 to 140.1). LAMAs (MD 103.5, 95\% CrI 81.8 to 124.9) and LABAs (MD 99.4, 95\% CrI 72.0 to 127.8) showed roughly equivalent results at six months, and ICSs were the fourth ranked class (MD 65.4, 95\% CrI 33.1 to 96.9). As with SGRQ, initial differences between classes were not so prominent at 12 months. Indacaterol and salmeterol/fluticasone were ranked slightly better than others in their class, and formoterol 12, aclidinium, budesonide and formoterol/budesonide combination were ranked lower within their classes. All credible intervals for individual rankings were wide.

\section{Authors' conclusions}

This network meta-analysis compares four different classes of long-acting inhalers for people with COPD who need more than shortacting bronchodilators. Quality of life and lung function were improved most on combination inhalers (LABA and ICS) and least on ICS alone at 6 and at 12 months. Overall LAMA and LABA inhalers had similar effects, particularly at 12 months. The network has demonstrated the benefit of ICS when added to LABA for these outcomes in participants who largely had an FEV F $_{1}$ that was less than $50 \%$ predicted, but the additional expense of combination inhalers and any potential for increased adverse events (which has been established by other reviews) require consideration. Our findings are in keeping with current National Institute for Health and Care Excellence (NICE) guidelines.

Long-acting inhaled therapy (beta-agonists, anticholinergics and steroids) for COPD: a network meta-analysis (Review)

Copyright @ 2014 The Cochrane Collaboration. Published by John Wiley \& Sons, Ltd. 


\section{PLAIN LANGUAGE SUMMARY}

Which long-acting inhaled drugs, used alone or in combination, are the most effective for people with COPD?

\section{Why is this question important?}

Inhaled drugs for COPD have been shown to relieve symptoms, improve quality of life and prevent or treat flare-ups. Treatment with these inhaled drugs tends to begin with one inhaler, and additional therapies are introduced as necessary. For persistent or worsening symptoms, long-acting inhaled drugs taken once or twice daily are preferred over short-acting ones. Several Cochrane reviews have looked at the risks and benefits of specific long-acting inhaled therapies compared with placebo or other treatments. However for patients and clinicians, it is important to understand the benefits of these treatments relative to each other, and whether a particular type of inhaled therapy is more beneficial than the others.

\section{How did we answer the question?}

We looked for studies in existing Cochrane reviews and performed detailed electronic searches up to September 2013. Studies were included if they lasted at least six months and compared any of the following treatments versus any other for people with COPD: long-

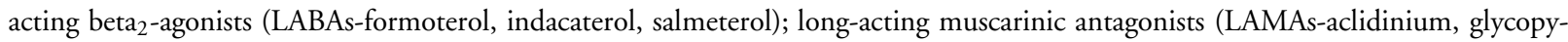
rronium, tiotropium); inhaled corticosteroids (ICSs-budesonide, fluticasone, mometasone); combination long-acting beta 2 -agonist and inhaled corticosteroid (LABA/ICS-formoterol/budesonide, formoterol/mometasone, salmeterol/fluticasone); and placebo.

We conducted a network meta-analysis to assess the benefits of each type of treatment (e.g. long-acting beta 2 -agonists) relative to the others for quality of life and lung function. We also looked at how much individual treatments varied (e.g. How different were the three inhaled steroids from one other?) and whether particular treatments were more effective than others. We assessed the data for six months and 12 months separately and reported six months as the primary findings.

\section{What did we find?}

We found 71 relevant studies, but not all measured the outcomes we were interested in. Forty-two studies were included in the quality of life analyses (measured on St George's Respiratory Questionnaire), and 46 were included in the lung function analyses.

Evidence from good quality and similar trials supported LABA/ICS combinations as the most likely treatment strategy to bring the greatest improvement to quality of life and lung function. Combination therapy gave an average benefit of 3.9 units over placebo at six months. LAMAs and LABAs were ranked second and third at six months $(-2.63$ and -2.29 units, respectively), especially when unreliable trials were not included, but a large degree of overlap in the estimates was noted.

Combination LABA/ICS was the highest ranked class for trough forced expiratory volume in one second $\left(\mathrm{FEV}_{1}\right)$, with mean improvement over placebo of $133 \mathrm{~mL}$ at six months (95\% credible Interval (CrI) 101 to 164). As was the case for SGRQ, LAMAs (mean difference (MD) 104, 95\% CrI 82 to 125) were ranked just ahead of LABAs (MD 99, 95\% CrI 72 to 128) at six months, and ICSs were the lowest ranked class (MD 65, 95\% CrI 33 to 97).

For both outcomes, the effects of LABA and ICS used alone appeared to increase when used together for six months, but initial differences between the treatment classes were less obvious after a year of treatment.

\section{Conclusion}

Quality of life and lung function were improved most on combination inhalers (LABA and ICS) and least on ICS alone at 6 and 12 months. Overall LAMA and LABA inhalers had similar effects, particularly at 12 months. The network has demonstrated the benefit of ICS when added to LABA for these outcomes in participants who largely had an FEV 1 that was less than 50\% predicted, but the additional expense of combination inhalers and any potential for increased adverse events (which has been shown by other reviews) require consideration. Our findings are in keeping with current National Institute for Health and Care Excellence (NICE) guidelines.

Long-acting inhaled therapy (beta-agonists, anticholinergics and steroids) for COPD: a network meta-analysis (Review) 


\section{B A C K G R O U N D}

\section{Description of the condition}

Chronic obstructive pulmonary disease (COPD) is a respiratory disease characterised by chronic and progressive breathlessness, cough, sputum production and airflow obstruction, all of which lead to restricted activity and poor quality of life (GOLD). The World Health Organization (WHO) has estimated that COPD is the fourth or fifth most common single cause of death worldwide, and the treatment and management costs present a significant burden to public health. In the UK, the annual cost of COPD to the National Health Service (NHS) is estimated to be $£ 1.3$ million per 100,000 people (NICE 2011). Furthermore, because of slow onset and under-recognition of the disease, it is heavily under-diagnosed (GOLD). COPD comprises a combination of bronchitis and emphysema and involves chronic inflammation and structural changes in the lung. Cigarette smoking is the most important risk factor; however, air pollution and occupational dust and chemicals can also increase the risk of developing the disease. COPD is a progressive disease that leads to decreased lung function over time, even with the best available care. Currently no cure for COPD is known, although it is both preventable and treatable. Management of the disease is multifaceted and includes interventions for smoking cessation (van der Meer 2001), pharmacological treatments (GOLD), education (Effing 2007) and pulmonary rehabilitation (Lacasse 2006; Puhan 2011). Pharmacological therapy is aimed at relieving symptoms, improving exercise tolerance and quality of life, slowing decline and even improving lung function and preventing and treating exacerbations. COPD exacerbations impair patients' quality of life (GOLD), and a large part of the economic burden of COPD is attributed to the cost of managing exacerbations, particularly those resulting in use of acute care services or hospitalisation (Hutchinson 2010). In the UK, one in eight emergency admissions to hospital is for COPD, and it is one of the most costly conditions treated by the NHS (NICE 2011). Appropriate pharmacological management of the disease is therefore important, particularly for reducing and preventing exacerbations.

\section{Description of the interventions}

Pharmacological management of COPD tends to begin with one treatment, and additional therapies are introduced as necessary to control symptoms and reduce the frequency and severity of exacerbations (GOLD). The first step is often a short-acting bronchodilator for control of breathlessness when needed: either a short-acting beta 2 -agonist (SABA; e.g. salbutamol) or the short-acting muscarinic antagonist (SAMA) ipratropium. Both bronchodilators have a duration of action of four to six hours (Beeh 2010), and they improve lung function and breathlessness
(Appleton 2006; Sestini 2009). For persistent or worsening breathlessness associated with lung function decline, long-acting bronchodilators may be introduced (GOLD). These comprise longacting beta 2 -agonists, such as salmeterol or formoterol (LABAs; duration of action 12 hours) and indacaterol (duration of action 24 hours), and long-acting anticholinergic agents, such as tiotropium (duration of action 24 hours) and more recently aclidinium bromide and glycopyrronium bromide. Regular treatment with longacting bronchodilators is preferred over treatment with regular short-acting bronchodilators on the basis of efficacy and adverse effects (Beeh 2010; GOLD). An alternative when bronchodilators are not available or affordable is theophylline, an oral phosphodiesterase (PDE) inhibitor. However, theophylline is less effective and is less well tolerated than inhaled long-acting bronchodilators. For patients with severe or very severe COPD (forced expiratory volume in one second $\left(\mathrm{FEV}_{1}\right)<50 \%$ predicted) with repeated exacerbations, GOLD recommends the addition of inhaled corticosteroids (ICSs) to bronchodilator treatment. ICSs are anti-inflammatory drugs that are licensed as combination inhalers with LABAs. The most common combinations of ICS and LABA in combination inhalers are fluticasone and salmeterol, and budesonide and formoterol. The most severely ill group of patients with advanced COPD may also benefit from treatment with the $\mathrm{PDE}_{4}$ inhibitor roflumilast, which may reduce the risk of exacerbations (GOLD), alongside other beta 2 -agonists or anticholinergic agents and ICS, but these combinations are not considered in this review.

\section{How the interventions might work}

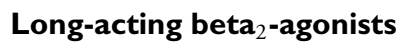

Inhaled long-acting beta 2 -agonists (LABAs) activate beta 2 -receptors in the smooth muscle of the airway, leading to a cascade of reactions that result in bronchodilation. Commonly used LABAs include salmeterol, formoterol and indacaterol. The duration of action for salmeterol and formoterol is approximately 12 hours; therefore they are usually taken twice daily. Indacaterol has a duration of action of 24 hours and therefore can be taken once daily. As with long-acting muscarinic antagonists (LAMAs), LABAs are commonly used to control symptoms and reduce exacerbations in stable COPD (Moen 2010; Rodrigo 2008). Possible side effects of LABAs include cardiac effects such as arrhythmia and palpitations, muscle tremors, headache and dry mouth (Berger 2008).

\section{Inhaled corticosteroids}

Inhaled corticosteroids (ICSs) are anti-inflammatory drugs. ICSs are licensed as combination inhalers with LABA. The most common combinations of ICS and LABA in combination inhalers are fluticasone and salmeterol, and budesonide and formoterol. Combination inhalers have similar effects to LABA alone, reducing exacerbation rates and improving patients' quality of life. However, 
some have argued that the difference is small (Rodrigo 2009), and ICS therapy, alone or in combination with beta 2 -agonists, is associated with increased risk of pneumonia and osteoporotic fracture (GOLD; Loke 2011; Singh 2010).

\section{Long-acting muscarinic antagonists}

Long-acting muscarinic antagonists (LAMAs) are anticholinergic agents that block the action of the neurotransmitter acetylcholine. The LAMA tiotropium has gained widespread acceptance as oncedaily maintenance therapy in stable COPD for its effects on symptoms and exacerbations (Barr 2005; GOLD). Two newer LAMAs that can be taken once daily-aclidinium bromide and glycopyrronium bromide-have recently been licensed for the maintenance treatment of people with COPD. Anticholinergic adverse effects that may occur include dry mouth, constipation and tachycardia (Tashkin 2008).

\section{Why it is important to do this review}

Several systematic reviews have looked at the risks and benefits of specific inhaled therapies compared with placebo or other inhaled therapies. However for patients or for clinicians facing patients, the question is often this: Which of the long-acting therapy options is the most beneficial treatment option for patients no longer obtaining symptom relief from short-acting therapies, but for whom $\mathrm{PDE}_{4}$ inhibitors or other additional therapies are not yet necessary? Two recent network meta-analyses have focused primarily on safety outcomes (Decramer 2013; Dong 2013).

\section{O B JECT IVES}

To assess the efficacy of treatment options for patients whose chronic obstructive pulmonary disease cannot be controlled by short-acting therapies alone. The review will not look at combination therapies usually considered later in the course of the disease.

As part of this network meta-analysis, we will address the following issues:

1. How does long-term efficacy compare between different pharmacological treatments for COPD?

2. Are there limitations in the current evidence base that may compromise the conclusions drawn by this network metaanalysis? If so, what are the implications for future research?

\section{METHODS}

\section{Criteria for considering studies for this review}

\section{Types of studies}

We included randomised control trials (RCTs) with a parallelgroup design of at least 24 weeks' duration. Cross-over trials were not included, as the pharmaceutical treatments under study can have long-acting effects.

\section{Types of participants}

We included RCTs that recruited participants with a clinical diagnosis of COPD, such as ATS/ERS 2004. We looked for the following inclusion criteria.

1. Forced expiratory volume in one second $\left(\mathrm{FEV}_{1}\right) /$ forced vital capacity (FVC) ratio $<0.7$, which confirms the presence of persistent airflow limitation.

2. One or more of the following key indicators.

i) Progressive and/or persistent dyspnoea.

ii) Chronic cough.

iii) Chronic sputum production.

iv) History of exposure to risk factors (tobacco smoke, smoke from home cooking and heating fuels, occupational dusts and chemicals).

\section{Types of interventions}

We included studies that compared any of the following therapies versus any other.

1. LABA (formoterol, salmeterol, indacaterol).

2. LAMA (tiotropium, aclidinium bromide, glycopyrronium bromide).

3. ICS (budesonide, fluticasone, mometasone).

4. LABA/ICS combination (formoterol/budesonide, formoterol/mometasone, salmeterol/fluticasone).

5. Placebo.

Treatment classes and individual treatments were compared versus every other using a class-model network meta-analysis. The list of included treatments comprised commonly used agents within each class.

Participants were allowed other concomitant COPD medications as prescribed by their healthcare practitioner, provided these medications were not part of the trial treatment under study.

\section{Types of outcome measures}

For studies of six months' duration, we used end of study as time of analysis for all outcomes. For longer studies, we extracted data reported at six-month and 12-month intervals when available. Two measures of efficacy were chosen as outcomes because previous network meta-analyses have primarily assessed safety outcomes (mortality, Dong 2013; exacerbations and adverse events, Decramer 2013).

Long-acting inhaled therapy (beta-agonists, anticholinergics and steroids) for COPD: a network meta-analysis (Review) 


\section{Primary outcomes}

1. Quality of life (measured as change from baseline assessed with St George's Respiratory Questionnaire (SGRQ)).

2. Trough $\mathrm{FEV}_{1}$ (change in $\mathrm{mL}$ from baseline).

\section{Cost-effectiveness}

We did not carry out a formal cost-effectiveness analysis, but we sought to identify economic evaluations that have compared the included interventions to supplement the main systematic review of effects. These are summarised in a short commentary in the discussion.

\section{Search methods for identification of studies}

\section{Electronic searches}

To avoid duplication of effort, we first identified RCTs for inclusion by searching for relevant Cochrane systematic reviews. Cochrane systematic reviews use extensive search strategies that include several databases, manufacturers' websites and handsearching of conference abstracts. We searched the Cochrane Database of Systematic Reviews (CDSR) in The Cochrane Library (2013, Issue 7) to look for all Cochrane systematic reviews on COPD, using the search strategy provided in Appendix 1, and from those, we handpicked the reviews that included relevant comparisons. From these reviews, we identified individual RCTs that met our inclusion criteria.

In addition, we ran a search on the Cochrane Airways Group Register (CAGR) of trials (see Appendix 2 for details of the Register) to find studies that may have been missed in the review search (e.g. because of discrepancies in inclusion criteria between individual reviews and this network, as a result of review searches more than 12 months out of date or when no reviews existed for a particular comparison). The search was done according to guidance provided in the Cochrane Handbook for Systematic Reviews of Interventions (Higgins 2011) and in consultation with an information specialist (see Appendix 3 for the search strategy). No date or language restrictions were applied. We searched NHS Economic Evaluation Database (EED) and Health Economic Evaluations Database (HEED) for economic evaluations using the strategy provided in Appendix 1, adapted as appropriate.

\section{Data collection and analysis}

\section{Selection of studies}

One review author assessed for inclusion all potentially eligible reviews retrieved through the search and assessed all potentially eligible RCTs within these reviews (KMK). The CAGR database search was sifted by the same review author, and uncertainties were resolved by discussion with a second review author (CJC).

\section{Data extraction and management}

For the following characteristics, one review author extracted information for all included RCTs from their published reports (KMK) if they were already included in a Cochrane review.

1. Individual trial study characteristics (design, duration, location, participant inclusion/exclusion criteria, funding).

2. Trial arms of interest (drug, dose, inhaler type, allowed comedications).

3. Individual trial population details: mean baseline lung function, pack-years, age and \% male.

4. Individual trial outcome data.

Information from studies identified in other reviews was subsequently cross-checked (data in each of the existing reviews were extracted and verified by at least two review authors). Inconsistencies and uncertainties were resolved by consultation with a second review author (CJC).

\section{Assessing transitivity (similarity of participants, interventions and trial methodology)}

The sets of trials for each treatment must be similar in their distribution of effect modifiers to permit conclusions based on a network meta-analysis combining direct and indirect evidence (Cipriani 2013). We constructed summary tables organised by class pair-wise comparisons (e.g. LABA vs ICS, LAMA vs placebo) to assess clinical and methodological similarities of the trials and their populations.

\section{Assessment of risk of bias in included studies}

Although existing reviews were used to identify RCTs, data and methodological quality were dealt with at an individual trial level. One review author extracted information related to risk of bias for all trials and subsequently cross-checked judgements from existing reviews, standardising ratings across them for consistency. Judgements were made for the following domains in each study in accordance with recommendations provided in Chapter 8 of the Cochrane Handbook for Systematic Reviews of Interventions (Higgins 2012).

1. Random sequence generation (selection bias).

2. Allocation concealment (selection bias).

3. Blinding (performance bias and detection bias).

4. Incomplete outcome data (attrition bias).

5. Selective reporting.

We did not exclude trials on the basis of risk of bias but conducted sensitivity analyses to explore the effects of including unblinded study comparisons. 


\section{Measures of treatment effect}

\section{Direct pairwise meta-analysis}

We analysed data for the two continuous outcomes as fixed-effect mean differences (MDs) with 95\% confidence intervals (CIs) and a fixed-effect model. The fixed-effect model assumes that each study is estimating exactly the same intervention effect, and the random-effects model assumes that estimated intervention effects are not all the same but follow a normal distribution across studies. Data were extracted and analysed as change from baseline in all studies, and this was extracted from text or tables or was calculated from figures when necessary. Associated variance for change per arm was not always available (or could not be derived from the presented information), and in these cases we used available data from other trials to estimate a population variance. For SGRQ and trough $\mathrm{FEV}_{1}$, we calculated the mean of available standard deviations (SDs) for change scores, which was weighted by sample size.

\section{Network meta-analysis}

We conducted a network meta-analysis (NMA) to estimate the effect for each class and for each individual intervention using Markov chain Monte Carlo methods implemented in WinBUGS 1.4.3. Analyses were based on a class model, which assumes that effects of individual treatments within a class are exchangeable and are distributed around a class mean (Cooper 2009). Correlations in multiarm trials were accounted for in the model, which was adapted from Dias 2013. Non-informative normal priors were used for class effects, and Uniform $(0,5)$ and $(0,100)$ prior distributions were used for between-trials and between-classes heterogeneity SDs for SGRQ and $\mathrm{FEV}_{1}$, respectively. Three chains with different initial values were run simultaneously to assess convergence using Brooks-Gelman-Rubin diagnostic plots. The first 20,000 (fixed-effect models) or 40,000 iterations (random-effects models) were discarded, and 50,000 further iterations were run, on which all estimates are based. We decided whether to use a fixed-effect or a random-effects approach on the basis of model fit statistics and deviance information criteria (DIC) (Dias 2013; Spiegelhalter 2002), as well as the amount of heterogeneity present in the pair-wise meta-analyses. The model with lower values on the DIC was preferred, with differences of three or more units considered meaningful. If two models had similar DIC, the simplest model (i.e. fixed-effect) was preferred.

\section{Unit of analysis issues}

No unit of analysis issues were noted, as we did not analyse any dichotomous data.

\section{Dealing with missing data}

When data or study characteristics were not reported in the primary publication, we searched clinical trial reports, trial registries and drug company websites to look for additional data. When possible, we used data from intention-to-treat (ITT) analyses from all randomly assigned participants.

\section{Assessment of heterogeneity}

In the presence of statistical heterogeneity $\left(\mathrm{I}^{2}>30 \%\right)$ in the direct pair-wise meta-analysis, we analysed data using a random-effects model and investigated possible sources. They could be of a clinical and methodological nature (i.e. differences between individual studies) in study design (inclusion/exclusion criteria, study duration), participants' baseline characteristics (disease severity, comorbidities, age, gender), risk of bias (open vs blinded studies) or study sponsorship. The extent of heterogeneity observed informed our decision of whether to use fixed-effect or random-effects models for the network meta-analysis.

For the network meta-analysis, we assessed the extent to which direct evidence and indirect evidence were consistent both qualitatively and statistically (Dias 2013a; Lu 2006). Consistency refers to the agreement between direct and one or more indirect sources of evidence in a "closed loop" of trials (i.e. a path by which three or more trials are connected, starting and ending with the same node) (Lu 2006). We assessed consistency by comparing model fit from a consistency and 'independent mean effects' model and by informally comparing output from the NMA versus estimates from the pair-wise meta-analyses. We used this global test to determine the presence of inconsistency and to locate areas in the network at which large inconsistencies were present. The output from the network meta-analysis was informally compared with estimates from the pair-wise meta-analyses to check for broad agreement. When evidence of inconsistency was found, we further investigated potential sources of inconsistency using the node-split approach (Dias 2010), as this was most appropriate given the structure of the networks. In cases in which substantial inconsistency was identified, we explored factors, including participant and design characteristics, that might contribute to inconsistency, and we restricted our analysis to a subset of trials for which the evidence might be more comparable.

\section{Assessment of reporting biases}

We tried to minimise reporting bias from non-publication of studies or selective outcome reporting by using a broad search strategy, and by checking references of included studies and relevant systematic reviews. For each outcome, we commented on the proportion of studies contributing data to the analysis.

\section{Data synthesis}

Long-acting inhaled therapy (beta-agonists, anticholinergics and steroids) for COPD: a network meta-analysis (Review) 
Using a class-model network meta-analysis, we modelled the relative effectiveness of any two classes as a function of each class relative to a reference treatment (placebo). We prespecified five unique classes of interventions (or nodes) in the network: LABA (salmeterol, formoterol and indacaterol), LAMA (tiotropium, aclidinium bromide and glycopyrronium bromide), ICS (fluticasone, budesonide and mometasone), LABA/ICS (salmeterol/fluticasone, formoterol/budesonide and formoterol/mometasone) and placebo. We estimated the probability that each class ranks at one of the five possible positions (e.g. the best, second best, third best). We obtained estimates of each overall class effect, as well as of the effects of each treatment within the class compared with every other. Estimates for within-class variability in treatment effects, as well as for between-class variability in treatment effects, are presented, as are ranking probabilities, in tables and figures as appropriate.

\section{Subgroup analysis and investigation of heterogeneity}

We planned to perform subgroup analyses based on baseline disease severity and dose, provided that treatments could be compared indirectly with other trial comparisons through one or more common comparators (i.e. the networks remained 'connected'). However, differences in individual doses were built into the network structure, and baseline disease severity was assessed across nodes as part of the transitivity assessment.

For the network meta-analysis, available data were insufficient to include baseline severity as a co-variate as a way of exploring subgroup effects. We extracted key severity criteria for each trial in- dividually, and we summarised the data across pair-wise comparisons to investigate potential differences.

\section{Sensitivity analysis}

We assessed the robustness of our analyses by performing sensitivity analyses, excluding studies from the overall analysis of high risk of bias due to lack of blinding (participants and personnel and/or outcome assessors), and by considering separately studies of different duration.

\section{R E S U L T S}

\section{Description of studies}

Basic study characteristics, including duration, intervention details and population characteristics, are summarised in Table 1, and full details of each included study can be found in Characteristics of included studies.

\section{Results of the search}

Results of the search are presented in Figure 1, broken down by the search for Cochrane reviews on the left and the electronic database search on the right. 
Figure I. Study flow diagram.aAll 58 studies identified in the review search were also identified in the electronic database search.Abbreviations: CDSR = Cochrane Database of Systematic Reviews.

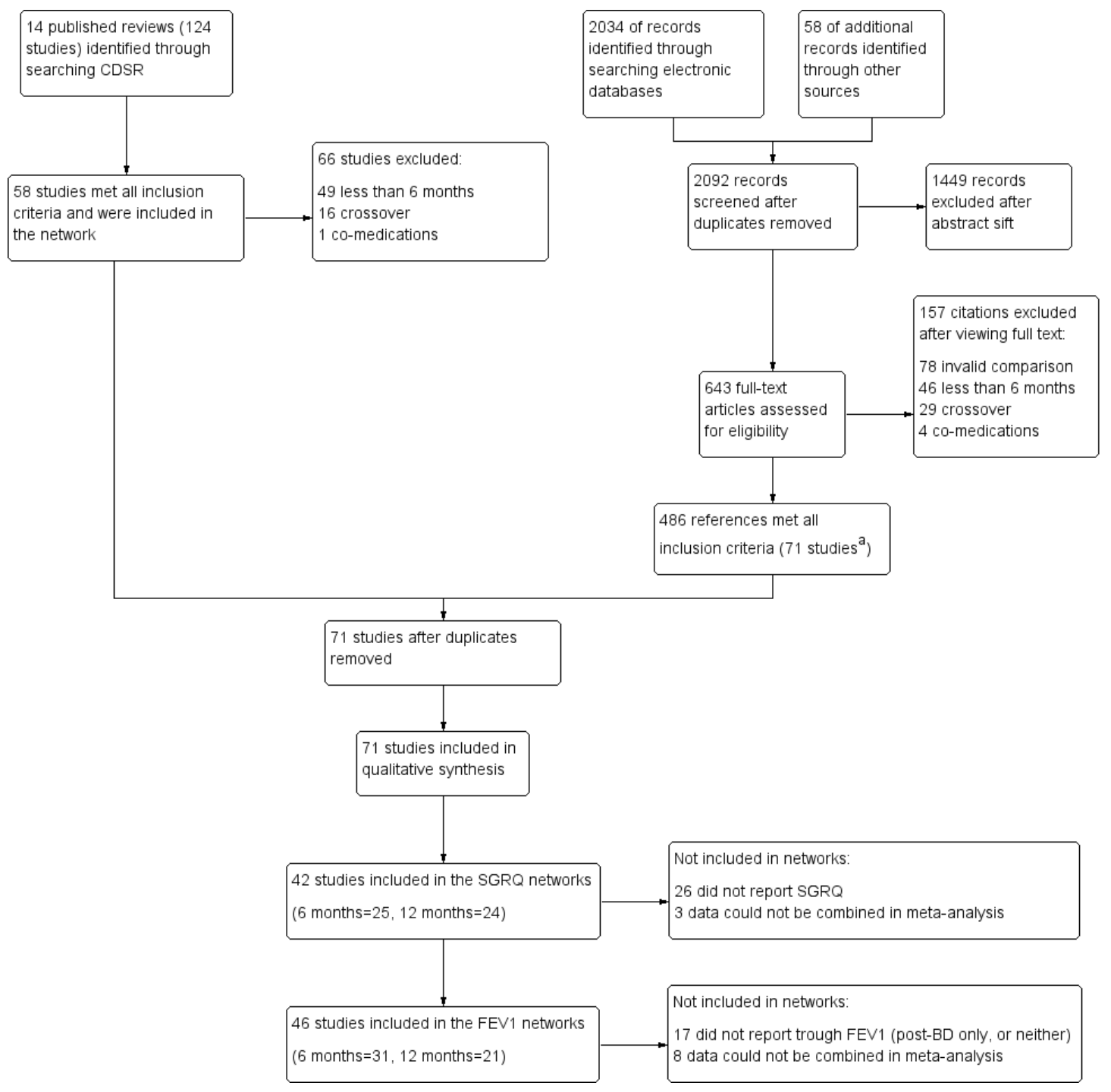

Fourteen relevant Cochrane reviews were identified (Chong 2012; Geake 2012; Karner 2011; Karner 2011a; Karner 2012; Karner 2012a; Kew 2013; Kew 2014; Nannini 2012; Nannini 2013; Nannini 2013a; Spencer 2011; Welsh 2013; Yang 2012a), including a total of 124 studies. Sixty-six studies were excluded because of differences in the reviews' inclusion criteria, most commonly, 'duration less than six months' $(\mathrm{n}=49)$, and 'cross-over design' ( $\mathrm{n}$ = 16). The remaining 58 studies were included in the review.

Searching the CAGR of trials returned 2034 references, and 58 additional references were identified by searching reference lists and drug company websites. We excluded 1449 references after sifting titles and abstracts, and we reviewed full texts after studification for the remaining 643 . Four hundred eighty-six references met all inclusion criteria, most of which related to the 58 studies identified from the review search. The remaining references were collated into 13 additional studies that met the inclusion criteria. The most common reasons for excluding citations after viewing full texts were 'invalid comparison for this review' ( $\mathrm{n}=78$ ), 'duration less than six months' $(\mathrm{n}=46)$ and 'cross-over design' $(\mathrm{n}=$ 29). 


\section{Included studies}

Seventy-one studies met the inclusion criteria, randomly assigning 73,062 people with a diagnosis of COPD to 184 treatment arms of interest (including placebo). The number of participants included in the trials ranged from 18 (Dal Negro 2003) to 7384 (Vogelmeier 2011 [POET]); the mean number per arm of a trial was 397. Table 1 lists all 71 studies that met the inclusion criteria, along with their total duration, treatment arms relevant to the network and summary characteristics for each study population. Table 2 and Table 3 present pooled characteristics for each class and for individual nodes within them for studies contributing data to the SGRQ and trough $\mathrm{FEV}_{1}$ data sets, respectively.

\section{Design and duration}

All of the studies were parallel-group, randomised controlled trials, and most were conducted at multiple centres in several countries. A vast majority were double-blind; five included one open-label treatment (see sensitivity analyses), a subset were double-blind and double-dummy and blinding was unclear in four others.

All studies had a randomly assigned treatment period of at least 24 weeks. Similar numbers of six-month and 12-month studies were identified ( $n=30$ and $n=29$, respectively), but six-month data were available in a number of the longer trials. Twelve studies lasted between two and four years (Burge 2000 [ISOLDE]; Calverley 2007 [TORCH]; Cooper 2010; Lapperre 2009; Pauwels 1999; Renkema 1996; Schermer 2009; SCO40041; Shaker 2009; Tashkin 2008a [UPLIFT]; Vestbo 1999; Wedzicha 2008 [INSPIRE]). For these studies, we used data measured and reported for six and 12 months in the NMA, rather than endpoint. Data entered in the six-month analysis were reported between 24 and 32 weeks, and data included in the 12-month networks were measured between 44 and 56 weeks in the individual studies.

\section{Participant inclusion and exclusion criteria}

The trials were relatively consistent in their key inclusion and exclusion criteria. All studies required a clinical diagnosis of COPD, and most specified that this was in accordance with recent guidelines (usually ATS/ERS 2004 or GOLD). The cutoff for forced expiratory volume in one second $\left(\mathrm{FEV}_{1}\right)$ expressed as the percentage predicted normal value ranged from $50 \%$ to $80 \%$. Additional inclusion criteria that were common across trials were these: smokers or ex-smokers with a smoking history of at least 10 pack-years, 40 years of age or older and $\mathrm{FEV}_{1} / \mathrm{FVC}$ ratio less than $70 \%$.

Exclusion criteria that were common across most trials were these: history of asthma or other respiratory disease, any significant disease other than COPD and the need for supplemental oxygen. Patients who had a COPD exacerbation or upper respiratory tract infection in the run up to screening (usually within four to six weeks) were usually excluded. Trials often listed additional exclusion criteria specific to the drugs under study, such as sensitivities to active ingredients, or medical conditions that might be affected by known adverse effects.

\section{Baseline characteristics of participants in the trials}

Baseline characteristics are presented for all included studies in Table 1, and for the subsets of studies contributing data to the SGRQ and $\mathrm{FEV}_{1}$ analyses in Table 2 and Table 3, respectively. In the SGRQ data set, the overall mean age per class was very similar, ranging from 62.9 to 64.5 years. In the $\mathrm{FEV}_{1}$ data set, the overall mean age for each comparison was also very similar, ranging from 63.3 to 64.3 . Both data sets consistently included more men than women, and the means of trial percentages were similar between and within comparisons (SGRQ range $69.5 \%$ to $82.5 \%, \mathrm{FEV}_{1}$ range $67.1 \%$ to $73.2 \%$ ). As might be expected from variation in inclusion criteria, greater variability was noted in the summary statistics for percentage predicted $\mathrm{FEV}_{1}$, with the LABA versus LAMA comparison having somewhat higher scores in both data sets than the other classes (both means around 55\% compared with $39 \%$ to $47 \%$ in the other comparisons). Overall, most population means for percentage predicted $\mathrm{FEV}_{1}$ were less than $50 \%$ predicted. Mean pack-years were between 40 and 50 for all comparisons in both data sets. In general, the data indicated a fairly consistent moderate to severe population across both outcome data sets and across direct between-class comparisons, which satisfied the transitivity assumption.

\section{Characteristics of the interventions}

Table 4 shows the distribution of treatment arms across all 71 included studies, organised by the five prespecified treatment classes. The text below summarises information about all 71 included studies. Table 2 and Table 3 show the number of studies making each class comparison represented in the SGRQ or $\mathrm{FEV}_{1}$ analyses, respectively.

Lists of allowed co-medications varied between studies, but participants were always allowed a short-acting beta-agonist reliever inhaler and short-term treatment for exacerbations during the randomised period (course of oral corticosteroids or antibiotics).

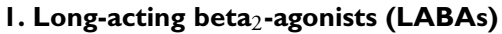

Thirty-seven LABA treatment arms were identified across 30 studies $(\mathrm{n}=15,266)$. Twelve studies included a formoterol arm with treatment given at $12 \mathrm{mcg}$ twice daily, and Rossi 2002 also randomly assigned participants to a higher dose of twice-daily $24 \mathrm{mcg}$. Formoterol was most commonly given via a dry powder inhaler but sometimes via a metered-dose inhaler (to retain blinding in the newer multiarm mometasone studies). Salmeterol was given at $50 \mathrm{mcg}$ twice daily in 17 studies $(\mathrm{n}=9019)$, primarily via the Diskus device. Indacaterol, a once-daily preparation, was given as $150 \mathrm{mcg}$ in three studies (Bateman 2013 [SHINE]; Donohue 2010 [INHANCE]; Kornmann 2011) and as $300 \mathrm{mcg}$ in three 
studies (Dahl 2010; Donohue 2010 [INHANCE]; To 2011), one of which also used a higher dose of $600 \mathrm{mcg}$. Donohue 2010 [INHANCE] was conducted in two stages, and the data derived are for the four randomly assigned groups from stage 2 .

\section{Long-acting muscarinic antagonists (LAMAs)}

Thirty-four LAMA treatment arms were included across 28 studies $(\mathrm{n}=21,805)$. Most studies used tiotropium $18 \mathrm{mcg}$ daily, delivered most often via the HandiHaler. Six studies included two arms that met criteria for inclusion in the LAMA category: Bateman 2010b used two tiotropium doses ( 5 and $10 \mathrm{mcg}$ daily via Respimat), ATTAIN 2011 and Gelb 2012 used two aclidinium doses (200 and 400 mcg daily) and Bateman 2013 [SHINE], GLOW2 2012 and SPARK 2013 included both glycopyrronium $50 \mathrm{mcg}$ and openlabel tiotropium. Two additional glycopyrronium studies used 50 mcg via the Breezhaler, and two other aclidinium studies used the lower of the two doses via the Genuair device. Two other tiotropium studies used the Respimat device to deliver 5 mcg daily (Abrahams 2013 and Bateman 2010a).

\section{Inhaled corticosteroids (ICSs)}

Twenty-seven studies included an ICS arm $(n=6788)$, with two including two doses of the same drug that were relevant to the review (Calverley 2008; FLTA3025). Twelve studies ( $\mathrm{n}=3491$ ) reported a fluticasone arm: two studies used $250 \mathrm{mcg}$ twice daily, and the rest $500 \mathrm{mcg}$, delivered most often via the Diskus device. Twelve studies with around half as many people used budesonide ( $n=1900)$ : two at the higher dose of $800 \mathrm{mcg}$ twice daily, and the rest at $400 \mathrm{mcg}$, with both doses delivered via dry powder inhalers. Mometasone was used in four studies $(\mathrm{n}=1397)$ and was given as $400 \mathrm{mcg}$ twice daily or $800 \mathrm{mcg}$ once daily.

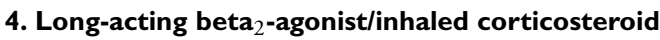 combinations (LABA/ICS)}

Thirty LABA/ICS treatment arms were identified in 25 studies ( $\mathrm{n}=9727$ ). Three studies used two budesonide doses $(160 \mathrm{mcg}$ and 320 mcg; Rennard 2009; Sharafkhaneh 2012; Tashkin 2008 [SHINE]), and seven additional studies used only the higher dose (total $\mathrm{N}=3221$ ). Two identically designed studies included two formoterol/mometasone doses each, 200 and $400 \mathrm{mcg}(\mathrm{n}=888)$. Sixteen studies had a salmeterol/fluticasone arm $(\mathrm{n}=5618)$, six at the lower ICS dose of 50/250 mcg and 11 at the higher dose of 50/500 mcg. All LABA/ICS inhalers were prescribed for twicedaily use and drugs were delivered by dry powder or pressurised metered-dose inhalers.

\section{Placebo}

Most studies included a placebo control arm ( $n=55)$, which consisted of a total of 19,476 people. Inhalers varied across studies depending on the device used to deliver the study drugs. Oncedaily and twice-daily placebos were combined in the same node as the reference treatment to increase the number of comparisons that could be made.

\section{Transitivity (similarity of participants, interventions and trial methodology)}

1. Inclusion and exclusion criteria, as described above, did not vary systematically across classes; although variation in the allowed co-medications and in the maximum allowed percentage predicted $\mathrm{FEV}_{1}$ was noted, these did not translate to systematic differences in the characteristics of the recruited population.

2. Baseline characteristics were varied between individual trials, but summary baseline characteristics were comparable across pair-wise comparisons between classes for both outcome data sets (see above and Table 2; Table 3). Mean percentage predicted $\mathrm{FEV}_{1}$ was somewhat higher in the LABA versus LAMA comparisons conducted in two studies (55\% vs 39\% to $47 \%$ in the other comparisons).

3. Intervention characteristics introduced some potential sources of systematic variation between trials, notably as a result of the devices used and the dosing schedule. However, as all nodes showed variation in the delivery device used and in oncedaily and twice-daily regimens, we did not consider these factors to violate assumptions needed for indirect comparisons. The placebo-controlled trials used matching inhalers to control for bias at a trial level, and variation within classes was similar, so we considered a combined placebo class valid as the reference treatment (regardless of device or dosing regimen).

4. Methodology was similar across trials, and no issues with the comparability of trial duration arose, as we included only data relevant to the time points specified. Funding sources varied across classes, depending on the drug manufacturers, but this variability did not translate into systematic differences in the way that trials were conducted, nor in the populations recruited (i.e. similar inclusion criteria, baseline characteristics and study designs). Average sample size per class was higher in the LAMA trials (659 and 633 for SGRQ and $\mathrm{FEV}_{1}$, respectively) than in the four other classes (range 189 to 471 across both outcome data sets), but variation within the classes was comparable.

\section{Outcomes and analysis structure}

For both outcomes, the overall fit of the network meta-analysis class model was compared with the fit of a class model without the consistency assumption (broadly equivalent to a pair-wise meta-analysis with random class effects), using the total residual deviance. Statistical inconsistency was not significant on SGRQ at 12 months nor on the $\mathrm{FEV}_{1}$ analyses (six and 12 months). However some evidence of inconsistency was noted in the network for SGRQ at six months. This was investigated further us- 
ing the node-split approach (Dias 2010), which found some evidence of inconsistency (P value 0.01 , although multiple comparisons were made) in the direct evidence comparing indacaterol $150 \mathrm{mcg}$ and tiotropium $18 \mathrm{mcg}$. We investigated the possible clinical explanation for this inconsistency and found that studies directly comparing these two treatments delivered tiotropium open-label, which affected comparability with other tiotropium studies, and increased risk of bias (see sensitivity analyses). The dose was misclassified in one study comparing salmeterol versus salmeterol/fluticasone combination (salmeterol/fluticasone as 50/ 500 bid instead of 50/250). Because the study did not appear in the main six-month results nor change the class comparisons, we did not rerun the analyses.

\section{St George's Respiratory Questionnaire (SGRQ)}

The SGRQ is a well-validated and widely used measure of health status in patients with chronic airflow limitation; the total score ranges from zero (perfect health) to 100 (most severe status) and includes the three components of symptoms, activity and impacts.
In the main network of effects at six months, 18 of 25 possible treatments were represented across 72 treatment arms in 25 studies ( $n=27,024)$. The fixed-effect model was preferred, as statistical heterogeneity was not significant. We extracted and analysed data as change from baseline per arm and estimated population variance on the basis of data from studies reporting variance for change per arm (see Measures of treatment effect). The mean of SDs, weighted by sample size, was imputed as 14 when variance for change could not be obtained.

The 12-month analysis contained slightly fewer data and had a broadly similar structure (containing data for 19 treatment comparisons in 24 studies). The fixed-effect model was preferred, as with the six-month analysis, but Calverley 2003 [TRISTAN] showed some lack of fit. Data from four studies were removed from the six-month network in the blinding sensitivity analysis (Bateman 2013 [SHINE]; Donohue 2010 [INHANCE]; GLOW2 2012; SPARK 2013), and data from two studies were removed from the 12-month network (GLOW2 2012; SPARK 2013).

The network structure for SGRQ at six months is shown in Figure 2 . 
Figure 2. Network structures for both outcomes at six months.
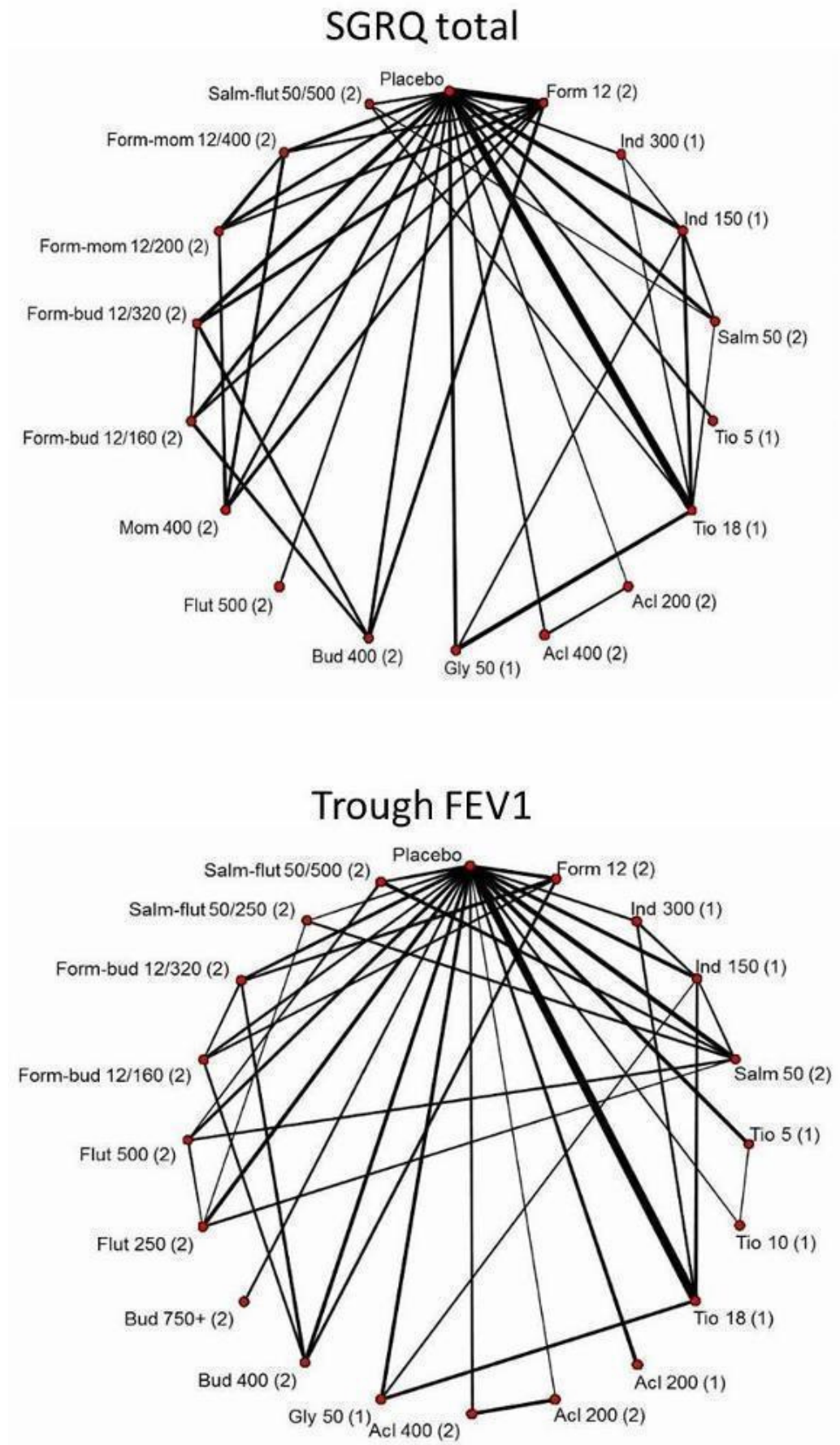

Long-acting inhaled therapy (beta-agonists, anticholinergics and steroids) for COPD: a network meta-analysis (Review) 


\section{Trough forced expiratory volume in one second $\left(\mathrm{FEV}_{1}\right)$}

In the main network of effects at six months, 20 of 25 possible treatments were represented across 82 treatment arms in 31 studies $(n=29,271)$. A random-effects model was preferred, as the fixedeffect model has very poor fit. Data for eight studies were available only as treatment contrasts, and the rest were entered as change from baseline per arm, along with the associated variance. For trials reporting treatment contrasts, we included co-variance, which was calculated as the variance of the mean in the control arm (placebo for all trials). For the rest of the trials, missing variance for change from baseline was imputed as $283(\mathrm{~mL})$ from the mean of available SDs weighted by sample size.

One very small trial was excluded from the six-month analysis (SLMF4010, $\mathrm{n}=34$ ) because of the unusually high dropout from already very small groups (seven of 17 dropped out in both groups). The study showed very poor fit, even in random-effects models, because the results contradicted all other trials.

The 12-month analysis contained fewer data (19 treatments compared in 21 studies) but again had a structure broadly similar to the main six-month analysis. As with the six-month analysis, the random-effects model was preferred, as the fixed-effect model had very poor fit. Data from the same four studies were removed from the six-month and 12-month networks, as for the SGRQ sensitivity analyses (see Table 5).

The network structure for trough $\mathrm{FEV}_{1}$ at six months is shown in Figure 2.

\section{Sensitivity analyses}

Five studies included a randomly assigned group that received tiotropium as an open-label treatment (Bateman 2013 [SHINE]; Donohue 2010 [INHANCE]; GLOW2 2012; SPARK 2013;
Vogelmeier 2008). As this introduced the potential for performance and assessment bias, we removed these arms from the affected networks in a risk of bias sensitivity analysis, as detailed in Table 5. Blinding led to unclear or high risk of bias in four additional studies, mainly as the result of insufficient reporting, but none of the studies reported data that could be included in the networks (Fang 2008; Mahmud 2007; Ohar 2013; To 2011). As stated in the protocol, we analysed separately data collected at six months and at 12 months.

\section{Excluded studies}

Sixty-six studies were excluded from the 14 relevant Cochrane reviews, and five others that came up in the electronic database search are recorded in Characteristics of excluded studies. We did not record every reference excluded after the full-text sift $(\mathrm{n}=157)$, as review of the full paper revealed that most trials were apparently of less than six months' duration, or they compared treatments that were not within the scope of the study.

\section{Risk of bias in included studies}

Methodological quality of the included studies was generally good. Across all six domains, around $60 \%$ of judgements were 'low risk', and $13 \%$ were 'high' risk. It is unlikely that the evidence presented in this review is affected by biases associated with unacceptable sequence generation, and most trials were double-blinded. The most common reasons for probable bias were attrition and selective reporting in the individual trials. A degree of uncertainly regarding the risk of bias associated with allocation concealment and blinding of outcome assessors was due mostly to insufficient reporting. Risk of bias judgements for all of the included studies are summarised in Figure 3 
Figure 3. Risk of bias summary: review authors' judgements about each risk of bias item for each included study.

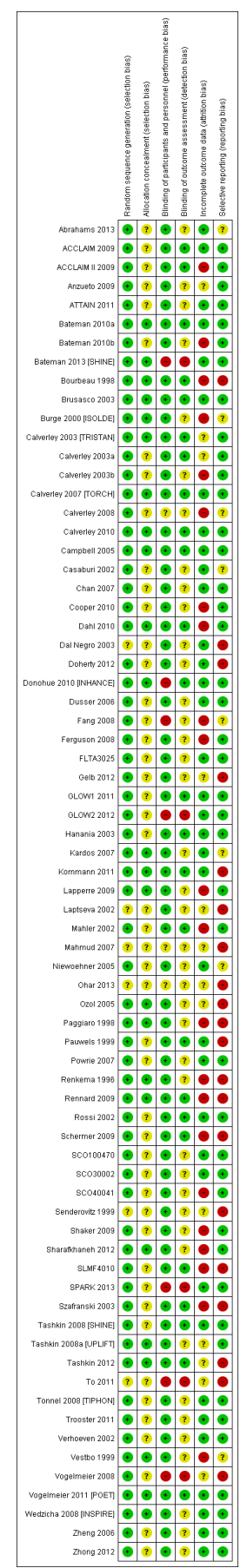

Long-acting inhaled therapy (beta-agonists, anticholinergics and steroids) for COPD: a network meta-analysis (Review) 


\section{Allocation}

\section{Random sequence generation}

All studies were randomised trials, and none were given high risk ratings for either of the selection bias domains. Most were funded by drug manufacturers with whom the authors had had previous contact to confirm methods of sequence generation. As such, all studies were considered to be at low risk of bias for this domain, with the exception of six studies for which only a conference abstract was available (rated unclear). Of these, none appeared in the SGRQ data set, and only two contributed $\mathrm{FEV}_{1}$ data.

\section{Allocation concealment}

A third of studies described methods of allocation concealment (interactive voice response system or sealed envelopes) and were rated as having low risk of bias $(n=24)$. The remaining studies did not explicitly describe their methods and were rated as unclear. This information is likely to be conservative given the high proportion of industry-funded trials, which generally have rigorous controls for selection bias.

\section{Blinding}

\section{Blinding of participants and personnel}

A large majority of trials stated that they were double-blind, which, unless otherwise stated, was understood to pertain to at least participants and personnel. For this reason, more than $85 \%$ of the trials were rated at low risk for performance bias. Seven trials (10\%) were given a high risk of bias rating, which was due mostly to the fact that one arm of the trial was delivered open-label. In these instances, treatment comparisons that did not involve the openlabel arm were not affected, and sensitivity analyses removing these arms assessed the effects of removing these high-risk comparisons from the networks.

\section{Blinding of outcome assessors}

A third of trials gave enough detail to warrant a low risk of bias rating, which was usually obtained from the clinicaltrials.gov registration. Most trials did not describe how outcomes were assessed in sufficient detail to rule out bias associated with unblinded outcome assessors and hence were rated as unclear. As with allocation concealment, an unclear rating for studies not explicitly describing outcome assessor blinding is likely to be conservative. Five studies were rated as high risk for the same reasons outlined for the participant and personnel domain.

\section{Incomplete outcome data}

Around half the trials were judged to be at low risk of bias because the level of dropout was acceptable and balanced between groups, or because sufficient efforts were made to impute missing data. Twenty-two trials were given a high risk rating, indicating a significant risk that unbalanced or especially high attrition may have compromised the validity of the results, and 13 were rated as unclear. However, several of the high risk ratings were given to the longer trials (two years or longer), in which a significant proportion of participants had dropped out by the end of the trial. By including data at the six-month and 12-month time points rather than at endpoint in these unusual trials, the risk from attrition may be reduced, as higher percentages of the randomly assigned populations were generally included in the earlier analyses.

\section{Selective reporting}

Most trials could be linked to a prospectively registered protocol for cross-checking of reported outcomes (on clinicaltrials.gov or manufacturers' websites). Most reported the named outcomes well in published reports, and a subset had additionally posted results summaries on clinicaltrials.gov, warranting a low risk rating $(\mathrm{n}=$ 43). A third were judged to be at high risk of bias, usually because outcomes stated in the protocol or important study methods were missing from published reports, regardless of whether this directly affected our analyses. Some trials were rated at high risk of bias because SGRQ or $\mathrm{FEV}_{1}$ data were reported but not in an acceptable format to be combined in meta-analysis. Although some early trials did not use the SGRQ or used a different $\mathrm{FEV}_{1}$ measurement for legitimate reasons, this fact and selective outcome reporting resulted in omission of a significant proportion of relevant trials from the SGRQ and $\mathrm{FEV}_{1}$ analyses. Eight were rated as unclear, usually because a protocol could not be located to confirm that all planned outcomes had been reported.

\section{Effects of interventions}

For each outcome, we presented six-month data for the main analyses, along with the number of treatments included, the number of pair-wise comparisons made and estimates of model fit and heterogeneity. Results are presented first as class effects and second for individual treatments. As the class analysis assumes that treatments within the same class are exchangeable and are distributed around a class mean, we have also outlined the effects of fitting the class model on individual treatment effects.

Results from the 12-month networks for each outcome are also presented (shown graphically alongside the six-month class results in Figure 4 and Figure 5), and sensitivity analyses for risk of bias (open-label delivery) are presented for the six-month class analyses. 
Figure 4. St George's Respiratory Questionnaire (SGRQ) change from baseline-six-month and I2-month class results.

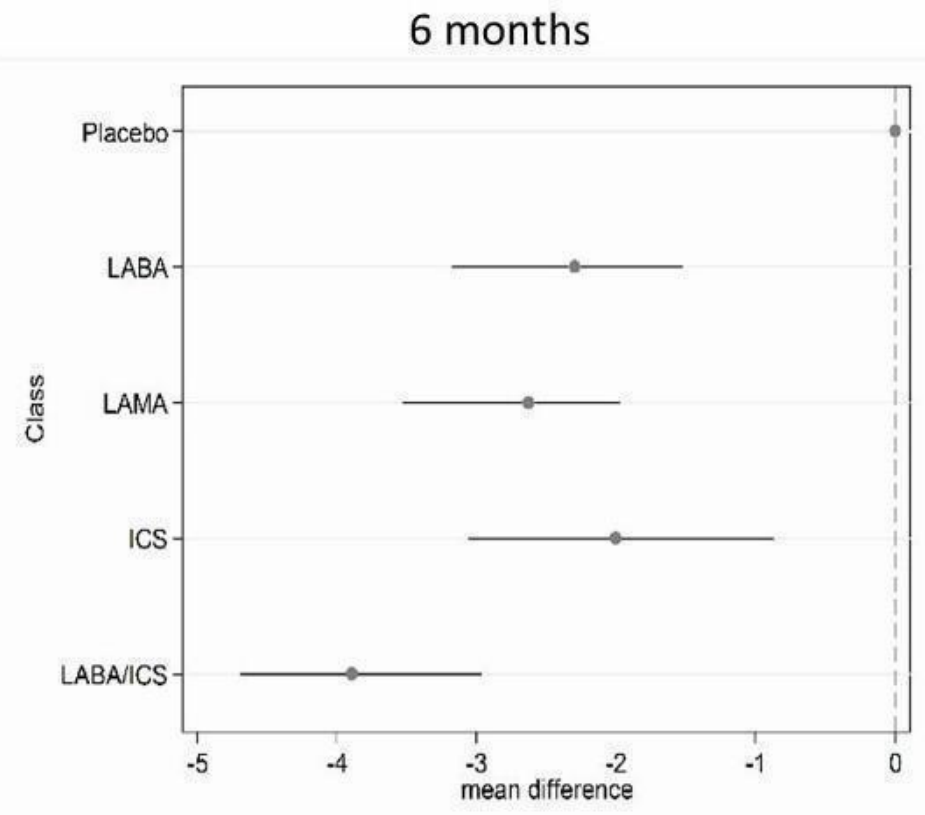

\section{2 months}

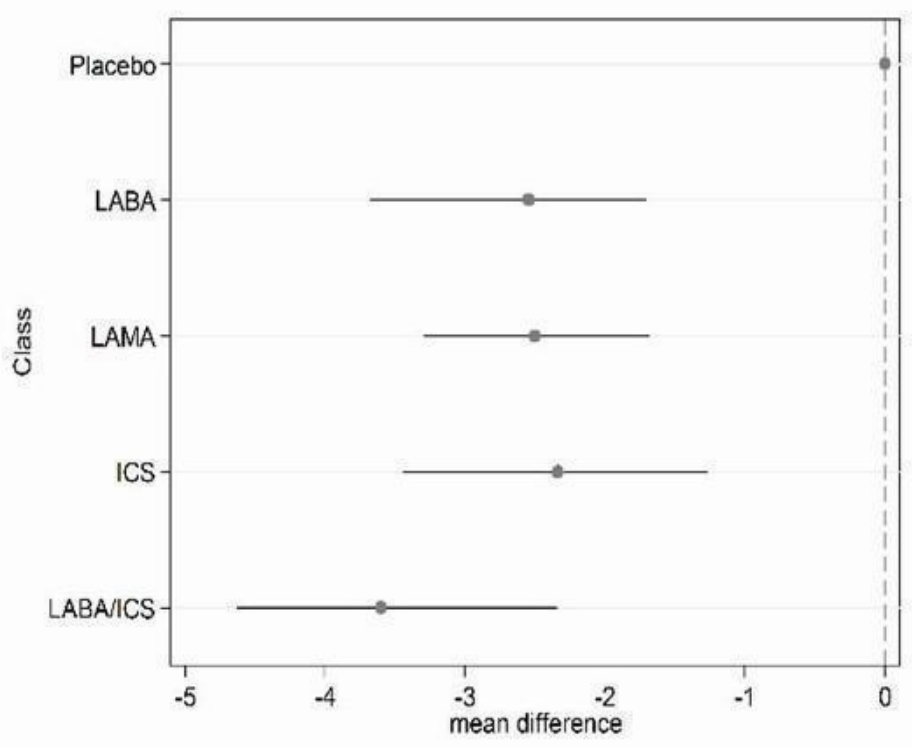


Figure 5. Trough forced expiratory volume in one second (FEVI) change from baseline-six-month and I2month class results.

\section{6 months}

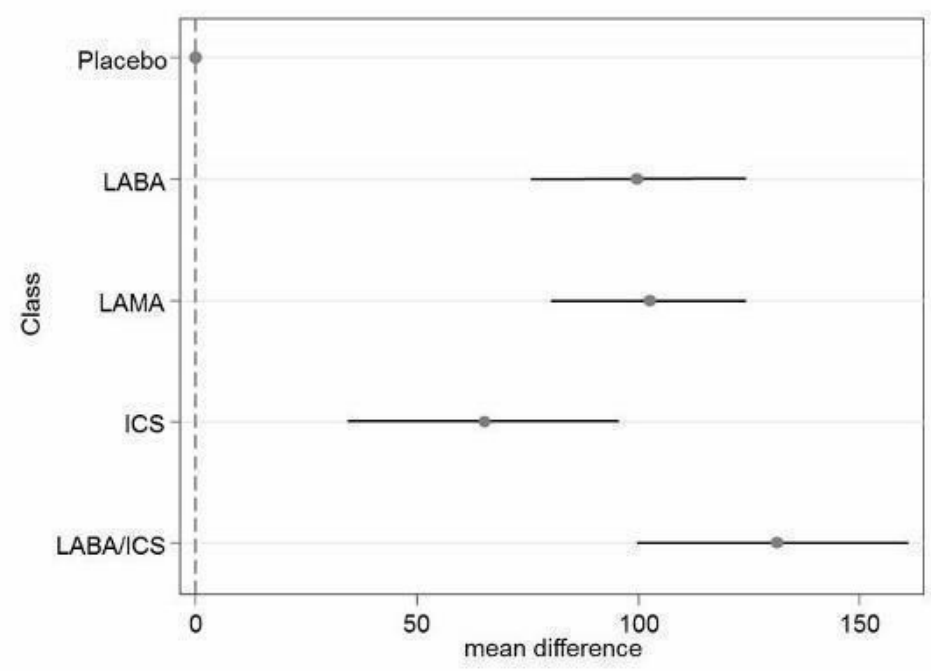

12 months

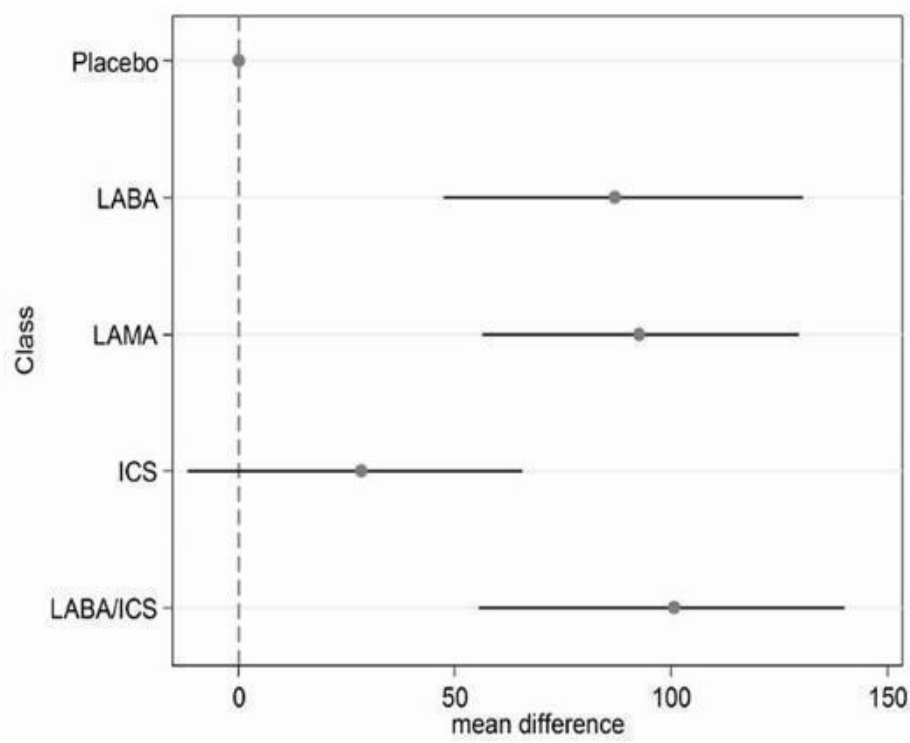




\section{St George's Respiratory Questionnaire}

Across six months and 12 months, 42 studies with 118 individual treatment nodes were included in the networks $(n=54,613)$.

\section{Main analysis-six months}

Eighteen treatments were compared over a total of 72 treatment arms in 25 studies $(\mathrm{n}=27,024)$. Thirty-nine pair-wise comparisons were made, and the fixed-effect model was preferred because statistical heterogeneity was not significant $($ DIC random $=214.9$, fixed = 214.5).

\section{Class effects}

Table 6 shows each class effect relative to placebo (i.e. the combined treatment benefit over placebo), expressed as change from baseline.
The classes are also ranked (mean and median) and are presented with estimates of the probability that each is the best class. Figure 4 displays class effects against the reference treatment (placebo), shown by the vertical dashed line on the right-hand side of the graph.

Combination LABA/ICS was the highest ranked treatment, with a mean improvement over placebo of 3.89 units $(95 \%$ credible interval (CrI) -4.70 to -2.97$)$. LAMAs and LABAs were ranked second and third, with mean differences of -2.63 (95\% CrI -3.53 to -1.97$)$ and $-2.29(95 \% \mathrm{CrI}-3.18$ to -1.53$)$, respectively, but a large degree of overlap was noted between their credible intervals. Inhaled corticosteroids were the fourth ranked class but still showed a mean two-unit benefit over placebo at six months $(95 \%$ CrI -3.06 to -0.87). Figure 6 shows graphs of the probabilities that each class ranks in any one of the five possible positions. The median within-class variance was 0.44 units (95\% CrI 0.03 to 1.09$)$. 

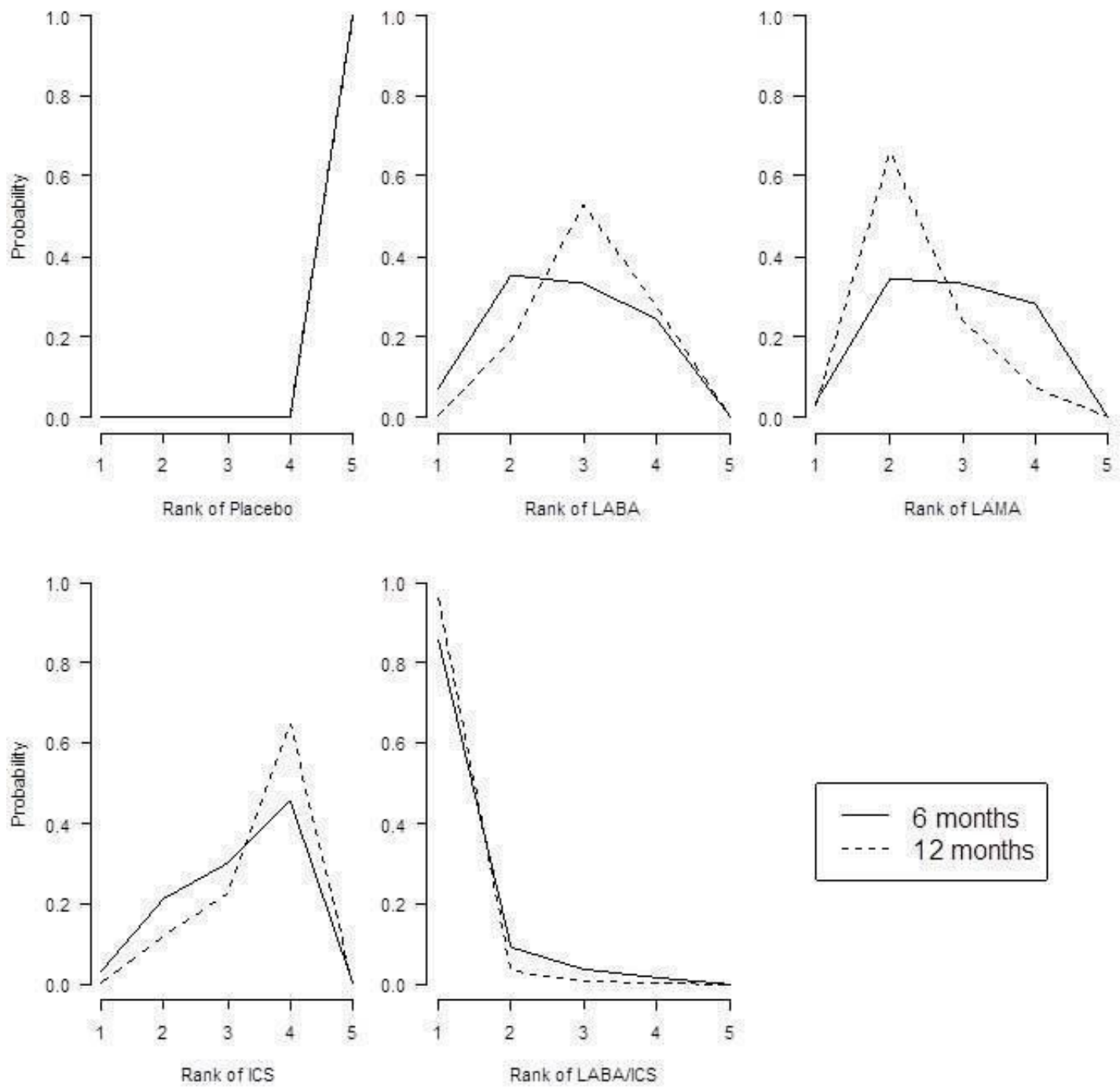

\section{Individual treatment effects}

Effects relative to placebo are presented separately for each treatment in Table 7, along with ranks and estimates with and without the class model for comparison. The credible intervals for each treatment were wide and largely overlapping (for both ranks and mean differences from placebo).

Individual treatment effects of particular note within a class were associated with indacaterol and aclidinium for LABA and LAMA, respectively. Effects for both doses of each of these drugs were dampened by the class model in the six-month SGRQ network (indacaterol by 0.72 and 0.92 for $300 \mathrm{mcg}$ and $150 \mathrm{mcg}$, respectively, and aclidinium by 1.13 and 1.78 for $200 \mathrm{mcg}$ and 400 mcg, respectively). Treatments of note for which estimates were inflated by fitting the class model were formoterol $12 \mathrm{mcg}$ (by 0.64 ), budesonide $400 \mathrm{mcg}$ (by 0.79 ) and formoterol/mometasone combination $2 / 400 \mathrm{mcg}$ (by 0.66 ).

Additional analyses 


\section{2 months}

Nineteen treatments were compared in 24 studies, but a dose comparison of aclidinium made in Gelb 2012 was disconnected from the rest of the network. These treatments can be used in class analysis, as they "borrow" the class effect. The fixed-effect model was preferred.

In the class analysis (Appendix 4 and Figure 4), LABA/ICS combinations remained the highest ranked at 12 months, with only a slightly smaller mean effect over placebo than at six months (-3.60, $95 \%$ CrI -4.63 to -2.34$)$. Compared with the six-month analysis, LABA, LAMA and ICS showed more similar benefits over placebo at 12 months, ranging between -2.34 and -2.55 , with similar credible intervals. Within-class variance was slightly larger than in the six-month analysis (median $0.53,95 \% \mathrm{CrI} 0.04$ to 1.27 ).

Individual treatment effects for the 12-month analysis are presented in Appendix 5.

\section{Sensitivity analysis-blinding}

Table 6 shows how the six-month effects were affected by removal of data at high risk of bias for blinding (see 'Effect vs placebo sensitivity analysis'). The difference between point estimates of LAMA over LABA was larger with less overlap in the credible intervals, and within-class variance was smaller than in the main analysis (median 0.35 , 95\% CrI 0.02 to 0.98 ). Inconsistency associated with Donohue 2010 [INHANCE] was resolved by removing the open-label tiotropium arm, but unexplained poor fit of three further trials remained (Kornmann 2011; Rennard 2009; Tashkin 2012). As all open-label arms removed were given tiotropium, it is possible that the expected treatment benefit over placebo in these studies was reduced by lack of blinding for these comparisons, which dampened the overall treatment effect within the LAMA class.

\section{Trough FEV}

Across six months and 12 months, 46 studies with 120 individual treatment nodes were included in the networks $(\mathrm{n}=47,409)$.

\section{Main analysis-six months}

Twenty treatments were compared over a total of 82 treatment arms in 31 studies $(n=29,271)$. Forty-one pair-wise comparisons were made. The random-effects model was preferred (DIC = 691), as the fixed-effect model has very poor fit $(\mathrm{DIC}=719.1)$.

\section{Class effects}

Table 8 shows each class effect relative to placebo. As for SGRQ, the classes are also ranked (mean and median) and are presented with estimates of the probability that each is the best. Figure 6 displays trough $\mathrm{FEV}_{1}$ class effects $(\mathrm{mL})$ compared with placebo. Results at six months showed a similar pattern to the SGRQ analysis. Combination LABA/ICS was the highest ranked treatment, with a mean improvement over placebo of $133.3 \mathrm{~mL}$ (95\% CrI 100.6 to 164.0) after six months. As was the case for quality of life, LAMAs and LABAs were ranked second and third, with mean differences of 103.5 (95\% CrI 81.8 to 124.9$)$ and 99.4 (95\% CrI 72.0 to 127.8 ), respectively, but again a large degree of overlap was noted between the credible intervals. Inhaled corticosteroids were the fourth ranked class but still showed a mean $65.4 \mathrm{~mL}$ benefit over placebo at six months $(95 \%$ CrI 33.1 to 96.9$)$. The median within-class variance was $9.04 \mathrm{~mL}$ ( $95 \% \mathrm{CrI} 0.41$ to 34.85$)$. Figure 7 shows graphs of the probabilities that each class ranks in any one of the five possible positions. 
Figure 7. Forced expiratory volume in one second (FEVI) probability ranking diagrams-six months and $I 2$ months.
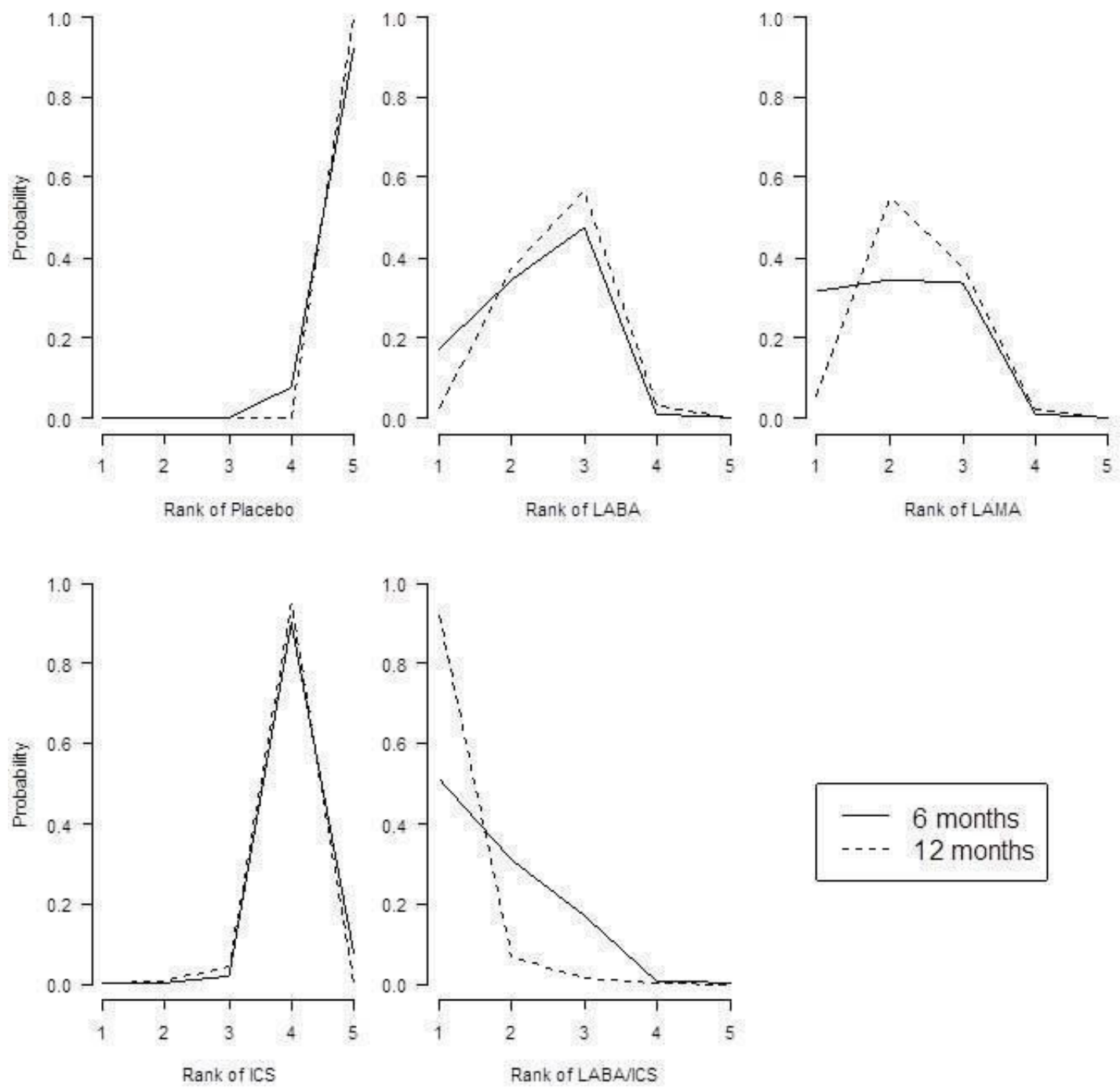

\section{Individual treatment effects}

Effects relative to placebo are presented separately for each treatment in Table 9, along with ranks and estimates with and without the class model for comparison.

The class model affected individual treatment effects to a lesser extent in the $\mathrm{FEV}_{1}$ network than in the SGRQ one, because less intra class variation was present. Several treatment effects that were higher than the class mean were dampened by the class model, including indacaterol 300 (by $34.6 \mathrm{~mL}$ ) and salmeterol-fluticasone $50 / 250$ mcg combination therapy (by $33.3 \mathrm{~mL}$ ). Effects for formoterol $12 \mathrm{mcg}$ and both formoterol/budesonide combination doses were less favourable within their classes and were inflated by the class model (by $41.0 \mathrm{~mL}$, and 50.3 and $54.5 \mathrm{~mL}$, respectively). Although aclidinium was particularly effective in the SGRQ analysis, the relative effects for both lower doses on trough $\mathrm{FEV}_{1}$ appeared less favourable than other members of the LAMA class (MD 59.3 and $74.8 \mathrm{~mL}$ without the class model compared with the overall class mean of 103.5). Within the ICS class, the two budesonide doses showed less benefit over placebo than the two fluticasone doses. However, credible intervals for the individual 
treatment groups were wide and overlapping.

\section{Additional analyses}

\section{2 months}

Nineteen treatments were compared in 22 studies. As with the 12month SGRQ analysis, the dose comparison of aclidinium made in Gelb 2012 was disconnected from the rest of the network. The random-effects model was preferred (DIC $=485.4)$, as the fixedeffect model had very poor fit (DIC $=557.4)$.

In the class analysis (Appendix 6 and Figure 6), LABA/ICS remained the highest ranked treatment strategy, although the effect over placebo was lower than at six months (100 mL, 95\% CrI 55.5 to 140.1). As with SGRQ, the benefit of LAMA over LABA was much less clear at 12 months, and their credible intervals showed a large degree of overlap with each other and with the LABA/ICS class. Within-class variance was larger than in the six-month analysis (median 18.02, 95\% CrI 1.22 to 47.80 ).

Individual treatment effects for the 12-month analysis are presented in Appendix 7.

\section{Sensitivity analysis-blinding}

Table 8 shows how the six-month effects were influenced by removal of data at high risk of bias for blinding. Within-class variance was similar to that in the main analysis (median 10.49, 95\% CrI 0.54 to 37.66). The effects were very similar with and without the open-label data, unlike in the SGRQ analysis. This may reflect the nature of the two measurements, with SGRQ perhaps more susceptible to performance or detection bias than measures of lung function.

\section{ISCUSSION}

\section{Summary of main results}

Evidence from good quality and similar trials supports LABA/ICS combination therapy as the highest ranking treatment strategy to improve quality of life and to benefit lung function in the included trials (mostly with participants whose $\mathrm{FEV}_{1}$ was less than $50 \%$ predicted). Combination therapy gave an average benefit of 3.9 units over placebo at six months (95\% CrI -4.70 to -2.97$)$. LAMAs (MD -2.63 , 95\% CrI -3.53 to -1.97 ) were ranked second and LABAs ranked third at six months (MD -2.29, 95\% CrI -3.18 to 1.53), especially when trials at high risk of bias were not included, but the difference between these classes was small, and a large degree of overlap was noted in their estimates.

Combination LABA/ICS was the highest ranked class for trough $\mathrm{FEV}_{1}$, with a mean improvement over placebo of $133.3 \mathrm{~mL}$ at six months (95\% CrI 100.6 to 164.0 ). As was the case for SGRQ, LAMAs ranked second (MD 103.5, 95\% CrI 81.8 to 124.9) and LABAs ranked third (MD 99.4, 95\% CrI 72.0 to 127.8) at six months; ICSs were the fourth ranking class (MD $65.4 \mathrm{~mL}, 95 \%$ CrI 33.1 to 96.9).

For both outcomes, the effects of LABA and ICS monotherapies appeared to be additive at six months, but initial differences between treatment classes were less prominent after a year of treatment.

\section{Overall completeness and applicability of evidence}

The SGRQ analyses showed that combination LABA/ICS treatment had a mean difference over placebo in line with the minimal clinically important difference (MCID) of four units, and the point estimates and $95 \%$ confidence intervals of the other classes were lower than four units. However, it is not appropriate to imply that LABA/ICS provides a meaningful quality of life benefit while the other classes do not. A previous review demonstrated that a treatment that has a mean difference and $95 \%$ CI of lower than four units on the SGRQ can nevertheless lead to a significantly higher number of patients who reach a four-unit change on the SGRQ in the treatment group than in the placebo group (Karner 2012a). For $\mathrm{FEV}_{1}$, with the exception of ICS monotherapy, treatment differences ranged from 99 to $133 \mathrm{~mL}$, which is in keeping with the threshold of clinical significance suggested by Cazzola 2008 (100 to $140 \mathrm{~mL}$ ).

National guidelines recommend the treatments included in this review (LABA, LAMA or LABA/ICS) over regular short-acting medications for patients with exacerbations or persistent breathlessness (NICE 2011), otherwise referred to as those with moderate (stage II) or severe (stage III) COPD (GOLD). NICE 2011 recommends the addition of ICS in people who also have less than $50 \%$ predicted $\mathrm{FEV}_{1}$. By collating information about participants included in each of the included trials and assessing for transitivity, we were able to be clear about the types of patients to whom the conclusions of this review are likely to apply. Although some individual trials within the network included participants who exceeded or fell short of the criteria described in the guidelines, summary statistics suggest that participant groups in the trials fell into the moderate and severe categories, and most participants had an $\mathrm{FEV}_{1}$ of less than $50 \%$ predicted. As a result, the evidence is not applicable to those with mild symptoms. Similarly, because of the common exclusion criteria in the trials related to co-morbidities, and asthma in particular, these findings may not be relevant to some groups of patients. Finally, because the decision was made not to include some newer treatments and combination therapies in the network, class results may not be applicable to emerging treatments.

To supplement the efficacy findings, we sought to identify evidence of cost-effectiveness. As LABA/ICS was the most effective 
treatment for both outcomes and is likely to be the most costly treatment strategy in many settings, we sought to identify studies evaluating its cost-effectiveness against other treatment options, and whether this varied across patients with varying levels of symptoms. Three recent studies based on reanalysis of clinical trials were found, all of which concluded that LABA/ICS is a cost-effective treatment strategy for moderate to severe COPD (Chuck 2008; Earnshaw 2007; Fattore 2005). Evidence suggests that the reduction in healthcare resource use associated with LABA/ICS compared with placebo or with the single components outweighs the additional cost of combination inhalers. One study (Chuck 2008) showed that this benefit was more prominent in patients with severe disease $(\$ 39,000$ per quality-adjusted life-year (QALY)) than in those with moderate and severe disease combined $(\$ 47,500$ per QALY).

Karner 2012a raised concerns about the safety of tiotropium when delivered via the Respimat inhaler, arising from indirect comparisons between trials using Respimat and Handihaler devices. Published evidence from a very large trial that randomly assigned participants to tiotropium via Respimat or Handihaler does not show a higher risk of mortality when the Respimat inhaler was used (Wise 2013).

\section{Quality of the evidence}

We assessed the methodological quality of all included studies and concluded that risk of bias was generally low across the five domains. Uncertainties associated with allocation concealment and outcome reporting could have been resolved in part by contacting trial authors, but because most of the included studies were already included in other Cochrane reviews, it is unlikely that this would have substantially increased our confidence in the results, especially because a vast majority of trials were sponsored by manufacturers with whom we have confirmed the adequacy of methods in the past. The sensitivity analysis removing comparisons at high risk of performance or detection bias further increased our confidence in the findings.

The transitivity assumption was upheld across both outcome data sets. The trials were similar in their conduct, and when discrepancies were noted (especially with allowed co-medications and inhaler devices), these did not appear to differ systematically between nodes or classes. Because of the nature of indirect comparisons, the similarity in baseline characteristics and methodology justified analysing the trials in a network and increased the applicability of the results. Participants randomly assigned to the LABA/ICS arms had somewhat more impaired lung function than those assigned to the other classes, but this did not translate into any real differences when transitivity across pairwise comparisons between classes was assessed. The presence of several large multi-arm trials allowed us to combine the indirect evidence obtained via common comparators with a good quantity of head-to-head data within and across classes, and this increased the reliability of the network findings.

\section{Potential biases in the review process}

By including studies from existing Cochrane reviews and performing additional electronic searches to both update the data and fill gaps not covered by other reviews, it is likely that the relevant literature has been covered by this review. Around $80 \%$ of the studies included in this review had already been included in another Cochrane review and so had already been assessed for risk of bias and had data extracted by two review authors. We were not able to contact study authors to ask for additional data, but we were able to extract and include data for the vast majority of studies that measured the outcomes.

\section{Agreements and disagreements with other studies or reviews}

Several recent network meta-analyses of treatments for COPD have been published with varying inclusion criteria and outcomes. Decramer 2013 and Dong 2013 focused on safety outcomes and included only longer-term studies of at least six months' duration. Decramer 2013 included only LABA therapy and found no association between LABA and increased COPD-related adverse events or mortality. In addition, "LABA treatment was generally associated with significant or numerical reductions in COPD exacerbations compared with placebo," which is in keeping with the effects of LABA shown in our review. Dong 2013 had very similar inclusion criteria to those of our network and focused on mortality. Alongside our findings on the additive efficacy of the LABA/ ICS combination, the Dong 2013 network provided evidence that "LABA-ICS was associated with the lowest risk of death among all treatments," and that "no excess risk was noted for tiotropium HandiHaler or LABA." These reviews provide comparative evidence relating to safety, especially Dong 2013, which included a similar network of treatments and listed similar trial inclusion criteria.

Cope 2012 included a similar list of COPD treatments in their network and assessed efficacy using similar outcomes on shorter time scales (SGRQ and lung function at three months). Although their focus was on indacaterol, their conclusions regarding its efficacy in comparison with older LABAs were in keeping with our findings. Similarly, a subsequent network meta-analysis including glycopyrronium but not including LABA/ICS combinations (Cope 2013) concluded that indacaterol, glycopyrronium and tiotropium were the most favourable bronchodilators (based on evidence for SGRQ and $\mathrm{FEV}_{1}$ at three months and at six months). Although these treatments were amongst the best LABAs and LAMAs, differences between the two network meta-analyses (i.e. the list of included 
treatments, time points and analysis model) explain the discrepancies in conclusions.

With regard to other important outcomes, a network meta-analysis by Puhan 2009 focusing on exacerbations and the same treatment classes found "no evidence that one single inhaled drug regimen is more effective than another in reducing exacerbations." The authors also concluded that "inhaled corticosteroids when added to long-acting beta-agonists reduce exacerbations only in patients with COPD with $\mathrm{FEV}_{1} \leq 40 \%$." Because of issues of network connectivity, we did not consider it reasonable to analyse our data sets with baseline severity as a co-variate, but Puhan 2009 raises the question of whether certain treatments may be more beneficial or may cause different adverse effects for particular patient groups.

\section{A U THORS'CONCLUSIONS}

\section{Implications for practice}

This network meta-analysis compares three different classes of long-acting inhalers for people with COPD who need more than short-acting bronchodilators. Quality of life and lung function were improved most on combination inhalers (LABA and ICS) and least on ICS alone at 6 and at 12 months. Overall LAMA and LABA inhalers had similar effects, particularly at 12 months. The network has demonstrated the benefit of ICS when added to LABA for these outcomes in participants who largely had an $\mathrm{FEV}_{1}$ that was less than $50 \%$ predicted, but the additional expense of combination inhalers and any potential for increased adverse events (which has been established by other reviews) require consideration. Our findings are in keeping with current NICE guidelines.

\section{Implications for research}

Studies assessing emerging treatments in head-to-head trials with older members of their class would be particularly useful for assessing relative efficacy. When including active treatment controls, studies should deliver all treatments in a double-blind fashion to minimise performance and detection bias for all comparisons. As more studies are conducted and published for emerging LABAs, LAMAs, ICSs and LABA/ICS combinations, widening the scope of the network might increase the usefulness of this review.

\section{ACKNOW LEDGEMENTS}

We are grateful to Elizabeth Stovold for her help in designing the search strategy.

Milo Puhan was the Editor for this review and commented critically on the review.

CRG Funding Acknowledgement: The National Institute for Health Research (NIHR) is the largest single funder of the Cochrane Airways Group.

Disclaimer: The views and opinions expressed therein are those of the authors and do not necessarily reflect those of the NIHR, NHS or the Department of Health.

\section{REF ER E N C ES}

\section{References to studies included in this review}

\section{Abrahams 2013 \{published data only\}}

* Abrahams R, Moroni-Zentgraf P, Ramsdell J, Schmidt H, Joseph E, Karpel J. Safety and efficacy of the once-daily anticholinergic BEA2180 compared with tiotropium in patients with COPD. Respiratory Medicine 2013;107(6): 854-62.

Abrahams R, Ramsdell J, Moroni-Zentgraf P, Schmidt H, Joseph B, Karpel J. Comparison of BEA2180 to tiotropium and placebo via respimat in patients with chronic obstructive pulmonary disease (COPD) [Abstract]. Respirology 2012;17 (Suppl 2):46 [292].

\section{ACCLAIM 2009 \{published data only\}}

Jones P, Agusti A, Chanez P, Magnussen H, Fabbri L, Maroni J, et al.Efficacy and safety of aclidinium bromide, a novel long-acting muscarinic antagonist, in patients with moderate to severe COPD [Abstract]. European Respiratory Society Annual Congress; Sep 12-16; Vienna.
2009:[P2022].

* Jones PE, Chanez P, Agusti A, Magnussen H, Fabbri L, Caracta C, et al.A phase III study evaluating aclidinium bromide, a novel long-acting antimuscarinic, in patients with COPD: ACCLAIM/COPD I [Abstract]. Thorax 2009;64(Suppl IV):A168 [P213].

Jones PW, Agusti A, Chanez P, Magnussen H, Fabbri L, Maroni J, et al.A phase III study evaluating aclidinium bromide, a novel long-acting antimuscarinic, in patients with COPD: ACCLAIM/COPD 1 [Abstract]. American Thoracic Society International Conference; May 15-20; San Diego. 2009:A6180 [Poster \#207].

ACCLAIM II 2009 \{published data only\}

* Jones PW, Rennard SI, Agusti A, Chanez P, Magnussen H, Fabbri L, et al.Efficacy and safety of once-daily aclidinium in chronic obstructive pulmonary disease. Respiratory Research 2011;12:55.

Rennard S, Donohue J, Bateman E, Gross N, Garcia Gil E, Caracta C. ACCLaim/COPD ii: efficacy and safety of aclidinium bromide; a novel long-acting muscarinic 
antagonist in COPD patients, a phase III study [Abstract]. European Respiratory Society Annual Congress; Sep 12-16; Vienna. 2009:[E4351].

Rennard S, Donohue J, Bateman E, Gross N, Garcia Gil E, Caracta C. Efficacy and safety of the novel, long-acting antimuscarinic, aclidinium bromide, in COPD patients in a phase III study: ACCLAIM/COPD II [Abstract]. American Thoracic Society International Conference; May 15-20; San Diego. 2009:A6178 [Poster \#205].

\section{Anzueto 2009 \{published data only\}}

Anzueto A, Ferguson G, Feldman G, Selbert A, Chinsky

$\mathrm{K}$, Emmett A, et al.A randomized, double-blind trial comparing the effect of fluticasone/salmeterol 250/50 with salmeterol on COPD exacerbations [Abstract]. American Thoracic Society International Conference; May 16-21; Toronto. 2008:Poster \#D40.

* Anzueto A, Ferguson GT, Feldman G, Chinsky K, Seibert A, Emmett A, et al.Effect of fluticasone propionate/ salmeterol (250/50) on COPD exacerbations and impact on patient outcomes. COPD 2009;6(5):320-9.

Dalal AA, Blanchette CM, Petersen H, St. Charles M. Cost-effectiveness of fluticasone propionate/salmeterol $(250 / 50 \mathrm{mcg})$ compared to salmeterol $(50 \mathrm{mcg})$ in patients with chronic obstructive pulmonary disease: economic evaluation of study SCO100250 [Abstract]. American Thoracic Society International Conference; May 15-20; San Diego. 2009:A1502 [Poster \#K54].

DiSantostefano RL, Li H, Rubin DB, Stempel DA. Which patients with chronic obstructive pulmonary disease benefit from the addition of an inhaled corticosteroid to their bronchodilator? A cluster analysis. BMJ Open 2013;3(4): 1-9.

GlaxoSmithKline. A randomized, double-blind, parallelgroup, 52-week study to compare the effect of fluticasone propionate/salmeterol DISKUS 250/50mcg BID with salmeterol DISKUS $50 \mathrm{mcg}$ BID on the annual rate of moderate/severe exacerbations in subjects with chronic obstructive pulmonary disease (COPD). http://www.gskclinicalstudyregister.com/ (accessed 3 March 2014).

\section{ATTAIN 2011 \{published data only\}}

Agusti A, Jones PW, Bateman E, Singh D, Lamarca R, de Miquel G, et al.Improvement in symptoms and rescue medication use with aclidinium bromide in patients with chronic obstructive pulmonary disease: results from ATTAIN [Abstract]. European Respiratory Journal 2011;38 (55):149s [P874].

Bateman ED, Singh D, Jones PW, Agusti A, Lamarca R, de Miquel G, et al.The ATTAIN study: safety and tolerability of aclidinium bromide in chronic obstructive pulmonary disease [Abstract]. European Respiratory Journal 2011;38 (55):730s [P4005].

Jones P, Agusti A, Bateman E, Singh D, Lamarca R, De Miquel $\mathrm{G}$, et al.Aclidinium bromide in patients with chronic obstructive pulmonary disease (COPD): reduction in exacerbations as defined by health-care utilization and the EXACT diary card [Abstract]. Chest 2011;140(4):529A. Jones P, Agusti A, Bateman E, Singh D, Lamarca R, de
Miquel G, et al.Aclidinium bromide in patients with chronic obstructive pulmonary disease: improvement in symptoms and health status in the ATTAIN study [Abstract]. Chest 2011;140(4):547A.

Jones P, Bateman E, Singh D, Agusti A, Lamarca R, De Miquel G, et al.Attain: efficacy and safety of twice-daily aclidinium bromide in chronic obstructive pulmonary disease (COPD) [Abstract]. Chest 2011;140(4):975A. Jones PW, Agusti A, Bateman ED, Singh D, Lamarca R, de Miquel G, et al.Aclidinium bromide in patients with chronic obstructive pulmonary disease: efficacy and safety results from ATTAIN [Abstract]. American Journal of Respiratory and Critical Care Medicine 2011;183:A6350. Jones PW, Agusti A, Bateman ED, Singh D, Lamarca R, de Miquel G, et al.Aclidinium bromide in patients with chronic obstructive pulmonary disease: improvement in health status in ATTAIN [Abstract]. European Respiratory Journal 2011;38(55):150s [P877].

Jones PW, Chuecos F, Lamarca R, Singh D, Agusti A, Bateman ED, et al.Unreported exacerbations of chronic obstructive pulmonary disease are associated with a reduction in health status: results from the ATTAIN study. American Journal of Respiratory and Critical Care Medicine 2013;187:A6072.

Jones PW, Singh D, Agusti A, Bateman ED, Lamarca R, de Miquel G, et al.Aclidinium bromide reduces COPD exacerbations as defined by healthcare utilisation and EXACT: results from ATTAIN [Abstract]. European Respiratory Journal 2012;40(Suppl 56):9s [195].

* Jones PW, Singh D, Bateman ED, Agusti A, Lamarca $\mathrm{R}$, de Miquel G, et al.Efficacy and safety of twice-daily aclidinium bromide in COPD patients: the ATTAIN study. European Respiratory Journal 2012;40(4):830-6.

Singh D, Bateman ED, Jones PW, Agusti A, Lamarca R, de Miquel G, et al.The ATTAIN study: bronchodilatory effect of aclidinium bromide in chronic obstructive pulmonary disease (COPD) [Abstract]. European Respiratory Journal 2011;38(55):149s [P875].

Singh D, Jones PW, Bateman ED, Agusti A, Lamarca R, De Miquel G, et al.Attain: twice-daily aclidinium bromide in patients with moderate to severe chronic obstructive pulmonary disease [Abstract]. Thorax 2011;66(Suppl 4): A171 [P255].

\section{Bateman 2010a \{published data only\}}

* Bateman ED, Tashkin D, Siafakas N, Dahl R, Towse L, Massey D, et al.A one-year trial of tiotropium Respimat plus usual therapy in COPD patients. Respiratory Medicine 2010;104(10):1460-72.

\section{Bateman 2010b \{published data only\}}

* Bateman E, Singh D, Smith D, Disse B, Towse L, Massey $\mathrm{D}$, et al.Efficacy and safety of tiotropium Respimat SMI in COPD in two 1-year randomized studies. International Journal of Chronic Obstructive Pulmonary Disease 2010;5: 197-208.

Hodder R, Pavia D, Lee A, Bateman E. Lack of paradoxical bronchoconstriction after administration of tiotropium via Respimat Soft Mist Inhaler in COPD. International 
Journal of Chronic Obstructive Pulmonary Disease 2011;6(1): $245-51$.

Bateman 2013 [SHINE] \{published data only\}

Barnes N, Bateman E, Gallagher N, Green Y, Horton R, Henley M, et al.QVA149 once daily provides superior bronchodilation versus indacaterol, glycopyrronium, tiotropium and placebo: the SHINE study [Abstract]. Thorax 2012;67(Suppl 2):A147 [P192].

Bateman E, Ferguson GT, Barnes N, Gallagher N, Green Y, Horton R, et al.Benefits of dual bronchodilation with QVA149 once daily versus placebo, indacaterol, NVA237 and tiotropium in patients with COPD: the SHINE study [Abstract]. European Respiratory Journal 2012;40(Suppl 56):509s [2810].

Bateman E, Hashimoto S, Gallagher N, Green Y, Horton R, Henley M, et al.Glycopyrronium once daily provides rapid and sustained bronchodilation and is well tolerated in patients with COPD: the SHINE study [Abstract]. Thorax 2012;67(Suppl 2):A148 [P193].

* Bateman ED, Ferguson GT, Barnes N, Gallagher N, Green Y, Henley M, et al.Dual bronchodilation with QVA149 versus single bronchodilator therapy: the SHINE study. European Respiratory Journal 2013;42(6):1484-94. Bateman ED, Welte T, Hashimoto S, Gallagher N, Green Y, Horton R, et al.Dual bronchodilation with once-daily QVA149 provides superior bronchodilation compared to its mono-components and tiotropium in all subgroups of patients with COPD: the SHINE study. American Journal of Respiratory and Critical Care Medicine 2013;187:A4263. Frith P, Thompson P, Wark P, Lindstrom S, Bateman E. Benefits of dual bronchodilation with QVA149 once daily versus placebo, indacaterol, NVA237 and tiotropium in patients with COPD: the Shine study [Abstract]. Respirology 2013;18(Suppl 2):20 [O041].

Welte T, Barnes N, Nagase T, Gallagher N, Green Y, Horton $\mathrm{R}$, et al.QVA149 once daily is safe and well tolerated in patients with COPD: the SHINE study. American Journal of Respiratory and Critical Care Medicine 2013;187:A1478. Welte T, Gallagher N, Green Y, Henley M, Banerji D. Dual bronchodilation with once-daily QVA149 provides significantly improved clinical outcomes versus monobronchodilator therapy: the SHINE study. American Journal of Respiratory and Critical Care Medicine 2013;187: A 4272.

Bourbeau 1998 \{published data only\}

* Bourbeau J, Rouleau MY, Boucher S. Randomised controlled trial of inhaled corticosteroids in patients with chronic obstructive pulmonary disease. Thorax 1998;53(6): $477-82$.

Brusasco 2003 \{published data only\}

* Bateman ED, Hodder R, Miravitlles M, Lee A, Towse L, Serby C. A comparative trial of tiotropium, salmeterol and placebo: health-related quality of life. European Respiratory Journal 2001;18(Suppl 33):26s.

Bateman ED, Jenkins C, Korducki L, Keston S. Tiotropium (TIO) improves health care resource utilization (HRU) and patient disability in patients with COPD. American Journal of Respiratory and Critical Care Medicine 2002;165(Suppl 8):A111.

Brusasco V, Hodder R, Miravitlles M, Korducki L, Towse L, Kesten S. Health outcomes following treatment for six months with once daily tiotropium compared with twice daily salmeterol in patients with COPD. Thorax 2003;58 (5):399-404.

Brusasco V, Menjoge SS, Kesten S. Flow and volume responders following treatment with tiotropium and salmeterol in patients with COPD [abstract]. American Thoracic Society 99th International Conference; May 1621; Seattle. 2003.

Brusasco V, Menjoge SS, Kesten S. Flow and volume responders over 12 hours following treatment with tiotropium or salmeterol in patients with COPD [Abstract]. Proceedings of the American Thoracic Society; May 19-24; San Diego. 2006:A110 [Poster J10].

Brusasco V, Thompson P, Vincken W, Lee A, Towse L, Witek TJ. Improvement of dyspnea following six months of treatment with tiotropium but not with salmeterol in patients with COPD. European Respiratory Journal 2001;18 (Suppl 33):26s.

Donohue JF. Alterations in bronchodilator effectiveness over six months with tiotropium and salmeterol. American Journal of Respiratory and Critical Care Medicine 2002;165 (Suppl 8):A227.

Donohue JF, Menjoge S, Kesten S. Tolerance to bronchodilating effects of salmeterol in COPD. Respiratory Medicine 2003;97(9):1014-20.

Donohue JF, van Noord JA, Bateman ED, Langley SJ, Lee A, Witek TJ, et al.A 6-month, placebo-controlled study comparing lung function and health status changes in COPD patients treated with tiotropium or salmeterol. Chest 2002;122(1):47-55. [: 0012-3692]

Donohue JF, van Noord JA, Langley SJ, Lee A, Kesten S, Towse LJ. Superior bronchodilation of once daily tiotropium compared to twice daily salmeterol in patients with COPD. European Respiratory Journal 2001;18(Suppl 33):26s.

Gunther K, Lee A, Kesten S, Towse L. Superior bronchodilation of once daily tiotropium compared with twice daily salmeterol in patients with COPD [Abstract]. International Primary Care Respiratory Group Congress; Jun 7-9; Amsterdam. 2002:p112.

Rutten-van Mölken MP, Oostenbrink JB, Miravitlles M, Monz BU. Modelling the 5-year cost effectiveness of tiotropium, salmeterol and ipratropium for the treatment of chronic obstructive pulmonary disease in Spain. The European Journal of Health Economics: Health Economics in Prevention and Care 2007;8(2):123-35.

Burge 2000 [ISOLDE] \{published data only\}

Bale G, Martinez-Camblor P, Burge PS, Soriano JB. Longterm mortality follow-up of the ISOLDE participants: causes of death during 13 years after trial completion. Respiratory Medicine 2008;102(10):1468-72.

Bale GA, Burge PS, Burge C, Moore VC. The Isolde study 11-13 years on: what were the causes of death? [Abstract]. 
American Thoracic Society International Conference; May 18-23; San Francisco. 2007:Poster \#H42.

Briggs AH, Lozano-Ortega G, Spencer S, Bale G, Spencer $\mathrm{MD}$, Burge PS. Estimating the cost-effectiveness of fluticasone propionate for treating chronic obstructive pulmonary disease in the presence of missing data. Value in Health 2006;9(4):227-35.

Burge PS, Calverley PM, Jones PW, Spencer S, Anderson JA. Prednisolone response in patients with chronic obstructive pulmonary disease: results from the ISOLDE study. Thorax 2003;58(8):654-8.

* Burge PS, Calverley PM, Jones PW, Spencer S, Anderson JA, Maslen TK. Randomised, double blind, placebo controlled study of fluticasone propionate in patients with moderate to severe chronic obstructive pulmonary disease: the ISOLDE trial. BMJ 2000;320(7245):1297-303. Burge S, Sondhi S, Williams MK, Wilson K, Efthimiou $\mathrm{J}$. An economic evaluation of fluticasone propionate in patients with moderate to severe chronic obstructive pulmonary disease (COPD) from the isolde trial. American Journal of Respiratory and Critical Care Medicine 2000;161 (3 Suppl):A491.

Calverley P, Spencer S, Willits L, Burge PS, Jones P. Inhaled corticosteroids prevent treatment failure in COPD. American Journal of Respiratory and Critical Care Medicine 2002;165(8 Suppl):A271.

Calverley PM, Burge PS, Spencer S, Anderson JA, Jones PW. Bronchodilator reversibility testing in chronic obstructive pulmonary disease. Thorax 2003;58(8):659-64.

Calverley PM, Spencer S, Willits L, Burge PS, Jones PW, Group IO. Withdrawal from treatment as an outcome in the ISOLDE study of COPD. Chest 2003;124(4):1350-6. Calverley PMA, Spencer S, Willets L, Burge PS, Jones PW. Inhaled corticosteroids prevent treatment failure in COPD. American Journal of Respiratory and Critical Care Medicine 2002;165(Suppl 8):A271.

D'Urzo AD. Withdrawal of treatment in the ISOLDE study. Chest 2004;125(6):2368.

Jarad NA, Wedzicha JA, Burge PS, Calverley PM. An observational study of inhaled corticosteroid withdrawal in stable chronic obstructive pulmonary disease. ISOLDE Study Group. Respiratory Medicine 1999;93(3):161-6. Jones PW, Willits LR, Burge PS, Calverley PM, Inhaled Steroids in Obstructive Lung Disease in Europe Study Investigators. Disease severity and the effect of fluticasone propionate on chronic obstructive pulmonary disease exacerbations. European Respiratory Journal 2003;21(1): 68-73.

Scott PH, Bale GA, Burge PS. COPD rapid decliners have better FEV1 response to inhaled fluticasone propionate 500

$\mathrm{g}$ bd than slower decliners [abstract]. American Journal of Respiratory and Critical Care Medicine 2000;161(3 Suppl): A581.

Scott PH, Bale GA, Burge PS. Inhaled fluticasone propionate in COPD: better response in those with more rapid FEV1 decline. European Respiratory Journal 2000;16
(Suppl 31):276s.

Spencer S, Calverley PM, Burge PS, Jones PW. Impact of preventing exacerbations on deterioration of health status in COPD. European Respiratory Journal 2004;23(5):698-702. Spencer S, Calverley PM, Sherwood Burge P, Jones PW, ISOLDE Study Group. Inhaled Steroids in Obstructive Lung Disease. Health status deterioration in patients with chronic obstructive pulmonary disease. American Journal of Respiratory and Critical Care Medicine 2001;163(1):122-8.

\section{Calverley 2003 [TRISTAN] \{published data only\}} Calverley P, Pauwels R, Vestbo J. Erratum. Combined salmeterol and fluticasone in the treatment of chronic obstructive pulmonary disease: a randomised controlled trial. Lancet 2003;361(9369): 1660.

* Calverley P, Pauwels R, Vestbo J, Jones P, Pride N, Gulsvik A, et al.Combined salmeterol and fluticasone in the treatment of chronic obstructive pulmonary disease: a randomised controlled trial. Lancet 2003;361(9356): 449-56.

Calverley P, Pauwels RA, Jones PW, Anderson JA, Vestbos $\mathrm{J}$. The severity of airways obstruction as a determinant of treatment response in COPD. International Journal of COPD 2006;1(3):209-18.

Calverley PMA, Pauwels R, Vestbo J, Jones P, Pride NB, Gulsvik A, et al.Safety of salmeterol/fluticasone propionate combination in the treatment of chronic obstructive pulmonary disease (COPD) for one year [abstract]. European Respiratory Journal 2002;20(Suppl 38):242s [P1572].

Calverley PMA, Pauwels RA, Vestbo J, Jones PW, Pride NB, Gulsvik A, et al.Clinical improvements with salmeterol/ fluticasone propionate combination in differing severities of COPD. American Thoracic Society 99th International Conference; May 16-21; Seattle. 2003:A035 Poster D50. Calverley PMA, Pauwels RA, Vestbo J, Jones PW, Pride $\mathrm{NB}$, Gulsvik A, et al.Salmeterol/fluticasone propionate combination for one year provides greater clinical benefit than its individual components in COPD. American Journal of Respiratory and Critical Care Medicine 2002;165(Suppl 8):A226.

Claverley PMA, Pauwels RA, Vestbo J, Jones PW, Pride $\mathrm{NB}$, Gulsvik A, et al.Salmeterol/fluticasone propionate combination for one year provides greater clinical benefit than its individual components in COPD. American Journal of Respiratory and Critical Care Medicine 2002;165(8 Suppl): A226.

Edin HM, Price MJ, Wire P, Lee B, Chang C, Darken P, et al.Fluticasone propionate/salmeterol combination improves quality of life in patients with COPD. American Journal of Respiratory and Critical Care Medicine 2001;163(5 Suppl): A506.

GlaxoSmithKline. A multicentre, randomised, doubleblind, parallel group, placebo-controlled study to compare the efficacy and safety of the salmeterol/FP combination product at a strength of $50 / 500 \mathrm{mcg}$ bd with salmeterol $50 \mathrm{mcg}$ bd alone and FP 500mcg bd alone, delivered via the 
DISKUS /ACCUHALER , in the treatment of subjects with chronic obstructive pulmonary disease (COPD) for 12 months. http://www.gsk-clinicalstudyregister.com/study/ SFCB3024\#rs (accessed 11 February 2014).

Hunjan MK, Chandler F. Numbers needed to treat (NNT) to avoid an exacerbation in patients with chronic obstructive pulmonary disease (COPD) using salmeterol/fluticasone propionate combination (SFC) and associated costs [Abstract]. American Thoracic Society 100th International Conference; May 21-26; Orlando. 2004:D22 [Poster 503]. Hunjan MK, Williams DT. Costs of avoiding exacerbations in patients with chronic obstructive pulmonary disease (COPD) treated with salmeterol/fluticasone propionate combination (seretide) and salmeterol [Abstract]. European Respiratory Journal 2004;24(Suppl 48):291s.

Hunjan MK, Williams DT. Salmeterol/fluticasone propionate combination is clinically effective in avoiding exacerbations in patients with moderate/severe COPD [Abstract]. European Respiratory Journal 2004;24(Suppl 48):513s.

Jones PW, Edin HM, Anderson J. Salmeterol/fluticasone propionate combination improves health status in COPD patients. American Journal of Respiratory and Critical Care Medicine 2002;165(Suppl 8):A111.

Khamis RYRRK, Khamis RY, Rajakulasingam RK. Combined salmeterol and fluticasone for COPD. Lancet 2003;361(9369): 1652; author reply 1652-3.

Nitschmann S. Inhalational combination therapy in chronic obstructive lung disease. Tristan study. German Internist 2004;45(6):727-8.

Pauwels RA, Calverley PMA, Vestbo J, Jones P, Pride NB, Gulsvik A, et al.Reduction of exacerbations with salmeterol/ fluticasone combination $50 / 500 \mathrm{mcg}$ bd in the treatment of chronic obstructive pulmonary disease (COPD) [abstract]. European Respiratory Journal 2002;20 Suppl 38:240 [P1569].

Pauwels RA, Vestbo J, Calverley PA, Jones PW, Pride NB, Gulsvik A, et al.Characterization of exacerbations in the TRISTAN study of salmeterol/fluticasone propionate (SFC) combination in moderate to severe COPD [abstract]. American Thoracic Society 99th International Conference; May 16-21; Seattle. 2003:D092 Poster 215.

Spencer MD, Karia N, Anderson J. The clinical significance of treatment benefits with the salmeterol/fluticasone propionate $50 / 500 \mathrm{mcg}$ combination in COPD [Abstract]. European Respiratory Journal 2004;24(Suppl 48):290s. Vestbo J, Calverley PMA, Pauwels R, Jones P, Pride NB, Gulsvik A, et al.Absence of JOURder susceptibility to the combination of salmeterol and fluticasone in the treatment of chronic obstructive pulmonary disease [abstract]. European Respiratory Journal 2002;20 Suppl 38:240 [P1570].

Vestbo J, Pauwels R, Anderson JA, Jones P, Calverley P, TRISTAN Study Group. Early onset of effect of salmeterol and fluticasone propionate in chronic obstructive pulmonary disease. Thorax 2005;60(4):301-4. Vestbo J, Pauwels RA, Calverley PA, Jones PW, Pride
NB, Gulsvik A, et al.Salmeterol/fluticasone propionate combination produces improvement in lung function detectable within 24 hours in moderate to severe COPD [abstract]. American Thoracic Society 99thInternational Conference; May 16-21; Seattle. 2003:A035 Poster D48. Vestbo J, Soriano JB, Anderson JA, Calverley P, Pauwels R, Jones $P$, et al.Gender does not influence the response to the combination of salmeterol and fluticasone propionate in COPD. Respiratory Medicine 2004;98(11):1045-50.

\section{Calverley 2003a \{published data only\}}

AstraZeneca SD. A placebo-controlled 12-month efficacy study of the fixed combination budesonide/formoterol compared to budesonide and formoterol as monotherapies in patients with chronic obstructive pulmonary disease (COPD). http://www.astrazenecaclinicaltrials.com/ (accessed 6 March 2014).

Borgstrom L, Asking L, Olsson H, Peterson S. Lack of interaction between disease severity and therapeutic response with budesonide/formoterol in a single inhaler [Abstract]. American Thoracic Society 100th International Conference; May 21-26; Orlando. 2004:C22 [Poster 505].

* Calverley PM, Boonsawat W, Cseke Z, Zhong N, Peterson $\mathrm{S}$, Olsson $\mathrm{H}$, et al.Maintenance therapy with budesonide and formoterol in chronic obstructive pulmonary disease. European Respiratory Journal 2003;22(6):912-9.

Calverley PM, Szafranski W, Calverley PMA, Andersson A. Budesonide/formoterol is a well-tolerated long term maintenance therapy for COPD [Abstract]. European Respiratory Journal 2005;26(Suppl 49):Abstract No. 1917. Calverley PMA. Effect of Budesonide/Formoterol on severe exacerbations and lung function in moderate to severe COPD. Thorax 2002;57(Suppl III):iii44.

Calverley PMA, Olsson H, the Symbicort International CSG, Symbicort International CSG, Calverley PA, Symbicort International CG. Budesonide/formoterol in a single inhaler sustains improvements in lung function over 12 months compared with monocomponents and placebo in patients with COPD [abstract]. American Thoracic Society 99th International Conference; May 16-21; Seattle. 2003:B024 [Poster 418].

Calverley PMA, Peterson S. Combining budesonide/ formoterol in a single inhaler reduces exacerbation frequency in COPD [abstract]. American Thoracic Society 99th International Conference; May 16-21; Seattle. 2003:D092 [Poster 211].

Calverley PMA, Sthal E, Jones PW, Ståhl E. Budesonide/ formoterol improves the general health status of patients with COPD [Abstract]. American Thoracic Society International Conference; May 20-25; San Diego. 2005: B93 [Poster 303].

Calverley PMA, Thompson NC, Olsson H. Budesonide/ formoterol in a single inhaler sustains lung function improvements in COPD [Abstract]. European Respiratory Journal 2003;22(Suppl 45):P435.

Calverly PMA, Cseke Z, Peterson S, Calverley PMA. Budesonide/formoterol reduces the use of oral corticosteroids in the treatment of COPD [Abstract]. 
European Respiratory Journal 2003;22 Suppl 45:Abstract No: [P436].

Calverly PMA, Kuna P, Olsson H, Calverley PMA. COPD exacerbations are reduced by budesonide/formoterol in a single inhaler [Abstract]. European Respiratory Journal 2003; 22(Suppl 45):P1587.

Halpin D, Stahl E, Lundback B, Anderson F, Peterson S. Treatment costs and number needed to treat (NNT) with budesonide/formoterol to avoid one exacerbation of COPD [Abstract]. American Thoracic Society 100th International conference, May 21-26, 2004, Orlando. 2004:D22 [Poster 525].

Halpin DMG, Larsson T, Calverley PMA. How many patients with COPD must be treated with budesonide/ formoterol compared with formoterol alone to avoid 1 day of oral steroid use? [Abstract]. American Thoracic Society 2005 International Conference; May 20-25; San Diego. 2005: [B93] [Poster: 314].

Jones PW, Stahl E. Budesonide/formoterol in a single inhaler improves health status in patients with COPD [abstract]. American Thoracic Society 99th International Conference; May 16-21, 2003; Orlando. 2003:B024 [Poster 419]. Jones PWSE, Jones PW, Ståhl E, Stahl E. Budesonide / formoterol sustains clinically relevant improvements in health status in COPD [Abstract]. European Respiratory Journal 2005;26(Suppl 49):Abstract No. 1352.

Lofdahl CG. Reducing the impact of COPD exacerbations: clinical efficacy of budesonide/formoterol. European Respiratory Review 2004;13(88):14-21.

Lofdahl CG, Andreasson E, Svensson K, Ericsson A. Budesonide/formoterol in a single inhaler improves overall health status in patients with COPD without increasing healthcare costs [abstract]. American Thoracic Society 99th International Conference; May 16-21; Seattle. 2003:A035 Poster D46.

Lofdahl CG, Andreassson E, Svensson K, Ericsson A, Andreasson E. Budesonide/formoterol in a single inhaler improves health status in patients with COPD without increasing healthcare costs [Abstract]. European Respiratory Journal 2003;22(Suppl 45):P433.

Lofdahl CG, Ericsson A, Svensson K, Andreasson E. Cost effectiveness of budesonide/formoterol in a single inhaler for COPD compared with each monocomponent used alone. PharmacoEconomics 2005;23(4):365-75.

Calverley 2003b \{published data only\}

* Calverley P, Pauwels R, Nieminem M, Stryszak P, Staudinger H, Lee T. Once daily mometasone furoate dry powder inhaler preserves lung function, reduces symptoms and delays exacerbations in patients with COPD previously maintained on ICS [Abstract]. European Respiratory Journal 2003;22(Suppl 45):Abstract No: [155].

Calverley 2007 [TORCH] \{published data only\}

Allegra L. TORCH study: an invitation to clinical considerations. Giornale Italiano delle Malattie del Torace 2007;61(1):15-23.

Briggs AH, Glick HA, Lozano-Ortega G, Spencer M, Calverley PM, Jones PW, et al.Is treatment with ICS and
LABA cost-effective for COPD? Multinational economic analysis of the TORCH study. European Respiratory Journal 2010;35(3):532-9.

Briggs AH, Lozano-Ortega G, Spencer S, Bale G, Spencer MD, Burge PS. Estimating the cost-effectiveness of fluticasone propionate for treating chronic obstructive pulmonary disease in the presence of missing data. Value in Health 2006;9(4):227-35. [CRS-ID: 4900100000020068] Calverley P, Celli B, Anderson J, Ferguson G, Jenkins C, Jones $\mathrm{P}$, et al.Salmeterol/fluticasone propionate combination (SFC) improves survival in COPD over three years: ontreatment analysis from the TORCH study [Abstract]. American Thoracic Society International Conference; May 15-20; San Diego. 2009:A6191[Poster \#219].

Calverley P, Celli B, Anderson JA, Ferguson GT, Jenkins $\mathrm{C}$, Jones PW, et al.The TOwards a Revolution in COPD Health (TORCH) study: salmeterol/fluticasone propionate improves survival in COPD over three years [Abstract]. Respirology 2006;11(Suppll 5):A149 [PS-3-8]. Calverley PM, Anderson JA, Celli B, Ferguson GT, Jenkins $\mathrm{C}$, Jones $\mathrm{PW}$, et al.Cardiovascular events in patients with chronic obstructive pulmonary disease: TORCH study results. Thorax 2010;65(8):719-25.

* Calverley PM, Anderson JA, Celli B, Ferguson GT, Jenkins $\mathrm{C}$, Jones PW, et al.Salmeterol and fluticasone propionate and survival in chronic obstructive pulmonary disease. New England Journal of Medicine 2007;356(8):775-89.

Calverley PM, Celli B, Anderson JA, Ferguson GT, Jenkins $\mathrm{C}$, Jones PW, et al.The towards a revolution in COPD health (TORCH) study: fluticasone propionate/salmeterol improves survival in COPD over three years [Abstract]. Chest 2006;130(4):122s.

Calverley PMA, Celli B, Andersen JA, Ferguson GT, Jenkins $\mathrm{C}$, Jones PW, et al.The TORCH (towards a revolution in COPD health) study: salmeterol/fluticasone propionate (SFC) improves health status reduces exacerbations and improves lung function over three years [Abstract]. European Respiratory Journal 2006;28(Suppl 50):34s [E311]. Calverley PMA, Celli B, Ferguson G, Jenkins C, Jones P, Pride NB, et al.Baseline characteristics of the first 5,000 COPD patients enrolled in the TORCH survival study. European Respiratory Journal 2003;22(Suppl 45):578s. [CRS-ID: 4900100000023124]

Celli B, Calverley PM, Anderson JA, Ferguson GT, Jenkins $\mathrm{C}$, Jones $\mathrm{P}$, et al.The TOwards a Revolution in COPD HEalth (TORCH) study: salmeterol/fluticasone propionate reduces the rate of exacerbations over three years [Abstract]. Respirology 2006;11(Suppl 5):A140 [O-9-2].

Celli B, Calverley PM, Anderson JA, Ferguson GT, Jenkins $\mathrm{C}$, Jones $\mathrm{PW}$, et al.The towards a revolution in COPD health (TORCH) study: fluticasone propionate/salmeterol reduces the rate of exacerbations over 3 years [Abstract]. Chest 2006;130(4):177s.

Celli B, Calverley PMA, Anderson JA, Ferguson GT, Jenkins $\mathrm{C}$, Jones PW, et al.The TORCH (towards a revolution in COPD health) study: salmeterol/fluticasone propionate (SFC) improves health status, reduces exacerbations

Long-acting inhaled therapy (beta-agonists, anticholinergics and steroids) for COPD: a network meta-analysis (Review) 
and improves lung function over three years [Abstract]. European Respiratory Journal 2006;28(Suppl 50):34s [E312]. Celli B, Emmett A, Crater G, Kalberg C. Fluticasone propionate/salmeterol (FSC) improves the inspiratory to total lung capacity ratio (IC/TLC) and exercise endurance time in patients with COPD [Abstract]. American Thoracic Society International Conference; May 19-21; San Diego. 2006:A320 [Poster 323].

Celli B, Emmett A, Crater G, Kalberg C, Celli D. Salmeterol/fluticasone propionate (SFC) improves the inspiratory to total lung capacity ratio (IC/TLC) and exercise endurance time in patients with COPD [Abstract]. European Respiratory Journal 2006;28(Suppl 50):764s [4395].

Celli B, Ferguson GT, Anderson JA, Jenkins CR, Jones PW, Vestbo J, et al.Salmeterol/fluticasone propionate (SFC) improves lung function and reduces the rate of decline over three years in the TORCH survival study [Abstract]. American Thoracic Society International Conference; May 18-23; San Francisco. San Francisco, California, USA, 2007:[A763].

Celli B, Vestbo J, Jenkins CR, Jones PW, Ferguson GT, Calverley PM, et al.Sex differences in mortality and clinical expressions of patients with chronic obstructive pulmonary disease. The TORCH experience. American Journal of Respiratory and Critical Care Medicine 2011;183(3):317-22. Celli BR, Thomas NE, Anderson JA, Ferguson GT, Jenkins $\mathrm{CR}$, Jones PW, et al.Effect of pharmacotherapy on rate of decline of lung function in chronic obstructive pulmonary disease: results from the TORCH study. American Journal of Respiratory and Critical Care Medicine 2008;178(4): 332-8.

Corhay JL, Louis R. [Clinical study of the month: the TORCH study (TOwards a Revolution in COPD Health)]. [French]. Revue Medicale de Liege 2007;62(4):230-4. Crim C, Calverley PM, Anderson JA, Celli B, Ferguson GT, Jenkins $C$, et al.Pneumonia risk in COPD patients receiving inhaled corticosteroids alone or in combination: TORCH study results. European Respiratory Journal 2009; 34(3):641-7.

Ferguson GT, Calverley PM, Anderson JA, Celli B, Jenkins $\mathrm{C}$, Jones PW, et al.The towards a revolution in COPD health (TORCH) study: fluticasone propionate/salmeterol is well tolerated in patients with COPD over 3 years [Abstract]. Chest 2006;130(4):178s.

Ferguson GT, Calverley PM, Anderson JA, Celli B, Jenkins $\mathrm{CR}$, Jones PW, et al.Effect of salmeterol/fluticasone propionate (SFC) on bone mineral density (BMD) and eye disorders over three years in the TORCH trial [Abstract]. American Thoracic Society International Conference, May 18-23, San Francisco. San Francisco, California, USA, 2007:[A763].

Ferguson GT, Calverley PM, Anderson JA, Jenkins CR, Jones PW, Willits LR, et al.Prevalence and progression of osteoporosis in patients with COPD: results from the TOwards a Revolution in COPD Health study. Chest 2009;
136(6):1456-65.

GlaxoSmithKline. A multi-centre, randomised, doubleblind, parallel group study to investigate the efficacy and safety of the salmeterol/fluticasone propionate combination at a strength of 50/500 $\mu \mathrm{g} \mathrm{BD}$, compared with placebo via Accuhaler, added to usual chronic obstructive pulmonary disease (COPD) therapy, in subjects with COPD for 24 weeks [SCO100540]. http://www.gskclinicalstudyregister.com/study/100540? study ${ }^{\prime i d s=}$ SCO100540\#rs (accessed 3 March 2014).

GlaxoSmithKline. A multicentre, randomised, doubleblind, parallel group, placebo-controlled study to compare the efficacy and safety of the salmeterol/FP combination product at a strength of $50 / 500 \mathrm{mcg}$ bd with salmeterol $50 \mathrm{mcg}$ bd alone and FP $500 \mathrm{mcg}$ bd alone, delivered via the DISKUS Accuhaler, in the treatment of subjects with chronic obstructive pulmonary disease (COPD) for 12 months. SFCB3024. http://www.gskclinicalstudyregister.com/ (accessed 3 March 2014). [CRS-ID: 4900100000078008]

GlaxoSmithKline. A multicentre, randomised, doubleblind, parallel group, placebo-controlled study to investigate the long-term effects of salmeterol/fluticasone propionate (SERETIDE®/VIANI®/ADVAIR®) 50/500 mcg bd, salmeterol $50 \mathrm{mcg}$ bd and fluticasone propionate 500 mcg bd, all delivered via the DISKUS®/ACCUHALER $®$ inhaler, on the survival of subjects with chronic obstructive pulmonary disease (COPD) over 3 years of treatment. http: //www.gsk-clinicalstudyregister.com/ (accessed 3 March 2014).

Glick H, Briggs A, Lozano-Ortega G, Spencer M, Vestbo J, Calverley P. Is treatment with ICS/LABA combination good value for money in COPD? Evidence from the TORCH study [Abstract]. American Thoracic Society International Conference; May 18-23; San Francisco. 2007:[C97]. Houghton CM, Lawson N, Borrill ZL, Wixon CL, Yoxall S, Langley SJ, et al.Comparison of the effects of salmeterol/ fluticasone propionate with fluticasone propionate on airway physiology in adults with mild persistent asthma. Respiratory Research 2007;8:52. [CRS-ID: 4900102000000754] Jenkins C, Celli B, Anderson J, Ferguson G, Calverley P, Jones $\mathrm{P}$, et al.Salmeterol/fluticasone propionate (SFC) is efficacious in GOLD stage II COPD patients: analysis from the TORCH study [Abstract]. American Thoracic Society International Conference; May 15-20; San Diego. 2009: A6186 [Poster \#213].

Jenkins CR, Calverley PMA, Celli B, Ferguson G, Jones $\mathrm{PW}$, Pride N, et al.Seasonal patterns of exacerbation rates in the TORCH survival study [Abstract]. American Thoracic Society International Conference; May 19-24; San Diego. 2006:A839 [Poster 603]. [CRS-ID: 4900100000020491] Jenkins CR, Celli B, Anderson JA, Ferguson GT, Jones PW, Vestbo J, et al.Seasonality and determinants of moderate and severe COPD exacerbations in the TORCH study. European Respiratory Journal 2012;39(1):38-45. Jenkins CR, Celli B, Anderson JA, Ferguson GT, Jones PW, Vestbo J, et al.The TORCH survival study: consistent

Long-acting inhaled therapy (beta-agonists, anticholinergics and steroids) for COPD: a network meta-analysis (Review) 
efficacy results seen in geographic regions in a multi-national study [Abstract]. American Thoracic Society International Conference; May 18-23; San Francisco. 2007:[C97]. Jenkins CR, Jones PW, Calverley PM, Celli B, Anderson JA, Ferguson GT, et al.Efficacy of salmeterol/fluticasone propionate by GOLD stage of chronic obstructive pulmonary disease: analysis from the randomised, placebocontrolled TORCH study. Respiratory Research 2009;10:59. Johnson M, Agusti AG, Barnes NC. Reflections on TORCH: potential mechanisms for the survival benefit of salmeterol/fluticasone propionate in COPD patients. COPD 2008;5(6):369-75.

Jones P, Calverley P, Celli B, Ferguson G, Jenkins C, Pride N, et al.Trans-regional validity of the SGRQ in the TORCH survival study [Abstract]. American Thoracic Society International Conference; May 19-21; San Diego. 2006:A122 [Poster J79]. [CRS-ID: 4900100000020810] Jones PW, Anderson JA, Calverley PM, Celli BR, Ferguson GT, Jenkins C, et al.Health status in the TORCH study of COPD: treatment efficacy and other determinants of change. Respiratory Research 2011;12:71.

Jones PW, Calverley P, Celli B, Ferguson G, Jenkins C, Pride $\mathrm{N}$. Trans-regional validity of the SGRQ in the TORCH survival study. American Thoracic Society International Conference; May 19-24; San Diego. 2006:A122, Poster J79. [CRS-ID: 4900100000061615]

Jones PW, Calverley PM, Celli B, Anderson JA, Ferguson GT, Jenkins $\mathrm{C}$, et al.The towards study a revolution in COPD health (TORCH) study: fluticasone propionate/ salmeterol improves and sustains health status in COPD over 3 years [Abstract]. Chest 2006;130(4):177s.

Jones PW, Vestbo J, Anderson JACB, Ferguson GT, Jenkins $\mathrm{CR}$, Yates JC, et al.Informative withdrawal in a COPD study. An example from the TORCH Study [Abstract]. American Thoracic Society International Conference; May 18-23; San Francisco. 2007:[C97].

Keene ON, Vestbo J, Anderson JA, Calverley PMA, Celli B, Ferguson GT, et al.Methods for therapeutic trials in COPD: lessons from the TORCH trial. European Respiratory Journal 2009;34(5):1018-23.

McDonough C, Blanchard AR. TORCH study results: pharmacotherapy reduces lung function decline in patients with chronic obstructive pulmonary disease. Hospital Practice (1995) 2010;38(2):92-3.

McGarvey LP, John M, Anderson JA, Zvarich M, Wise RA, Committee TCE, et al.Ascertainment of cause-specific mortality in COPD: operations of the TORCH Clinical Endpoint Committee. Thorax 2007;62(5):411-5. Mehta RS, Kathman SJ, Daley-Yates PT, Cahn T, Beerahee M, Kunka RL, et al.Pharmacokinetics and pharmacodynamics in COPD patients following long-term twice-daily treatment with salmeterol/fluticasone propionate (SFC) 50/500mg and the individual components [Abstract]. American Thoracic Society International Conference; May 18-23; San Francisco. San Francisco, California, USA, 2007:Poster \#A41.

NCT. A multicenter, randomized, double-blind, parallel group, placebo controlled study to investigate the effects of salmeterol/fluticasone $50 / 500 \mathrm{mcg}$ bd, salmeterol $50 \mathrm{mcg}$ bd, and fluticasone $500 \mathrm{mcg}$ bd, all delivered via the DISKUS/ ACCUHALER inhaler, on the survival of subjects with chronic obstructive pulmonary disease over 3 years of treatment. ClinicalTrials.gov 2000.

NCT00268216. Survival of subjects with chronic obstructive pulmonary disease (COPD). http:// clinicaltrials.gov/show/NCT00268216 (accessed 3 March 2014). [CRS-ID: 4900100000080627]

SCO30003. A multicentre, randomised, double-blind, parallel group, placebo-controlled study to investigate the long-term effects of salmeterol/fluticasone propionate (SERETIDE ADVAIR®) 50/500mcg bd, salmeterol $50 \mathrm{mcg}$ bd and fluticasone propionate $500 \mathrm{mcg}$ bd, all delivered via the DISKUS $® / A C C U H A L E R \circledR$ inhaler, on the survival of subjects with chronic obstructive pulmonary disease (COPD) over 3 years of treatment. http://www.gskclinicalstudyregister.com/study/SCO30003\#ps (accessed 3 March 2014). [CRS-ID: 4900100000033585]

Sacchetta A. Long term therapy and outcome of chronic obstructive pulmonary disease with or without comorbidity: the TORCH study. Italian Journal of Medicine 2008;2(3):11-5.

Vestbo J, Anderson JA, Calverley PM, Celli B, Ferguson GT, Jenkins $C$, et al.Adherence to inhaled therapy, mortality and hospital admission in COPD. Thorax 2009;64(11):939-43. Vestbo J, Anderson JA, Calverley PMA, Celli B, Ferguson GT, Jenkins $C$, et al.Bias due to withdrawal in long-term randomised trials in COPD: evidence from the TORCH study. Clinical Respiratory Journal 2011;5(1):44-9.

Vestbo J, TORCH SG, Calverley P, Celli B, Ferguson G, Jenkins C, et al.The TORCH (towards a revolution in COPD health) survival study protocol. European Respiratory Journal 2004;24(2):206-10. [CRS-ID: 4900100000017206]

Wise RA, McGarvey LP, John M, Anderson JA, Zvarich MT. Reliability of cause-specific mortality adjudication in a COPD clinical trial. American Thoracic Society International Conference; May 18-23; San Francisco. 2007: A120. [CRS-ID: 4900100000080628]

Wise RA, McGarvey LP, John M, Anderson JA, Zvarich MT, Anderson JA, et al.Reliability of cause specific mortality adjudication in a COPD clinical trial [Abstract]. American Thoracic Society International Conference; May 19-21; San Diego. 2006:A120 [Poster J68]. [CRS-ID: 4900100000020230]

\section{Calverley 2008 \{published data only\}}

* Calverley PM, Rennard S, Nelson HS, Karpel JP, Abbate EH, Stryszak P, et al.One-year treatment with mometasone furoate in chronic obstructive pulmonary disease. Respiratory Research 2008;9:73.

Nelson H, Karpel JP, Staudinger H, Busse WW. Mometasone furoate dry powder inhaler (MF-DPI) improves FEV1, symptoms, and quality of life and reduces exacerbations in patients with COPD [Abstract]. Chest 2004;126(4 Suppl):709S-c, 710. 
Calverley 2010 \{published data only\}

* Calverley PMA, Kuna P, Monsó E, Costantini M, Petruzzelli S, Sergio F, et al.Beclomethasone/formoterol in the management of COPD: a randomised controlled trial. Respiratory Medicine 2010;104(12):1858-68.

Campbell 2005 \{published data only\}

AstraZeneca. A 6-month study to compare the efficacy and safety of 9 microg formoterol (Oxis) Turbuhaler b.i.d. with placebo b.i.d. in patients with chronic obstructive pulmonary disease (COPD). Furthermore to compare formoterol 4.5 microg as needed with terbutaline $0.5 \mathrm{mg}$ as needed. SD-037-0709. http:// www.astrazenecaclinicaltrials.com/ (accessed 12 December 2012).

Bogdan M, Eliraz A, McKinnon C, Nihlen U, Radeczky E, Soliman S, et al.Formoterol turbuhaler is an effective maintenance and maintenance plus reliever therapy in patients with chronic obstructive pulmonary disease (COPD) irrespective of the level of lung function impairment and reversibility [abstract]. European Respiratory Society 12th Annual Congress; Sep 14-18; Stockholm. 2002:abstract nr: P1578.

* Campbell M, Eliraz A, Johansson G, Tornling G, Nihlén $\mathrm{U}$, Bengtsson T, et al.Formoterol for maintenance and asneeded treatment of chronic obstructive pulmonary disease. Respiratory Medicine 2005;99(12):1511-20.

Campbell M, Rabe KF, Andersson A. Formoterol turbuhaler for maintenance and as-needed use is effective and well tolerated in patients with COPD [abstract]. American Thoracic Society 99th International Conference; May 1621; Seattle. 2003:B024 Poster 417.

Eliraz A, Bengtsson T, Bogdan M, Coenen PDM, Johanson $\mathrm{G}$, Osmanilev D, et al.Formoterol turbuhaler is effective and safe as maintenance or maintenance plus reliever therapy in patients with chronic obstructive pulmonary disease (COPD) [abstract]. European Respiratory Society 12th Annual Congress; Sep 14-18; Stockholm. 2002:abstract nr: P1580.

\section{Casaburi 2002 \{published data only\}}

Adams SG, Anzueto A, Briggs DD, Menjoge SS, Kesten S. Tiotropium in COPD patients not previously receiving maintenance respiratory medications. Respiratory Medicine 2006;100(9):1495-503.

Anzueto A, Kesten S. Effects of tiotropium in COPD patients only treated with PRN albuterol [Abstract]. American Thoracic Society 100th International Conference; May 21-26; Orlando. 2004:C47 Poster F81.

Anzueto A, Tashkin D, Menjoge S, Kesten S. One-year analysis of longitudinal changes in spirometry in patients with COPD receiving tiotropium. Pulmonary Pharmacology \& Therapeutics 2005;18(2):75-81.

* Casaburi R, Mahler DA, Jones PW, Wanner A, San PG, ZuWallack RL, et al.A long-term evaluation of oncedaily inhaled tiotropium in chronic obstructive pulmonary disease. European Respiratory Journal 2002;19(2):217-24. Friedman M, Bell T, Menjoge SS, Anton S, Koch P. Cost consequences of tiotropium plus existing therapy versus existing therapy alone following one year of treatment in patients with COPD. European Respiratory Journal 2001;18 (Suppl 33):5s.

Kesten S, Menjoge S. Can patient demographics be used to predict future choices for antibiotics, steroids, or both for exacerbations of COPD? [Abstract]. National COPD conference; November 14-15; Arlington, Virginia. 2003: Abstract no: 1189.

Mahler DA, Montner P, Brazinsky SA, Goodwin B, Menjoge SS, Witek TJ. Tiotropium (Spiriva), a new longacting anticholinergic bronchodilator, improves dyspnea in patients with COPD [abstract]. American Journal of Respiratory and Critical Care Medicine 2000;161(3 Suppl): A892.

Rutten-van Mölken MP, Oostenbrink JB, Miravitlles M, Monz BU. Modelling the 5-year cost effectiveness of tiotropium, salmeterol and ipratropium for the treatment of chronic obstructive pulmonary disease in Spain. European Journal of Health Economics 2007;8(2):123-35.

Serby CW. Impact of tiotropium on COPD exacerbations: 1 -Yr studies versus placebo or ipratropium. European Respiratory Review 2002;12(82):16-7. Spencer S. Decline in health status over one year is eliminated by tiotropium. American Journal of Respiratory and Critical Care Medicine 2002;165(Suppl 8):A228.

Spencer SJPW, Spencer S, Jones PW. Short-term changes in health status with tiotropium predict long-term changes in health status [abstract]. European Respiratory Society 12th Annual Congress; Sep 14-18; Stockholm. 2002:abstract nr: P1611.

Tashkin D, Kesten S. Long-term treatment benefits with tiotropium in COPD patients with and without short-term bronchodilator responses. Chest 2003;123(5):1441-9. Zu Wallack R, Jones PW, Kotch A, Goodwin B, Menjoge SS, Serby CW, et al.Tiotropium (Spiriva) improves health status in patients with COPD [abstract]. American Journal of Respiratory and Critical Care Medicine 2000;161(3 Suppl): A892.

\section{Chan 2007 \{published data only\}}

* Chan CK, Maltais F, Sigouin C, Haddon JM, Ford GT, Group SS, et al.A randomized controlled trial to assess the efficacy of tiotropium in Canadian patients with chronic obstructive pulmonary disease. Canadian Respiratory Journal [Revue canadienne de pneumologie] 2007;14(8):465-72.

\section{Cooper 2010 \{published data only\}}

* Cooper CB, Abrazado M, Legg D, Kesten S. Development and implementation of treadmill exercise testing protocols in COPD. International Journal of Chronic Obstructive Pulmonary Disease 2010;5:375-85.

Cooper CB, Celli B, Wise RA, Jardim JR, Legg D, Guo J, et al.'Treadmill endurance during 2 years' treatment with tiotropium in patients with COPD [Abstract]. American Journal of Respiratory and Critical Care Medicine 2011;183 (Meeting Abstracts):A4586.

Cooper CB, Celli BR, Wise R, de Brito Jardim JR, Guo $\mathrm{J}$, et al.Relationship between quality of life and exercise endurance in a long-term study of tiotropium in COPD 
patients [Abstract]. American Journal of Respiratory and Critical Care Medicine 2012;185(Meeting Abstracts): A1534.

\section{Dahl 2010 \{published data only\}}

Buhl R, Pieters W, Jack D, Owen R, Kramer B, Higgins M. Indacaterol once-daily improves dyspnoea and BODE index in COPD patients: a 52-week study [Abstract]. European Respiratory Society Annual Congress; Sep 12-15; Vienna. 2009:[P2026].

Buhl R, Pieters W, Jack D, Owen R, Kramer B, Higgins $\mathrm{M}$. Indacaterol once-daily reduces COPD exacerbations over 52 weeks of treatment [Abstract]. American Thoracic Society International Conference; May 15-20; San Diego. 2009:A6185 [Poster \#212].

Chung F, Kornmann O, Jack D, Owen R, Kramer B, Higgins M. Safety and tolerability of indacaterol over 52 weeks of treatment in COPD [Abstract]. European Respiratory Society 19th Annual Congress; Sep 12-15; Vienna. 2009:[E4359].

Chung KF, Kornmann O, Jack D, Owen R, Kramer B, Higgins $\mathrm{M}$, et al.Safety and tolerability of indacaterol over 52 weeks of treatment in COPD [Abstract]. European Respiratory Society 19th Annual Congress; Sep 12-15; Vienna. 2009:A4546 [Poster \#J56].

* Dahl R, Chung KF, Buhl R, Magnussen H, Nonikov V, Jack D, et al.Efficacy of a new once-daily long-acting inhaled beta2-agonist indacaterol versus twice-daily formoterol in COPD. Thorax 2010;65(6):473-9.

Dahl R, Kolman P, Jack D, Bleasdale P, Owen R, Higgins $\mathrm{M}$, et al.Bronchodilator therapy with indacaterol oncedaily in COPD: a 52-week comparison with formoterol [Abstract]. European Respiratory Society 19th Annual Congress; Sep 12-15; Vienna. 2009:[E4350].

Dahl R, Kolman P, Jack D, Owen R, Kramer B, Higgins

$\mathrm{M}$. Indacaterol once-daily provides sustained 24-h bronchodilation over 52 weeks of treatment in COPD [Abstract]. American Thoracic Society International Conference; May 15-20; San Diego. 2009:A4545 [Poster \# J55].

Magnussen H, Paggiaro P, Jack D, Owen R, Higgins M, Kramer B, et al.Bronchodilator treatment with indacaterol once-daily vs formoterol twice-daily in COPD: a 52-week study [Abstract]. American Thoracic Society International Conference; May 15-20 San Diego. 2009:A6184 [Poster \# 211].

Magnussen H, Verkindre C, Jack D, Jadayel D, Owen R, Higgins $\mathrm{M}$, et al.Indacaterol once-daily is equally effective dosed either in the evening or morning in COPD patients [Abstract]. European Respiratory Society 19th Annual Congress; Sep 12-15; Vienna. 2009:[E4361].

Nonikov V, Verkindre C, Jack D, Bleasdale P, Owen R, Kramer B, et al.Indacaterol once-daily improves symptom control in COPD patients: a 52-week evaluation vs placebo (pbo) and formoterol (for) [Abstract]. European Respiratory Society 19th Annual Congress; Sep 12-15; Vienna. 2009: [P2024].

Nonikov V, Verkindre C, Jack D, Owen R, Higgins M,
Kramer B. Indacaterol once-daily reduces days of poor control in COPD over 52 weeks of treatment [Abstract]. American Thoracic Society International Conference; May 15-20 San Diego. 2009:A6190 [Poster \#218].

Dal Negro 2003 \{published data only\}

Dal Negro R, Micheletto C, Trevison F, Tognells S, Pomari C, Spencer S, et al.Salmeterol \& fluticasone $50 \mu \mathrm{g} / 250 \mu \mathrm{g}$ bid vs salmeterol $50 \mu \mathrm{g}$ bid and vs placebo in the long-term treatment of COPD. American Journal of Respiratory and Critical Care Medicine 2002;165(Suppl 8):A228.

* Dal Negro RW, Pomari C, Tognella S, Micheletto C, Dal Negro R. Salmeterol \& fluticasone 50 microg/250 microg bid in combination provides a better long-term control than salmeterol 50 microg bid alone and placebo in COPD patients already treated with theophylline. Pulmonary Pharmacology and Therapeutics 2003;16(4):241-6.

Doherty 2012 \{published data only\}

Doherty D, Tashkin D, Kerwin E, Eduardo Matiz-Bueno C, Shekar T, Banerjee S, et al.Efficacy and safety of mometasone furoate/formoterol in subjects with moderate to very severe chronic obstructive pulmonary disease: results from two phase three 26-week trials [Abstract]. Chest 2011; 140(4):535A.

Doherty DE, Kerwin E, Tashkin DP, Matiz-Bueno CE, Shekar T, Banerjee $S$, et al.Combined mometasone furoate and formoterol in patients with moderate to very severe chronic obstructive pulmonary disease (COPD): phase 3 efficacy and safety study [Abstract]. Journal of Allergy and Clinical Immunology 2012;129(2 Suppl):AB75 [283].

* Doherty DE, Tashkin DP, Kerwin E, Knorr BA, Shekar T, Banerjee $S$, et al.Effects of mometasone furoate/formoterol fumarate fixed-dose combination formulation on chronic obstructive pulmonary disease (COPD): results from a 52-week Phase III trial in subjects with moderate-to-very severe COPD. International Journal of Chronic Obstructive Pulmonary Disease 2012;7:57-71.

Kerwin E, Tashkin D, Matiz-Bueno CE, Doherty D, Shekar T, Banerjee $S$, et al.Quality of life following 26 weeks of mometasone furoate/formoterol therapy: results from two phase three trials in subjects with moderate to very severe chronic obstructive pulmonary disease [Abstract]. Chest 2011;140(4):558A.

Matiz-Bueno CE, Doherty D, Kerwin E, Tashkin D, Shekar $\mathrm{T}$, Banerjee $\mathrm{S}$, et al.The long-term safety characteristics of mometasone furoate/formoterol for the treatment of moderate to very severe chronic obstructive pulmonary disease: pooled findings from two 1-year multicenter clinical trials [Abstract]. Chest 2011;140(4):548A.

Tashkin D, Doherty D, Kerwin E, Matiz-Bueno CE, Shekar $\mathrm{T}$, Banerjee $\mathrm{S}$, et al.The effect of mometasone furoate/ formoterol combination therapy on chronic obstructive pulmonary disease (COPD) exacerbations: results from two phase three trials in subjects with moderate to very severe COPD [Abstract]. Chest 2011;140(4):549A.

Tashkin DP, Doherty DE, Kerwin E, Matiz-Bueno CE, Knorr B, Shekar T, et al.Efficacy and safety characteristics of mometasone furoate/formoterol fumarate fixed-dose 
combination in subjects with moderate to very severe COPD: findings from pooled analysis of two randomized, 52-week placebo-controlled trials. International Journal of COPD 2012;7:73-86.

\section{Donohue 2010 [INHANCE] \{published data only\}} Barnes PJ, Pocock SJ, Magnussen H, Iqbal A, Kramer $\mathrm{B}$, Higgins $\mathrm{M}$, et al.Indacaterol dose selection: utilising an adaptive seamless design in a clinical study in COPD [Abstract]. European Respiratory Society 19th Annual Congress; Sep 12-15; Vienna. 2009:[E4358].

Barnes PJ, Pocock SJ, Magnussen H, Iqbal A, Kramer B, Higgins $M$, et al.Integrating indacaterol dose selection in a clinical study in COPD using an adaptive seamless design. Pulmonary Pharmacology and Therapeutics 2010;23(3): 165-71.

Barnes PJ, Pocock SJ, Magnussen H, Iqbal A, Lawrence $\mathrm{D}$, Kramer B, et al.Integrating indacaterol dose selection in a clinical study in COPD using an adaptive seamless design [Abstract]. American Thoracic Society International conference, May 15-20, San Diego. 2009:A4543 [Poster \# J53].

Chapman KR, Rennard SI, Dogra A, Owen R, Lassen C, Kramer B. Long-term safety and efficacy of indacaterol, a long-acting beta2-agonist, in subjects with COPD: a randomized, placebo-controlled study. Chest 2011;140(1): 68-75.

* Donohue JF, Fogarty C, Lotvall J, Mahler DA, Worth $\mathrm{H}$, Yorgancioglu A, et al.Once-daily bronchodilators for chronic obstructive pulmonary disease: indacaterol versus tiotropium. American Journal of Respiratory and Critical Care Medicine 2010;182(2):155-62.

Fogarty C, Hebert J, Iqbal A, Owen R, Higgins M, Kramer B. Indacaterol once-daily provides effective 24-h bronchodilation in COPD patients: a 26-week evaluation vs placebo and tiotropium [Abstract]. European Respiratory Society 19th Annual Congress; Sep 12-15; Vienna. 2009: [P2025].

Fogarty C, Worth H, Herbert J, Iqbal A, Owen R, Higgins $\mathrm{M}$, et al.Sustained 24-h bronchodilation with indacaterol once-daily in COPD: a 26-week efficacy and safety study [Abstract]. American Thoracic Society International Conference; May 15-20 San Diego. 2009:A4547 [Poster \# J57].

Jones PW, Mahler DA, Gale R, Owen R, Kramer B. Profiling the effects of indacaterol on dyspnoea and health status in patients with COPD. Respiratory Medicine 2011; 105(6):892-9.

Lotvall J, Cosio BG, Iqbal A, Swales J, Owen R, Kramer $\mathrm{B}$, et al.Indacaterol once-daily improves day and nighttime symptom control in COPD patients: a 26-week study versus placebo and tiotropium [Abstract]. European Respiratory Society 19th Annual Congress; Sep 12-15; Vienna. 2009:[P2029].

Mahler D, Palange P, Iqbal A, Owen R, Higgins M, Kramer B. Indacaterol once-daily improves dyspnoea in COPD patients: a 26-week placebo-controlled study with open-label tiotropium comparison [Abstract]. European
Respiratory Society 19th Annual Congress; Sep 12-15;

Vienna. 2009:[E4360].

Rennard S, Bantje T, Centanni S, Chanez P, Chuchalin A, D'Urzo A, et al.A dose-ranging study of indacaterol in obstructive airways disease, with a tiotropium comparison. Respiratory Medicine 2008;102(7):1033-44.

Rennard SI, Chapman KR, Luthra A, Swales J, Lassen C, Owen R, et al.Once-daily indacaterol provides effective bronchodilation over 1 year of treatment in patients with chronic obstructive pulmonary disease (COPD) [Abstract]. Chest 2009;136(4):4S-f.

Worth H, Kleerup E, Iqbal A, Owen R, Kramer B, Higgins M. Safety and tolerability of indacaterol once-daily in COPD patients versus placebo and tiotropium: a 26week study [Abstract]. European Respiratory Society 19th Annual Congress; Sep 12-15; Vienna. 2009:[P2030]. Yorgancioglu A, Mahler D, Iqbal A, Owen R, Higgins M, Kramer B. Indacaterol once-daily improves health-related quality of life in COPD patients: a 26 -week comparison with placebo and tiotropium [Abstract]. European Respiratory Society 19th Annual Congress; Sep 12-15; Vienna. 2009:[P2028].

\section{Dusser 2006 \{published data only\}}

* Dusser D, Bravo ML, Iacono P, Lacono P. The effect of tiotropium on exacerbations and airflow in patients with COPD. European Respiratory Journal 2006;27(3):547-55. Dusser D, Bravo ML, Iacono P, Lacono P. Tiotropium reduces health resource utilization associated with COPD exacerbations [Abstract]. European Respiratory Journal 2004; 24(Suppl 48):513s.

Dusser D, Bravo ML, Ianono P, Lanono P. Tiotropium COPD exacerbations the MISTRAL study [Abstract]. European Respiratory Journal 2004;24(Suppl 48):513s. Dusser D, Viel K, Bravo ML, Iacono P. Tiotropium reduces moderate-to-severe exacerbations in COPD patients irrespective of concomitant use of inhaled corticosteroids (ICS) [Abstract]. American Thoracic Society International Conference; May 19-21; San Diego. 2006:A603 [Poster H6].

Dusser D, Viel K, Rouyrre N, Iancono P. Tiotropium reduces COPD exacerbations requiring treatment with systemic corticosteroids, antibiotics, or hospitalizations [Abstract]. American Thoracic Society International Conference; May 19-21; San Diego. 2006:A603 [Poster $\mathrm{H} 5]$.

Fang 2008 \{published data only\}

* Fang LZ, Liang X, Zhang JQ, Liu L, Fu WP, Zhao $\mathrm{ZH}$, et al.Combination of inhaled salmeterol/fluticasone and tiotropium in the treatment of chronic obstructive pulmonary disease: a randomised controlled trial. ChungHua Chieh Ho Ho Hu Hsi Tsa Chih Chinese Journal of Tuberculosis \& Respiratory Diseases 2008;31(11):811-4.

Ferguson 2008 \{published data only\}

Dalal AA, Blanchette CM, Petersen H, Manavi K, St. Charles M. Cost-effectiveness of fluticasone propionate/ salmeterol $(250 / 50 \mathrm{mcg})$ compared to salmeterol $(50$ $\mathrm{mcg}$ ) in patients with COPD: economic evaluation of a 
randomized, double-blind, parallel-group, multicenter trial (Study SCO40043) [Abstract]. Chest 2008;134(4): 106003s.

Dalal AA, St Charles M, Petersen HV, Roberts MH, Blanchette CM, Manavi-Zieverink K. Cost-effectiveness of combination fluticasone propionate-salmeterol 250/ 50 microg versus salmeterol in severe COPD patients. International Journal of Chronic Obstructive Pulmonary Disease 2010;5:179-87.

* Ferguson G, Anzueto A, Fei R, Emmett A, Crater G, Knobil K, et al.A randomized, double-blind trial comparing the effect of fluticasone/salmeterol 250/50 to salmeterol on COPD exacerbations in patients with COPD. Chest 2007; 132(4):530b-531.

Ferguson GT, Anzueto A, Fei R, Emmett A, Knobil K, Kalberg C. Effect of fluticasone propionate/salmeterol (250/50 microg) or salmeterol (50 microg) on COPD exacerbations. Respiratory Medicine 2008;102(8):1099-108. SCO40043 G. A randomized, double-blind, parallelgroup, 52-week study to compare the effect of fluticasone propionate/salmeterol DISKUS \& 250/50mcg bid with salmeterol DISKUS $® 50 \mathrm{mcg}$ bid on the annual rate of moderate/severe exacerbations in subjects with chronic obstructive pulmonary disease (COPD). http://www.gskclinicalstudyregister.com/study/SCO40043\#ps (accessed 3 March 2014). [CRS-ID: 4900100000033604 ]

FLTA3025 \{published data only\}

Eden HM, Price MJ, Jenkins R, Darken P, Horstman D. Fluticasone propionate improves quality of life in patients with COPD. American Journal of Respiratory and Critical Care Medicine 2001;163(5 Suppl):A643.

Rennard S, Bailey W, Tashkin D, Abrahams R, Horstman $\mathrm{D}, \mathrm{Ho} S$, et al.Improvements in airflow $\&$ dyspnea in COPD patients following BID treatment with fluticasone propionate (FP) $250 \mathrm{mcg} \& 500 \mathrm{mcg}$ for 24 weeks via the diskus(r) inhaler [abstract]. American Journal of Respiratory and Critical Care Medicine 2001;163(5 Suppl):A279.

Gelb 2012 \{published data only\}

* Gelb A, Tashkin D, Make B, Zhong X, Garcia Gil E, Caracta C. Long-term safety of twice-daily aclidinium bromide in COPD patients: a one-year, double-blind study [Abstract]. European Respiratory Society 22nd Annual Congress; Sep 1-5; Vienna. 2012; Vol. 40, issue Suppl 56: 376s [P2118].

Gelb AF, Make BJ, Tashkin DP, Zhong X, Garcia GE, Caracta C. Long-term efficacy and safety of twice-daily aclidinium bromide in COPD patients: a one-year study [Abstract]. American Journal of Respiratory and Critical Care Medicine 2012;185(Meeting Abstracts):A2256.

Tashkin D, Gelb A, Make B, Zhong X, Garcia Gil E, Caracta C. Long-term efficacy of twice-daily aclidinium bromide in COPD patients: a one-year study [Abstract]. European Respiratory Society 22nd Annual Congress; Sep 1-5; Vienna. 2012; Vol. 40, issue Suppl 56:528s [P2893].

GLOW1 2011 \{published data only\}

* D'Urzo A, Ferguson GT, van Noord JA, Hirata K,

Martin C, Horton R, et al.Efficacy and safety of once-daily
NVA237 in patients with moderate-to-severe COPD: the GLOW1 trial. Respiratory Research 2011;12:156.

D'Urzo A, Van Noord JA, Martin C, Horton R, Banerji $\mathrm{D}, \mathrm{Lu} \mathrm{Y}$, et al.Once-daily NVA237 improves symptoms, and reduces COPD exacerbations and associated hospitalisations: the GLOW1 trial [Abstract]. Thorax 2011; 66(Suppl 4):P252.

D’Urzo T, Ferguson G, Martin C, Alagappan VKT, Banerji D, Lu Y, et al.NVA237 once daily offers rapid and clinically meaningful bronchodilation in COPD patients that is maintained for $24 \mathrm{~h}$ : the GLOW1 trial [Abstract]. Thorax 2011;66(Suppl 4):P253.

DUrzo A, Ferguson G, Kato M, Atis S, Martin C, Alagappan VKT, et al.NVA237 once daily provides rapid, clinically meaningful and sustained 24-h bronchodilation in patients with COPD: the GLOW1 trial [Abstract]. European Respiratory Society 21st Annual Congress; Sep 24-28; Amsterdam. 2011; Vol. 38, issue 55:147s [P866]. [GLOW1: NCT01005901]

DUrzo A, Ferguson G, Martin C, Alagappan VKT, Banerji $\mathrm{D}, \mathrm{Lu}$ Y, et al.NVA237 once daily offers rapid and clinically meaningful bronchodilation in COPD patients that is maintained for 24-hours: the GLOW1 trial [Abstract]. 6th IPCRG World Conference; Apr 25-28; Edinburgh. 2012: Abstract 133.

DUrzo A, Ferguson G, Martin C, Lu Y, Banerji D, Overend T. NVA237 once daily reduces the percentage of patients with exacerbations of COPD and associated hospitalizations: the GLOW1 trial [Abstract]. European Respiratory Society 21st Annual Congress; Sep 24-28; Amsterdam. 2011; Vol. 38, issue 55:608s [3427]. DUrzo A, van Noord JA, Martin C, Horton R, Banerji D, Lu Y, et al.Once-daily NVA237 improves symptoms, and reduces COPD exacerbations and associated hospitalisations: the GLOW1 trial [Abstract]. 6th IPCRG World Conference; Apr 25-28; Edinburgh. 2012:Abstract 134.

Kato M, D’Urzo A, Martin C, Banerji D, Lu Y, Overend T. NVA237 once daily improves symptoms and reduces exacerbations of COPD and associated hospitalizations: the GLOW1 trial [Abstract]. Respirology (Carlton, Vic.) 2011; 16(Suppl 2):105 [634].

van Noord JA, Hirata K, DUrzo A, Martin C, Horton R, Lu $\mathrm{Y}$, et al.NVA237 once daily improves dyspnea and healthrelated quality of life (HRQoL) in patients with COPD: the GLOW1 trial [Abstract]. European Respiratory Society 21st Annual Congress; Sep 24-28; Amsterdam. 2011; Vol. 38, issue 55:148s [P867].

\section{GLOW2 2012 \{published data only\}}

* Kerwin EM, Hebert J, Pedinoff A, Gallagher N, Martin C, Banerji D. NVA237 once daily provides rapid and sustained bronchodilation in COPD patients, with efficacy similar to tiotropium: the GLOW2 trial [Abstract]. American Journal of Respiratory and Critical Care Medicine 2012;185 (Meeting Abstracts):A2920.

Kerwin EM, Pedinoff A, Casale TB, Gallagher N, Martin C, Banerji D. NVA237 once daily reduces COPD 
exacerbations with similar rates to tiotropium: the GLOW2 trial [Abstract]. American Journal of Respiratory and Critical Care Medicine 2012;185(Meeting Abstracts):A2255.

Korenblat PE, Hebert J, Gallagher N, Martin C, Banerji D, $\mathrm{Lu}$ Y. NVA237 once daily improves dyspnea and healthrelated quality of life in patients with COPD: the GLOW2 trial [Abstract]. American Journal of Respiratory and Critical Care Medicine 2012;185(Meeting Abstracts):A2254.

\section{Hanania 2003 \{published data only\}}

GlaxoSmithKline. A randomized, double-blind, placebocontrolled, parallel-group trial evaluating the safety and efficacy of the DISKUS formulations of salmeterol (SAL) $50 \mathrm{mcg}$ BID and fluticasone propionate (FP) $500 \mathrm{mcg}$ BID individually and in combination as salmeterol $50 \mathrm{mcg} /$ fluticasone propionate $500 \mathrm{mcg}$ BID (SFC 50/500) compared to placebo in COPD subjects. http://www.gskclinicalstudyregister.com/ (accessed 3 March 2014). Hanania NA. Inhaled salmeterol/fluticasone propionate combination in chronic obstructive pulmonary disease. American Journal of Respiratory Medicine 2002;1 (4):284. * Hanania NA, Darken P, Horstman D, Reisner C, Lee $\mathrm{B}$, Davis $\mathrm{S}$, et al.The efficacy and safety of fluticasone propionate $(250 \mathrm{microg}) / \mathrm{salmeterol}$ (50 microg) combined in the Diskus inhaler for the treatment of COPD. Chest 2003;124(3):834-43.

Hanania NA, Knobil K, Watkins M, Wire P, Yates J, Darken $\mathrm{P}$, et al.Salmeterol and fluticasone propionate therapy administered by a single diskus in patients with COPD. [Abstract]. 68th Annual Chest Meeting; Nov 2-7; San Diego. 2002:S129.

Hanania NA, Ramsdell J, Payne K, Davis S, Horstman D, Lee $\mathrm{B}$, et al.Improvements in airflow and dyspnea in COPD patients following 24 weeks treatment with salmeterol $50 \mathrm{mcg}$ and fluticasone propionate $250 \mathrm{mcg}$ alone or in combination via the diskus. American Journal of Respiratory and Critical Care Medicine 2001;163(5 Suppl):A279.

Horstman D, Darken P, Davis S, Lee B. Improvements in FEV1 and symptoms in poorly reversible COPD patients following treatment with salmeterol $50 \mathrm{mcg} /$ fluticasone propionate $250 \mathrm{mcg}$ combination[Abstract]. European Respiratory Journal 2003;22(Suppl 45):Abstract No: [P434]. Knobil K, Yates J, Horstman D, Darken P, Wire P. Combination of fluticasone and salmeterol (Advair Diskus $\left.{ }^{\circledR}\right)$ improves cough in patients with chronic obstructive pulmonary disease. [Abstract]. 68th Annual Chest Meeting; Nov 2-7; San Diego. 2002:P288. Mahler DA, Darken P, Brown CP, Knobil K. Predicting lung function responses to combination therapy in chronic obstructive pulmonary disease (COPD) [Abstract]. National COPD conference; Nov 14-15; Arlington. 2003: Abstract no: 1081.

Mahler DA, Darken P, Brown CP, Knobil K. Predicting lung function responses to salmeterol/fluticasone propionate combination therapy in COPD [Abstract]. European Respiratory Journal 2003;22(Suppl 45):Abstract No: [P429]. Mahler DA, Wire P, Horstman D, Chang CN, Yates J, Fischer T, et al.Effectiveness of fluticasone propionate and salmeterol combination delivered via the diskus device in the treatment of chronic obstructive pulmonary disease. American Journal of Respiratory and Critical Care Medicine 2002;166(8):1084-91.

Spencer M, Wire P, Lee B, Chang C, Darken P, Hortsman $\mathrm{D}$, et al.Patients with COPD using salmeterol/fluticasone propionate combination therapy experience improved quality of life [Abstract]. European Respiratory Journal 2003; 22 Suppl 45:Abstract No: [P438].

Spencer MD, Anderson JA. Salmeterol/fluticasone combination produces clinically important benefits in dyspnea and fatigue [Abstract]. American Thoracic Society International Conference; May 20-25; San Diego. 2005: [B93] [Poster: 308].

\section{Kardos 2007 \{published data only\}}

GlaxoSmithKline. A multicentre, randomised, doubleblind, parallel group, placebo-controlled study to compare the efficacy and safety of inhaled salmeterol/fluticasone propionate combination product $25 / 250 \mu \mathrm{g}$ two puffs bd and fluticasone propionate $250 \mu \mathrm{g}$ two puffs bd alone, all administered via metered dose inhalers (MDI), in the treatment of subjects with chronic obstructive pulmonary disease (COPD) for 52 weeks. http://www.gskclinicalstudyregister.com/ (accessed 3 March 2014).

Kardos P, Wencker M. Combination therapy with salmeterol and fluticasone propionate (SFC) is more effective than salmeterol (SAL) alone in reducing exacerbations of COPD [Abstract]. European Respiratory Journal 2005;26(Suppl 49):Abstract No. 1944.

* Kardos P, Wencker M, Glaab T, Vogelmeier C. Impact of salmeterol/fluticasone propionate versus salmeterol on exacerbations in severe chronic obstructive pulmonary disease. American Journal of Respiratory and Critical Care Medicine 2007;175(2):144-9.

Vogelmeier C, Wencker M, Glaab T, Kardos P. Combination therapy with salmeterol and fluticasone propionate (SFC) improves quality of life (QOL) more than salmeterol (SAL) alone in COPD [Abstract]. Norwegian Thoracic Society 42nd Nordic Lung Conference; June 9-11; Trondheim. 2005; Vol. 15, issue Suppl 22.

Vogelmeier CF, Wencker M, Glaab TH, Kardos P. Number needed to treat (NNT) to reduce exacerbations in severe COPD comparing salmeterol/fluticasone propionate (SFC) with salmeterol (SAL) treatment [Abstract]. American Thoracic Society International Conference; May 19-21; San Diego. 2006:A110 [Poster J8].

\section{Kornmann 2011 \{published data only\}}

* Kornmann O, Dahl R, Centanni S, Dogra A, Owen R, Lassen $\mathrm{C}$, et al.Once-daily indacaterol versus twice-daily salmeterol for COPD: a placebo-controlled comparison. European Respiratory Journal 2011;37(2):273-9. Kornmann O, Luthra A, Owen R, Lassen C, Kramer B. Once-daily indacaterol provides superior bronchodilation, health status and clinical outcomes compared with salmeterol in patients with chronic obstructive COPD: a 26-week placebo-controlled study [Abstract]. Chest 2009; 136(4): $152 \mathrm{~S}$ 
Lapperre 2009 \{published data only\}

Gosman MME, Lapperre TS, Snoeck-Stroband JB, Jansen DF, Kerstjens HAM, Hiemstra PS, et al.Effect of 6 months therapy with inhaled fluticasone propionate (FP) with or without salmeterol $(S)$ on bronchial inflammation in COPD [Abstract]. American Thoracic Society International Conference; May 19-21; San Diego. 2006:A111 [Poster J15].

Kunz LIZ, Strebus J, Budulac SE, Lapperre TS, Sterk PJ, Postma DS, et al.Inhaled steroids modulate extracellular matrix composition in bronchial biopsies of COPD patients: a randomized, controlled trial. PLoS One 2013;8 (5):e63430.

* Lapperre TS, Snoeck-Stroband JB, Gosman MM, Jansen DF, van Schadewijk A, Thiadens HA, et al.Effect of fluticasone with and without salmeterol on pulmonary outcomes in chronic obstructive pulmonary disease: a randomized trial. Annals of Internal Medicine 2009;151(8): $517-27$.

Lapperre TS, Snoeck-Stroband JB, Gosman MM, Sont JK, Jansen DF, Rabe KF, et al.Effects of 30 vs 6 months treatment with inhaled fluticasone $(\mathrm{FP})$ with or without salmeterol (S) on bronchial inflammation in COPD [Abstract]. American Thoracic Society International Conference; May 18-23; San Francisco. 2007:Poster \#A39. Snoeck-Stroband JB, Kerstjens HAM, Lapperre TS, Boezen HM, Thiadens HA, ten Hacken NHT, et al.Smoking, sputum cell counts, diffusion capacity and hyperinflation predict beneficial effects of long-term inhaled corticosteroids (ICS) on FEV1-decline in patients with mild-to-moderate COPD [Abstract]. European Respiratory Society 20th Annual Congress; Sep 18-22; Barcelona. 2010:[P4015]. Snoeck-Stroband JB, Lapperre TS, Boezen HM, Sont JK, Thiadens HA, Timens W, et al.Predicting the benefits by inhaled steroids on the accelerated decline of FEV1 in COD [Abstract]. American Thoracic Society International Conference; May 16-21; Toronto. 2008:A519[\#705]. Snoeck-Stroband JB, Lapperre TS, Gosman MME, Assendelft WJJ, Boezen HM, ten Hacken NHT, et al.Patient-reported clinical control and peak-flow:effects of 30 versus 6 month treatment with inhaled corticosteroids (ICS) with/without long-acting B2-agonists (LABA) in moderately severe COPD [Abstract]. American Thoracic Society International Conference; May 15-20 San Diego. 2009:A2923 [Poster \#G37].

Snoek-Stroband JB, Lapperre TS, Gosman MM, Sont JK, Jansen DF, Stolk J, et al.Effects of 30 vs 6 months treatment with inhaled fluticasone propionate (FP) with or without salmeterol (S) on FEV1 PC20 and health status in COPD [Abstract]. American Thoracic Society International Conference; May 18-23; San Francisco. 2007:Poster \#A38.

Laptseva 2002 \{published data only\}

* Laptseva IM, Laptseva EA, Borshchevsky VV, Gurevich G, Kalechits O. Inhaled budesonide in the management of chronic obstructive pulmonary diseases [abstract]. European Respiratory Society 12th Annual Congress; Sep 14-18; Stockholm. 2002:abstract nr: P1584.
Mahler 2002 \{published data only\}

Ferguson G, Funck-Brentano C, Fischer T, Darken P, Troy $\mathrm{S}$, Compton C, et al.Cardiovascular safety of salmeterol in patients with COPD. American Journal of Respiratory and Critical Care Medicine 2002;165(Suppl 8):A228.

Ferguson GT, Funck-Brentano C, Fischer T, Darken P, Reisner C. Cardiovascular safety of salmeterol in COPD. Chest 2003;123(6): 1817-24.

GlaxoSmithKline. A randomized, double-blind, placebocontrolled, parallel-group trial evaluating the safety and efficacy of the DISKUS formulations of salmeterol (SAL) $50 \mathrm{mcg}$ BID and fluticasone propionate (FP) $250 \mathrm{mcg}$ BID individually and in combination as salmeterol $50 \mathrm{mcg} /$ fluticasone propionate $250 \mathrm{mcg}$ BID (SFC 50/250) compared to placebo in COPD subjects. http://www.gskclinicalstudyregister.com/ (accessed 3 March 2014). Littner M, Yates J, Fischer T, Horstman D, Wire P. Improvements in FEV1 and symptoms in poorly-reversible COPD patients following 24 weeks of treatment with the salmeterol/fluticasone propionate combination 50/500 BID

via the Diskus inhaler. European Respiratory Journal 2001; 18(Suppl 33):176s.

Mahler DA, Wire P, Horstman D, Chang CN, Yates J, Fischer $\mathrm{T}$, et al.Effectiveness of fluticasone propionate and salmeterol combination delivered via the Diskus device in the treatment of chronic obstructive pulmonary disease. American Journal of Respiratory and Critical Care Medicine 2002;166(8):1084-91.

* Mahler DA, Wong E, Giessel G, Clifford D, Chang $\mathrm{C}$, Yates J, et al.Improvements in FEV1 and symptoms in COPD patients following 24 weeks of twice daily treatment with salmeterol 50/ fluticasone propionate 500 combination. American Journal of Respiratory and Critical Care Medicine 2001;163(5 Suppl):A279.

Spencer M, Wire P, Lee B, Chang C, Darken P, Hortsman D. Patients with COPD using salmeterol/fluticasone propionate combination therapy experience improved quality of life [Abstract]. European Respiratory Journal 2003; 22(Suppl 45):Abstract P438.

Spencer MD, Anderson JA. Salmeterol/fluticasone combination produces clinically important benefits in dyspnea and fatigue [Abstract]. American Thoracic Society International Conference; May 20-25; San Diego. 2005. Spencer MD, Karia N, Anderson J. The clinical significance of treatment benefits with the salmeterol/fluticasone propionate 50/500 mcg combination in COPD [Abstract]. European Respiratory Journal 2004;24(Suppl 48):290s.

Mahmud 2007 \{published data only\}

* Mahmud AM, Gupta DK, Khan AS, Hassan R, Hossain A, Rahman M, et al.Comparison of once daily tiotropium with twice daily salmeterol in Bangladeshi patients with moderate COPD [Abstract]. Respirology (Carlton, Vic.) 2007;12(Suppl 4):A211. 
Niewoehner 2005 \{published data only\}

Anonymous. Tiotropium reduces exacerbations in COPD.

Pharmaceutical Journal 2004;272(7302):696.

Kesten S, Plautz M, Piquette CA, Habib MP, Niewoehner

DE. Premature discontinuation of patients: a potential bias in COPD clinical trials. European Respiratory Journal 2007; 30(5):898-906.

Niewoehner D, Gonzalez-Rothi R, Shigeoka J, Korducki L, Cassino C, Kesten S, et al.Reduced COPD exacerbations in patients without first-dose peak FEV increases 15\% with tiotropium [Abstract]. American Thoracic Society International Conference; May 20-25; San Diego. 2005: [B93] [Poster: 319].

Niewoehner D, Rice K, Cote C, Korducki L, Cassino C, Kesten S. Characteristics of COPD and response to oncedaily tiotropium in African Americans in the VA medical system [Abstract]. American Thoracic Society International Conference; May 20-25; San Diego. 2005:[A43] [Poster: F41].

Niewoehner D, Rice K, Cote C, Paulson D, Cooper JA, Korducki L, et al.Reduced COPD exacerbations and associated health care utilization with once-daily tiotropium (TIO) in the VA medical system [Abstract]. American Thoracic Society 100th International Conference, May 2126, Orlando. 2004:A84.

* Niewoehner DE, Lokhnygina Y, Rice K, Kuschner WG, Sharafkhaneh A, Sarosi GA, et al.Risk indexes for exacerbations and hospitalizations due to COPD. Chest 2007;131(1):20-8.

Niewoehner DE, Rice K, Cassino C, Leimer I, Kesten S. Reductions in COPD exacerbations with tiotropium in African Americans in the VA medical system [Abstract]. American Thoracic Society International Conference; May 18-23; San Francisco. 2007:Poster \#A51.

Niewoehner DE, Rice K, Cote C, Paulson D, Cooper JAD $\mathrm{Jr}$, Korducki L, et al.Prevention of exacerbations of chronic obstructive pulmonary disease with tiotropium, a oncedaily inhaled anticholinergic bronchodilator: a randomized trial. Annals of Internal Medicine 2005;143(5):317-26.

Rice KL, Leimer I, Kesten S, Niewoehner DE. Responses to tiotropium in African-American and Caucasian patients with chronic obstructive pulmonary disease. Translational Research 2008;152(2):88-94.

Ohar 2013 \{published data only\}

* Ohar JA, Crater G, Emmett A, Ferro T, Morris A, Raphiou I, et al.Effects of fluticasone propionate/salmeterol combination $250 / 50 \mathrm{mcg}$ bid (advair diskus) vs. salmeterol $50 \mathrm{mcg}$ bid (serevent diskus) on chronic obstructive pulmonary disease (COPD) exacerbation rate, following acute exacerbation or hospitalization. American Journal of Respiratory and Critical Care Medicine 2013;187(Meeting Abstracts):A2439.

Ozol 2005 \{published data only\}

Ozol D, Aysan T, Aytemur Z, Veral A, Sebik F. The effect of inhaled corticosteroids on bronchoalveolar lavage interleukin-8 levels and cell percentage in stable chronic obstructive pulmonary disease patients. European Respiratory Journal 2001;18(Suppl 33):212s.

* Ozol D, Aysan T, Solak ZA, Mogulkoc N, Veral A, Sebik F. The effect of inhaled corticosteroids on bronchoalveolar lavage cells and IL-8 levels in stable COPD patients.

Respiratory Medicine 2005;99(12):1494-500.

\section{Paggiaro 1998 \{published data only\}}

GlaxoSmithKline. A multi-centre, randomised, doubleblind, parallel group study of the efficacy and safety of inhaled fluticasone propionate $1000 \mathrm{mcg}$ daily with placebo in chronic obstructive pulmonary disease. http://www.gskclinicalstudyregister.com/ (accessed 3 March 2014). [GSK: FLIT97]

GlaxoSmithKline. A multicentre, double-blind, placebocontrolled, parallel group study of the efficacy and tolerability of long-term inhaled fluticasone propionate 500 mcg twice daily via a Volumatic Spacer device in patients with non-asthmatic chronic obstructive pulmonary disease, including an acute oral corticosteroid trial. http://www.gskclinicalstudyregister.com/ (accessed 6 March 2014). [GSK: FLTB3054]

* Paggiaro PL, Dahle R, Bakran I, Frith L, Hollingworth $\mathrm{K}$, Efthimiou J. Multicentre randomised placebo-controlled trial of inhaled fluticasone propionate in patients with chronic obstructive pulmonary disease. International COPD Study Group. Lancet 1998;351(9105):773-80. Paggiaro PL, Dahle R, Bakran I, Hollingworth K, Efthimiou J. A multicentre double-blind, placebo-controlled study investigating the effect of inhaled fluticasone propionate in patients with chronic obstructive pulmonary disease. European Respiratory Journal 1997;10 Suppl 25:427S. Paggiaro PL, Dahle R, Bakran I, Hollingworth K, Efthimiou J. A multicentre, randomised, double-blind, placebocontrolled trial of inhaled fluticasone propionate (FP) in patients with chronic obstructive pulmonary disease. American Journal of Respiratory and Critical Care Medicine 1998;157(3 Suppl):A799.

\section{Pauwels 1999 \{published data only\}}

Johnell O, Pauwels R, Löfdahl CG, Laitinen LA, Postma DS, Pride NB, et al.Bone mineral density in patients with chronic obstructive pulmonary disease treated with budesonide Turbuhaler(R). European Respiratory Journal 2002;19(6):1058-63.

Liesker JJ, van der Velde V, Meysman M, Vinckek W, Wollmer P, Hansson L, et al.The effects of formoterol on exercise capacity in COPD. European Respiratory Society 9th Annual Congress; Oct 9-13; Madrid. 1999:[P2511]. Löfdahl CG, Postma DS, Laitinen LA, Ohlsson SV, Pauwels RA, Pride NB. The European Respiratory Society study on chronic obstructive pulmonary disease (EUROSCOP): recruitment methods and strategies. Respiratory Medicine 1998;92(3):467-72.

Noppen M, Vincken W. Effects of high-dose inhaled fluticasone propionate (FP) on cellular and solute composition in bronchial (Brl) and bronchoalveolar (BAL) lavage fluid in COPD: a placebo controlled, double-blind 
study. American Journal of Respiratory and Critical Care Medicine 1998;157(3 Suppl):A803.

* Pauwels RA, Löfdahl CG, Laitinen LA, Schouten JP, Postma DS, Pride NB, et al.Long-term treatment with inhaled budesonide in persons with mild chronic obstructive pulmonary disease who continue smoking. European Respiratory Society Study on Chronic Obstructive Pulmonary Disease. [see comment]. New England Journal of Medicine 1999;340(25):1948-53.

Pauwels RA, Löfdahl CG, Pride NB, Postma DS, Laitinen LA, Ohlsson SV. European Respiratory Society study on chronic obstructive pulmonary disease (EUROSCOP): hypothesis and design. European Respiratory Journal 1992;5 (10):1254-61.

\section{Powrie 2007 \{published data only\}}

Powrie D, Wilkinson T, Donaldson G, Viel K, Jones P, Scrine K, et al.The effect of tiotropium on diary based exacerbation frequency in COPD [Abstract]. American Thoracic Society International Conference; May 19-21; San Diego. 2006:A604 [Poster H11].

Powrie DJ, Donaldson GC, Wilkinson TM, Jones P, Viel K, Kesten S, et al.Tiotropium reduces exacerbations and common colds in patients with COPD [Abstract]. American Thoracic Society International Conference; May 18-23; San Francisco. 2007:Poster \#A50.

* Powrie DJ, Wilkinson TMA, Donaldson GC, Jones P, Scrine K, Viel K, et al.Effect of tiotropium on sputum and serum inflammatory markers and exacerbations in COPD. European Respiratory Journal 2007;30(3):472-8.

Powrie j, Wilkinson M, Donaldson C, Wedzicha A.

Tiotropium reduces subjectively reported sputum production in COPD. European Respiratory Journal 2006; 28(Suppl 50):661s [P3839].

Renkema 1996 \{published data only\}

Renkema TE, Kerstjens HA, Schouten JP, Vonk JM, Koëter $\mathrm{GH}$, Postma DS. The importance of serum IgE for level and longitudinal change in airways hyperresponsiveness in COPD. Clinical and Experimental Allergy 1998;28(10): $1210-8$.

* Renkema TE, Schouten JP, Koëter GH, Postma DS. Effects of long-term treatment with corticosteroids in COPD. Chest 1996;109(5):1156-62.

Rennard 2009 \{published data only\}

Bleecker ER, Meyers DA, Bailey WC, Sims AM, Bujac SR, Goldman M, et al.ADRB2 polymorphisms and budesonide/ formoterol responses in COPD. Chest 2012;142(2):320-8. Celli BR, Tashkin DP, Rennard SI, McElhattan J, Martin UJ. Bronchodilator responsiveness and onset of effect with budesonide/formoterol pMDI in COPD. Respiratory Medicine 2011;105(8):1176-88.

Laties A, Rennard SI, Tashkin DP, Suchower LJ, Martin UJ. Effect of budesonide/formoterol pressurized metereddose inhaler (bud/fm pmdi) on ophthalmologic assessments in moderate to very severe chronic obstructive pulmonary disease (COPD) patients: results from a 1-year, randomized, controlled clinical trial [Abstract]. Chest 2010;138(4):468A. Nelson HS, Tashkin DP, Rennard SI, Martin P, Goldman
M, Silkoff PE. Onset of bronchodilation with budesonide and formoterol administered in one pressurized metereddose inhaler in patients with moderate to very severe chronic obstructive pulmonary disease [Abstract]. Chest 2008;134 (4):105002s.

Rennard SI, Tashkin DP, Martin P, Goldman M, Martin UJ. Effect of budesonide/formoterol pressurized metereddose inhaler (pMDI) on exacerbations in patients with moderate to very severe chronic obstructive pulmonary disease (COPD) [Abstract]. American Thoracic Society International Conference; May 15-20 San Diego. 2009: A1513 [Poster \#K65].

* Rennard SI, Tashkin DP, McElhattan J, Goldman M, Ramachandran S, Martin UJ, et al.Efficacy and tolerability of budesonide/formoterol in one hydrofluoroalkane pressurized metered-dose inhaler in patients with chronic obstructive pulmonary disease: results from a 1-year randomized controlled clinical trial. Drugs 2009;69(5): 549-65.

Rennard SI, Tashkin DP, McElhattan J, Goldman M, Silkoff PE. Long-term efficacy of budesonide/formoterol administered via one pressurized metered-dose inhaler in patients with moderate to very severe chronic obstructive pulmonary disease [Abstract]. Chest 2008;134(4):103001s. Rennard SI, Tashkin DP, McElhattan J, Goldman M, Silkoff PE. Long-term tolerability of budesonide and formoterol administered in one pressurized metered-dose inhaler in patients with moderate to very severe chronic obstructive pulmonary disease [Abstract]. Chest 2008;134(4):103003s. Rennard SI, Tashkin DP, Suchower LJ, Martin UJ. Effect of budesonide/formoterol pressurized metered-dose inhaler (BUD/FM pMDI) on bone mineral density (BMD) in moderate to very severe chronic obstructive pulmonary disease (COPD) patients: results from a 1-year, randomized, controlled clinical trial [Abstract]. Chest 2010;138(4):863A.

\section{Rossi 2002 \{published data only\}}

Amgott TR, Kristufek P, Levine B, Byrne A, Till D. Effect of inhaled formoterol and oral slow-release theophylline on peak expiratory flow and symptoms in patients with COPD. American Journal of Respiratory and Critical Care Medicine 2000;161(3 Suppl):A582.

Kristufek P, Amgott TR, Levine B, Byrne A, Colacchio C. Comparison of the efficacy and safety of inhaled formoterol dry powder and oral slow-release theophylline in patients with COPD. American Journal of Respiratory and Critical Care Medicine 2000;161(Suppl 3):A489.

Kristufek P, Levine B, Della Cioppa G, Byrne A, Till D. Bronchodilatory effects of formoterol in patients with chronic obstructive pulmonary disease (COPD) are not influenced by concomitant corticosteroid use. European Respiratory Journal 2001;18(Suppl 33):514s.

Kristufek P, Levine B, Till D, Byrne A. Inhaled formoterol (foradil(r)) improves lung function in patients with both reversible and poorly reversible COPD [abstract]. American Journal of Respiratory and Critical Care Medicine 2001;163 (5 Suppl):A280.

* Rossi A, Kristufek P, Levine BE, Thomson MH, Till D, 
Kottakis J, et al.Comparison of the efficacy, tolerability, and safety of formoterol dry powder and oral, slow-release theophylline in the treatment of COPD. Chest 2002;121 (4):1058-69.

\section{Schermer 2009 \{published data only\}}

Chavannes N, Schermer T, Woulters EFM, Folgering H, Akkermans R, Metsemakers J, et al.Demographic and clinical determinants of response to $\mathrm{N}$-acetylcysteine versus fluticasone in mild to moderate COPD in primary care: the COOPT study [Abstract]. European Respiratory Journal 2005;26(Suppl 49):Abstract No. 1356.

Chavannes NH, Schermer TR, Wouters EF, Akkermans RP, Dekhuijzen RP, Muris JW, et al.Predictive value and utility of oral steroid testing for treatment of COPD in primary care: the COOPT study. International Journal of Chronic Obstructive Pulmonary Disease 2009;4:431-6.

Chavannes NH, Schermer TRJ, Wouters EFM, van Weel C, van Schayck CP. Treatment of COPD in general practice: the COOPT study. European Respiratory Journal 2001;18 (Suppl 33):348s.

* Schermer T, Chavannes N, Dekhuijzen R, Wouters E, Muris J, Akkermans R, et al.Fluticasone and Nacetylcysteine in primary care patients with COPD or chronic bronchitis. Respiratory Medicine 2009;103(4): 542-51.

Van Weel C, Schermer T. Quality of life is not an indicator of COPD severity. Huisarts en Wetenschap 2011;54(6): $294-7$.

\section{SCO100470 \{published data only\}}

* GlaxoSmithKline. A multicentre, randomised, doubleblind, parallel group, 24-week study to compare the effect of the salmeterol/fluticasone propionate combination product $50 / 250 \mathrm{mcg}$, with salmeterol $50 \mathrm{mcg}$ both delivered twice daily via the DISKUS/ACCUHALER inhaler on lung function and dyspnoea in subjects with chronic obstructive pulmonary disease (COPD). http://www.gskclinicalstudyregister.com/ (accessed 6 March 2014).

\section{SCO30002 \{published data only\}}

* GlaxoSmithKline. A multicentre, randomised, doubleblind, parallel group, placebo-controlled study to compare the efficacy and safety of inhaled salmeterol/fluticasone propionate combination product $25 / 250 \mu \mathrm{g}$ two puffs $\mathrm{Bd}$ and fluticasone propionate $250 \mu \mathrm{g}$ two puffs Bd alone, all administered via metered dose inhalers (MDI), in the treatment of subjects with chronic obstructive pulmonary disease (COPD) for 52 weeks. http://www.gskclinicalstudyregister.com/ (accessed 6 March 2014).

SCO40041 \{published data only\}

ZuWallack R, Fogarty C, Giessel G, McClung, Locantore $\mathrm{N}$, Raphiou I, et al.Effect of fluticasone propionate/ salmeterol combination on change in bone mineral density in subjects with COPD [Abstract]. Chest 2008;134(4): 104002s.

Senderovitz 1999 \{published data only\}

Senderovitz T, Maltbaek N, Pedersen B, Norgaard M, Nielsen C, Vestbo J, et al.Prednisolone followed by inhaled budesonide vs placebo in chronic obstructive pulmonary disease. European Respiratory Journal 1997;10(Suppl 25):

257S.

* Senderovitz T, Vestbo J, Frandsen J, Maltbaek N, Norgaard $\mathrm{M}$, Nielsen C, et al.Steroid reversibility test followed by inhaled budesonide or placebo in outpatients with stable chronic obstructive pulmonary disease. The Danish Society of Respiratory Medicine. Respiratory Medicine 1999;93(10): $715-8$.

Shaker 2009 \{published data only\}

* Shaker SB, Dirksen A, Ulrik CS, Hestad M, Stavngaard $\mathrm{T}$, Laursen LC, et al.The effect of inhaled corticosteroids on the development of emphysema in smokers assessed by annual computed tomography. COPD 2009;6(2):104-11. Shaker SB, Stavngaard T, Laursen LC, Stoel BC, Dirksen A. Rapid fall in lung density following smoking cessation in COPD. COPD 2011;8(1):2-7.

Shaker SB, Stavngaard T, Stoel B, Dirksen A. The effect of inhaled corticosteroids on CT-lung density in current smokers with COPD [Abstract]. American Thoracic Society International Conference; May 20-25; San Diego. 2005:[A92] [Poster: 814].

\section{Sharafkhaneh 2012 \{published data only\}}

Sharafkhaneh A, Southard J, Goldman M, Uryniak T, Martin UJ. Long-term effect of budesonide/formoterol pressurized metered-dose inhaler on exacerbations and pulmonary function in patients with chronic obstructive pulmonary disease [Abstract]. American Journal of Respiratory and Critical Care Medicine 2011;183(Meeting Abstracts):A1599.

* Sharafkhaneh A, Southard JG, Goldman M, Uryniak T, Martin UJ. Effect of budesonide/formoterol pMDI on COPD exacerbations: a double-blind, randomized study. Respiratory Medicine 2012;106(2):257-68.

Sharafkhaneh A, Uryniak T, Martin U. Long-term effects of budesonide/formoterol pressurized metered-dose inhaler on chronic obstructive pulmonary disease (COPD) symptoms and health status in patients with COPD [Abstract]. Chest 2011;140(4):528A.

Southard JG, Sharafkhaneh A, Goldman M, Uryniak T, Martin UJ. Long-term tolerability of budesonide/formoterol pressurized metered-dose inhaler in patients with chronic obstructive pulmonary disease and a history of exacerbations [Abstract]. American Journal of Respiratory and Critical Care Medicine 2011;183(Meeting Abstracts):A1597.

\section{SLMF4010 \{published data only\}}

* GlaxoSmithKline. Multicentre, randomised, parallel group, placebo-controlled, double-blind study, stratified on tobacco status at enrolment, evaluating during 6 months the efficacy of salmeterol powder for inhalation, $50 \mu \mathrm{g}$ two times per day for the reduction of thoracic distension in subjects with chronic obstructive pulmonary disease (COPD). http: //www.gsk-clinicalstudyregister.com/ (accessed 6 March 2014).

SPARK 2013 \{published data only\}

Decramer M, Wedzicha JA, Ficker J, Fowler Taylor A, D'Andrea P, Arrasate C, et al.Once-daily QVA149 improves health-related quality of life in patients with severe to very 
severe COPD: the SPARK study. American Journal of Respiratory and Critical Care Medicine 2013;187(Meeting Abstracts):A4257.

Decramer M, Wedzicha JA, Sandstrom T, Niewoehner D, Fowler Taylor A, D'Andrea P, et al.Safety and tolerability of QVA149, glycopyrronium and tiotropium in patients with severe to very severe COPD: the SPARK study. American Journal of Respiratory and Critical Care Medicine 2013;187 (Meeting Abstracts):A1479.

Wedzicha JA, Decramer M, Ficker J, Fowler Taylor A, D'Andrea P, Arrasate C, et al.Dual bronchodilation with QVA149 reduces COPD exacerbations: the SPARK study. American Journal of Respiratory and Critical Care Medicine 2013;187(Meeting Abstracts):A2428.

Wedzicha JA, Decramer M, Ficker J, Niewoehner DE, Sandstrom T, Fowler Taylor A. Efficacy and safety of QVA149 versus glycopyrronium and tiotropium in severe to very severe COPD: the SPARK study. American Journal of Respiratory and Critical Care Medicine 2013;187(Meeting Abstracts):A2429.

* Wedzicha JA, Decramer M, Ficker JH, Niewoehner DE, Sandstrom T, Taylor AF, et al.Analysis of chronic obstructive pulmonary disease exacerbations with the dual bronchodilator QVA149 compared with glycopyrronium and tiotropium (SPARK): a randomised, double-blind, parallel-group study. The Lancet Respiratory Medicine 2013; 1(3): 199-209.

\section{Szafranski 2003 \{published data only\}}

Anderson P. Budesonide/formoterol in a single inhaler (Symbicort) provides early and sustained improvement in lung function in moderate to severe COPD [Abstract]. Thorax 2002;57(Suppl III):iii43.

AstraZeneca. A placebo-controlled 12 month efficacy study of the fixed combination budesonide/formoterol compared with budesonide and formoterol as monotherapies in patients with chronic obstructive pulmonary disease (COPD). http://www.astrazenecaclinicaltrials.com/ (accessed 6 March 2014). [AstraZeneca: SD-039-0629] Borgstrom L, Asking L, Olsson H, Peterson S. Lack of interaction between disease severity and therapeutic response with budesonide/formoterol in a single inhaler [Abstract]. American Thoracic Society 100th international conference; May 21-26; Orlando. 2004:C22 [Poster 505]. [CRS-ID: 4900126000002246]

Calverley P, Pauwels Dagger R, Lofdahl CG, Svensson K, Hi JT, Carlsson LG, et al.Relationship between respiratory symptoms and medical treatment in exacerbations of COPD. European Respiratory Journal 2005;26(3):406-13. Calverley PM, Szafranski W, Calverley PMA, Andersson A. Budesonide/formoterol is a well-tolerated long term maintenance therapy for COPD [Abstract]. European Respiratory Journal 2005;26(Suppl 49):Abstract No. 1917. [CRS-ID: 4900100000023248]

Calverley PMA (on behalf of the Symbicort ${ }^{\circledR}$ study group). Effect of budesonide/formoterol on severe exacerbations and lung function in moderate to severe COPD. Thorax
2002;57(Suppl III):iii44. [CRS-ID: 4900100000013852] Calverley PMA, Thompson NC, Olsson H. Budesonide/ formoterol in a single inhaler sustains lung function improvements in COPD [Abstract]. European Respiratory Journal 2003;22(Suppl 45):P435. [CRS-ID: 4900100000016773]

Campbell LMSW, Campell LW, Szafranski W, Campbell L, Campbell LM. Budesonide/formoterol in a single inhaler (symbicort(r)) reduces severe exacerbations in patients with moderate to severe COPD [Abstract]. Thorax 2002;57 (Suppl III):iii43.

Dahl R, Cukier A, Olsson H. Budesonide/formoterol in a single inhaler reduces severe and mild exacerbations in patients with moderate to severe COPD [abstract]. European Respiratory Society 12th Annual Congress; Sep 14-18; Stockholm. 2002:abstract nr: P1575.

Egede FMG, Egede F, Menga G. Budesonide/formoterol in a single inhaler provides sustained relief from symptoms and night-time awakenings in moderate to severe COPD: results from a 1-year study [abstract]. European Respiratory Society 12th Annual Congress; Sep 14-18; Stockholm. 2002:abstract nr: P1574.

Halpin D, Stahl E, Lundback B, Anderson F, Peterson S. Treatment costs and number needed to treat (NNT) with budesonide/formoterol to avoid one exacerbation of COPD [Abstract]. American Thoracic Society 100th international conference; May 21-26; Orlando. 2004:D22 [Poster 525]. [CRS-ID: 4900100000017391]

Jones PW, Stahl E, Svensson K. Improvement in health status in patients with moderate to severe COPD after treatment with budesonide/formoterol in a single inhaler [abstract]. European Respiratory Society 12th Annual Congress; Sep 14-18; Stockholm. 2002:abstract nr: P1613. Korsgaard JSR, Korsgaard J, Sansores R. Budesonide/ formoterol (single inhaler) provides sustained relief from shortness of breath and chest tightness in a 1-year study of patients with moderate to severe COPD [abstract]. European Respiratory Society 12th Annual Congress; Sep 14-18; Stockholm. 2002:abstract nr: P1577.

Lange PSC, Lange P, Saenz C. Budesonide/formoterol in a single inhaler is well tolerated in patients with moderate to severe COPD: results of a 1-year study [abstract]. European Respiratory Society 12th Annual Congress; Sep 14-18; Stockholm. 2002:abstract nr: P1573.

Lofdahl C G, Lofdahl CG. Reducing the impact of COPD exacerbations: clinical efficacy of budesonide/ formoterol. European Respiratory Review 2004;13(88): 14-21. [CRS-ID: 4900100000060705]

Milanowski JNS, Milanowski J, Nahabedian S. Budesonide/ formoterol in a single inhaler acts rapidly to improve lung function and relieve symptoms in patients with moderate to severe COPD [abstract]. European Respiratory Society 12th Annual Congress; Sep 14-18; Stockholm. 2002: abstract nr: P1576.

* Szafranski W, Cukier A, Ramirez A, Menga G, Sansores R, Nahabedian S, et al.Efficacy and safety of budesonide/ formoterol in the management of chronic obstructive

Long-acting inhaled therapy (beta-agonists, anticholinergics and steroids) for COPD: a network meta-analysis (Review) 
pulmonary disease. European Respiratory Journal 2003;21 (1):74-81.

Szafranski W, Ramirez A, Peterson S. Budesonide/formoterol in a single inhaler provides sustained improvements in lung function in patients with moderate to severe COPD [abstract]. European Respiratory Society 12th Annual Congress; Sep 14-18; Stockholm. 2002:abstract nr: P2453.

Tashkin 2008 [SHINE] \{published data only\} AstraZeneca. A 6-month double-blind, double-dummy, randomized, parallel group, multicenter efficacy \& safety study of SYMBICORT® pMDI 2 x 160/4.5 mcg \& 80/ $4.5 \mathrm{mcg}$ bid compared to formoterol $\mathrm{TBH}$, budesonide pMDI ( $\&$ the combination) \& placebo in COPD patients. http://www.astrazenecaclinicaltrials.com/ (accessed 6 March 2014).

Bleecker ER, Meyers DA, Bailey WC, Sims AM, Bujac SR, Goldman M, et al.ADRB2 polymorphisms and budesonide/ formoterol responses in COPD. Chest 2012;142(2):320-8. [CRS-ID: 4900100000063501$]$

Bleecker ER, Meyers DA, Bailey WC, Sims AM, Bujac SR, Goldman M, et al.Effect of beta 2 -adrenergic receptor gene polymorphism gly16arg on response to budesonide/ formoterol pressurized metered-dose inhaler in chronic obstructive pulmonary disease [Abstract]. American Journal of Respiratory and Critical Care Medicine 2011;183(Meeting Abstracts):A4086. [CRS-ID: 4900100000043833] Celli BR, Tashkin DP, Rennard SI, McElhattan J, Martin UJ. Bronchodilator responsiveness and onset of effect with budesonide/formoterol pMDI in COPD. Respiratory Medicine 2011;105(8):1176-88. [CRS-ID: 4900100000026611]

Nelson HS, Tashkin DP, Rennard SI, Martin P, Goldman M, Silkoff PE. Onset of bronchodilation with budesonide and formoterol administered in one pressurized metereddose inhaler in patients with moderate to very severe chronic obstructive pulmonary disease [Abstract]. Chest 2008;134 (4):105002s. [CRS-ID: 4900100000024197$]$

Tashkin DP, Rennard SI, Martin P, Goldman M, Silkoff PE. Efficacy of budesonide/formoterol administered via one pressurized metered-dose inhaler over 6 months in patients with chronic obstructive pulmonary disease [Abstract]. Chest 2008;134(4):105001s.

* Tashkin DP, Rennard SI, Martin P, Ramachandran S, Martin UJ, Silkoff PE, et al.Efficacy and safety of budesonide and formoterol in one pressurized metereddose inhaler in patients with moderate to very severe chronic obstructive pulmonary disease: results of a 6-month randomized clinical trial. Drugs 2008;68:1975-2000.

Tashkin 2008a [UPLIFT] \{published data only\} Antoniu SA. UPLIFT study: the effects of long-term therapy with inhaled tiotropium in chronic obstructive pulmonary disease. Expert Opinion on Pharmacotherapy 2009;10(4):719-22.

Boehringer Ingelheim. A randomized, double-blind, placebo-controlled, parallel group trial assessing the rate of decline of lung function with tiotropium $18 \mathrm{mcg}$ inhalation capsule once daily in patients with chronic obstructive pulmonary disease (COPD). www.trials.boehringeringelheim.com (accessed 3 March 2014). [CRS-ID: 4900100000042876]

Braido F. UPLIFT study: the results and their implications. Multidisciplinary Respiratory Medicine 2009;4(Suppl 1): 6s-12s.

Buhl R, Welte T, Vogelmeier C, Gillissen A, Voshaar T, Kogler H, et al.Early treatment of COPD with tiotropium. [German]. Pneumologie (Stuttgart, Germany) 2012;66(10): 589-95.

Celli B, Decramer M, Kesten S, Liu D, Mehra S, Tashkin DP, et al.Mortality in the 4-year trial of tiotropium (UPLIFT) in patients with chronic obstructive pulmonary disease. American Journal of Respiratory and Critical Care Medicine 2009;180(10):948-55.

Celli B, Decramer M, Tashkin D, Cassino C, Burkhart D, Kesten S. Frequency of acute flow and volume responses to bronchodilator administration in patients with COPD [Abstract]. European Respiratory Journal 2007;30(Suppl 51):525s [3163].

Celli B, Decramer M, Tashkin DP, Bukhart D, Kesten S, Cassino C. Differences in baseline FEV1 and tobacco use in COPD patients from different racial subgroups [Abstract]. American Thoracic Society International Conference; May 18-23; San Francisco. 2007:Poster \#923.

Celli B, Kesten S, Lystig T, Tashkin DP, Decramer M. Longterm changes in inspiratory capacity: an analysis from the UPLIFT(R) trial [Abstract]. American Journal of Respiratory and Critical Care Medicine 2010;181 (Meeting Abstracts): A4482. [CRS-ID: 4900100000025219]

Celli B, Tashkin D, Decramer M, Burkhart D, Cassino C, Kesten S. Acute bronchodilator responsiveness in a global respiratory trial (UPLIFT) following maximal inhaled bronchodilators. European Respiratory Journal 2005;26 (Suppl 49):716s. [CRS-ID: 4900100000035643] Celli BR, Decramer M, Lystig T, Kesten S, Tashkin DP. Longitudinal inspiratory capacity changes in chronic obstructive pulmonary disease. Respiratory Research 2012; 13:66.

Corhay JL, Louis R. The UPLIFT study (Understanding Potential Long-term Impacts on Function with Tiotropium). Revue Medicale de Liege 2009;64(1):52-7.

Decramer M, Celli B, Burkhart D, Kesten S, Mehra S, Liu $\mathrm{D}$, et al.The effect of tiotropium on COPD GOLD stage II during the four-year UPLIFT trial [Abstract]. American Thoracic Society International Conference; May 16-21; Toronto. 2008:A2466.

Decramer M, Celli B, Kesten S, Liu D, Menjoge S, Senn S, et al.Statistical approaches to analysis of exacerbations in the UPLIFT(R) trial [Abstract]. American Journal of Respiratory and Critical Care Medicine 2010;181(Meeting Abstracts): A1527.

Decramer M, Celli B, Kesten S, Lystig T, Mehra S, Tashkin DP, et al.Effect of tiotropium on outcomes in patients with moderate chronic obstructive pulmonary disease (UPLIFT): a prespecified subgroup analysis of a randomised controlled 
trial. [see comment]. Lancet 2009;374(9696):1171-8. Decramer M, Celli B, Tashkin DP, Burkhart D, Kesten $S$, Cassino C. Regional differences in the treatment of patients with moderate COPD enrolled in a global clinical trial. European Respiratory Journal 2006;28(Suppl 50):526s. [CRS-ID: 4900100000035644]

Decramer M, Celli B, Tashkin DP, Pauwels RA, Burkhart $\mathrm{D}$, Cassino $\mathrm{C}$, et al.Clinical trial design considerations in assessing long-term functional impacts of tiotropium in COPD: the UPLIFT trial. Journal of Chronic Obstructive Pulmonary Disease 2004;1(2):303-12.

Decramer M, Kesten S, Celli B, Tashkin DP. How much lift to the UPLIFT study? - Authors' reply. Lancet 2010;375 (9710):198.

Decramer M, Molenberghs G, Liu D, Celli B, Kesten $S$, Lystig $T$, et al.Premature discontinuation during the UPLIFT study. Respiratory Medicine 2011;105(10): 1523-30.

Decramer M, Pauwels R, Celli B, Tashkin D, Burkhart $\mathrm{D}$, Cassino C, et al.Effectiveness of a spirometric quality assurance program in a large-scale global COPD trial (UPLIFT). European Respiratory Journal 2004;24(Suppl 48):32s. [CRS-ID: 4900100000035646]

Decramer M, Tashkin D, Celli B, Franceschina J, Fiori L. Use of regular feedback on spirometry testing in a long-term multinational COPD trial [Abstract]. American Thoracic Society International Conference; May 16-21; Toronto. 2008:Poster \#D79. [CRS-ID: 4900100000023039] Fernandez L, Kesten S, Liu D, Decramer M, Tashkin D, Celli B, et al.Efficacy of tiotropium in COPD patients from Asia: a subgroup analysis from the UPLIFT trial [Abstract]. Congress of the Asian Pacific Society of Respirology; Nov 22-25; Manila. 2010.

Fukuchi Y, Fernandez L, Kuo HP, Mahayiddin A, Celli B, Decramer M, et al.Efficacy of tiotropium in COPD patients from Asia: a subgroup analysis from the UPLIFT trial. Respirology (Carlton, Vic.) 2011;16(5):825-35.

Halpin D, Decramer M, Celli B, Martin A, Leimer I, Metzdorf N, et al.Effectiveness of tiotropium in lowrisk patients according to new GOLD severity grading [Abstract]. European Respiratory Journal 2012;40(Suppl 56):392s [P2190].

Halpin DG, Decramer M, Celli B, Kesten S, Liu D, Tashkin DP. Exacerbation frequency and course of COPD. International Journal of Chronic Obstructive Pulmonary Disease 2012;7:653-61.

Halpin DM, Decramer M, Celli B, Kesten S, Leimer I, Tashkin DP. Risk of nonlower respiratory serious adverse events following COPD exacerbations in the 4-year UPLIFT trial. Lung 2011;189(4):261-8.

Hanania N, Kesten S, Celli B, Decramer M, Sharafkhaneh A, Lystig $\mathrm{T}$, et al.Acute bronchodilator response does not predict health outcomes in patients with COPD treated with tiotropium [Abstract]. European Respiratory Society 19th Annual Congress; Sep 12-15; Vienna. 2009:[E4353]. [CRS-ID: 4900100000024978]

Hanania NA, Sharafkhaneh A, Celli B, Decramer M, Lystig
T, Kesten S, et al.Acute bronchodilator responsiveness and health outcomes in COPD patients in the UPLIFT trial. Respiratory Research 2011;12(1):6.

Hettle R, Wouters H, Ayres J, Gani R, Kelly S, Lion M, et al.Cost-utility analysis of tiotropium versus usual care in patients with COPD in the UK and Belgium. Respiratory Medicine 2012;106(12):1722-33.

Inoue $\mathrm{H}$, Asai Y. UPLIFT (Understanding Potential Long-term Impacts on Function with Tiotropium) study. Respiration and Circulation 2009;57(8):813-8.

Janssens W, Liu D, Kesten S, Tashkin DP, Celli BR, Decramer M. Spirometry in UPLIFT®: quality and reproducibility over time [Abstract]. European Respiratory Society 21st Annual Congress; Sep 24-28; Amsterdam. 2011; Vol. 38, issue 55:638s [P3567]. [CRS-ID: 4900100000054049]

Janssens W, Liu Y, Liu D, Kesten S, Tashkin DP, Celli $\mathrm{BR}$, et al.Quality and reproducibility of spirometry in COPD patients in a randomized trial (UPLIFT). Respiratory Medicine 2013;107(9):1409-16. [CRS-ID: 4900100000088355]

Kesten S, Celli B, Decramer M, Liu D, Tashkin D. Adverse health consequences in COPD patients with rapid decline in FEV1-evidence from the UPLIFT trial. Respiratory Research 2011;12:129.

McGarvey L, Magder SA, Liu D, Kesten S, Manuel R, Niewoehner DE. A comparison of the classification of cause of death between site investigators and a mortality adjudication committee in the UPLIFT(R) trial [Abstract]. American Journal of Respiratory and Critical Care Medicine 2010;181(Meeting Abstracts):A5916.

McGarvey LP, Magder S, Burkhart D, Kesten S, Liu D, Manuel RC, et al.Cause-specific mortality adjudication in the UPLIFT COPD trial: findings and recommendations. Respiratory Medicine 2012;106(4):515-21.

Morice AH, Celli B, Kesten S, Lystig T, Tashkin D, Decramer M. COPD in young patients: a pre-specified analysis of the four-year trial of tiotropium (UPLIFT). Respiratory Medicine 2010;104(11):1659-67. Morice AH, Celli B, Kesten S, Lystig T, Tashkin D, Decramer M. COPD patients under 50 years of age: 4year follow-up in the UPLIFT trial [Abstract]. Primary Care Respiratory Journal 2010;19(2):A12 [46]. [CRS-ID: 4900100000025536]

Osztovits J, Feher J. Safety of tiotropium therapy in chronic obstructive lung diseases (COPD). [Hungarian]. Orvosi Hetilap 2010;151(18):749-50.

Paggiaro P, Rossi A. 'Prince Charming'? Some considerations about the decline of FEV1 and on data from UPLIFT study. Rassegna di Patologia dell'Apparato Respiratorio 2009;24(5): 278-86.

Rodriguez Gonzalez-Moro JM, Lucero S, de Lucas Ramos P. The UPLIFT study: future perspectives. [Spanish]. Archivos de Bronconeumologia 2008;44(Suppl 2):39-48. Rutten-van Molken M, Oostenbrink J, Monz B. EQ-5D discriminates between COPD patients of different severity. European Respiratory Journal 2005;26(Suppl 49):470s.

Long-acting inhaled therapy (beta-agonists, anticholinergics and steroids) for COPD: a network meta-analysis (Review) 
[CRS-ID: 4900100000035648]

Rutten-van Mölken MP, Oostenbrink JB, Tashkin DP, Burkhart D, Monz BU. Does quality of life of COPD patients as measured by the JOUReric EuroQol fivedimension questionnaire differentiate between COPD severity stages?. Chest 2006;130(4):1117-28.

Tashkin D, Celli B, Decramer M, Burkhart D, Kesten $S$, Cassino C. Comorbid conditions reported in patients with COPD recruited into a global clinical trial (UPLIFT) [Abstract]. European Respiratory Journal 2005;26(Suppl 49):Abstract No. 4203.

Tashkin D, Celli B, Decramer M, Paulwels R, Burkhart $\mathrm{D}$, Kesten S. Regional patterns in the characteristics of patients recruited into a long-term global clinical trial in COPD (UPLIFT) [Abstract]. American Thoracic Society International Conference; May 20-25; San Diego. 2005: [B46] [Poster: J126]. [CRS-ID: 4900100000018885] Tashkin D, Celli B, Kesten S, Lystig T, Decramer M. Effect of tiotropium in men and women with COPD: results of the 4-year UPLIFT trial. Respiratory Medicine 2010;104 (10):1495-504.

Tashkin D, Celli B, Lystig T, Kesten S, Decramer M. Efficacy of tiotropium in COPD patients with FEV1: 60\% participating in the UPLIFT trial [Abstract]. European Respiratory Society Annual Congress, Barcelona, Spain, September 18-22. 2010:[P1186].

Tashkin D, Celli B, Senn S, Burkhart D, Kesten S, Menjoge $S$, et al.A 4-year trial of tiotropium in chronic obstructive pulmonary disease (UPLIFT trial). Revista Portuguesa de Pneumologia 2009;15(1):137-40.

Tashkin DP. Impact of tiotropium on the course of moderate-to-very severe chronic obstructive pulmonary disease: the UPLIFT trial. [Review] [51 refs]. Expert Review of Respiratory Medicine 2010;4(3):279-89. [CRS-ID: 4900100000025628]

Tashkin DP, Celli B, Burkhart D, Kesten S, Liu D, Mehra $S$, et al.Long-term efficacy of tiotropium in continuing smokers vs sustained ex-smokers in the UPLIFT trial [Abstract]. American Thoracic Society International JOURerence, May 15-20, San Diego. 2009:A6175 [Poster \#201].

Tashkin DP, Celli B, Decramer M, Liu D, Burkhart D, Cassino C, et al.Bronchodilator responsiveness in patients with COPD. European Respiratory Journal 2008;31(4): 742-50.

Tashkin DP, Celli B, Kesten S, Liu D, Decramer M. Reduced reporting of respiratory failure in the UPLIFT(R) trial [Abstract]. American Journal of Respiratory and Critical Care Medicine 2010;181(Meeting Abstracts):A4483. Tashkin DP, Celli B, Kesten S, Lystig T, Mehra S, Decramer M. Long-term efficacy of tiotropium in relation to smoking status in the UPLIFT trial. European Respiratory Journal 2010;35(2):287-94. [CRS-ID: 4900100000025372] Tashkin DP, Celli B, Senn S, Burkhart D, Kesten S, Menjoge $S$, et al.A 4-year trial of tiotropium in chronic obstructive pulmonary disease. New England Journal of Medicine 2008;
359(15):1543-54. [CRS-ID: 4900100000022535]

Tashkin DP, Celli BR, Decramer M, Lystig T, Liu D, Kesten S. Efficacy of tiotropium in COPD patients with FEV1 $\geq$ $60 \%$ participating in the UPLIFT® trial. COPD 2012;9 (3):289-96.

Tashkin DP, Celli BR, Kesten S, Liu D, Decramer M. Cardiovascular adverse events according to GOLD stage in the UPLIFT trial [Abstract]. Chest 2009;136(4):52S-g. Tashkin DP, Celli BR, Kesten S, Lystig T, Mehra S, Decramer M. Efficacy of tiotropium in men and women: 4-year follow-up in the uplift trial [Abstract]. Chest 2009; 136(4):24S-h, 25.

Tashkin DP, Decramer M, Celli B, Burkhart D, Cassino C, Kesten S. Baseline characteristics according to JOURder in a global respiratory trial [Abstract]. American Thoracic Society International Conference; May 18-23; San Francisco. 2007:Poster \#924.

Troosters T, Celli B, Kesten S, Liu D, Mehra S, Tashkin D, et al.Effectiveness of combination therapy with tiotropium in COPD. A secondary analysis of the UPLIFT trial [Abstract]. European Respiratory Society 19th Annual Congress; Sep 12-15; Vienna. 2009:[P3808]. [CRS-ID: 4900100000025093]

Troosters T, Celli B, Kesten S, Liu D, Tashkin D, Decramer M. Effectiveness of combination therapy with tiotropium in COPD. A secondary analysis of the UPLIFT trial [Abstract]. Primary Care Respiratory Journal 2010;19(2):A13 [49]. Troosters T, Celli B, Lystig T, Kesten S, Mehra S, Tashkin DP, et al.Tiotropium as a first maintenance drug in COPD: secondary analysis of the UPLIFT trial. European Respiratory Journal 2010;36(1):65-73.

Troosters T, Kesten S, Burkhart D, Celli B, Liu D, Mehra S, et al.Effectiveness of tiotropium as first maintenance drug in patients with COPD. Secondary analysis of the UPLIFT Trial [Abstract]. American Thoracic Society International Conference; May 15-20 San Diego. 2009:A2467.

Zaniolo O, Iannazzo S, Pradelli L, Miravitlles M. Pharmacoeconomic evaluation of tiotropium bromide in the long-term treatment of chronic obstructive pulmonary disease (COPD) in Italy. European Journal of Health Economics 2012;13(1):71-80.

\section{Tashkin 2012 \{published data only\}}

Doherty D, Tashkin D, Kerwin E, Eduardo Matiz-Bueno C, Shekar T, Banerjee S, et al.Efficacy and safety of mometasone furoate/formoterol in subjects with moderate to very severe chronic obstructive pulmonary disease: results from two phase three 26-week trials [Abstract]. Chest 2011; 140(4): $535 \mathrm{~A}$.

Kerwin E, Tashkin D, Matiz-Bueno CE, Doherty D, Shekar T, Banerjee S, et al.Quality of life following 26 weeks of mometasone furoate/formoterol therapy: results from two phase three trials in subjects with moderate to very severe chronic obstructive pulmonary disease [Abstract]. Chest 2011;140(4):558A.

Matiz-Bueno CE, Doherty D, Kerwin E, Tashkin D, Shekar $\mathrm{T}$, Banerjee $\mathrm{S}$, et al.The long-term safety characteristics of mometasone furoate/formoterol for the treatment of 
moderate to very severe chronic obstructive pulmonary disease: pooled findings from two 1-year multicenter clinical trials [Abstract]. Chest 2011;140(4):548A. Tashkin D, Doherty D, Kerwin E, Matiz-Bueno CE, Shekar $T$, Banerjee $S$, et al.The effect of mometasone furoate/ formoterol combination therapy on chronic obstructive pulmonary disease (COPD) exacerbations: results from two phase three trials in subjects with moderate to very severe COPD [Abstract]. Chest 2011;140(4):549A.

* Tashkin DP, Doherty DE, Kerwin E, Matiz-Bueno CE, Knorr B, Shekar T, et al.Efficacy and safety characteristics of mometasone furoate/formoterol fumarate fixed-dose combination in subjects with moderate to very severe COPD: findings from pooled analysis of two randomized, 52-week placebo-controlled trials. International Journal of Chronic Obstructive Pulmonary Disease 2012;7:73-86. Tashkin DP, Doherty DE, Kerwin E, Matiz-Bueno CE, Knorr B, Shekar T, et al.Efficacy and safety of a fixeddose combination of mometasone furoate and formoterol fumarate in subjects with moderate to very severe COPD: results from a 52-week Phase III trial. International Journal of Chronic Obstructive Pulmonary Disease 2012;7:43-55.

\section{To 2011 \{published data only\}}

* To Y, Nishimura M, Fukuchi Y, Kitawaki T, Okino $\mathrm{N}$, Lassen C, et al.Long-term safety and tolerability of indacaterol versus salmeterol in Japanese COPD patients: a 52-week open-labeled study [Abstract]. Respirology (Carlton, Vic.) 2011;16(Suppl 2):96 [240].

Tonnel 2008 [TIPHON] \{published data only\} Tonnei AB, Bravo ML, Brun M, Tonnel AB. Clinically significant improvements of health status of COPD patients after 9 months treatment with tiotropium bromide: the TIPHON study [Abstract]. American Thoracic Society International Conference; May 20-25; San Diego. 2005: [B93] [Poster: 302].

Tonnei AB, Perez T, Grosbois JM, Bravo ML, Brun M, Tonnel AB. Improvement in HRQoL of COPD patients after 9 months treatment with tiotropium bromide: use of a new scale for daily medical practice [Abstract]. European Respiratory Journal 2005;26(Suppl 49):Abstract No. 1934. * Tonnel AB, Perez T, Grosbois JM, Verkindre C, Bravo ML, Brun M. Effect of tiotropium on health-related quality of life as a primary efficacy endpoint in COPD. International Journal of Chronic Obstructive Pulmonary Disease 2008;3(2): 301-10.

Trooster 2011 \{published data only\}

* Sciurba FC, Siafakas N, Troosters T, Klioze SS, Sutradhar $\mathrm{S}$, Weisman I, et al.The efficacy and safety of tiotropium handihaler, $18 \mu \mathrm{g}$, once daily plus PRN salbutamol versus placebo plus PRN salbutamol in COPD subjects naive to maintenance therapy [Abstract]. American Journal of Respiratory and Critical Care Medicine 2011;183(Meeting Abstracts):A1589.

Verhoeven 2002 \{published data only\} Verhoeven GT, Garrelds IM, Hoogsteden HC, Zijlstra FJ. Effects of fluticasone propionate inhalation on levels of arachidonic acid metabolites in patients with chronic obstructive pulmonary disease. Mediators of Inflammation 2001;10(1):21-6.

Verhoeven GT, Hegmans J, Hoogsteden HC, Prins JB. Inhaled fluticasone propionate (FP) reduces the number of inflammatory cells in bronchial biopsies of COPD patients with bronchial hyperresponsiveness (BHR). American Journal of Respiratory and Critical Care Medicine 1998;157 (3 Suppl):A798.

* Verhoeven GT, Hegmans JP, Mulder PG, Bogaard JM, Hoogsteden HC, Prins JB. Effects of fluticasone propionate in COPD patients with bronchial hyperresponsiveness. Thorax 2002;57(8):694-700.

Verhoeven GT, Mulder PGH, Bogaard JM, Hoogsteden HC. Inhaled fluticasone propionate (FP) has a significant effect on FEV1 of COPD patients with bronchial hyperresponsiveness (BHR). American Journal of Respiratory and Critical Care Medicine 1998;157(3 Suppl):A799.

Verhoeven GT, Wijkhuijs AJ, Hooijkaas H, Hoogsteden HC, Sluiter W. Effect of an inhaled glucocorticoid on reactive oxyJOUR species production by bronchoalveolar lavage cells from smoking COPD patients. Mediators of Inflammation 2000;9(2):109-13.

Vestbo 1999 \{published data only\}

* Vestbo J, Sorensen T, Lange P, Brix A, Torre P, Viskum $K$. Long-term effect of inhaled budesonide in mild and moderate chronic obstructive pulmonary disease: a randomised controlled trial. Lancet 1999;353(9167): 1819-23.

Vestbo J, Sorensen T, Lange P, Brix A, Torre P, Viskum K. Long-term effect of inhaled budesonide in patients with mild to moderate chronic obstructive lung disease. The Osterbro Study. Ugeskrift for Laeger 2000;162(4):493-7.

\section{Vogelmeier 2008 \{published data only\}}

Arievich H, Potena A, Fonay K, Vogelmeier CF, Overend $\mathrm{T}$, Smith J, et al.Formoterol given either alone or together with tiotropium reduces the rate of exacerbations in stable COPD patients [Abstract]. European Respiratory Journal 2006;28(Suppl 50):440s [P2514].

* Vogelmeier C, Kardos P, Harari S, Gans SJ, Stenglein S, Thirlwell J. Formoterol mono- and combination therapy with tiotropium in patients with COPD: a 6-month study. Respiratory Medicine 2008;102(11):1511-20.

Vogelmeier CF, Harari SA, Fonay K, Beier J, Overend T, Till $\mathrm{D}$, et al.Formoterol and tiotropium both improve lung function in stable COPD patients with some additional benefit when given together [Abstract]. European Respiratory Journal 2006;28(Suppl 50):429s [P2506].

Vogelmeier 2011 [POET] \{published data only\}

Beeh KM, Hederer B, Glaab T, Müller A, Rutten-van Moelken M, Kesten S, et al.Study design considerations in a large COPD trial comparing effects of tiotropium with salmeterol on exacerbations. International Journal of Chronic Obstructive Pulmonary Disease 2009;4(1):119-25. Beeh KM, Vogelmeier C, Rutten-van Mölken M, Rabe KF, Glaab T, et al.Tiotropium vs salmeterol in GOLD II and maintenance-naive COPD patients: subgroup analyses of POET-COPD ${ }^{\mathrm{TM}}$ trial $[\mathrm{Abstract}]$. European Respiratory 
Society 21st Annual Congress; Sep 24-28; Amsterdam. 2011; Vol. 38, issue 55:20s [P251].

Fabbri LM, Vogelmeier C, Rutten-van Mölken MPMH, Rabe KF, Glaab T, Ruhmkorf F, et al.Baseline characteristics of patients with frequent exacerbations in the POETCOPD trial [Abstract]. European Respiratory Society 21st Annual Congress; Sep 24-28; Amsterdam. 2011; Vol. 38, issue 55:49s [405]. [CRS-ID: 4900100000053958] Glaab T, Vogelmeier C, Schmidt H, Rutten-van Mölken $\mathrm{M}$, Beeh KM, Rabe K, et al.Seasonal distribution of exacerbations in the POET-COPD study [Abstract]. American Journal of Respiratory and Critical Care Medicine 2011;183(Meeting Abstracts):A3726. [CRS-ID: 4900100000053911]

Hoogendoorn M, Al MJ, Beeh KM, Bowles D, Graf von der Schulenburg JM, Lungershausen J, et al.Costeffectiveness of tiotropium versus salmeterol: the POETCOPD trial. European Respiratory Journal 2013;41(3): 556-64. [CRS-ID: 4900100000076226]

Rabe KF, Fabbri LM, Vogelmeier C, Kögler H, Schmidt $\mathrm{H}$, Beeh KM, et al.Seasonal distribution of COPD exacerbations in the prevention of exacerbations with tiotropium in COPD trial. Chest 2013;143(3):711-9. Rutten-van Mölken MPMH, Fabbri LM, Rabe KF, Kögler $\mathrm{H}$, Glaab T, Schmidt H, et al.Do exacerbation outcomes in the POET-COPD trial differ between regions? [Abstract]. European Respiratory Society 21st Annual Congress; Sep 24-28; Amsterdam. 2011; Vol. 38, issue 55:82s [P559]. [CRS-ID: 4900100000053963]

Vogelmeier C, Fabbri LM, Rabe KF, Beeh KM, Schmidt H, Metzdorf N, et al.Effect of tiotropium vs. salmeterol on exacerbations: GOLD II and maintenance therapy naive patients. Respiratory Medicine 2013;107(1):75-83.

* Vogelmeier C, Hederer B, Glaab T, Schmidt H, Ruttenvan Mölken MP, Beeh KM, et al.Tiotropium versus salmeterol for the prevention of exacerbations of COPD. New England Journal of Medicine 2011;364(12):1093-103. Vogelmeier C, Rabe K, Beeh KM, Glaab T, Schmidt $\mathrm{H}$, Rutten-van Molken M, et al.Tiotropium reduces exacerbations versus salmeterol irrespective of baseline ICS treatment in the POET-COPD study [Abstract]. American Journal of Respiratory and Critical Care Medicine 2011;183 (Meeting Abstracts):A1600.

Vogelmeier CF, Beeh KM, Rutten-van Molken M, Glaab T, Schmidt H, Hederer B. Baseline characteristics according to gender in a large exacerbations trial [Abstract]. American Journal of Respiratory and Critical Care Medicine 2010;181 (Meeting Abstracts):A4495.

Wedzicha 2008 [INSPIRE] \{published data only\} Calverley P, Stockley R, Seemungal T, Hagan G, Wedzicha J. Adverse events and mortality in the INSPIRE study (investigating new standards for prophylaxis in reduction of exacerbations) [Abstract]. European Respiratory Journal 2007;30(Suppl 51):125s [P847].

Calverley PM, Stockley RA, Seemungal TA, Hagan G, Willits LR, Riley JH, et al.Reported pneumonia in patients with COPD: findings from the INSPIRE study. Chest
2011;139(3):505-12.

GlaxoSmithKline. Multicentre, randomised, doubleblind, double dummy, parallel group, 104-week study to compare the effect of the salmeterol/fluticasone propionate combination product (SERETIDE*) 50/500mcg delivered twice daily via the DISKUS*/ACCUHALER* inhaler with tiotropium bromide $18 \mathrm{mcg}$ delivered once daily via the HandiHaler inhalation device on the rate of health care utilisation exacerbations in subjects with severe chronic obstructive pulmonary disease (COPD). http://www.gskclinicalstudyregister.com/ (accessed 6 March 2014). Seemungal T, Stockley R, Calverley P, Hagan G, Wedzicha J. Effect of salmeterol/fluticasone propionate versus tiotropium bromide on exacerbations: the INSPIRE study (investigating new standards for prophylaxis in reduction of exacerbations) [Abstract]. European Respiratory Journal 2007;30(Suppl 51):688s [E4055].

Seemungal T, Stockley R, Calverley P, Hagan G, Wedzicha JA. Investigating new standards for prophylaxis in reduction of exacerbations-the INSPIRE study methodology. Journal of Chronic Obstructive Pulmonary Disease 2007;4(3):177-83. Stockley R, Calverley P, Seemungal T, Hagan G, Wedzicha J. Effect of salmeterol/fluticasone propionate versus tiotropium bromide on withdrawal rate, health status, lung function and mortality INSPIRE (investigating new standards for prophylaxis in reduction of exacerbations study) [Abstract]. European Respiratory Journal 2007;30 (Suppl 51):34s [388].

Wedzicha J, Stockley R, Seemungal T, Hagan G, Calverley P. The INSPIRE study: effect of salmeterol/fluticasone propionate versus tiotropium bromide on COPD exacerbations [Abstract]. Respirology (Carlton, Vic.) 2007; 12(Suppl 4):A112.

* Wedzicha JA, Calverley PM, Seemungal TA, Hagan G, Ansari Z, Stockley RA, et al.The prevention of chronic obstructive pulmonary disease exacerbations by salmeterol/ fluticasone propionate or tiotropium bromide. American Journal of Respiratory and Critical Care Medicine 2008;177 (1):19-26.

\section{Zheng 2006 \{published data only\}}

GlaxoSmithKline. A multi-centre, randomised, doubleblind, parallel group study to investigate the efficacy and safety of the salmeterol/fluticasone propionate combination at a strength of 50/500 $\mu \mathrm{g} \mathrm{BD}$, compared with placebo via Accuhaler, added to usual chronic obstructive pulmonary disease (COPD) therapy, in subjects with COPD for 24 weeks. http://www.gsk-clinicalstudyregister.com (accessed 6 March 2014).

Zheng J, Zhong N, Yang L, Wu Y, Chen P, Wen Z, et al.The efficacy and safety of fluticasone propionate $500 \mathrm{mg} /$ salmeterol $50 \mathrm{mg}$ combined via diskus/accuhaler in Chinese patients with chronic obstructive pulmonary disease (COPD) [Abstract]. Chest 2006;130(4 Suppl):182s.

* Zheng JP, Yang L, Wu YM, Chen P, Wen ZG, Huang WJ, et al.The efficacy and safety of combination salmeterol (50 microg)/fluticasone propionate (500 microg) inhalation twice daily via accuhaler in Chinese patients with COPD. 
Chest 2007;132(6):1756-63.

Zhong N, Zheng J, Yang L, Wu Y, Chen P, Wen Z, et al.The efficacy and safety of salmeterol $50 \mu \mathrm{g}$ /fluticasone propionate $500 \mu \mathrm{g}$ combined via accuhaler in Chinese patients with chronic obstructive pulmonary disease [Abstract]. Respirology (Carlton, Vic.) 2006;11(Suppl 5): A150 [PS-3-9].

\section{Zhong 2012 \{published data only\}}

* Zhong N, Zheng J, Wen F, Yang L, Chen P, Xiu Q, et al.Efficacy and safety of budesonide/formoterol via a dry powder inhaler in Chinese patients with chronic obstructive pulmonary disease. Current Medical Research and Opinion 2012;28(2):257-65.

Zhong N, Zheng J, Wen F, Yang L, Chen P, Xiu Q, et al.Efficacy and safety of inhalation of budesonide/formoterol via turbuhaler in Chinese patients with chronic obstructive pulmonary disease [Abstract]. Chest 2011;140(4):5225A.

\section{References to studies excluded from this review}

\section{Aalbers 2002 \{published data only\}}

Aalbers R, Ayres J, Backer V, Decramer M, Lier PA, Magyar $\mathrm{P}$, et al.Formoterol in patients with chronic obstructive pulmonary disease: a randomized, controlled, 3-month trial. European Respiratory Journal 2002;19(5):936-43. [: 0903-1936]

Sybrecht GW. Inhaled formoterol was an effective and safe treatment in COPD patients. European Respiratory Society 9th Annual Congress; Oct 9-13; Madrid. 1999:2510.

ACCORD II 2012 \{published data only\}

D’Urzo A, Kerwin E, Donohue J, Rennard S, Gelb A, Lakkis $\mathrm{H}$, et al.Effects of twice-daily aclidinium bromide in COPD patients: a long-term extension of ACCORDCOPD I [Abstract]. European Respiratory Society 22nd Annual Congress; Sep 1-5; Vienna. 2012; Vol. 40, issue Suppl 56:528s [P2890]. [ACCORD: COPD II] D’Urzo A, Kerwin E, Rennard S, He T, Garcia Gil E, Caracta C. Improvements in lung function with twicedaily aclidinium bromide: results of a long-term, phase 3 trial in patients with chronic obstructive pulmonary disease [Abstract]. Chest 2012;142(4):740A. [ACCORD-COPD: 1 SID - NCT00891462]

D'Urzo AD, Kerwin EM, Donohue JF, Rennard SI, Gelb AF, Lakkis H. Long-term extension study of ACCORD COPD I: effects of two doses of twice-daily aclidinium bromide in COPD patients [Abstract]. American Journal of Respiratory and Critical Care Medicine 2012;185(Meeting Abstracts):A2913. [ACCORD: COPD II]

Kerwin EM, D'Urzo AD, Gelb AF, Lakkis H, Garcia Gil E, Caracta CF, et al.Efficacy and safety of a 12-week treatment with twice-daily aclidinium bromide in COPD patients (ACCORD COPD I). COPD 2012;9(2):90-101. [ACCORD-COPD: 1 SID - NCT00891462]

Ambrosino 2008 \{published data only\} Ambrosino N, Foglio K, Balzano G, Paggiaro PL, Lessi $\mathrm{P}$, Kesten S. Tiotropium and exercise training in COPD patients: effects on dyspnea and exercise tolerance.
International Journal of Chronic Obstructive Pulmonary

Disease 2008;3(4):771-80.

\section{Auffarth 1991 \{published data only\}}

Auffarth B, Postma DS, de Monchy JG, van der Mark TW, Boorsma M, Koeter GH. Effects of inhaled budesonide on spirometric values, reversibility, airway responsiveness, and cough threshold in smokers with chronic obstructive lung disease. Thorax 1991;46(5):372-7.

Barnes 2006 \{published data only\} Barnes NC, Qiu Y, Pavord I, Parker D, Johnson M, Thompson M, et al.Salmeterol/fluticasone propionate (SFC): anti-inflammatory effects in COPD [Abstract]. American Thoracic Society International Conference; May 20-25; San Diego. 2005:B93 [Poster 320].

Barnes NC, Qiu Y-S, Pavord ID, Parker D, Davis PA, Zhu $\mathrm{J}$, et al.Antiinflammatory effects of salmeterol/fluticasone propionate in chronic obstructive lung disease. American Journal of Respiratory and Critical Care Medicine 2006;173 (7):736-43.

GlaxoSmithKline. A 13-week, double-blind, parallelgroup, multicentre study to compare the bronchial antiinflammatory activity of the combination of salmeterol/ fluticasone propionate (SERETIDETM/ADVAIRTM/

VIANI ${ }^{\mathrm{TM}}$ ) 50/500 mcg twice daily compared with placebo twice daily in patients with chronic obstructive pulmonary disease. http://www.gsk-clinicalstudyregister.com/ (accessed 10 June 2013). [GSK: SCO30005]

Qiu Y, Parker D, Barnes NC, Johnson M, Pavord L, et al.The effect of salmeterol/fluticasone propionate (SFC) on eosinophils and mast cells in COPD [Abstract]. American Thoracic Society International Conference; May 20-25; San Diego. 2005:A43 [Poster F36].

Qiu YS, Davis P, Zhu J, Peachey L, Barnes NC, Pavord I, et al.Anti-inflammatory effects of salmeterol/fluticasone propionate (SFC) on airway T-lymphocyte populations in COPD. European Respiratory Journal 2005;26 Suppl 49: 203s.

Qiu YS, Davis P, Zhu J, Peachey L, Barnes NC, Pavord I, et al.Effects of salmeterol/fluticasone propionate (SFC) on airway inflammation in COPD: a placebo-controlled study of endobronchial biopsies. European Respiratory Journal 2005;26 Suppl 49:203s.

Zhu J, Qiu Y, Barnes NC, Johnson M, Pavord I, Jeffery PK. The effect of salmeterol/fluticasone propionate (SFC) on pro-inflammatory gene expression in COPD [Abstract]. American Thoracic Society International Conference; May 20-25; San Diego. 2005:A43 [Poster F6].

\section{Beeh 2006 \{published data only\}}

Beeh KM, Beier J, Buhl R, Gerken FMN. Efficacy of tiotropium (Spiriva) in patients with COPD switched from previous treatment with short-acting anticholinergics [Abstract]. American Thoracic Society International Conference; May 19-21; San Diego. 2006:A113 [Poster J27].

Beeh KM, Beier J, Buhl R, Stark-Lorenzen P, Gerken F, Metzdorf N, et al.Efficacy of tiotropium bromide (Spiriva) in patients with chronic-obstructive 
pulmonary disease (COPD) of different severities [Wirksamkeit von Tiotropiumbromid (Spiriva) bei verschiedenen Schweregraden derchronisch-obstruktiven Lungenerkrankung (COPD)]. Pneumologie 2006;60(6): 341-6. [CTG: NCT00274573]

Beeh KM, Beier J, Buhl R, Strak-Lorenzen P, Gerken F, Metzdorf N. Efficacy of tiotropium in patients with mild to moderate COPD [Abstract]. American Thoracic Society 100th international conference; May 21-26; Orlando. 2004:P513.

Boehringer Ingelheim. Acute and long-term effects of once daily oral inhalation of tiotropium $18 \mathrm{mcg}$ dry powder inhalation capsules in a placebo controlled parallel group design study in patients with chronic obstructive pulmonary disease (COPD) of different severity. www.trials.boehringeringelheim.com (accessed 6 March 2014). [trial number: 205.257]

\section{Bogdan 2011 \{published data only\}}

Bogdan M, Aizawa H, Fukuchi Y, Mishima M, Nishimura M, Ichinose M. Efficacy and safety of inhaled formoterol 4.5 and 9 microg twice daily in Japanese and European COPD patients: phase III study results. BMC Pulmonary Medicine 2011;11(1):51. [: 1471-2466]

Bogdan MA, Kudo T, Umemiya M. Efficacy and safety of inhaled formoterol 4.5 and $9 \mathrm{mcg}$ twice daily in Japanese and European patients with COPD: results of a Phase III study [Abstract]. American Journal of Respiratory and Critical Care Medicine 2010;181:A4494.

Ichinose M, Aizawa H, Fukuchi Y, Mishima M, Nishimura M, Bogdan M. Patient-reported outcomes (PROs) and reliever use in Japanese and European patients with chronic obstructive pulmonary disease receiving formoterol 4.5 and 9 microg twice daily: results of the OCEAN phase III study [Abstract]. European Respiratory Society 20th Annual Congress; Sep 18-22; Barcelona. 2010.

Bourbeau 2007 \{published data only\} Bourbeau J, Christodoulopoulos P, Maltais F, Yamauchi Y, Olivenstein R, Hamid Q. Effect of salmeterol/ fluticasone propionate on airway inflammation in COPD: a randomised controlled trial. Thorax 2007;62(11):938-43.

Briggs 2005 \{published data only\}

Briggs D Jr, Covelli H, Lapidus R, Bhattacharya S, Kesten $S$, Cassino C. Improved daytime spirometric efficacy of tiotropium compared to salmeterol in COPD patients [Abstract]. American Thoracic Society 100th international conference; May 21-26; Orlando. 2004:C22 Poster 511. Briggs DD Jr, Covelli H, Lapidus R, Bhattycharya S, Kesten $S$, Cassino C. Improved daytime spirometric efficacy of tiotropium compared with salmeterol in patients with COPD. Pulmonary Pharmacology and Therapeutics 2005;18 (6):397-404.

Brusasco V, Menjoge SS, Kesten S. Flow and volume responders over 12 hours following treatment with tiotropium or salmeterol in patients with COPD [Abstract]. American Thoracic Society International Conference; May 19-21; San Diego. 2006:A110 [Poster J10].

Langley J, Briggs D Jr, Bhattacharya S, Kesten S, Cassino
C. Spirometric outcomes of COPD patients with tiotropium compared with salmeterol according to previous maintenance long acting beta-agonist use [Abstract]. European Respiratory Journal 2004;24(Suppl 48):289s.

Brightling 2005 \{published data only\}

Brightling CE, McKenna S, Hargadon B, Birring S, Green

$\mathrm{R}$, Siva R, et al.Sputum eosinophilia and the short term response to inhaled mometasone in chronic obstructive pulmonary disease. Thorax 2005;60(3):193-8.

\section{Burl 2011 \{published data only\}}

Buhl R, Dunn LJ, Disdier C, Lassen C, Amos C, Henley M et al.Blinded 12-week comparison of once-daily indacaterol and tiotropium in COPD. European Respiratory Journal 2011;38:797-803.

Dunn LJ, Buhl R, Lassen C, Henley M, Kramer B. Blinded 12-week comparison of once-daily indacaterol and tiotropium in COPD [Abstract]. Chest 2010;138:719A.

\section{Cazzola 2007 \{published data only\}}

Cazzola M, Ando F, Santus P, Ruggeri P, Di Marco F, Sanduzzi A, et al.A pilot study to assess the effects of combining fluticasone propionate/salmeterol and tiotropium on the airflow obstruction of patients with severe-to-very severe COPD. Pulmonary Pharmacology and Therapeutics 2007;20(5):556-61.

D’Amato M, Ando F, Santus P, Ruggeri P, Di Marco F, Cazzola M. Clinical effects of adding fluticasone propionate/ salmeterol (FSC) and tiotropium (TIO) in severe-to-very severe COPD [Abstract]. European Respiratory Journal 2005;26(Suppl 49):Abstract No. 218.

\section{Choudhury 2005 \{published data only\}} Choudhury AB, Dawson CM, Kilvington HE, Eldridge HE, James WY, Wedzicha JA, et al.Withdrawal of inhaled corticosteroids in people with chronic obstructive pulmonary disease (COPD) in primary care-a randomised controlled trial [Abstract]. European Respiratory Journal 2005;26(Suppl 49):Abstract No. 1328.

\section{Covelli 2005 \{published data only\}}

Boehringer Ingelheim. Efficacy and safety (including 24hour holter monitoring) of tiotropium inhalation capsules in patients with chronic obstructive pulmonary disease (a 12-week, parallel group, randomized, placebo-controlled, double-blind study). www.trials.boehringer-ingelheim.com (accessed 6 March 2014). [trial number: 205.284] Covelli H, Bhattacharya S, Cassino C, Conoscenti C, Kesten $\mathrm{S}$. Absence of electrocardiographic findings and improved function with once-daily tiotropium in patients with chronic obstructive pulmonary disease. Pharmacotherapy 2005;25(12):1708-18. [CTG: NCT00239460] Kesten S, Cassino C, Conoscenti C. Absence of electrocardiographic findings with daily tiotropium in patients with chronic obstructive pulmonary disease [Abstract]. Chest 2004;126(4 Suppl):837S.

Culpitt 1999 \{published data only\} Culpitt SV, Maziak W, Loukidis S, Nightingale JA, Matthews JL, Barnes PJ. Effect of high dose inhaled steroid on cells, cytokines, and proteases in induced sputum in 
chronic obstructive pulmonary disease. American Journal of Respiratory and Critical Care Medicine 1999;160(5 Pt 1): 1635-9.

\section{Dahl 2001 \{published data only\}}

Dahl R, Greefhorst AP, Byrne AM. Onset of inhaled formoterol compared to ipratropium bromide in patients with COPD. European Respiratory Journal 2000;16(Suppl 31):5s.

Dahl R, Greefhorst APM, Nowak D, Nonikov V, Byrne A, Colacchio C, et al.Comparison of the efficacy and safety of inhaled formoterol and ipratropium bromide in patients with COPD. American Journal of Respiratory and Critical Care Medicine 2000;161(Suppl 3):A489.

Dahl R, Greefhorst APM, Thomson MH, Till D. Formoterol $\left(\right.$ Foradil $\left.^{\circledR}\right)$ improves lung function and quality of life (QOL) parameters in patients with reversible or poorly reversible COPD. American Journal of Respiratory and Critical Care Medicine 2001;163(Suppl 5):A280.

Dahl R, Greefhorst LA, Nowak D, Nonikov V, Byrne AM, Thomson $\mathrm{MH}$, et al.Inhaled formoterol dry powder versus ipratropium bromide in chronic obstructive pulmonary disease. American Journal of Respiratory and Critical Care Medicine 2001;164(5):778-84. [: 1073-449X]

Dahl R, Kristufek P, Greefhorst APM, Amgott TR, Della Cioppa G, Thompson MH. The cardiac safety profile of formoterol dry powder is similar to placebo in patients with COPD. European Respiratory Journal 2000;16(Suppl 31): 51 s.

Greefhorst APM, Dahl R, Nowak D, Nonikov V, Byrne

A, Colacchio C, et al.Effect of inhaled formoterol and ipratropium bromide on quality of life, "bad days" and exacerbations in patients with COPD. American Journal of Respiratory and Critical Care Medicine 2000;161 (Suppl 3): A490.

Greefhorst APM, Dahl R, Nowak D, Nonikov V, Colacchio C, Byme AM. Formoterol dry powder improves the quality of life of patients with COPD whereas the effect of ipratropium bromide is similar to placebo. European Respiratory Journal 2000;16(Suppl 31):51s.

Greefhorst APM, Thomson MH, Byrne A, Till D. The efficacy of formoterol in patients with chronic obstructive pulmonary disease (COPD) is not influenced by concomitant corticosteroid use. European Respiratory Journal 2001;18(Suppl 33):515s.

Hogan TJ, Geddes R, Gonzalez ER. An economic assessment of inhaled formoterol dry powder versus ipratropium bromide pressurized metered dose inhaler in the treatment of chronic obstructive pulmonary disease. Clinical Therapeutics 2003;25(1):285-97. [: 0149-2918]

Dahl 2013 [BEACON] \{published data only\} Dahl R, Jadayel D, Alagappan VKT, Chen H, Banerji D. Efficacy and safety of QVA149 compared to the concurrent administration of its monocomponents indacaterol and glycopyrronium: the BEACON study. International Journal of Chronic Obstructive Pulmonary Disease 2013;8:501-8.

Dawber 2005 \{published data only\}

Dawber F, Tandy D, Haussermann S, Betz R. Efficacy of salmeterol/fluticasone propionate $50 / 500 \mathrm{mcg}$ bd versus tiotropium on lung function and mucociliary clearance in COPD patients [Abstract]. Respirology (Carlton, Vic.) 2005; 10(Suppl 3):A99.

\section{Derenne 1995 \{published data only\}}

Derenne JP. Effects of high dose inhaled beclomethasone on the rate of decline in FEV1 in patients with chronic obstructive pulmonary disease: results of a 2 years prospective multicentre study. American Journal of Respiratory and Critical Care Medicine 1995;151(4):A463. [CRS-ID: 4900100000023687]

\section{Dransfield 2013 \{published data only\}}

Dransfield MT, Bourbeau J, Jones PW, Hanania NA, Mahler DA, Vestbo J, et al.Once-daily inhaled fluticasone furoate and vilanterol versus vilanterol only for prevention of exacerbations of COPD: two replicate double-blind, parallel-group, randomised controlled trials. The Lancet Respiratory Medicine 2013;1(3):210-23.

\section{FCO30002 \{published data only\}}

GlaxoSmithKline. A multicentre, randomised, placebocontrolled, double-blind comparison with 3 parallel groups to investigate the efficacy and safety of inhaled glucocorticoid fluticasone $\left(500 \mu \mathrm{g}\right.$ bd via Diskus $\left.{ }^{\mathrm{TM}}\right)$ vs. oral glucocorticoid therapy vs. placebo in subjects with chronic obstructive airway disease (COPD) under therapy with Salmeterol $(50 \mu \mathrm{g}$ bd). http://www.gskclinicalstudyregister.com/ (accessed 6 March 2014). [GSK: FCO30002]

\section{Ferreira 2001 \{published data only\}}

Ferreira IM, Hazari MS, Gutierrez C, Zamel N, Chapman $\mathrm{KR}$. Exhaled nitric oxide and hydrogen peroxide in patients with chronic obstructive pulmonary disease: effects of inhaled beclomethasone. American Journal of Respiratory and Critical Care Medicine 2001;164(6):1012-5.

\section{Ferreira 2003 \{published data only\}}

Ferreira IM, Sandrini A, Zamel N, Balter M, Chapman KR. Effects of inhaled fluticasone propionate (FP) on exhaled nitric oxide (ENO), functional exercise capacity and quality of life in stable patients with COPD. American Thoracic Society 99th International Conference; May 16-21; Seattle. 2003:B024 Poster 404.

\section{Freeman 2007 \{published data only\}}

Freeman D. A randomised, double-blind, parallel group, 12 week study, comparing the effect of once daily tiotropium lactose capsule with placebo in patients with chronic obstructive pulmonary disease (COPD), naive to anticholinergic agents in addition to receiving their usual COPD care. www.trials.boehringer-ingelheim.com (accessed 6 March 2014). [trial number: 205.276] Freeman D, Lee A, Price D. Efficacy and safety of tiotropium in COPD patients in primary care-the SPiRiva Usual CarE (SPRUCE) study. Respiratory Research 2007;8:45. [CTG: NCT00274079]

Freeman D, Sarno M, White L, Lee A, Price D. Spruce: tiotropium in UK primary care [Abstract]. Thorax 2004;59 
(Suppl II):ii100.

Price D, Sarno M, Lee A, Freeman D. SPiRiva usual carE-SPRUCE-tiotropium in a UK primary care COPD population other regular inhaled treatment [Abstract]. American Thoracic Society International Conference; May 20-25; San Diego. 2005:[A43] [Poster: F26].

Fukuchi 2013 \{published data only\}

Fukuchi Y, Samoro R, Fassakhov R, Taniguchi H, Ekelund J, Carlsson LG, et al.Budesonide/formoterol via Turbuhaler versus formoterol via Turbuhaler in patients with moderate to severe chronic obstructive pulmonary disease: phase III multinational study results. Respirology (Carlton, Vic.) 2013;18(5):866-73.

Guenette 2011 \{published data only\} Guenette JA, Raghavan N, Harris-McAllister V, Preston ME, Webb KA, O'Donnell DE. Effect of adjunct fluticasone propionate on airway physiology during rest and exercise in COPD. Respiratory Medicine 2011;105(12):1836-45. [1532-3064: (Electronic)]

Hanrahan 2008 \{published data only\} Baumgartner RA, Hanania NA, Calhoun WJ, Sahn SA, Sciarappa K, Hanrahan JP. Nebulized arformoterol in patients with COPD: a 12-week, multicenter, randomized, double-blind, double-dummy, placebo- and activecontrolled trial. Clinical Therapeutics 2007;29(2):261-78. Grogan DR, Hanrahan JP, Morganroth J, Cheng H, Baumgartner RA. Arrhythmias in COPD: Holter monitoring results from 2 arformoterol pivotal trials [Abstract]. American Thoracic Society International Conference; May 18-23; San Francisco. 2007:Poster 413. Hanrahan JP, Grogan DR, Baumgartner RA, Wilson A, Cheng $\mathrm{H}$, Zimetbaum PJ, et al.Arrhythmias in patients with chronic obstructive pulmonary disease (COPD): occurrence frequency and the effect of treatment with the inhaled longacting beta2-agonists arformoterol and salmeterol. Medicine 2008;87(6):319-28.

Hanrahan JP, Hanania NA, Calhoun WJ, Sahn SA, Sciarappa K, Baumgartner RA. Effect of nebulized arformoterol on airway function in COPD: results from two randomized trials. Journal of Chronic Obstructive Pulmonary Disease 2008;5(1):25-34.

Hanrahan JP, Kerwin E, Cheng H, Grogan DR, Baumgartner RA. Arformoterol in COPD safety results from two pooled phase 3 trials [Abstract]. European Respiratory Journal 2006;28(Suppl 50):428s [P2500]. Hanrahan JP, Sahn SA, Busse WW, Sciarappa K, Baumgartner RA. Efficacy of nebulized arformoterol: a long acting B2 adrenergic bronchodilator in patients with COPD [abstract]. European Respiratory Journal 2006;28 (Suppl 50):215s [P1276].

Hanrahan JP, Sahn SA, Fogarty CM, Sciarappa K, Baumgartner RA. Efficacy and safety of arformoterol in COPD: a prospective phase 3 clinical trial [Abstract]. American Thoracic Society International Conference; May 19-21; San Diego. 2006:A847 Poster 509.

Hanrahan JP, Smith WB, Sciarappa K, McVicar WK, Baumgartner RA. Efficacy and safety of nebulized arformoterol in COPD: a prospective, phase III clinical trial [Abstract]. Chest 2006;130(4):181s.

Sciurba FC, Baumgartner RA, Sciarappa K, Benzo RP, Hanrahan JP. Degree of exercise limitation in COPD: impact on 6 minute walk in response to long acting beta agonist (LABA) treatment [Abstract]. European Respiratory Journal 2007;30(Suppl 51):76s [P596].

Sepracor. A double-blind, double-dummy, randomized, placebo- and active-controlled, multicenter, parallel group study of $(\mathrm{R}, \mathrm{R})$-formoterol in the treatment of subjects with chronic obstructive pulmonary disease. www.clinicaltrials.gov (accessed 20 November 2012). [clinicaltrials.gov: NCT00064402; clinicaltrials.gov: NCT00064415]

Hattotuwa 2002 \{published data only\} Gizycki MJ, Hattotuwa KL, Barnes N, Jeffery PK. Effects of fluticasone propionate on inflammatory cells in COPD: an ultrastructural examination of endobronchial biopsy tissue. Thorax 2002;57(9):799-803.

Hattotuwa KL, Gizycki MJ, Ansari TW, Jeffery PK, Barnes NC. The effects of inhaled fluticasone on airway inflammation in chronic obstructive pulmonary disease. American Journal of Respiratory and Critical Care Medicine 2002;165(12):1592-9.

\section{Johansson 2008 \{published data only\}}

Johansson G. A 12-week, double-blind, randomised, parallel-group, multi-centre study evaluating the efficacy of tiotropium versus placebo in patients with mild COPD according to Swedish guidelines (SPIRIMILD). www.trials.boehringer-ingelheim.com (accessed 6 March 2014). [trial number: 205.281]

Johansson G, Lindberg A, Romberg K, Nordstrom L, Gerken F, Roquet A. Bronchodilator efficacy of tiotropium in patients with mild COPD [Abstract]. European Respiratory Journal 2006;28(Suppl 50):616s [E3614]. Johansson G, Lindberg A, Romberg K, Nordstrom L, Gerken F, Roquet A. Bronchodilator efficacy of tiotropium in patients with mild to moderate COPD. Primary Care Respiratory Journal 2008; Vol. 17, issue 3:169-75. [CTG: NCT00144196]

\section{John 2005 \{published data only\}}

John M, Bosse S, Oltmanns U, Schumacher A, Witt C. Effects of inhaled HFA beclomethasone on pulmonary function and symptoms in patients with chronic obstructive pulmonary disease. Respiratory Medicine 2005;99(11): 1418-24.

John M, Bosse S, Schumacher A, Oltmanns U, Witt C. Effects of inhaled beclomethasone HFA 134 (qvar/ ventoiair) on health related quality of life in patients with chronic obstructive pulmonary disease [Abstract]. American Thoracic Society International Conference; May 20-25; San Diego. 2005:Poster A43.

Kerstjens 1992 \{published data only\} Kaptein AA, Brand PL, Dekker FW, Kerstjens HA, Postma DS, Sluiter HJ. Quality-of-life in a long-term multicentre trial in chronic nonspecific lung disease: assessment at 
baseline. The Dutch CNSLD Study Group. European Respiratory Journal 1993;6(10):1479-84.

Kerstjens HA, Brand PL, Quanjer PH, van der BruggenBogaarts BA, Koeter GH, Postma DS. Variability of bronchodilator response and effects of inhaled corticosteroid treatment in obstructive airways disease. Dutch CNSLD Study Group. Thorax 1993;48(7):722-9.

Kerstjens HA, Brand PL, de Jong PM, Koeter GH, Postma DS. Influence of treatment on peak expiratory flow and its relation to airway hyperresponsiveness and symptoms. The Dutch CNSLD Study Group. Thorax 1994;49(11): 1109-15.

Kerstjens HA, Overbeek SE, Schouten JP, Brand PL, Postma DS. Airways hyperresponsivenes, bronchodilator response, allergy and smoking predict improvement in FEV1 during long-term inhaled corticosteroid treatment. Dutch CNSLD Study Group. European Respiratory Journal 1993;6(6): 868-76.

Kerstjens HA, Postma DS, van Doormaal JJ, van Zanten AK, Brand PL, Dekhuijzen PN, et al.Effects of short-term and long-term treatment with inhaled corticosteroids on bone metabolism in patients with airways obstruction. Dutch CNSLD Study Group. Thorax 1994;49(7):652-6. Kerstjens HA, Schouten JP, Brand PL, Schoonbrood DF, Sterk PJ, Postma DS. Importance of total serum IgE for improvement in airways hyperresponsiveness with inhaled corticosteroids in asthma and chronic obstructive pulmonary disease. The Dutch CNSLD Study Group. American Journal of Respiratory and Critical Care Medicine 1995;151(2 Pt 1):360-8.

Kerstjens HAM, Brand PLP, Hughes MD, Robinson NJ, Postma DS, Sluiter HJ, et al.A comparison of bronchodilator therapy with or without inhaled corticosteroid therapy for obstructive airways disease. New England Journal of Medicine 1992;327(20):1413-9.

Overbeek SE, Kerstjens HA, Bogaard JM, Mulder PG, Postma DS. Is delayed introduction of inhaled corticosteroids harmful in patients with obstructive airways disease (asthma and COPD)? The Dutch CNSLD Study Group. The Dutch Chronic Nonspecific Lung Disease Study Groups. Chest 1996;110(1):35-41.

Rutten-van Molken MP, Van Doorslaer EK, Jansen MC, Kerstjens HA, Rutten FF. Costs and effects of inhaled corticosteroids and bronchodilators in asthma and chronic obstructive pulmonary disease. American Journal of Respiratory and Critical Care Medicine 1995;151(4):975-82. van Grunsven PM, van Schayck CP, Derenne JP, Kerstjens HA, Renkema TE, Postma DS, et al.Long term effects of inhaled corticosteroids in chronic obstructive pulmonary disease: a meta-analysis. Thorax 1999;54(1):7-14.

Kerwin 2013 \{published data only\}

Kerwin EM, Scott-Wilson C, Sanford L, Rennard S, Agusti A, Barnes $\mathrm{N}$, et al.A randomised trial of fluticasone furoate/ vilanterol (50/25 mug; 100/25 mug) on lung function in COPD. Respiratory Medicine 2013;107(4):560-9.

Llewellyn-Jones 1996 \{published data only\} Llewellyn-Jones CG, Harris TA, Stockley RA. Effect of fluticasone propionate on sputum of patients with chronic bronchitis and emphysema. American Journal of Respiratory and Critical Care Medicine 1996;153(2):616-21.

Loppow 2001 \{published data only\}

Loppow D, Schleiss MB, Kanniess F, Taube C, Jorres RA, Magnussen $\mathrm{H}$. In patients with chronic bronchitis a four week trial with inhaled steroids does not attenuate airway inflammation. Respiratory Medicine 2001;95(2):115-21.

Lung Health Study 2000 \{published data only\} Anthonisen NR, Connett JC, Murray RP. Smoking and lung function of Lung Health Study participants after 11 years. American Journal of Respiratory and Critical Care Medicine 2002;166(5):675-9.

Eichenhorn MS, Wise RA, Madhok TC, Gerald LB, Bailey WC, Tashkin DP, et al.Lack of long-term adverse adrenal effects from inhaled triamcinolone: Lung Health Study II. Chest 2003;124(1):57-62.

Lung Health Study Research Group. Effect of inhaled triamcinolone on the decline in pulmonary function in chronic obstructive pulmonary disease. New England Journal of Medicine 2000;343(26):1902-9.

Scanlon PD, Connett JE, Wise RA, Tashkin DP, Madhok $\mathrm{T}$, Skeans M, et al.Loss of one density with inhaled triamcinolone in Lung Health Study II. American Journal of Respiratory and Critical Care Medicine 2004;170(12): 1302-9.

Tashkin DP, Murray HE, Skeans M, Murray RP. Skin manifestations of inhaled corticosteroids in COPD patients. Chest 2004;126(4):1123-33.

\section{Magnussen 2008 \{published data only\}}

Boehringer Ingelheim. A trial evaluating the efficacy and safety of inhaled tiotropium $18 \mu \mathrm{g}$ qd in patients with COPD and a concomitant diagnosis of asthma. www.clinicaltrials.gov (accessed 6 March 2014).

Magnussen H. A 12-week randomised, double blind, placebo-controlled, parallel group trial evaluating the efficacy and safety of inhaled tiotropium $18 \mu \mathrm{g}$ q.d. in patients with COPD and a concomitant diagnosis of asthma. www.trials.boehringer-ingelheim.com (accessed 6 March 2014). [trial number: 205.301]

Magnussen H, Bugnas B, Van Noord J, Schmidt P, Gerken F, Kesten S. Improvements with tiotropium in COPD patients with concomitant asthma. Respiratory Medicine 2008;102(1):50-6. [CTG: NCT00152984]

Magnussen H, Bugnas B, Van Noord J, Schmidt P, Gerken F, Kesten S, et al.Spirometric improvements with tiotropium in COPD patients with concomitant asthma [Abstract]. American Thoracic Society International Conference; May 18-23; San Francisco. 2007:Poster \#A5.

\section{Mahler 1999 \{published data only\}}

Ferguson G, Funck-Brentano C, Fischer T, Darken P, Troy $\mathrm{S}$, Compton C, et al.Cardiovascular safety of salmeterol in patients with COPD. American Journal of Respiratory and Critical Care Medicine 2002;165(Suppl 8):A228.

Ferguson GT, Funck-Brentano C, Fischer T, Darken P, Reisner C. Cardiovascular safety of salmeterol in COPD. 
Chest 2003;123(6):1817-24.

GlaxoSmithKline. A randomized, double-blind, doubledummy, comparative clinical trial of 12-week courses of salmeterol xinafoate versus ipratropium bromide versus placebo (PRN Ventolin) in subjects with chronic obstructive pulmonary disease. www.gsk-clinicalstudyregister.com (accessed 20 December 2012). [GSK: SLGA4005] Mahler DA, Donohue JF, Barbee RA, Goldman MD, Gross $\mathrm{NJ}$, Wisniewski ME, et al.Efficacy of salmeterol xinafoate in the treatment of COPD. Chest 1999;115(4):957-65.

\section{Mahler 2010 \{published data only\}}

Mahler DA, D’Urzo A, Peckitt C, Lassen C, Kramer B, Filcek S. Combining once-daily bronchodilators In COPD: indacaterol plus tiotropium versus tiotropium alone. American Journal of Respiratory and Critical Care Medicine 2011;183:A1591.

Novartis. A randomized, double-blind, controlled, parallel group, 12-week treatment study to compare the efficacy and safety of the combination of indacaterol $150 \mu \mathrm{g}$ once daily with open label tiotropium $18 \mu \mathrm{g}$ once daily versus open label tiotropium $18 \mu \mathrm{g}$ once daily in patients with moderate-to-severe chronic obstructive pulmonary disease. www.novctrd.com (accessed 6 March 2014). [: CQAB149B2341]

Mahler 2010a \{published data only\}

Mahler DA, D’Urzo A, Peckitt C, Lassen C, Kramer B, Filcek $\mathrm{S}$. Combining once-daily bronchodilators In COPD: indacaterol plus tiotropium versus tiotropium alone. American Journal of Respiratory and Critical Care Medicine 2011;183:A1591.

Novartis. A randomized, double-blind, controlled, parallel group, 12-week treatment study to compare the efficacy and safety of the combination of indacaterol $150 \mu \mathrm{g}$ once daily with open label tiotropium $18 \mu \mathrm{g}$ once daily versus open label tiotropium $18 \mu \mathrm{g}$ once daily in patients with moderate-to-severe chronic obstructive pulmonary disease. www.novctrd.com (accessed 6 March 2014). [: CQAB149B2351]

\section{Martinez 2013 \{published data only\}}

Martinez FJ, Boscia J, Feldman G, Scott-Wilson C, Kilbride S, Fabbri L, et al.Fluticasone furoate/vilanterol (100/ 25; 200/25 mug) improves lung function in COPD: a randomised trial. Respiratory Medicine 2013;107(4):550-9.

\section{Mirici 2001 \{published data only\}}

Mirici A, Bektas Y, Ozbakis G, Erman Z. Effect of inhaled corticosteroids on respiratory function tests and airway inflammation in stable chronic obstructive pulmonary disease. Clinical Drug Investigation 2001;21(12):835-42.

\section{Moita 2008 \{published data only\}}

Boehringer Ingelheim. Spiriva ${ }^{\circledR}$ assessment of FEV1(SAFE-Portugal). The effect of inhaled tiotropium bromide (18 mcg once daily) on the change in FEV1 during treatment in patients with COPD. A three-month parallel group, double-blind, randomised, placebo-controlled study. www.trials.boehringer-ingelheim.com (accessed 6 March 2014). [trial number: 205.282]

Moita J, Barbara C, Cardoso J, Costa R, Sousa M, Ruiz J, et al.Tiotropium improves FEV1 in patients with COPD irrespective of smoking status. Pulmonary Pharmacology and Therapeutics 2008;21(1):146-51. [CTG: NCT00239408] Moita J, Costa R, Barbara C, Cardosa J, Rulz J, Sousa M. The effect of tiotropium bromide in a stable cohort of COPD patients in Portugal [Abstract]. European Respiratory Journal 2005;26(Suppl 49):Abstract No. 1955.

\section{NCT00144326 \{published data only\}}

García Río, F. A randomised, double-blind, placebocontrolled, 12 week trial to evaluate the effect of tiotropium inhalation capsules on the magnitude of exercise, measured using an accelerometer, in patients with chronic obstructive pulmonary disease (COPD). www.trials.boehringeringelheim.com (accessed 15 October 2007). [CTG: NCT00144326; trial number: 205.269]

\section{Nelson 2007 \{published data only\}}

Gross NJ, Lapidus R, Dunn LJ, Lynn LD, Denis-Mize $\mathrm{K}$, Rinehart M. Nebulized formoterol is an effective bronchodilator and improves the quality of life for COPD patients [Abstract]. American Thoracic Society International Conference; May 18-23; San Francisco. 2007: Poster A10.

Gross NJ, Nelson HS, Lapidus RJ, Dunn L, Lynn L, Rinehart M, et al.Efficacy and safety of formoterol fumarate delivered by nebulization to COPD patients. Respiratory Medicine 2008;102(2):189-97.

Nelson HS, Gross NJ, Levine B, Kerwin EM, Rinehart $\mathrm{M}$, Denis-Mize K, et al.Cardiac safety profile of nebulized formoterol in adults with COPD: a 12-week, multicenter, randomized, double-blind, double-dummy, placebo- and active-controlled trial. Clinical Therapeutics 2007;29(10): 2167-78.

Nelson HS, Gross NJ, Rinehart M, Denis-Mize K. Cardiovascular safety of nebulized formoterol in COPD patients: a double-blind, placebo-controlled study. Chest 2007;132(4):529b-530.

Nelson HS, ZuWallack R, Levine B, Kerwin EM, DenisMize K, Rinehart M. Safety profile of formoterol fumarate delivered by nebulization to COPD patients [Abstract]. American Thoracic Society International Conference; May 18-23; San Francisco. 2007:Poster A11.

\section{Nishimura 1999 \{published data only\}}

Nishimura K, Koyama H, Ikeda A, Tsukino M, Hajiro

T, Mishima M, et al.The effect of high-dose inhaled beclomethasone dipropionate in patients with stable COPD. Chest 1999;115(1):31-7.

\section{O'Donnell 2006 \{published data only\}}

Celli B, Emmett A, Crater G, Kalberg C. Salmeterol/ fluticasone propionate (SFC) improves the inspiratory to total lung capacity ratio (IC/TLC) and exercise endurance time in patients with COPD. European Respiratory Journal 2006;28(Suppl 50):764s.

GlaxoSmithKline. A randomized, double-blind, placebocontrolled, parallel group clinical trial evaluating the effect 
of the fluticasone propionate/salmeterol combination product $250 / 50 \mathrm{mcg}$ bid via DISKUS and salmeterol $50 \mathrm{mcg}$ bid via DISKUS on lung hyperinflation in subjects with chronic obstructive pulmonary disease (COPD). http: //www.gsk-clinicalstudyregister.com/ (accessed 10 June 2013). [GSK: SCO40030]

Make B, Emmett A, Crater G, O’Dell D, Kalberg C. Improvement in exercise endurance time (EET) with fluticasone propionate/salmeterol correlations with spirometry and plethysmography. American Thoracic Society International Conference; May 19-21; San Diego. 2006.

O'Donnell DE, Sciurba F, Celli B, Mahler DA, Webb KA, Kalberg CJ, et al.Effect of fluticasone propionate/salmeterol on lung hyperinflation and exercise endurance in COPD. Chest 2006;130(3):647-56.

\section{Rennard 2001 \{published data only\}}

Ferguson G, Funck-Brentano C, Fischer T, Darken P, Troy $\mathrm{S}$, Compton C, et al.Cardiovascular safety of salmeterol in patients with COPD. American Journal of Respiratory and Critical Care Medicine 2002;165(Suppl 8):A228.

Ferguson GT, Funck-Brentano C, Fischer T, Darken P, Reisner C. Cardiovascular safety of salmeterol in COPD. Chest 2003;123(6):1817-24.

GlaxoSmithKline. A randomized, double-blind, doubledummy, comparative clinical trial of 12 -week courses of salmeterol xinafoate versus ipratropium bromide versus placebo (PRN Ventolin ${ }^{\circledR}$ ) in subjects with chronic obstructive pulmonary disease. www.gskclinicalstudyregister.com (accessed 7 December 2012). [GSK: SLGA4004]

Rennard SI, Anderson W, ZuWallack R, Broughton J, Bailey W, Friedman M, et al.Use of a long-acting inhaled beta2-adrenergic agonist, salmeterol xinafoate, in patients with chronic obstructive pulmonary disease. American Journal of Respiratory and Critical Care Medicine 2001;163 (5):1087-92.

Robertson 1986 \{published data only\}

Robertson AS, Gove RI, Wieland GA, Burge PS. A doubleblind comparison of oral prednisolone $40 \mathrm{mg} /$ day with inhaled beclomethasone dipropionate $1500 \mathrm{ug} /$ day in patients with adult onset chronic obstructive airways disease. European Journal of Respiratory Diseases 1986;146 (Suppl):565-9.

Rutgers 1998 \{published data only\}

Rutgers SR, Koeter GH, van der Mark TW, Postma DS. Short-term treatment with budesonide does not improve hyperresponsiveness to adenosine 5'-monophosphate in COPD. American Journal of Respiratory and Critical Care Medicine 1998;157(3 Pt 1):880-6.

SCO40034 \{published data only\}

GlaxoSmithKline. A multicentre, randomised, doubleblind, double dummy, parallel group 12-week exploratory study to compare the effect of the fluticasone/salmeterol propionate combination product (SERETIDETM) 50/ $500 \mathrm{mcg}$ bd via the DISKUS ${ }^{\mathrm{TM}} /$ ACCUHALER $^{\mathrm{TM}}$ inhaler with tiotropium bromide $18 \mathrm{mcg}$ od via the Handihaler inhalation device on efficacy and safety in patients with chronic obstructive pulmonary disease (COPD). www.gskclinicalstudyregister.com/files/pdf/23678.pdf (accessed 16 June 2009). [GSK: SCO40034]

\section{Sin 2004 \{published data only\}}

Sin DD, Lacy P, York E, Man SFP. Effects of fluticasone on systemic markers of inflammation in chronic obstructive pulmonary disease. American Journal of Respiratory and Critical Care Medicine 2004;170(7):760-5.

Sin 2008 \{published data only\}

Sin DD, Man SF, Marciniuk DD, Ford G, FitzGerald $\mathrm{M}$, Wong $\mathrm{E}$, et al.ABC (Advair, Biomarkers in COPD) Investigators. The effects of fluticasone with or without salmeterol on systemic biomarkers of inflammation in chronic obstructive pulmonary disease. American Journal of Respiratory and Critical Care Medicine 2008;177(11): 1207-14.

Sun 2007 \{published data only\}

Sun LH, Tan Y, Qiao Y, Fang SR, Xie H. Evaluation of clinical effect and safety of tiotropium bromide in treating stable chronic obstructive pulmonary disease. Zhongguo Xinyao yu Linchuang Zazhi 2007;26(5):328-31.

Yan L, Lu YK. Effect of domestic tiotropium bromide inhalation in patients with COPD at stable stage. Chinese Journal of New Drugs 2010;19(2):127-9, 138.

Tashkin 2009 \{published data only\}

Tashkin D, Varghese S. Formoterol treatment plus tiotropium results in greater improvements in lung function compared with tiotropium administered alone in patients with COPD [Abstract]. Journal of Allergy and Clinical Immunology 2007;119(1 Suppl):S4 [13].

Tashkin D, Varghese S. The therapeutic effect of treatment with formoterol plus tiotropium was greater than the effect of treatment with tiotropium alone in COPD: findings from a 12-week, multicenter, double-blind, placebo-controlled trial. Chest 2007;132(4):529a.

Tashkin DP. Formoterol and tiotropium reduces rescue medication use more than tiotropium alone in patients with moderate COPD: findings from a 12 week randomized placebo controlled trial [Abstract]. American Thoracic Society International Conference; May 16-21; Toronto. 2008:A647[\#F5].

Tashkin DP, Pearle J, Iezzoni D, Varghese ST. Formoterol and tiotropium compared with tiotropium alone for treatment of COPD. Journal of Chronic Obstructive Pulmonary Disease 2009;6(1):17-25.

Tashkin DP, Pearle JL, Varghese S. Improvement of lung function with coadministered formoterol and tiotropium, regardless of smoking status in patients with chronic obstructive pulmonary disease [Abstract]. Chest 2008;134 (4):103002s.

\section{Thompson 1992 \{published data only\}}

Thompson AB, Mueller MB, Heires AJ, Bohling TL, Daughton D, Yancey SW, et al.Aerosolized beclomethasone in chronic bronchitis: improved pulmonary function and diminished airway inflammation. American Review of 
Respiratory Disease 1992;146(2):389-95. [MEDLINE: 93143171]

Thompson 2002 \{published data only\}

Thompson WH, Carvalho P, Souza JP, Charan NB.

Controlled trial of inhaled fluticasone propionate in moderate to severe COPD. Lung 2002;180(4):191-201.

van der Valk 2002 \{published data only\}

van der Valk P, Monninkhof E, van der Palen J, Zielhuis G, van Herwaarden C, van der Phalen J. Effect of discontinuation of inhaled corticosteroids in patients with chronic obstructive pulmonary disease: the COPE study. American Journal of Respiratory and Critical Care Medicine 2002;166(10):1358-63.

van Grunsven 2003 \{published data only\}

van Grunsven P, Schermer T, Akkermans R, Albers M, van den Boom G, van Schayck O, et al.Short- and long-term efficacy of fluticasone propionate in subjects with early signs and symptoms of chronic obstructive pulmonary disease. Results of the DIMCA study. Respiratory Medicine 2003;97 (12):1303-12.

\section{Verkinde 2006 \{published data only\}}

Huchon G. Effect of a 12-week treatment with inhaled tiotropium (18 mcg once daily) on lung function and static lung volumes in stable, moderate to severe COPD patients. Correlation to dyspnoea scales: a double-blind, placebo-controlled, randomized, parallel group study. www.trials.boehringer-ingelheim.com (accessed 6 March 2014). [trial number: 205.215]

Huchon G, Verkindre C, Bart F, Aguilaniu B, Guerin JC, Lemerre C, et al.Improvements with tiotropium on endurance measure by the shuttle walking test (SWT) and on health related quality of life (HRQoL) in COPD patients. European Respiratory Society 12th Annual Congress; Sep 14-18; Stockholm. 2002.

Verkindre C, Bart F, Aguilaniu B, Fortin F, Guerin JC, Le Merre $\mathrm{C}$, et al.The effect of tiotropium on hyperinflation and exercise capacity in chronic obstructive pulmonary disease. Respiration 2006;73(4):420-7.

\section{Voshaar 2008 \{published data only\}}

Boehringer Ingelheim. A randomised, double-blind, double-dummy, placebo- and active-controlled, parallel group efficacy and safety comparison of 12 -week treatment of two doses $[5 \mathrm{mcg}(2$ actuations of $2.5 \mathrm{mcg}$ ) and 10 $\mathrm{mcg}$ ( 2 actuations of $5 \mathrm{mcg}$ )] of tiotropium inhalation solution delivered by the Respimat inhaler, placebo and ipratropium bromide inhalation aerosol (MDI) in patients with chronic obstructive pulmonary disease (COPD). www.trials.boehringer-ingelheim.com (accessed 6 March 2014). [trial number: 205.251]

Boehringer Ingelheim. A randomized, double-blind, double-dummy, placebo- and active-controlled, parallel group efficacy and safety comparison of 12-week treatment of two doses $(5 \mathrm{Mcg}$ and $10 \mathrm{Mcg}$ ) of tiotropium inhalation solution delivered by the Respimat inhaler, placebo and ipratropium bromide inhalation aerosol (MDI) in patients with chronic obstructive pulmonary disease (COPD). www.clinicaltrials.gov (accessed 6 March 2014). [trial number: 205.252]

Voshaar T, Lapidus R, Maleki-Yazdi R, Timmer W, Rubin E, Lowe $\mathrm{L}$, et al.A randomised study of tiotropium Respimat soft mist inhaler versus ipratropium PMDI in chronic obstructive pulmonary disease [Abstract]. Thorax 2006;61 (Suppl 2):ii40 [S112].

Voshaar T, Lapidus R, Maleki-Yazdi R, Timmer W, Rubin $\mathrm{E}$, Lowe $\mathrm{L}$, et al.A randomized study of tiotropium Respimat Soft Mist inhaler vs. ipratropium pMDI in COPD. Respiratory Medicine 2008;102(1):32-41. [CTG: NCT00239473; CTG: NCT00240435]

\section{Wadbo 2002 \{published data only\}}

Wadbo M, Lofdahl CG, Larsson K, Skoogh BE, Tornling G, Arwestrom E, et al.Effects of formoterol and ipratropium bromide in COPD: a 3-month placebo-controlled study. European Respiratory Journal 2002;20(5):1138-46. [: 0903-1936]

\section{Watkins 2002 \{published data only\}}

Watkins M, Wire P, Yates J, Fischer T, Chang C, Horstman $\mathrm{D}$, et al.Sustained FEV increases in COPD patients induced by salmeterol $50 \mathrm{mcg}$ twice daily via the diskus inhaler. American Journal of Respiratory and Critical Care Medicine 2002;165(Suppl 8):A228.

\section{Weiner 1995 \{published data only\}}

Weiner P, Weiner M, Azgad Y, Zamir D. Inhaled budesonide therapy for patients with stable COPD. Chest 1995;108(6): 1568-71.

\section{Weiner 1999 \{published data only\}}

Weiner P, Weiner M, Rabner M, Waizman J, Magadle R, Zamir D. The response to inhaled and oral steroids in patients with stable chronic obstructive pulmonary disease. Journal of Internal Medicine 1999;245(1):83-9.

\section{Weir 1990 \{published data only\}}

Weir DC, Gove RI, Robertson AS, Burge PS. Corticosteroid trials in non-asthmatic chronic airflow obstruction: a comparison of oral prednisolone and inhaled beclomethasone dipropionate. Thorax 1990;45(2):112-7. [MEDLINE: 90194025]

Weir DC, Gove RI, Robertson AS, Burge PS. Response to corticosteroids in chronic airflow obstruction: relationship to emphysema and airways collapse. European Respiratory Journal 1991;4(10):1185-90.

Weir DC, Robertson AS, Gove RI, Burge PS. Time course of response to oral and inhaled corticosteroids in nonasthmatic chronic airflow obstruction. Thorax 1990;45(2): $118-21$.

\section{Weir 1999 \{published data only\}}

Weir DC, Bale GA, Bright P, Sherwood Burge P. A doubleblind placebo-controlled study of the effect of inhaled beclomethasone dipropionate for 2 years in patients with nonasthmatic chronic obstructive pulmonary disease. Clinical and Experimental Allergy Supplement 1999;29(2): $125-8$. 
Welte 2009 \{published data only\}

Welte T, Hartman L, Polanowski T, Hernandez P. Budesonide/formoterol added to tiotropium is well tolerated and reduces risk of severe exacerbations in COPD patients [Abstract]. American Thoracic Society International Conference; May 15-20 San Diego. 2009:A6188 [Poster \# 215].

Welte T, Miravitlles M, Hernandez P, Eriksson G, Peterson S, Polanowski T, et al.Addition of budesonide/formoterol to tiotropium reduces the number of exacerbation days compared with tiotropium alone. Chest 2009;136(4):26S-f. Welte T, Miravitlles M, Hernandez P, Eriksson G, Peterson S, Polanowski T, et al.Budesonide/formoterol added to tiotropium provides rapid improvements in lung function and ability to undertake morning activities. Chest 2009;136 (4):24S-g.

Welte T, Miravitlles M, Hernandez P, Eriksson G, Peterson S, Polanowski T, et al.Efficacy and tolerability of budesonide/formoterol added to tiotropium in patients with chronic obstructive pulmonary disease. American Journal of Respiratory and Critical Care Medicine 2009;180(8):741-50.

Welte T, Miravitlles M, Hernandez P, Hartman L, Polanowski T, Kessler R. Budesonide/formoterol added to tiotropium improves lung function, health status, symptoms \& morning activities in COPD patients [Abstract]. European Respiratory Society 19th Annual Congress; Sep 12-15; Vienna. 2009:[P2005].

Welte T, Miravitlles M, Hernandez P, Peterson S, Polanowski T, Kessler R. Budesonide/formoterol added to tiotropium improves exacerbations and exacerbation-related antibiotic use in patients with COPD [Abstract]. European Respiratory Society 19th Annual Congress; Sep 12-15; Vienna. 2009:[P2012].

Welte T, Miravitlles M, Peterson S, Polanowski T, Kessler R. Budesonide/formoterol added to tiotropium improves the management of COPD patients [Abstract]. European Respiratory Society 19th Annual Congress; Sep 12-15; Vienna. 2009:A6192 [Poster \#216].

Wempe 1992 \{published data only\}

Wempe JB, Postma DS, Breederveld N, Kort E, van der Mark TW, Koeter GH. Effects of corticosteroids on bronchodilator action in chronic obstructive lung disease. Thorax 1992;47(8):616-21.

Wouters 2005 \{published data only\}

Rizzato G. COPD: immediate and sustained deterioration after withdrawal of fluticasone in patients under therapy with salmeterol + fluticasone. [Italian]. Internista 2005;13 (4):225-30

* Wouters EF, Postma DS, Fokkens B, Hop WC, Prins J, Kuipers AF, et al.Withdrawal of fluticasone propionate from combined salmeterol/fluticasone treatment in patients with COPD causes immediate and sustained disease deterioration: a randomised controlled trial. Thorax 2005 . 60(6):480-7.

Yang 2012 \{published data only\}

Yang W, Liu J, Gao B, Cheng K. Effect of fluticasone propionate/salmeterol on exercise endurance in moderate- severe COPD [Abstract]. European Respiratory Society 22nd Annual Congress; Sep 1-5; Vienna. 2012; Vol. 40: 624s [P3459].

Yildiz 2004 \{published data only\}

Yildiz F, Basyigit I, Yildirim E, Boyaci H, Ilgazli A. Does addition of inhaled steroids to combined bronchodilator therapy affect health status in patients with COPD? Respirology 2004;9(3):352-5.

\section{References to ongoing studies}

\section{INSTEAD \{unpublished data only\}}

Comparison of Indacaterol $150 \mu$ g Once Daily (o.d.) With Salmeterol/Fluticasone Propionate $50 \mu \mathrm{g} / 500 \mu \mathrm{g}$ Twice Daily (b.i.d.) (INSTEAD). clinicaltrials.gov (accessed 5 December 2013).

Vestbo 2013 \{published data only\} Vestbo J, Anderson J, Brook RD, Calverley PMA, Celli $\mathrm{BR}$, Crim C, et al.The study to understand mortality and morbidity in COPD (SUMMIT) study protocol. European Respiratory Journal 2013;41(5):1017-22.

\section{Additional references}

\section{Appleton 2006}

Appleton S, Jones T, Poole P, Pilotto L, Adams R, Lasserson Toby J, et al.Ipratropium bromide versus short acting beta- 2 agonists for stable chronic obstructive pulmonary disease. Cochrane Database of Systematic Reviews 2006, Issue 2. [DOI: 10.1002/14651858.CD001387]

\section{ATS/ERS 2004}

Celli BR, MacNee W. Standards for the diagnosis and treatment of patients with COPD: a summary of the ATS/ ERS position paper. European Respiratory Journal 2004;23 (6): $932-46$

\section{Barr 2005}

Barr RG, Bourbeau J, Camargo Carlos A. Tiotropium for stable chronic obstructive pulmonary disease. Cochrane Database of Systematic Reviews 2005, Issue 2. [DOI: 10.1002/14651858.CD002876]

Beeh 2010

Beeh KM, Beier J. The short, the long, and the "ultra-long": why duration of bronchodilator action matters in chronic obstructive pulmonary disease. Advances in Therapy 2010; 27(3):150-9.

Berger 2008

Berger WE, Nadel JA. Efficacy and safety of formoterol for the treatment of chronic obstructive pulmonary disease. Respiratory Medicine 2008;102(2):173-88.

\section{Cazzola 2008}

Cazzola M, MacNee W, Martinez FJ, Rabe KF, Franciosi LG, Barnes PJ, et al.Outcomes for COPD pharmacological trials: from lung function to biomarkers. European Respiratory Journal 2008;31(2):416-69.

Chong 2012

Chong J, Karner C, Poole P. Tiotropium versus long-acting beta-agonists for stable chronic obstructive pulmonary 
disease. Cochrane Database of Systematic Reviews 2012, Issue 9. [Airways code: TIO5-COP; DOI: 10.1002/ 14651858.CD009157]

\section{Chuck 2008}

Chuck A, Jacobs P, Mayers I, Marciniuk D. Costeffectiveness of combination therapy for chronic obstructive pulmonary disease. Canadian Respiratory Journal 2008;15 (8):437-43.

\section{Cipriani 2013}

Cipriani A, Higgins JPT, Geddes JR, Salanti GS. Conceptual and technical challenges in network meta-analysis. Annals of Internal Medicine 2013;159(2):130-7.

\section{Cooper 2009}

Cooper NJ, Sutton AJ, Morris D, Ades AE, Welton NJ. Addressing between-study heterogeneity and inconsistency in mixed treatment comparisons: application to stroke prevention treatments in individuals with non-rheumatic atrial fibrillation. Statistics in Medicine 2009;28:1861-81.

\section{Cope 2012}

Cope S, Zhang J, Williams J, Jansen JP. Efficacy of once-daily indacaterol $75 \mu \mathrm{g}$ relative to alternative bronchodilators in COPD: a study level and a patient level network meta-analysis. BMC Pulmonary Medicine 2012;12: 29.

\section{Cope 2013}

Cope S, Donohue JF, Jansen JP, Kraemer M, CapkunNiggli G, Baldwin M, et al.Comparative efficacy of longacting bronchodilators for COPD-a network meta-analysis. Respiratory Research 2013;14:100.

\section{Decramer 2013}

Decramer ML, Hanania NA, Lotvall, JO, Yawn BP. The safety of long-acting $\beta 2$-agonistsin the treatment of stable chronic obstructive pulmonary disease. International Journal of COPD 2013;8:53-64.

\section{Dias 2010}

Dias S, Welton NJ, Caldwell DM, Ades AE. Checking consistency in mixed treatment comparison meta-analysis. Statistics in Medicine 2010;29(7-8):932-44.

Dias 2013

Dias S, Sutton AJ, Ades AE, Welton NJ. Evidence synthesis for decision making 2: a generalized linear modeling framework for pairwise and network meta-analysis of randomized controlled trials. Medical Decision Making 2013;33:607-17. [DOI: 10.1177/0272989X12458724]

\section{Dias 2013a}

Dias S, Welton NJ, Sutton AJ, Caldwell DM, Lu G, Ades AE. Evidence synthesis for decision making 4: inconsistency in networks of evidence based on randomized controlled trials. Medical Decision Making 2013;33:641-56.

\section{Dong 2013}

Dong Y, Lin H, Shau W, Wu Y, Chang C, Lai M. Comparative safety of inhaled medications inpatients with chronic obstructive pulmonary disease:systematic review and mixed treatment comparison meta-analysis of randomised controlled trials. Thorax 2013;68:48-56.

\section{Earnshaw 2007}

Earnshaw SR, Wilson MR, Dalal AA, Chambers MG, Jhingran P, Stanford R, et al.Cost-effectiveness of fluticasone propionate/salmeterol $(500 / 50$ microg) in the treatment of COPD. Respiratory Medicine 2009;103(1):12-21.

\section{Effing 2007}

Effing T, Monninkhof Evelyn EM, van der Valk Paul PDLPM, Zielhuis Gerhard GA, Walters EH, van der Palen Job J, et al.Self-management education for patients with chronic obstructive pulmonary disease. Cochrane Database of Systematic Reviews 2007, Issue 4. [DOI: 10.1002/ 14651858.CD002990]

\section{Fattore 2005}

Fattore G, Torbica A, Mangone M. Cost-analysis of four treatment strategies in the management of moderate-tosevere COPD: an application of non-parametric bootstrap [Italian]. Pharmacoeconomics Italian Research Articles 2005;7 (2):135-43.

\section{Geake 2012}

Geake JB, Dabscheck EJ, Wood-Baker R. Indacaterol, a once-daily beta2-agonist, versus twice-daily betaagonists or placebo for chronic obstructive pulmonary disease. Cochrane Database of Systematic Reviews 2012, Issue 10. [Airways code: INDC-COP; DOI: 10.1002/ 14651858.CD010139]

\section{GOLD}

From the Global Strategy for the Diagnosis, Management and Prevention of COPD, Global Initiative for Chronic Obstructive Lung Disease (GOLD) 2013. http:// www.goldcopd.com (accessed 3 October 2013).

\section{Higgins 2011}

Higgins JPT, Green S, editors. Cochrane Handbook for Systematic Reviews of Interventions Version 5.1.0 [updated March 2011]. The Cochrane Collaboration, 2011. www.cochrane-handbook.org 2011.

\section{Higgins 2012}

Higgins JPT, Jackson D, Barrett JK, Lu G, Ades AE, White IR. Consistency and inconsistency in network metaanalysis: concepts and models for multi-arm studies. Research Synthesis Methods 2012; Vol. 3, issue 2:98-110.

Hutchinson 2010

Hutchinson A, Brand C, Irving L, Roberts C, Thompson P, Campbell D. Acute care costs of patients admitted for management of chronic obstructive pulmonary disease exacerbations: contribution of disease severity, infection and chronic heart failure. Internal Medicine Journal 2010; 40(5):364-71.

\section{Karner 2011}

Karner C, Cates CJ. Combination inhaled steroid and long-acting beta2-agonist in addition to tiotropium versus tiotropium or combination alone for chronic obstructive pulmonary disease. Cochrane Database of Systematic Reviews 2011, Issue 3. [Airways code: TIO2-COP; DOI: 10.1002/ 14651858.CD008532] 


\section{Karner 2011a}

Karner C, Cates CJ. The effect of adding inhaled corticosteroids to tiotropium and long-acting beta2-agonists for chronic obstructive pulmonary disease. Cochrane Database of Systematic Reviews 2011, Issue 9. [Airways code: TIO4-COP; DOI: 10.1002/14651858.CD009039]

\section{Karner 2012}

Karner C, Cates CJ. Long-acting beta2-agonist in addition to tiotropium versus either tiotropium or long-acting beta2-agonist alone for chronic obstructive pulmonary disease. Cochrane Database of Systematic Reviews 2012, Issue 4. [Airways code: TIO3-COP; DOI: 10.1002/ 14651858.CD008989]

\section{Karner 2012a}

Karner C, Chong J, Poole P. Tiotropium versus placebo for chronic obstructive pulmonary disease. Cochrane Database of Systematic Reviews 2012, Issue 7. [Airways code: TIO6-COP; DOI: 10.1002/14651858.CD009285]

Kew 2013

Kew KM, Mavergames C, Walters JAE. Long-acting beta2-agonists for chronic obstructive pulmonary disease. Cochrane Database of Systematic Reviews 2013, Issue 10. [Airways code: LABA-COP; DOI: 10.1002/ 14651858.CD010177]

\section{Kew 2014}

Kew KM, Seniukovich A. Inhaled steroids and risk of pneumonia for chronic obstructive pulmonary disease. Cochrane Database of Systematic Reviews 2014, Issue 3. [Airways code: PICS-COP; DOI: 10.1002/ 14651858.CD010115.pub2]

\section{Lacasse 2006}

Lacasse Y, Goldstein R, Lasserson Toby J, Martin S. Pulmonary rehabilitation for chronic obstructive pulmonary disease. Cochrane Database of Systematic Reviews 2006, Issue 4. [DOI: 10.1002/14651858.CD003793]

Loke 2011

Loke YK, Cavallazzi R, Singh S. Risk of fractures with inhaled corticosteroids in COPD: systematic review and meta-analysis of randomised controlled trials and observational studies. Thorax 2011;66(8):699-708.

\section{Lu 2006}

Lu G, Ades A. Assessing evidence consistency in mixed treatment comparisons. Journal of the American Statistical Association 2006;101:447-59.

\section{Moen 2010}

Moen MD. Indacaterol: in chronic obstructive pulmonary disease. Drugs 2010;70(17):2269-80.

\section{Nannini 2012}

Nannini LJ, Lasserson TJ, Poole P. Combined corticosteroid and long-acting beta2-agonist in one inhaler versus longacting beta2-agonists for chronic obstructive pulmonary disease. Cochrane Database of Systematic Reviews 2012, Issue 9. [DOI: 10.1002/14651858.CD006829; : CCB3-COP]

\section{Nannini 2013}

Nannini LJ, Poole P, Milan SJ, Holmes R, Normansell R. Combined corticosteroid and long-acting beta2-agonist in one inhaler versus placebo for chronic obstructive pulmonary disease. Cochrane Database of Systematic Reviews 2013, Issue 11. [Airways code: CCB-COP; DOI: 10.1002/ 14651858.CD003794]

\section{Nannini 2013a}

Nannini LJ, Poole P, Milan SJ, Kesterton A. Combined corticosteroid and long-acting beta2-agonist in one inhaler versus inhaled corticosteroids alone for chronic obstructive pulmonary disease. Cochrane Database of Systematic Reviews 2013, Issue 8. [Airways code: CCB2-COP; DOI: 10.1002/ 14651858.CD006826]

NICE 2011

National Institute for Health and Clinical Excellence. Chronic obstructive pulmonary disease, costing report, implementing NICE guidance. http:// guidance.nice.org.uk/CG101/CostingReport/pdf/English (accessed 3 October 2013).

\section{Puhan 2009}

Puhan MA, Bachmann LM, Kleijnen J, ter Riet G, Kessels AG. Inhaled drugs to reduce exacerbations in patients with chronic obstructive pulmonary disease: a network metaanalysis. BMC Medicine 2009;7:2.

Puhan 2011

Puhan MA, Gimeno-Santos E, Scharplatz M, Troosters T, Walters EH, Steurer J. Pulmonary rehabilitation following exacerbations of chronic obstructive pulmonary disease. Cochrane Database of Systematic Reviews 2011, Issue 10. [DOI: 10.1002/14651858.CD005305]

\section{Rodrigo 2008}

Rodrigo GJ, Nannini LJ, Rodríguez-Roisin R. Safety of long-acting $\beta$-agonists in stable COPD: a systematic review. Chest 2008;133(5):1079-87.

\section{Rodrigo 2009}

Rodrigo GJ, Castro-Rodriguez JA, Plaza V. Safety and efficacy of combined long-acting beta-agonists and inhaled corticosteroids vs long-acting beta-agonists monotherapy for stable COPD: a systematic review. Chest 2009;136(4): 1029-38.

Sestini 2009

Sestini P, Renzoni E, Robinson S, Poole P, Ram FSF. Short-acting beta2-agonists for stable chronic obstructive pulmonary disease. Cochrane Database of Systematic Reviews 2009, Issue 4. [DOI: 10.1002/14651858.CD001495]

\section{Singh 2010}

Singh S, Loke YK. An overview of the benefits and drawbacks of inhaled corticosteroids in chronic obstructive pulmonary disease. International Journal of Chronic Obstructive Pulmonary Disease 2010;5:189-95.

\section{Spencer 2011}

Spencer S, Karner C, Cates CJ, Evans DJ. Inhaled corticosteroids versus long-acting beta2-agonists for chronic obstructive pulmonary disease. Cochrane Database of Systematic Reviews 2011, Issue 12. [Airways code: IST-COP; DOI: 10.1002/14651858.CD007033] 
Spiegelhalter 2002

Spiegelhalter DJ, Best NG, Carlin BP, van der Linde A. Bayesian measures of model complexity and fit. Journal of the Royal Statistical Society. Series B (Statistical Methodology) 2002;64(4):583-639.

\section{Tashkin 2008}

Tashkin DP, Celli B, Senn S, Burkhart D, Kesten S, Menjoge $S$, et al.A 4-year trial of tiotropium in chronic obstructive pulmonary disease. New England Journal of Medicine 2008;359(15):1543-54.

van der Meer 2001

van der Meer Regina M, Wagena E, Ostelo Raymond WJG, Jacobs Annelies JE, van Schayck O. Smoking cessation for chronic obstructive pulmonary disease. Cochrane Database of Systematic Reviews 2001, Issue 1. [DOI: 10.1002/ 14651858.CD002999]

\section{Welsh 2013}

Welsh EJ, Cates CJ, Poole P. Combination inhaled steroid and long-acting beta2-agonist versus tiotropium for chronic obstructive pulmonary disease. Cochrane

Database of Systematic Reviews 2013, Issue 5. [Airways code:

TIO1-COP; DOI: 10.1002/14651858.CD007891]

WHO

World Health Organization. Chronic respiratory diseases. http://www.who.int/respiratory/en/ (accessed 3 October 2013).

Wise 2013

Wise RA, Anzueto A, Cotton D, Dahl R, Devins T Disse B, et al.Tiotropium Respimat inhaler and the risk of death in COPD. New England Journal of Medicine Vol. 369, issue 16:1491-501.

Yang 2012a

Yang IA, Clarke MS, Sim EHA, Fong KM. Inhaled corticosteroids for stable chronic obstructive pulmonary disease. Cochrane Database of Systematic Reviews 2012, Issue 7. [Airways code: STER-COP; DOI: 10.1002/ 14651858.CD002991]

* Indicates the major publication for the study 


\title{
CHARACTERISTICS OFSTUDIES
}

\section{Characteristics of included studies [ordered by study ID]}

\author{
Abrahams 2013
}

Methods

Design: multinational, randomised, double-blind, parallel study

Duration: 24 weeks (+ 2 week run-in)

Location: 178 investigational centres in 10 countries

Participants

Population: 2080 participants were randomised to tiotropium (427) and placebo (429) , and three other arms not eligible for this review (1224)

Baseline characteristics

Age (mean years): Tio 63.9, Pbo 64.4

$\%$ Male: Tio 65.8, Pbo 63.9

$\% \mathrm{FEV}_{1}$ predicted (Pre BD): Tio 43.3, Pbo 43.2

Pack-years (mean): Tio 47.3, Pbo 46.4

Inclusion criteria: Male and female smokers or ex-smokers with a smoking history of more than 10 pack-years who were $>40$ years old and able to perform PFTs were included in the study. All patients were diagnosed with COPD and demonstrated postbronchodilator FEV1 $<80 \%$ predicted with FEV1/forced vital capacity (FVC) $<70 \%$.

Exclusion criteria: never smoked or smoked $<10$ pack-years; a history of asthma; been treated for a myocardial infarction within the past year; unstable or life-threatening cardiac arrhythmia (or associated hospitalisations); been hospitalised for heart failure within the past 3 years; regular use of daytime oxygen therapy and the inability to abstain from the use of oxygen therapy during test days; thoracotomy with pulmonary resection and/ or the presence of a significant disease other than COPD that could preclude participation in the study or interfere with the study results

1. Tiotropium 5 qd (LAMA)
2. Placebo (PBO)
Inhaler device: Respimat Soft Mist
Allowed co-medications: The use of antibiotics was not restricted. The following med-
ications were allowed as long as they had been administered in stable doses over 6 weeks
prior to the study: oral corticosteroids (10 mg daily); inhaled LABAs, oral ICS, theo-
phylline preparations and mucolytic agents not containing bronchodilators. Short-acting
anticholinergic drugs were allowed during the 2-week baseline period and the 3-week
follow-up period




\section{Abrahams 2013 (Continued)}

\begin{tabular}{|c|c|c|}
\hline $\begin{array}{l}\text { Random sequence generation (selection } \\
\text { bias) }\end{array}$ & Low risk & $\begin{array}{l}\text { Randomised, no specific details but indus- } \\
\text { try-funded }\end{array}$ \\
\hline Allocation concealment (selection bias) & Unclear risk & No details \\
\hline $\begin{array}{l}\text { Blinding of participants and personnel } \\
\text { (performance bias) } \\
\text { All outcomes }\end{array}$ & Low risk & Double-blind \\
\hline $\begin{array}{l}\text { Blinding of outcome assessment (detection } \\
\text { bias) } \\
\text { All outcomes }\end{array}$ & Unclear risk & No mention of outcome assessors \\
\hline $\begin{array}{l}\text { Incomplete outcome data (attrition bias) } \\
\text { All outcomes }\end{array}$ & Low risk & $\begin{array}{l}\text { Dropout relatively low in both included } \\
\text { groups (tio } 10 \% \text {, placebo } 15 \% \text { ). } 98.6 \% \text { of } \\
\text { those randomised were included in the ITT } \\
\text { population }\end{array}$ \\
\hline Selective reporting (reporting bias) & Unclear risk & $\begin{array}{l}\text { Located trial registration - outcomes well } \\
\text { reported }\end{array}$ \\
\hline
\end{tabular}

\section{ACCLAIM 2009}

Methods

Participants
Design: double-blind, randomised, placebo-controlled, parallel-group study

Duration: 52 weeks (+ 2 week run-in)

Location: 139 centres in 16 European countries

Population: 843 participants were randomised to aclidinium (627) and placebo (216) Baseline characteristics

Age (mean years): Acl 62.6, Pbo 61.9

$\%$ Male: Acl 77.8, Pbo 81.0

$\% \mathrm{FEV}_{1}$ predicted (post BD): Acl 54.2, Pbo 52.9

Pack-years (mean): Acl 40.4, Pbo 38.4

Inclusion criteria: Male and non-pregnant, non-lactating female patients aged $\geq 40$ years were included if they had a diagnosis of COPD according to GOLD criteria, with a post-bronchodilator FEV1/FVC ratio of $\leq 70 \%$ and FEV $1<80 \%$ of the predicted value. The pre-dose FEV1 at randomisation had to be within $80-120 \%$ of the prebronchodilator FEV1 at screening. All patients were current or previous cigarette smokers with a smoking history of $\geq 10$ pack-years. A previous history of exacerbations was not required.

Exclusion criteria: history or current diagnosis of asthma, allergic rhinitis or atopy; blood eosinophil count $>600 \mathrm{cell} / \mathrm{mm} 3$; respiratory tract infection or COPD exacerbation within 6 weeks prior to screening or during the run-in period; hospitalisation for an acute COPD exacerbation within 3 months prior to screening; use of long-term oxygen therapy; clinically significant respiratory diseases other than COPD; unstable cardiac conditions 
ACCLAIM 2009 (Continued)

\begin{tabular}{|c|c|c|}
\hline Interventions & \multicolumn{2}{|c|}{$\begin{array}{l}\text { 1. Aclidinium } 200 \text { qd (LAMA) } \\
\text { 2. Placebo (PBO) } \\
\text { Inhaler device: Genuair } \\
\text { Allowed co-medications: Inhaled salbutamol was permitted on an as-needed basis, but } \\
\text { had to be discontinued } 6 \text { hours prior to and during a study visit. Inhaled corticosteroids } \\
\text { or oral sustained-release theophyllines; oral or parenteral corticosteroids at maximal doses } \\
\text { equivalent to } 10 \mathrm{mg} / \text { day of prednisone or } 20 \mathrm{mg} \text { every other day; oxygen therapy ( }<15 \\
\text { hours per day) were allowed, provided their administration had been stable for at least } 4 \\
\text { weeks prior to screening: }\end{array}$} \\
\hline Outcomes & \multicolumn{2}{|c|}{$\begin{array}{l}\text { Trough FEV1, St George's Respiratory Questionnaire (SGRQ), and time to first moderate } \\
\text { or severe COPD exacerbation }\end{array}$} \\
\hline Notes & \multicolumn{2}{|c|}{$\begin{array}{l}\text { Funding: Almirall, S. A., Barcelona, Spain, and Forest Laboratories, Inc, NY, USA } \\
\text { Identifier(s): NCT00363896 }\end{array}$} \\
\hline \multicolumn{3}{|l|}{ Risk of bias } \\
\hline Bias & Authors' judgement & Support for judgement \\
\hline $\begin{array}{l}\text { Random sequence generation (selection } \\
\text { bias) }\end{array}$ & Low risk & $\begin{array}{l}\text { Eligible patients were randomised in a } 3 \text { : } \\
1 \text { ratio to receive aclidinium } 200 \mathrm{mcg} \text { or } \\
\text { matching placebo. Industry funded }\end{array}$ \\
\hline Allocation concealment (selection bias) & Unclear risk & Not described \\
\hline $\begin{array}{l}\text { Blinding of participants and personnel } \\
\text { (performance bias) } \\
\text { All outcomes }\end{array}$ & Low risk & Double-blind, matching placebo \\
\hline $\begin{array}{l}\text { Blinding of outcome assessment (detection } \\
\text { bias) } \\
\text { All outcomes }\end{array}$ & Low risk & $\begin{array}{l}\text { A centralised quality-assurance review of all } \\
\text { spirometry data was conducted through- } \\
\text { out the study. The spirometry data were } \\
\text { electronically transmitted to a data-man- } \\
\text { agement centre where an independent, } \\
\text { blinded, spirometric expert reviewed the } \\
\text { acceptability and repeatability of the data } \\
\text { according to ATS/ERS acceptability crite- } \\
\text { ria. SGRQ self-rated }\end{array}$ \\
\hline $\begin{array}{l}\text { Incomplete outcome data (attrition bias) } \\
\text { All outcomes }\end{array}$ & Low risk & $\begin{array}{l}\text { Dropout higher in placebo group ( } 21.8 \% \\
\text { versus } 14.2 \text { in aclidinium group). ITT in- } \\
\text { cluded } 98 \% \text { of those randomised }\end{array}$ \\
\hline Selective reporting (reporting bias) & Low risk & $\begin{array}{l}\text { Trial registration located. Outcomes well } \\
\text { reported. }\end{array}$ \\
\hline
\end{tabular}

Long-acting inhaled therapy (beta-agonists, anticholinergics and steroids) for COPD: a network meta-analysis (Review) 
Methods

Participants
Design: double-blind, randomised, placebo-controlled, parallel-group study

Duration: 52 weeks (+ 2 week run-in)

Location: 119 sites in 7 countries (primarily in North America)

Population: 804 participants were randomised to aclidinium (600) and placebo (204) Baseline characteristics

Age (mean years): Acl 65.1, Pbo 65.2

\% Male: Acl 63.8, Pbo 60.8

$\% \mathrm{FEV}_{1}$ predicted (post BD): Acl 50.6, Pbo 49.4

Pack-years (mean): Acl 57.8, Pbo 58.2

Inclusion criteria: Male and non-pregnant, non-lactating female patients aged $\geq 40$ years were included if they had a diagnosis of COPD according to GOLD criteria, with a post-bronchodilator FEV1/FVC ratio of $\leq 70 \%$ and FEV1 $<80 \%$ of the predicted value. The pre-dose FEV1 at randomisation had to be within $80-120 \%$ of the prebronchodilator FEV1 at screening. All patients were current or previous cigarette smokers with a smoking history of $\geq 10$ pack-years. A previous history of exacerbations was not required.

Exclusion criteria: history or current diagnosis of asthma, allergic rhinitis or atopy; blood eosinophil count $>600 \mathrm{cell} / \mathrm{mm} 3$; respiratory tract infection or COPD exacerbation within 6 weeks prior to screening or during the run-in period; hospitalisation for an acute COPD exacerbation within 3 months prior to screening; use of long-term oxygen therapy; clinically significant respiratory diseases other than COPD; unstable cardiac conditions

Interventions

1. Aclidinium 200 qd (LAMA)

2. Placebo (PBO)

Inhaler device: Genuair

Allowed co-medications: Inhaled salbutamol was permitted on an as-needed basis, but had to be discontinued 6 hours prior to and during a study visit. Inhaled corticosteroids or oral sustained-release theophyllines; oral or parenteral corticosteroids at maximal doses equivalent to $10 \mathrm{mg} /$ day of prednisone or $20 \mathrm{mg}$ every other day; oxygen therapy $(<15$ hours per day) were allowed, provided their administration had been stable for at least 4 weeks prior to screening:

Outcomes

Trough FEV1, St George's Respiratory Questionnaire (SGRQ), and time to first moderate or severe COPD exacerbation

Notes

Funding: Almirall, S. A., Barcelona, Spain, and Forest Laboratories, Inc, NY, USA

Identifier(s): NCT00358436

Risk of bias

Bias Authors' judgement

Support for judgement

Random sequence generation (selection Low risk bias)

Eligible patients were randomised in a 3: 1 ratio to receive aclidinium $200 \mathrm{mcg}$ or matching placebo. Industry funded

Allocation concealment (selection bias)
Not described 


\section{ACCLAIM II 2009 (Continued)}

Blinding of participants and personnel Low risk (performance bias)

All outcomes

Blinding of outcome assessment (detection Low risk bias)

All outcomes
Double-blind, matching placebo

A centralised quality-assurance review of all spirometry data was conducted throughout the study. The spirometry data were electronically transmitted to a data-management centre where an independent, blinded, spirometric expert reviewed the acceptability and repeatability of the data according to ATS/ERS acceptability criteria. SGRQ self-rated

Incomplete outcome data (attrition bias) High risk All outcomes

Low risk
Dropout much higher in placebo group and high in both (42.2\% versus 25.7 in aclidinium group). ITT included $99 \%$ of those randomised but high dropout is likely to have introduced bias

Trial registration located. Outcomes well reported.

Anzueto 2009

Methods

Participants
Design: Randomised, double-blind, parallel-group, multicenter study

Duration: 52 weeks (+ 4 week run-in)

Location: 98 centres in the USA and Canada

Population: 797 participants were randomised to salmeterol alone (403) and salmeterol/ fluticasone combination therapy (394)

Baseline characteristics

Age (mean years): sal 65.3, sal/flut 65.4

\% Male: sal 57, sal/flut 51

$\% \mathrm{FEV}_{1}$ predicted (pre BD): sal 33.9, sal/flut 34.1

Pack-years (mean): sal 56.5, sal/flut 57.8

Inclusion criteria: $>40$ years of age with a diagnosis of COPD, a cigarette smoking history $\geq 10$ pack-years, a pre-albuterol FEV1/FVC $\leq 0.70$, a FEV $1 \leq 50 \%$ of predicted normal and a documented history of at least 1 COPD exacerbation the year prior to the study that required treatment with antibiotics, oral corticosteroids, and/or hospitalisation.

Exclusion criteria: current diagnosis of asthma, a respiratory disorder other than COPD, historical or current evidence of a clinically significant uncontrolled disease, or had a COPD exacerbation that was not resolved at screening

Interventions

1. Salmeterol 50 bid (LABA)

2. Salmeterol/fluticasone 50/250 bid (LABA/ICS)

Inhaler device: Diskus 


Allowed co-medications: As-needed albuterol was provided for use throughout the
study. As needed ipratropium was not provided; however, it could be used during the
study. The use of concurrent inhaled long-acting bronchodilators (beta2-agonist and an-
ticholinergic), ipratropium/albuterol combination products, oral beta-agonists, inhaled
corticosteroids (ICS), leukotriene modifiers, inhaled nedocromil and cromolyn, theo-
phylline preparations, ritonavir and other investigational medications were not allowed
during the treatment period. Oral corticosteroids and antibiotics were allowed for the
acute treatment of a COPD exacerbation

Outcomes

Notes
Annual rate of moderate/severe exacerbations, time to first moderate/severe exacerbation, the annual rate of exacerbations requiring oral corticosteroids, and pre-dose FEV1. Diary records and health status measured on the St George's Respiratory Questionnaire (SGRQ)

Funding: GlaxoSmithKline

Identifier(s): NCT00115492, GSK NCT00115492

\section{Risk of bias}

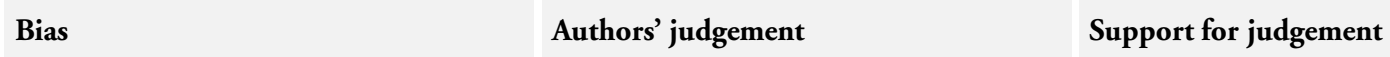

Random sequence generation (selection Low risk bias)

Treatments were assigned in blocks using a centre-based randomisation schedule. Since bronchodilator response to FSC $250 / 50$ is generally larger in subjects with COPD who demonstrate FEV1 reversibility to albuterol, assignment to blinded study medication was stratified based on subjects' FEV1 response to albuterol at screening to provide a similar distribution of albuterol-responsive and non-responsive subjects in each treatment group

\begin{tabular}{l|ll} 
Allocation concealment (selection bias) & Unclear risk & Not described \\
\hline $\begin{array}{l}\text { Blinding of participants and personnel } \\
\text { (performance bias) } \\
\text { All outcomes }\end{array}$ & Low risk & $\begin{array}{l}\text { Described as double-blind [assumed par- } \\
\text { ticipants and personnel/investigators] }\end{array}$ \\
\hline $\begin{array}{l}\text { Blinding of outcome assessment (detection } \\
\text { bias) } \\
\text { All outcomes }\end{array}$ & Unclear risk & Not described \\
\hline $\begin{array}{l}\text { Incomplete outcome data (attrition bias) } \\
\text { All outcomes }\end{array}$ & Unclear risk & $\begin{array}{l}\text { The withdrawal rates were very high com- } \\
\text { pared to the number of events for the dif- } \\
\text { ferent outcomes }\end{array}$ \\
\hline $\begin{array}{l}\text { Selective reporting (reporting bias) } \\
\text { L }\end{array}$ & Low risk & $\begin{array}{l}\text { All outcomes stated in the protocol were } \\
\text { reported and could be included }\end{array}$
\end{tabular}


Methods

Participants
Design: double-blind, randomised, placebo-controlled, parallel-group study

Duration: 24 weeks (+ 2 week run-in)

Location: 9 European countries and South Africa

\begin{abstract}
Partipants
272), and placebo (276)

Baseline characteristics

Age (mean years): acl200 62.3, acl400 62.9, pbo 62.0

$\%$ Male: acl200 65.3, acl400 67.7, pbo 69.2

$\% \mathrm{FEV}_{1}$ predicted: acl200 53.0, acl400 52.0, pbo 52.4

Pack-years (mean): acl200 40.0, acl400 41.7, pbo 38.9

Inclusion criteria: Male and female patients aged $>40 \mathrm{yrs}$ were included if they were current or former cigarette smokers with a smoking history of $>10$ pack-yrs

and had a diagnosis of COPD according to Global Initiative for Chronic Obstructive Lung Disease criteria (post-bronchodilator FEV1/forced vital capacity (FVC) ratio of $<70 \%$ and FEV1 $<80 \%$ of the predicted value). Patients had to demonstrate good technique during lung function assessments according to American Thoracic Society/ European Respiratory Society criteria.

Exclusion criteria: history or current diagnosis of asthma; respiratory tract infection or COPD exacerbation within 6 weeks ( 3 months if hospitalisation was required) before screening or during the run-in period; clinically relevant respiratory conditions other than COPD; unstable cardiac conditions, including myocardial

infarction, within the previous 6 months; and contraindications to the use of anticholinergic drugs

Interventions

1. Aclidinium bromide 200 qd (LAMA)

2. Aclidinium bromide $400 \mathrm{qd}$ (LAMA)

3. Placebo (PBO)

Inhaler device: multiple-dose dry powder inhaler (Genuair)

Allowed co-medications: Inhaled salbutamol was permitted as needed, but was discontinued $6 \mathrm{~h}$ before and during study visits. The following concomitant

medications were allowed if their administration had been stable for $>4$ weeks before screening: inhaled corticosteroids or oral sustained-release theophyllines; systemic corticosteroids at doses equivalent to $10 \mathrm{mg}$ per day of prednisone or $20 \mathrm{mg}$ every other day; and oxygen therapy (,15 h per day)
\end{abstract}

Population: 828 participants were randomised to two doses of aclidinium (280 and

Outcomes

Standard spirometric measurements (FEV1, FVC and inspiratory capacity) pre- and post- dose, health status using the St George's Respiratory Questionnaire (SGRQ), Baseline Dyspnoea Index (BDI) and Transitional Dyspnoea Index (TDI), diary card data, exacerbations, and safety

Notes

Funding: Almirall and Forest Laboratories

Identifier(s): NCT01001494

\section{Risk of bias}

Bias

Authors' judgement

Support for judgement 


\section{ATTAIN 2011 (Continued)}

Random sequence generation (selection Low risk bias)
Allocation described as randomised in the reports and on clinicaltrials.gov. Methods not described, but industry funded

\begin{tabular}{l|l|l}
\hline Allocation concealment (selection bias) & Unclear risk & Not described \\
\hline $\begin{array}{l}\text { Blinding of participants and personnel } \\
\text { (performance bias) }\end{array}$ & Low risk & $\begin{array}{l}\text { Described as double blind for subjects and } \\
\text { ill outcomes }\end{array}$
\end{tabular}

Blinding of outcome assessment (detection Unclear risk bias)

All outcomes

Incomplete outcome data (attrition bias) Low risk All outcomes
Not mentioned

Efficacy analyses were performed on the intent-to-treat (ITT) population, defined as all patients who took one or more dose of study medication and had a baseline and one or more post-baseline FEV1 assessment. Missing data were imputed using last observation carried forward (LOCF). $11 \%$ were not included in the ITT population, and dropout was higher in the placebo group but still relatively low (14.9\%)

Outcomes stated on pre-registered protocol were well reported

Bateman 2010a

Methods

Design: Randomised, double-blind, parallel-group study

Duration: 48 weeks (unclear run-in)

Location: 336 outpatient centres in 31 countries

Participants

Population: 3991 participants were randomised to tiotropium (1989) and placebo (2002)

\section{Baseline characteristics}

Age (mean years): tio 64.8, pbo 64.8

$\%$ Male: tio 78.1, pbo 77.0

$\% \mathrm{FEV}_{1}$ predicted: tio 39.9, pbo 39.8

Pack-years (mean): tio 46, pbo 45

Inclusion criteria: COPD patients of either sex were eligible for study entry if they were aged 40 years, had pre-bronchodilator FEV1 of $60 \%$ of predicted normal and a ratio of FEV1 to forced vital capacity (FVC) of $70 \%$, and were current or ex-smokers (smoking history of 10 pack-years).

Exclusion criteria: significant disease other than COPD that, in the investigator's judgment, could affect the patient's ability to complete the trial, or if they had clinically significant abnormal results of haematology, urinalysis, or blood chemistry tests, a history 
Bateman 2010a (Continued)

of asthma or allergic rhinitis, or a blood eosinophil count of $600 / \mathrm{mm} 3$. Other exclusion criteria included previous lung resection surgery, participation in a pulmonary rehabilitation programme in the previous 6 weeks, and regular daytime oxygen use $(>1 \mathrm{~h} /$ day $)$

\begin{tabular}{|c|c|c|}
\hline Interventions & \multicolumn{2}{|c|}{$\begin{array}{l}\text { 1. Tiotropium } 5 \text { qd (LAMA) } \\
\text { 2. Placebo (PBO) } \\
\text { Inhaler device: Respimat } \\
\text { Allowed co-medications: Salbutamol pMDI was provided to all patients for use as rescue } \\
\text { medication at any time during the study. All respiratory medications were permitted } \\
\text { during the trial other than inhaled anticholinergics }\end{array}$} \\
\hline Outcomes & \multicolumn{2}{|c|}{$\begin{array}{l}\text { Trough FEV1 response and time to first COPD exacerbation were the co-primary } \\
\text { endpoints. Secondary included FVC, number of exacerbations per patient, and the St } \\
\text { George's Respiratory Questionnaire (SGRQ) }\end{array}$} \\
\hline Notes & \multicolumn{2}{|c|}{$\begin{array}{l}\text { Funding: Boehringer-Ingelheim } \\
\text { Identifier(s): NCT00387088, BI } 205.372\end{array}$} \\
\hline \multicolumn{3}{|l|}{ Risk of bias } \\
\hline Bias & Authors' judgement & Support for judgement \\
\hline $\begin{array}{l}\text { Random sequence generation (selection } \\
\text { bias) }\end{array}$ & Low risk & $\begin{array}{l}\text { Treatment allocation was determined by } \\
\text { a computer-generated randomisation code } \\
\text { provided by Boehringer Ingelheim. Ran- } \\
\text { domisation was stratified by study cen- } \\
\text { tre and within centres, and performed in } \\
\text { blocks to ensure balanced distribution of } \\
\text { the treatment groups at any time }\end{array}$ \\
\hline Allocation concealment (selection bias) & Low risk & $\begin{array}{l}\text { Individuals directly involved in the conduct } \\
\text { and analysis of the trial had no access to the } \\
\text { allocation sequence until after the trial was } \\
\text { completed }\end{array}$ \\
\hline
\end{tabular}

Blinding of participants and personnel Low risk (performance bias)

Identity of treatments was blinded to investigators, assessors and patients

All outcomes

Blinding of outcome assessment (detection Low risk bias)

All outcomes

Incomplete outcome data (attrition bias) Low risk All outcomes
Identity of treatments was blinded to investigators, assessors and patients

Dropout was relatively low and even between groups (16 and 19\%). The co-primary endpoints were analysed in all patients who were randomly assigned and treated and who provided a trough FEV1 measurement at baseline and at least one 
Bateman 2010a (Continued)

subsequent visit

Selective reporting (reporting bias) Low risk

Trial registration was located. Outcomes were well reported.

Bateman 2010b

Methods

Design: two identical multicenter, randomized, double-blind, parallel-group studies

Duration: 48 weeks (+ 2 week run-in)

Location: 73 centres in 14 countries (NCT00168844), and 78 in 15 countries

(NCT00168831)

Participants

Population: 1990 participants were randomised to two doses of tiotropium (670 and 665), and placebo (653)

Baseline characteristics

Age (mean years): tio5 64.7, tio10 65.1, pbo 65.2

$\%$ Male: tio5 73.3, tio10 74.7, pbo 74.6

$\% \mathrm{FEV}_{1}$ predicted: tio5 38.0, tio10 37.7, pbo 37.5

Pack-years (mean): not reported

Inclusion criteria: Males and females aged > 40 years with a diagnosis of COPD and stable, moderate-to-severe airway obstruction as defined by the American Thoracic Society (pre-bronchodilator FEV1 $<60 \%$ predicted and FEV1 $<70 \%$ of FVC), and with a smoking history of $>10$ pack years were included.

Exclusion criteria: Patients with a confounding disease, including other significant respiratory conditions, were excluded, as were those who had a disease that might put them at risk because of study participation. Other exclusion criteria included known hypersensitivity to anticholinergics or any component of the Respimat ${ }^{\circledR}$ inhalation solution; drugs contraindicated with anticholinergics; prior use of Spiriva ${ }^{\circledR}$ HandiHaler ${ }^{\circledR}$; regular use of daytime oxygen therapy, oral $\beta$-adrenergics, or long-acting $\beta$-adrenergics; or significant alcohol or drug abuse

Interventions

1. Tiotropium 5 qd (LAMA)

2. Tiotropium 10 qd (LAMA)

3. Placebo (PBO)

Inhaler device: Respimat ${ }^{\circledR}$ Soft Mist Inhaler

Allowed co-medications: Oral (up to $10 \mathrm{mg}$ daily of prednisone) and inhaled corticosteroids, theophylline preparations, mucolytic agents and antileukotrienes were allowed if stabilized for at least 6 weeks prior to and during the study. Patients on long-acting $\beta$-adrenergics and inhaled corticosteroids were switched to a monoproduct inhaled corticosteroid prior to run-in. Salbutamol MDI was used as rescue medication

Outcomes Trough FEV1, St George's Respiratory Questionnaire (SGRQ) < Mahler Transition Dyspnoea Index (TDI) focal score, exacerbations per patient year, FVC, PEF, diary card data and safety

Notes

Funding: Boehringer Ingelheim

Identifier(s): BI 205.254 and 205.255, corresponding to NCT00168844 and NCT00168831 respectively

Long-acting inhaled therapy (beta-agonists, anticholinergics and steroids) for COPD: a network meta-analysis (Review)

Copyright @ 2014 The Cochrane Collaboration. Published by John Wiley \& Sons, Ltd. 
Bateman 2010b (Continued)

\section{Risk of bias}

\begin{tabular}{|c|c|c|}
\hline Bias & Authors' judgement & Support for judgement \\
\hline $\begin{array}{l}\text { Random sequence generation (selection } \\
\text { bias) }\end{array}$ & Low risk & $\begin{array}{l}\text { Allocation described as randomised in the } \\
\text { reports and on clinicaltrials.gov. Methods } \\
\text { not described, but industry funded }\end{array}$ \\
\hline Allocation concealment (selection bias) & Unclear risk & Not described \\
\hline $\begin{array}{l}\text { Blinding of participants and personnel } \\
\text { (performance bias) } \\
\text { All outcomes }\end{array}$ & Low risk & $\begin{array}{l}\text { Double-blind. Not defined, assumed at } \\
\text { least participants and personnel }\end{array}$ \\
\hline $\begin{array}{l}\text { Blinding of outcome assessment (detection } \\
\text { bias) } \\
\text { All outcomes }\end{array}$ & Unclear risk & Not described \\
\hline $\begin{array}{l}\text { Incomplete outcome data (attrition bias) } \\
\text { All outcomes }\end{array}$ & High risk & $\begin{array}{l}\text { Only those patients with baseline and on- } \\
\text { treatment data for at least one primary end- } \\
\text { point were included in the efficacy analy- } \\
\text { ses. Randomized patients who received at } \\
\text { least } 1 \text { dose of study medication were in- } \\
\text { cluded in the safety analysis. The primary } \\
\text { article stated that the data reported were the } \\
\text { per protocol analysis. Dropout was much } \\
\text { higher in the placebo group }(31.4 \%) \text { than } \\
\text { the two tiotropium groups }(17.2 \% \text { and } 20 \text {. } \\
4 \%)\end{array}$ \\
\hline Selective reporting (reporting bias) & Low risk & $\begin{array}{l}\text { Studies were prospectively registered and } \\
\text { results were well reported }\end{array}$ \\
\hline
\end{tabular}

\section{Bateman 2013 [SHINE]}

Methods
Design: multi-centre, randomised, double-blind, parallel-group, placebo- and activecontrolled trial

Duration: 26 weeks (+ 2 week run-in)

Location: academic and clinical research centres in Europe, North America, South America, Asia (Philippines, Japan, India), Australia, China, Taiwan and South Africa

Participants

Population: 2144 participants were randomised to indacaterol (477), glycopyrronium (475), open-label tiotropium (483), placebo (234), and one other arm that was not included in this review (QVA149 combination, 475)

Baseline characteristics

Age (mean years): ind 63.6, gly 64.3, tio 63.5, pbo 64,4

$\%$ Male: ind 74.4, gly 77.2, tio 75.0, pbo 72.8

$\% \mathrm{FEV}_{1}$ predicted: ind 54.9, gly 55.1, tio 55.1, pbo 55.2 
Bateman 2013 [SHINE] (Continued)

Pack-years (mean): not reported

Inclusion criteria: Participants were aged $\geq 40$ years, had moderate-to-severe stable COPD (Stage II or III according to GOLD 2008 criteria), and a smoking history of $\geq 10$ pack-years. At screening, they were required to have a post-bronchodilator forced expiratory volume in 1 second (FEV1) $\geq 30 \%$ and $<80 \%$ of predicted normal and postbronchodilator FEV1/forced vital capacity (FVC) $<0.70$.

Exclusion criteria: respiratory tract infection within 4 weeks prior to Visit 1; concomitant pulmonary disease; history of asthma; lung cancer or a history of lung cancer; history of certain cardiovascular co-morbid conditions; known history and diagnosis of alpha1 antitrypsin deficiency; in the active phase of a supervised pulmonary rehabilitation program; contraindicated for inhaled anticholinergic agents and $\beta 2$ agonists; other protocol-defined inclusion/exclusion criteria may apply

Interventions
$\begin{aligned} & \text { 1. Indacaterol } 150 \text { qd (LABA) } \\ & \text { 2. Glycopyrronium } 50 \text { qd (LAMA) } \\ & \text { 3. Tiotropium } 18 \text { qd (LAMA) - open label } \\ & \text { 4. Placebo }(\mathrm{PBO}) \\ & \text { Inhaler device: All medications were administered once daily in the morning via the } \\ & \text { Breezhaler® device except for tiotropium, which was administered open-label via the } \\ & \text { Handihaler® device } \\ & \text { Allowed co-medications: Participants remained on a stable dose of inhaled corticos- } \\ & \text { teroid }(\mathrm{ICS}) \text { and salbutamol/albuterol was available for use as rescue medication through- } \\ & \text { out the study }\end{aligned}$

Outcomes

Trough FEV1, dyspnoea, health status measured on the SGRQ, rescue medication use and safety

$\begin{array}{ll}\text { Notes } & \text { Funding: Novartis } \\ & \text { Identifier(s): NCT01202188 }\end{array}$

Risk of bias

\begin{tabular}{|c|c|c|}
\hline Bias & Authors' judgement & Support for judgement \\
\hline $\begin{array}{l}\text { Random sequence generation (selection } \\
\text { bias) }\end{array}$ & Low risk & $\begin{array}{l}\text { No specific details of sequence generation } \\
\text { but done electronically and presumed valid }\end{array}$ \\
\hline Allocation concealment (selection bias) & Low risk & $\begin{array}{l}\text { Eligible patients were assigned a randomi- } \\
\text { sation number via Interactive Response } \\
\text { Technology (IRT), linking the patient to } \\
\text { a treatment arm and specific unique med- } \\
\text { ication number for the study drug. The } \\
\text { randomisation number was not communi- } \\
\text { cated to the investigator contacting the IRT }\end{array}$ \\
\hline $\begin{array}{l}\text { Blinding of participants and personnel } \\
\text { (performance bias) } \\
\text { All outcomes }\end{array}$ & High risk & $\begin{array}{l}\text { Blinding procedures were sound, but } \\
\text { tiotropium was delivered open label which } \\
\text { introduced bias for these comparisons } \\
\text { Blinding of patients, investigator staff, per- }\end{array}$ \\
\hline
\end{tabular}

Long-acting inhaled therapy (beta-agonists, anticholinergics and steroids) for COPD: a network meta-analysis (Review) 


\begin{tabular}{|c|c|c|}
\hline & & $\begin{array}{l}\text { sonnel performing assessments and data } \\
\text { analysts was maintained by ensuring ran- } \\
\text { domisation data remained strictly confi- } \\
\text { dential and inaccessible to anyone involved } \\
\text { in the study until the time of unblind- } \\
\text { ing. In addition, the identity of the treat- } \\
\text { ments was concealed by the use of study } \\
\text { drugs that were all identical in packaging, } \\
\text { labelling, and schedule of administration, } \\
\text { appearance, taste and odour. Unblinding } \\
\text { occurred in the case of emergencies and at } \\
\text { the conclusion of the study }\end{array}$ \\
\hline $\begin{array}{l}\text { Blinding of outcome assessment (detection } \\
\text { bias) } \\
\text { All outcomes }\end{array}$ & High risk & Same as for participants and personnel. \\
\hline $\begin{array}{l}\text { Incomplete outcome data (attrition bias) } \\
\text { All outcomes }\end{array}$ & Low risk & $\begin{array}{l}\text { Dropout was between } 9 \% \text { and } 20 \% \text { across } \\
\text { the five groups, and over } 99 \% \text { were in- } \\
\text { cluded in the analysis }\end{array}$ \\
\hline Selective reporting (reporting bias) & Low risk & $\begin{array}{l}\text { Prospectively registered and well reported } \\
\text { with additional online supplemental mate- } \\
\text { rial available }\end{array}$ \\
\hline
\end{tabular}

Bourbeau 1998

Methods

Participants
Design: double blind, randomised, parallel group trial

Duration: 6 months (originally intended to be 12 months)

Location: single centre in Canada

Population: 79 people were randomised to budesonide (39) and placebo (40) Baseline characteristics

Age (mean years): bud 66, pbo 66

Male \%: bud 84.6 , pbo 72.5

$\% \mathrm{FEV}_{1}$ predicted: bud 36, pbo 37

Pack-years (mean): bud 52, pbo 50

Inclusion criteria: Age 40 years old or older; smokers or ex-smokers; absence of an exacerbation in respiratory symptoms during the two months prior to the study; prebronchodilator FEV1 less than $65 \%$ of predicted 12 and FEV1/forced vital capacity (FVC) less than 0.65; post-bronchodilator FEV1 less than $80 \%$; regular treatment with at least one bronchodilator

Exclusion criteria: history of allergic asthma during childhood or as an adult; inhaled corticosteroids in the previous month or oral corticosteroids in the previous two months; any other active lung disease; diabetes, active peptic ulcer disease, uncontrolled high blood pressure, or congestive heart failure; disease other than COPD that might interfere with quality of life 
Bourbeau 1998 (Continued)

\begin{tabular}{|c|c|c|}
\hline Interventions & \multicolumn{2}{|c|}{$\begin{array}{l}\text { 1. Budesonide } 800 \text { bid (ICS) } \\
\text { 2. Placebo (PBO) } \\
\text { Inhaler device: Turbohaler } \\
\text { Allowed co-medications: All medication for the well-being of the patients was permitted } \\
\text { except inhaled corticosteroids other than budesonide. In case of treatment failure, rescue } \\
\text { medication with beta-2 agonists or systemic steroids was available }\end{array}$} \\
\hline Outcomes & \multicolumn{2}{|c|}{$\begin{array}{l}\text { Pre- and post-bronchodilator FEV1 and FVC, pre-bronchodilator six minute walking } \\
\text { test, dyspnoea with exercise, quality of life questionnaires, morning and evening PEFR, } \\
\text { symptom scores and adverse events }\end{array}$} \\
\hline Notes & \multicolumn{2}{|c|}{$\begin{array}{l}\text { Funding: Astra Pharma Inc } \\
\text { Identifier(s): unknown }\end{array}$} \\
\hline \multicolumn{3}{|l|}{ Risk of bias } \\
\hline Bias & Authors' judgement & Support for judgement \\
\hline $\begin{array}{l}\text { Random sequence generation (selection } \\
\text { bias) }\end{array}$ & Low risk & $\begin{array}{l}\text { Central computer-generated list of random } \\
\text { numbers }\end{array}$ \\
\hline Allocation concealment (selection bias) & Low risk & $\begin{array}{l}\text { Identification of individual treatment as- } \\
\text { signments was only possible in case of } \\
\text { emergency by breaking the sealed envelope } \\
\text { kept by the investigator. The envelopes had } \\
\text { to be kept with the case record forms and be } \\
\text { returned unbroken at the end of the study }\end{array}$ \\
\hline $\begin{array}{l}\text { Blinding of participants and personnel } \\
\text { (performance bias) } \\
\text { All outcomes }\end{array}$ & Low risk & $\begin{array}{l}\text { To assure that outcomes were measured } \\
\text { similarly in the treatment groups, the pa- } \\
\text { tients and the investigators were blinded to } \\
\text { the study treatment }\end{array}$ \\
\hline $\begin{array}{l}\text { Blinding of outcome assessment (detection } \\
\text { bias) } \\
\text { All outcomes }\end{array}$ & Low risk & $\begin{array}{l}\text { To assure that outcomes were measured } \\
\text { similarly in the treatment groups, the pa- } \\
\text { tients and the investigators were blinded to } \\
\text { the study treatment }\end{array}$ \\
\hline $\begin{array}{l}\text { Incomplete outcome data (attrition bias) } \\
\text { All outcomes }\end{array}$ & High risk & $\begin{array}{l}\text { Uneven dropout. Much higher in placebo } \\
\text { group ( } 25 \% \text { versus } 7.7 \% \text { in the ICS group) }\end{array}$ \\
\hline Selective reporting (reporting bias) & High risk & $\begin{array}{l}\text { Key outcomes missing (mortality, adverse } \\
\text { events). No reply from author }\end{array}$ \\
\hline
\end{tabular}

Long-acting inhaled therapy (beta-agonists, anticholinergics and steroids) for COPD: a network meta-analysis (Review) 
Design: pooled results from two randomised, double-blind, double-dummy, parallelgroup studies

Duration: 6 months (+ 2 weeks run-in period)

Location: The studies were performed in 18 countries The only difference in the two studies was the duration of serial spirometry in the clinic ( 12 hours in one study, 3 hours in the second)

Participants

Population: 805 participants were randomised to salmeterol (405) and placebo (400) Baseline characteristics

Age (mean years): sal, 64.1; pbo, 64.6

$\%$ Male: sal, 75.1; pbo, 76.3

$\% \mathrm{FEV}_{1}$ predicted: sal 37.7; pbo, 38.7

Pack-years (mean): sal, 44.8; pbo, 42.4

Inclusion criteria: Participants were required to have relatively stable airway obstruction with $\mathrm{FEV}_{1}<65 \%$ of predicted normal and $<70 \%$ of FVC, $>40$ years of age, with a smoking history of $>10$ pack-years

Exclusion criteria: Patients with a history of asthma, allergic rhinitis or atopy or with an increased total eosinophil count were excluded. Other exclusion criteria included use of supplemental oxygen or an upper respiratory tract infection in the six weeks before screening. Patients with a significant disease other than COPD were not enrolled. Significant disease was defined as a disease that, in the opinion of the investigator, would put the patient at risk because of participation in the study, or a disease that would influence the results of the study

Interventions

1. Salmeterol 50 bid (LABA)

2. Tiotropium 18 qd (LAMA)

3. Placebo (PBO)

Inhaler device: metered dose

Allowed co-medications: Participants were allowed to continue previously prescribed regular inhaled steroids or regular oral steroids, not exceeding a dose equivalent to approximately $10 \mathrm{mg}$ prednisone daily. The number of participants taking these medications during the study was not located

Outcomes

Mean change from baseline on the SGRQ and number whose score decreased by at least 4 units; exacerbations (number, time to first etc.), hospital admissions, $\mathrm{FEV}_{1}, \mathrm{FVC}$, dyspnoea (evaluated using the Baseline Dyspnoea Index (BDI) and the TDI), diary card data

Notes

Funding: Boehringer Ingelheim

Identifier(s): 205.130/205.137

Risk of bias

\begin{tabular}{|c|c|c|}
\hline Bias & Authors' judgement & Support for judgement \\
\hline $\begin{array}{l}\text { Random sequence generation (selection } \\
\text { bias) }\end{array}$ & Low risk & $\begin{array}{l}\text { The randomisation list was generated by } \\
\text { Boehringer Ingelheim using a validated } \\
\text { system, which involved a pseudo-random } \\
\text { number generator so that the resulting }\end{array}$ \\
\hline
\end{tabular}


Brusasco 2003 (Continued)

treatment sequence was both reproducible and non-predictable

Allocation concealment (selection bias) Low risk
All investigational medication for each patient was identified by a unique medication number. Each eligible patient was assigned the lowest medication number available to the investigator at the time of randomisation

Blinding of participants and personnel Low risk (performance bias)

All outcomes

Boehringer Ingelheim was responsible for preparing and coding study medication in a blinded fashion (Boehringer Ingelheim study drug and control were indistinguishable). Patients, investigators and study personnel remained blinded with regard to the treatment assignments up to database lock. Double dummy technique was used to blind different application devices

In all studies, a selection of standard respiratory endpoints like pulmonary function, SGRQ, TDI, treadmill, exacerbations, etc. , were used. Outcome assessors remained blinded with regard to the treatment assignments up to database lock

Blinding of outcome assessment (detection Low risk bias)

All outcomes

Low risk

Incomplete outc
All outcomes

The withdrawal rates were relatively even between groups (salmeterol [18.8\%], placebo [25.8\%])

Selective reporting (reporting bias) Low risk
Results for all expected and specified outcomes were reported (except FEV1 [secondary outcome] was not reported in a way that could be included in the qualitative synthesis

Burge 2000 [ISOLDE]

Methods

Participants
Design: Double blind, placebo controlled study

Duration: 3 years

Location: Conducted at 18 hospitals in the UK

Population: 751 people were randomised to fluticasone (376) and placebo (375) Baseline characteristics:

Age (mean years): flut 63.7, placebo 63.8

Male \%: flut 75.0, placebo 74.1

$\% \mathrm{FEV}_{1}$ predicted: flut 50.3, placebo 50.0 
Burge 2000 [ISOLDE] (Continued)

Pack-years (mean): flut 44, pbo 44

Inclusion criteria: Current or former smokers aged 4075 years with nonasthmatic chronic obstructive pulmonary disease. Baseline FEV1 after bronchodilator was at least 0.8 litres but less than $85 \%$ of predicted normal, and the ratio of FEV1 to forced vital capacity was less than $70 \%$. Previous use of inhaled and oral corticosteroids was permitted.

Exclusion criteria: Patients were excluded if their FEV1 response to $400 \mu \mathrm{g}$ salbutamol exceeded $10 \%$ of predicted normal, they had a life expectancy of less than five years from concurrent diseases, or they used beta blockers

\begin{tabular}{ll} 
Interventions & $\begin{array}{l}\text { 1. Fluticasone } 500 \text { bid (ICS) } \\
\text { 2. Placebo (PBO) } \\
\text { Inhaler device: Metered dose inhaler with a spacer device } \\
\text { Allowed co-medications: Nasal and ophthalmic corticost } \\
\text { other bronchodilators were allowed during the study }\end{array}$ \\
\hline Outcomes & $\begin{array}{l}\text { Decline (ml/year) in FEV1 after bronchodilator, freque } \\
\text { in health status, withdrawals because of respiratory dise } \\
\text { concentrations, and adverse events }\end{array}$ \\
\hline Notes & $\begin{array}{l}\text { Funding: GlaxoWellcome Research and Development } \\
\text { Identifier(s): unknown }\end{array}$ \\
\hline
\end{tabular}

Risk of bias

\begin{tabular}{l|ll}
\hline Bias & Authors' judgement & Support for judgement \\
\hline $\begin{array}{l}\text { Random sequence generation (selection } \\
\text { bias) }\end{array}$ & Low risk & $\begin{array}{l}\text { Computer generated allocation (block size } \\
\text { of six) }\end{array}$ \\
\hline Allocation concealment (selection bias) & Low risk & $\begin{array}{l}\text { Patients were randomised sequentially } \\
\text { from a list comprising treatment numbers } \\
\text { only }\end{array}$ \\
\hline
\end{tabular}

Blinding of participants and personnel Low risk (performance bias)

Three year double blind phase using an All outcomes

identical placebo inhaler

\begin{tabular}{|c|c|c|}
\hline $\begin{array}{l}\text { Blinding of outcome assessment (detection } \\
\text { bias) } \\
\text { All outcomes }\end{array}$ & Unclear risk & Not described \\
\hline $\begin{array}{l}\text { Incomplete outcome data (attrition bias) } \\
\text { All outcomes }\end{array}$ & High risk & $\begin{array}{l}\text { Very high dropout in both groups }(43 \% \\
\text { and } 53 \%)\end{array}$ \\
\hline Selective reporting (reporting bias) & Unclear risk & $\begin{array}{l}\text { No outcomes appear to be missing but } \\
\text { couldn't locate protocol to ensure all were } \\
\text { reported. Author attempted contact with } \\
\text { GSK statistician but no data were provided }\end{array}$ \\
\hline
\end{tabular}


Burge 2000 [ISOLDE] (Continued)

in time for publication

\section{Calverley 2003 [TRISTAN]}

Methods

Design: randomised, double-blind, placebo-controlled, parallel-group design

Duration: 12 months (+ 2 weeks run-in period)

Location: 196 centres in 25 countries

Participants

Population: 1466 participants were randomised to salmeterol (372), fluticasone (375), salmeterol/fluticasone combination (358) and placebo (361)

Baseline characteristics

Mean age (years): salm 63.2, flut 63.5, salm/flut 62.7, pbo 63.4

\% Male: salm 70, flut 69.5, salm/flut 75.4, pbo 75

$\% \mathrm{FEV}_{1}$ predicted: salm 44.3, flut 45.0, salm/flut 44.8, pbo 44.2

Pack-years: salm 43.7, flut 41.5, salm/flut 42.0 , pbo 43.4

Inclusion criteria: $\geq 10$-Pack-year history of cigarette smoking; a history of cough productive of sputum on most days for at least 3 months of the year, for at least 2 years; documented history of COPD exacerbations each year for the previous 3 years, including at least one exacerbation in the last year that required oral corticosteroids and/or antibiotics; a baseline (pre-bronchodilator) $\mathrm{FEV}_{1} \geq 25 \%$ to $\leq 70 \%$ of predicted normal; poor reversibility of airflow obstruction (defined as an increase $<10 \%$ of predicted normal $\mathrm{FEV}_{1}$ value 30 minutes after inhalation of $400 \mu \mathrm{g}$ salbutamol) and $\mathrm{FEV}_{1} /$ forced vital capacity (FVC) ratio $\leq 70 \%$

Exclusion criteria: respiratory disorders other than COPD. Patients were also excluded if they had received systemic corticosteroids, high doses of inhaled corticosteroids or antibiotics in the 4 weeks before the 2 weeks run-in

Interventions
$\begin{aligned} & \text { 1. Salmeterol } 50 \text { bid (LABA) } \\ & \text { 2. Fluticasone } 500 \text { bid (ICS) } \\ & \text { 3. Salmeterol/fluticasone } 50 / 500 \text { bid (LABA/ICS) } \\ & \text { 4. Placebo (PBO) } \\ & \text { Inhaler device: multi-dose dry powder } \\ & \text { Allowed co-medications: Inhaled salbutamol was used as relief medication throughout } \\ & \text { the study, and regular treatment with anticholinergics, mucolytics and theophylline was } \\ & \text { allowed. Medications not allowed during the study period were inhaled corticosteroids } \\ & \text { and LABAs }\end{aligned}$

Outcomes

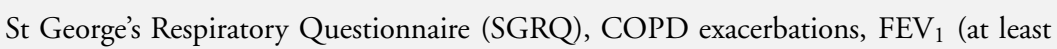
6 hours after medication), pretreatment FVC and post-bronchodilator $\mathrm{FEV}_{1}$ and FVC, morning PEF, diary card data

Notes

Funding: GlaxoSmithKline

Identifier(s): GSK SFCB3024

\section{Risk of bias}

Bias 


\section{Calverley 2003 [TRISTAN] (Continued)}

\begin{tabular}{|c|c|c|}
\hline $\begin{array}{l}\text { Random sequence generation (selection } \\
\text { bias) }\end{array}$ & Low risk & $\begin{array}{l}\text { We used a randomisation schedule gener- } \\
\text { ated by the patient allocation for clinical } \\
\text { trials (PACT) program to assign patients to } \\
\text { study treatment groups }\end{array}$ \\
\hline
\end{tabular}

$\begin{array}{lll}\text { Allocation concealment (selection bias) } \quad \text { Low risk } & \text { Every participating centre was supplied }\end{array}$ with a list of patient numbers (assigned to patients at their first visit) and a list of treatment numbers. Patients who satisfied the eligibility criteria were assigned the next sequential treatment number from the list

Blinding of participants and personnel Low risk

Study drugs were labelled in a way to ensure (performance bias) that both the patient and the investigator All outcomes were unaware of the allocated treatment

Blinding of outcome assessment (detection Low risk

No subjective assessor-rated outcomes and bias) investigators remained blind

All outcomes

Incomplete outcome data (attrition bias) Unclear risk All outcomes

Withdrawal relatively even but high in both groups (salmeterol $32.0 \%$, placebo $38.8 \%$ ) but the Intent-to-Treat (ITT) population, consisting of all subjects who were randomised to treatment and received at least one dose of the study medication, was used for all analyses of efficacy and safety. Unclear what method of imputation was used for each outcome

Selective reporting (reporting bias) Low risk

All outcomes stated in the protocol were reported in detail

Calverley 2003a

Methods

Design: randomised, double-blind, placebo-controlled, parallel-group study

Duration: 12 months (+ 2 weeks run-in)

Location: 109 centres in 15 countries or regions

Participants

Population: 1022 participants were randomised to formoterol (255), budesonide (257)

, formoterol/budesonide combination (254) and placebo (256)

Baseline characteristics

Mean age (years): form 63, bud 64, form/bud 64, pbo 65

$\%$ Male: form 75 , bud 74 , form/bud 78, pbo 75

$\% \mathrm{FEV}_{1}$ predicted: form 36 , bud, form/bud, pbo 36

Pack-years: form 38, bud 39, form/bud 39, pbo 39

Inclusion criteria: Males and females $>40$ years old; history of at least 10 pack-years;

$\mathrm{COPD}$ for at least 2 years; $<70 \% \mathrm{FEV}_{1} / \mathrm{FVC}, \mathrm{FEV}_{1}<50 \%$ predicted; $1+\mathrm{COPD}$

Long-acting inhaled therapy (beta-agonists, anticholinergics and steroids) for COPD: a network meta-analysis (Review)

Copyright (c) 2014 The Cochrane Collaboration. Published by John Wiley \& Sons, Ltd. 
exacerbations requiring medication in previous 2 to 12 months

Exclusion criteria: history of asthma or seasonal allergic rhinitis before age 40; any relevant cardiovascular disorders or other disease

$\begin{array}{ll}\text { Interventions } & \text { 1. Formoterol } 9 \text { bid (LABA) } \\ & \text { 2. Budesonide } 400 \text { bid (ICS) } \\ \text { 3. Formoterol/budesonide } 9 / 320 \\ \text { 4. Placebo (PBO) } \\ \text { Inhaler device: dry powder inhal } \\ \text { Allowed co-medications: terbut } \\ \text { oral corticosteroids and antibiotics } \\ \text { steroids and/or nebulised treatm } \\ \text { cluded during the study period w } \\ \text { costeroids; disodium cromoglyca } \\ \text { other bronchodilators; antihistan }\end{array}$

Risk of bias

\begin{tabular}{|c|c|c|}
\hline Bias & Authors' judgement & Support for judgement \\
\hline $\begin{array}{l}\text { Random sequence generation (selection } \\
\text { bias) }\end{array}$ & Low risk & $\begin{array}{l}\text { Patients were randomized to treatment. No } \\
\text { details of sequence generation methods but } \\
\text { assumed to adhere to usual AstraZeneca } \\
\text { methods }\end{array}$ \\
\hline Allocation concealment (selection bias) & Unclear risk & No details reported \\
\hline $\begin{array}{l}\text { Blinding of participants and personnel } \\
\text { (performance bias) } \\
\text { All outcomes }\end{array}$ & Low risk & $\begin{array}{l}\text { Study reported as double-blind (patient } \\
\text { and investigators) }\end{array}$ \\
\hline $\begin{array}{l}\text { Blinding of outcome assessment (detection } \\
\text { bias) } \\
\text { All outcomes }\end{array}$ & Low risk & $\begin{array}{l}\text { No subjective assessor-rated outcomes were } \\
\text { reported }\end{array}$ \\
\hline $\begin{array}{l}\text { Incomplete outcome data (attrition bias) } \\
\text { All outcomes }\end{array}$ & Unclear risk & $\begin{array}{l}\text { Withdrawal even but high in both groups } \\
\text { (formoterol, } 43.5 \% \text {; placebo, } 41.4 \% \text { ). An } \\
\text { intention-to-treat analysis was used and all } \\
\text { hypothesis testing but no information re- } \\
\text { garding method of imputation was pro- } \\
\text { vided }\end{array}$ \\
\hline
\end{tabular}


Calverley 2003a (Continued)

\begin{tabular}{|c|c|c|}
\hline Selective reporting (reporting bias) & Low risk & $\begin{array}{l}\text { All relevant outcomes could be included in } \\
\text { meta-analysis }\end{array}$ \\
\hline
\end{tabular}

Calverley 2003b

\begin{tabular}{|c|c|c|}
\hline Methods & \multicolumn{2}{|c|}{$\begin{array}{l}\text { Design: Randomised, placebo-controlled study } \\
\text { Duration: } 52 \text { weeks (+ } 2 \text { week run-in) } \\
\text { Location: not reported }\end{array}$} \\
\hline Participants & \multicolumn{2}{|c|}{$\begin{array}{l}\text { Population: } 631 \text { participants were randomised to mometasone (318) and placebo (313) } \\
\text { Baseline characteristics - not given per arm } \\
\text { Mean age (years): not reported } \\
\% \text { Male: not reported } \\
\% \text { FEV }_{1} \text { predicted: } 47 \\
\text { Pack-years: not reported } \\
\text { Inclusion criteria: adults } \geq 40 \text { years old with moderate COPD and a history of smoking } \\
\text { Exclusion criteria: not reported }\end{array}$} \\
\hline Interventions & \multicolumn{2}{|c|}{$\begin{array}{l}\text { 1. Mometasone } 800 \text { qd (ICS) } \\
\text { 2. Placebo (PBO) } \\
\text { Inhaler device: dry powder } \\
\text { Allowed co-medications: not reported }\end{array}$} \\
\hline Outcomes & \multicolumn{2}{|c|}{$\begin{array}{l}\text { Changes from baseline in post-bronchodilator FEV1 and COPD symptom scores; \% of } \\
\text { patients with } \geq 1 \text { COPD exacerbation; time to first COPD exacerbation }\end{array}$} \\
\hline Notes & \multicolumn{2}{|c|}{$\begin{array}{l}\text { Funding: unknown } \\
\text { Identifiers(s): unknown } \\
\text { Abstract only - minimal information }\end{array}$} \\
\hline \multicolumn{3}{|l|}{ Risk of bias } \\
\hline Bias & Authors' judgement & Support for judgement \\
\hline $\begin{array}{l}\text { Random sequence generation (selection } \\
\text { bias) }\end{array}$ & Low risk & $\begin{array}{l}\text { Randomised trial [no other details - funded } \\
\text { by AstraZeneca and presumed to adhere to } \\
\text { usual methods] }\end{array}$ \\
\hline Allocation concealment (selection bias) & Unclear risk & Not described \\
\hline $\begin{array}{l}\text { Blinding of participants and personnel } \\
\text { (performance bias) } \\
\text { All outcomes }\end{array}$ & Low risk & $\begin{array}{l}\text { Double-blind [assume participants and } \\
\text { personnel/investigators] }\end{array}$ \\
\hline $\begin{array}{l}\text { Blinding of outcome assessment (detection } \\
\text { bias) } \\
\text { All outcomes }\end{array}$ & Unclear risk & Not described \\
\hline
\end{tabular}

Long-acting inhaled therapy (beta-agonists, anticholinergics and steroids) for COPD: a network meta-analysis (Review)

Copyright @ 2014 The Cochrane Collaboration. Published by John Wiley \& Sons, Ltd. 
Calverley 2003b (Continued)

\begin{tabular}{l|ll}
$\begin{array}{l}\text { Incomplete outcome data (attrition bias) } \\
\text { All outcomes }\end{array}$ & High risk & $\begin{array}{l}\text { An intention-to-treat analysis was used but } \\
\text { dropout was high in all groups (ranging } \\
\text { from 29\% to 44\%) }\end{array}$ \\
\hline Selective reporting (reporting bias) & Low risk & $\begin{array}{l}\text { All outcomes stated in the industry docu- } \\
\text { ment were reported in full. Checked with } \\
\text { authors }\end{array}$ \\
\hline
\end{tabular}

\section{Calverley 2007 [TORCH]}

Methods

Design: multi-centre, randomised, double-blind, parallel-group, placebo-controlled study

Duration: 3 years (+ 3 weeks run-in period)

Location: 466 centres in 42 countries comprising 190 centres in USA, 134 centres in Western Europe, 46 centres in Eastern Europe, 37 centres in Asia Pacific, and 59 centres in other regions

Participants

Population: 6184 participants were randomised to salmeterol (1542), fluticasone (1551) , salmeterol/fluticasone combination (1546) and placebo (1545)

\section{Baseline characteristics}

Mean age (years): salm 65.1, flut 65.0, salm/flut 65.0, pbo 65.0

\% Male: salm 76.3, flut 75.4, salm/flut 75.1, pbo 76.3

$\% \mathrm{FEV}_{1}$ predicted: salm 43.6, flut 44.1, salm/flut 44.3, pbo 44.1

Pack-years: salm 49.3, flut 49.2, salm/flut 47.0, pbo 48.6

Inclusion criteria: male or female current or former smokers; history of at least 10 packyears; clinical diagnosis of COPD; aged 40 to 80 years inclusive, with pre-bronchodilator $\mathrm{FEV}_{1}<60 \%$ predicted at entry to the study

Exclusion criteria: current diagnosis of asthma; current respiratory disorders other than COPD; lung volume reduction surgery and/or transplant; serious uncontrolled disease; evidence of alcohol, drug or solvent abuse, hypersensitivity to ICS, bronchodilators or lactose; deficiency of alpha ${ }_{1}$-antitrypsin; exacerbation during run-in period

Interventions

1. Salmeterol 50 bid (LABA)

2. Fluticasone 500 bid (ICS)

3. Salmeterol/fluticasone 50/500 bid (LABA/ICS)

4. Placebo (PBO)

Inhaler device: multi-dose dry powder

Allowed co-medications: Ventolin as relief, inhaled long-acting bronchodilators and long-term oral corticosteroids (theophyllines long- and short-acting, SABAs and shortacting anticholinergic agents allowed). Medications not allowed during the study period were inhaled corticosteroids, inhaled long-acting bronchodilators, long-term oral corticosteroids and long-term oxygen therapy

Outcomes

St. George's Respiratory Questionnaire (SGRQ), COPD exacerbations, adjusted mean change $\mathrm{FEV}_{1}$

Notes

Funding: GlaxoSmithKline

Identifier(s): NCT0026821, GSK SCO30003

Long-acting inhaled therapy (beta-agonists, anticholinergics and steroids) for COPD: a network meta-analysis (Review)

Copyright (c) 2014 The Cochrane Collaboration. Published by John Wiley \& Sons, Ltd. 


\section{Calverley 2007 [TORCH] (Continued)}

\section{Risk of bias}

\begin{tabular}{|c|c|c|}
\hline Bias & Authors' judgement & Support for judgement \\
\hline $\begin{array}{l}\text { Random sequence generation (selection } \\
\text { bias) }\end{array}$ & Low risk & $\begin{array}{l}\text { [From protocol] Subjects will be assigned to } \\
\text { study treatment in accordance with the ran- } \\
\text { domisation schedule, which will be gener- } \\
\text { ated using the GW computer program Pa- } \\
\text { tient Allocation for Clinical Trials (PACT) }\end{array}$ \\
\hline Allocation concealment (selection bias) & Low risk & $\begin{array}{l}\text { [From protocol] Subjects will be centrally } \\
\text { randomised to one of the four treatment } \\
\text { groups via the System for Central Alloca- } \\
\text { tion of Drug (SCAD) and will be stratified } \\
\text { by smoking status }\end{array}$ \\
\hline
\end{tabular}

Blinding of participants and personnel Low risk (performance bias)

All outcomes
[From protocol] Once the database has been frozen, the treatment allocations will be unblinded and all of the analyses detailed in this document will be performed. The treatment allocations will be unblinded using standard GSK systems. The database will be frozen by BDS Respiratory Data Management, GSK

Blinding of outcome assessment (detection Low risk bias)

All outcomes

Incomplete outcome data (attrition bias) Low risk All outcomes
An independent clinical end point committee, whose members were unaware of the treatment assignments, determined the primary cause of death and whether death was related to COPD. No other outcomes were assessor-rated

Withdrawal rates quite similar but both high by the end of the 36 month treatment period. Acceptable methods of imputation used in all cases. For any subject who withdraws prematurely from the study, all available data up to the time of discontinuation were included in the analyses. Mortality data were collected for subjects who withdrew early

All relevant outcomes stated in the protocol were reported in detail 


\begin{tabular}{|c|c|}
\hline Methods & $\begin{array}{l}\text { Design: randomized, double-blind, placebo-controlled study } \\
\text { Duration: } 52 \text { weeks (+ } 2 \text { week run-in) } \\
\text { Location: } 95 \text { sites in } 11 \text { countries }\end{array}$ \\
\hline Participants & $\begin{array}{l}\text { Population: } 911 \text { participants were randomised to two doses of mometasone ( } 308 \text { and } \\
\text { 308), and placebo (295) } \\
\text { Baseline characteristics } \\
\text { Mean age (years): mom } 80065.3, \text { mom } 40065.0 \text {, pbo } 65.0 \\
\% \text { Male: mom } 80069 \text {, mom } 40067 \text {, pbo } 69 \\
\% \text { FEV }_{1} \text { predicted (pre-BD): mom } 80043 \text {, mom } 40042 \text {, pbo } 42 \\
\text { Pack-years: not reported } \\
\text { Inclusion criteria: All subjects had a diagnosis of COPD based on currently accepted } \\
\text { criteria, and were current smokers who failed a mandatory smoking cessation program } \\
\text { or self-reported ex-smokers who had stopped smoking } \geq 12 \text { months before the study. } \\
\text { Eligible subjects had a pre-bronchodilator FEV1/FVC (forced vital capacity) ratio } \leq \\
70 \% \text {, post-bronchodilator FEV1 between } 30 \% \text { and } 70 \% \text { predicted, and low post-bron- } \\
\text { chodilator FEV1 reversibility (< } 10 \% \text { of predicted normal) } \\
\text { Exclusion criteria: Subjects with a clinical history of asthma or any other clinically } \\
\text { significant medical illness other than COPD were excluded. Other exclusion criteria } \\
\text { included a COPD exacerbation within } 3 \text { months before the baseline visit; ventilator } \\
\text { support for respiratory failure within the past year; lobectomy, pneumonectomy, or lung } \\
\text { volume reduction surgery; lung cancer within the past } 5 \text { years; nasal continuous positive } \\
\text { airway pressure or oxygen use }>2 \mathrm{~L} / \mathrm{min} \text { or for }>2 \text { hours per day; initiation of pulmonary } \\
\text { rehabilitation within the past } 3 \text { months; treatment with chronic or prophylactic antibi- } \\
\text { otics; inability to use the MF-DPI inhaler; and }<80 \% \text { adherence in recording diary data } \\
\text { between screening and baseline }\end{array}$ \\
\hline
\end{tabular}

Interventions
$\begin{aligned} & \text { 1. Mometasone } 400 \mathrm{qd} \text { (ICS) } \\ & \text { 2. Mometasone } 800 \mathrm{qd} \text { (ICS) } \\ & \text { Inhaler device: dry powder } \\ & \text { Allowed co-medications: per protocol, subjects did not receive inhaled, oral, or par- } \\ & \text { enteral corticosteroids for } 6 \text { weeks prior to screening. During the study, ipratropium } \\ & \text { bromide, theophylline, short- and long-acting b2-adrenergic agonists (with appropriate } \\ & \text { washout before study visits) were allowed }\end{aligned}$
with a COPD exacerbation, and adverse events

$\begin{array}{ll}\text { Notes } & \text { Funding: Schering-Plough } \\ & \text { Identifier(s): unknown }\end{array}$

Risk of bias

\begin{tabular}{|c|c|c|}
\hline Bias & Authors' judgement & Support for judgement \\
\hline $\begin{array}{l}\text { Random sequence generation (selection } \\
\text { bias) }\end{array}$ & Low risk & $\begin{array}{l}\text { Randomized via computer-generated code } \\
\text { in a ratio of } 2: 2: 1: 1\end{array}$ \\
\hline
\end{tabular}

Long-acting inhaled therapy (beta-agonists, anticholinergics and steroids) for COPD: a network meta-analysis (Review) 
Calverley 2008 (Continued)

\begin{tabular}{|c|c|c|}
\hline Allocation concealment (selection bias) & Unclear risk & Not described \\
\hline $\begin{array}{l}\text { Blinding of participants and personnel } \\
\text { (performance bias) } \\
\text { All outcomes }\end{array}$ & Unclear risk & $\begin{array}{l}\text { Double-blind but 'dosing regimens (QD or } \\
\text { BID) were not blinded' }\end{array}$ \\
\hline $\begin{array}{l}\text { Blinding of outcome assessment (detection } \\
\text { bias) } \\
\text { All outcomes }\end{array}$ & Unclear risk & $\begin{array}{l}\text { Double-blind but 'dosing regimens (QD or } \\
\text { BID) were not blinded'. No reference to } \\
\text { outcome assessors }\end{array}$ \\
\hline $\begin{array}{l}\text { Incomplete outcome data (attrition bias) } \\
\text { All outcomes }\end{array}$ & High risk & $\begin{array}{l}\text { Dropout was }>30 \% \text { all groups, and espe- } \\
\text { cially high in the placebo group }(42.4 \%) \\
\text { The ITT population did not include } 11 \text {. } \\
5 \% \text { of the randomised population }\end{array}$ \\
\hline Selective reporting (reporting bias) & Unclear risk & $\begin{array}{l}\text { We could not locate a prospectively regis- } \\
\text { tered protocol to check all outcomes were } \\
\text { reported }\end{array}$ \\
\hline
\end{tabular}

Calverley 2010

Methods

Design: double-blind, double-dummy, randomised, active-controlled, parallel-group study

Duration: 11 months (+ 4 week run-in)

Location: Conducted at 76 centres in 8 countries across Europe

Participants

Population: 718 participants were randomised to formoterol (239) and formoterol/ budesonide combination (242), and one other treatment arm which was not eligible for this review (237)

Baseline characteristics

Age (mean years): bud/form 64.1, form 63.7

$\%$ Male: bud/form 81.5 , form 81.1

$\% \mathrm{FEV}_{1}$ predicted: bud/form 42.3, form 42.5

Pack-years (mean): bud/form 37.8, form 39.7

Inclusion criteria: Hospital outpatients with severe stable COPD according to the GOLD guidelines; aged 40 years with a diagnosis of symptomatic COPD for $>2$ years, at least a 20 pack-years smoking history, a post-bronchodilator FEV1 between $30 \%$ and $50 \%$ of the predicted normal and at least $0.7 \mathrm{~L}$ absolute value and a pre-dose FEV1/forced vital capacity (FVC) of 0.7 ; at least one exacerbation requiring medical intervention (oral corticosteroid and/or antibiotic treatment and/or need for a visit to an emergency department and/or hospitalisation) within 2-12 months before the screening visit and to be clinically stable for the 2 months before study entry; change in FEV $1<12 \%$ of predicted normal value $30 \mathrm{~min}$ following inhalation of $200 \mathrm{mg}$ of salbutamol pMDI

Exclusion criteria: History of asthma, allergic rhinitis or other atopic disease, variability of symptoms from day to day and frequent symptoms at night and early morning (suggestive of asthma); receiving long term oxygen therapy or they had a lower respiratory tract infection or had been hospitalised for an acute COPD exacerbation within two months before screening or during the run-in period. Treatment with oral, injectable

Long-acting inhaled therapy (beta-agonists, anticholinergics and steroids) for COPD: a network meta-analysis (Review) 
or depot corticosteroids and antibiotics, long-acting antihistamines or changes in the dose of an oral modified release theophylline in the two months preceding screening and during the run-in period were excluded

$\begin{array}{ll}\text { Interventions } & \text { 1. Formoterol } 12 \text { bid (LABA) } \\ \text { 2. Formoterol/budesonide 12/400 bid (LABA/ICS) } \\ \text { Inhaler device: Dry powder } \\ \text { Allowed co-medications: not described }\end{array}$

Outcomes

Change in pre-dose morning FEV1 and mean rate of COPD exacerbations per patient per year, FVC, PEF, SGRQ total score, six-minute walking test, BMI, BODE index, safety evaluations including ECG

Notes Funding: Chiesi Farmaceutici

Identifier(s): NCT00476099

\section{Risk of bias}

\begin{tabular}{l|l|l}
\hline Bias & Authors' judgement & Support for judgement \\
\hline $\begin{array}{l}\text { Random sequence generation (selection } \\
\text { bias) }\end{array}$ & Low risk & $\begin{array}{l}\text { The randomisation scheme followed a bal- } \\
\text { anced-block centre-stratified design and } \\
\text { was prepared via computerised system }\end{array}$ \\
\hline Allocation concealment (selection bias) & Low risk & $\begin{array}{l}\text { Patients were centrally assigned, in each } \\
\text { centre, to one of the three treatment arms } \\
\text { at the end of the run-in period through } \\
\text { an Interactive Voice/Web Response System } \\
\text { (IXRS) }\end{array}$ \\
\hline
\end{tabular}

Blinding of participants and personnel Low risk (performance bias)

All outcomes

Blinding of outcome assessment (detection Low risk bias)

All outcomes

Incomplete outcome data (attrition bias) Low risk All outcomes
On each study day, patients took both active medications and matched placebo twice daily, in order to maintain blinding

On each study day, patients took both active medications and matched placebo twice daily, in order to maintain blinding. In case of emergency, un-blinding of the treatment code was done through IXRS

$12.3 \%$ withdrew from the combination group and $14.2 \%$ from the formoterol group. Judged to be relatively low and even between groups, and the intention-to-treat population were used using last observation carried forward 
Calverley 2010 (Continued)

Selective reporting (reporting bias) Low risk

All outcomes stated in the prospectively registered protocol were reported in full

\section{Campbell 2005}

Methods

Design: randomised, double-blind, placebo-controlled, parallel-group study

Duration: 6 months (+ 3 weeks run-in period)

Location: 73 centres in 8 countries

Participants

Population: 432 participants were randomised to formoterol (215) and placebo (217)

Baseline characteristics

Mean age (years): form 60; pbo, 60

$\%$ Male: form 61, pbo, 73

$\% \mathrm{FEV}_{1}$ predicted: form 53.0, pbo 54.1

Pack-years (mean): form 37, pbo, 37

Inclusion criteria: older than 40 years of age; clinical diagnosis of COPD with at least 2 years of symptoms, $\mathrm{FEV}_{1} 40 \%$ to $70 \%$ predicted, $\mathrm{FEV}_{1}$ /slow $\mathrm{VC}<70 \%$; history of at least 10 pack-years

Exclusion criteria: history of asthma or seasonal allergic rhinitis; onset before age 40; inhaled corticosteroid dose change; oral steroid use or significant COPD exacerbation in the past mo

Interventions

1. Formoterol 12 bid (LABA)

2. Placebo (PBO)

Inhaler device: dry powder turbuhaler

Allowed co-medications: Allowed medications were terbutaline $(0.5 \mathrm{mg})$ used as reliever [in the two arms used in the review]; inhaled and nasal corticosteroids without modification of dosage or frequency of administration. Disallowed medications included domiciliary oxygen; disodium cromoglycate; ephedrine; antihistamines; beta-blockers and bronchodilators other than the study medication

Outcomes

St George's Respiratory Questionnaire (SGRQ), COPD exacerbations, FEV 1 \% change, morning PEF, slow VC, combined symptom score (CSS), reliever medication use

Notes $\quad$ Funding: AstraZeneca

Identifier(s): unknown

\section{Risk of bias}

\begin{tabular}{ll|l}
\hline Bias & Authors' judgement & Support for judgement \\
\hline $\begin{array}{l}\text { Random sequence generation (selection } \\
\text { bias) }\end{array}$ & Low risk & $\begin{array}{l}\text { Treatment was randomized in balanced } \\
\text { blocks using a computer generated scheme }\end{array}$ \\
\hline $\begin{array}{l}\text { Allocation concealment (selection bias) } \\
\text { Low risk }\end{array}$ & Randomisation scheme was provided in \\
coded envelopes
\end{tabular}




\section{Campbell 2005 (Continued)}

Blinding of participants and personnel Low risk (performance bias)

All outcomes

Blinding of outcome assessment (detection Low risk bias)

All outcomes

Incomplete outcome data (attrition bias) Low risk

All outcomes

Selective reporting (reporting bias)

Low risk
Double-blind treatment period (patients and investigators)

No outcomes used from this study in the present review were assessor-rated

Casaburi 2002

Methods

Participants
Design: 2 identical randomized double-blind placebo-controlled studies

Duration: 52 weeks (+ 2 week run-in)

Location: 50 clinical centres (? countries)

An intention-to-treat approach was used throughout. Unclear how data were imputed but withdrawal rates were similar and below 20\% in both groups (formoterol 14 . $0 \%$, placebo $18.0 \%$ )

All stated outcomes were reported and included in meta-analysis

Baseline characteristics
Mean age (years): tio 65, pbo 65
\% Male: tio 66.5, pbo 62.8
\% FEV 1 predicted: tio 39.1 , pbo 38.1
Pack years (mean): tio 63, pbo 59
Inclusion criteria: outpatients of either sex who were $>40$-yrs-old and had a clinical
diagnosis of COPD, as defined by the American Thoracic
Society (ATS). Participants were required to have at least a 10 pack-yr smoking history,
clinically stable airway obstruction, and a forced expiratory volume in one second (FEV1)
of $<65 \%$ of predicted normal values and $<70 \%$ of forced vital capacity (FVC)
Excusion criteria: history of asthma, allergic rhinitis or atopy or a total blood eosinophil
count of $>600$ cells/mm-3. Bronchodilator responsiveness was not an entry criterion.
Patients were also excluded if they required regular daytime supplemental oxygen or were
on doses exceeding the equivalent of 10 mg prednisone daily during the month prior
to entering the study. In addition, patients were excluded if they had a recent history of
myocardial infarction $(<1$ yr), heart failure (<3 yrs) or cardiac arrhythmia requiring drug
therapy

Interventions

1. Tiotropium 18 bid (LAMA)

2. Placebo (PBO)

Inhaler device: dry powder

Allowed co-medications: Patients were permitted an albuterol metered-dose inhaler, as needed, stable doses of theophylline (i.e. unchanging doses that had been used for $>6$ weeks prior to entry), inhaled glucocorticosteroids and the equivalent of $<10 \mathrm{mg} / \mathrm{day}-1$ 
oral prednisone throughout the study period. Finally, to treat acute COPD exacerbations during the trial, investigators were permitted to administer any additional medication deemed necessary (excluding anticholinergic or long-acting b-agonists). After 13 weeks, the investigators were permitted to prescribe glucocorticosteroids or theophylline preparations as necessary

Outcomes

The primary spirometric outcome was trough FEV1. Changes in dyspnoea were measured using the Transition Dyspnea Index, and health status with the disease-specific St. George's Respiratory Questionnaire and the generic Short Form 36. Medication use and adverse events were recorded

\begin{tabular}{ll}
\hline Notes & Funding: Boehringer Ingelheim \\
& Identifier(s): unknown
\end{tabular}

\section{Risk of bias}

\begin{tabular}{l|ll}
\hline Bias & Authors' judgement & Support for judgement \\
\hline $\begin{array}{l}\text { Random sequence generation (selection } \\
\text { bias) }\end{array}$ & Low risk & $\begin{array}{l}\text { Patients were randomized in a } 3: 2 \\
\text { tiotropium:placebo ratio in order to expose } \\
\text { a greater number of patients to tiotropium } \\
\text { for safety evaluation [industry funded] }\end{array}$ \\
\hline Allocation concealment (selection bias) & Unclear risk & Not described \\
\hline
\end{tabular}

Blinding of participants and personnel Low risk (performance bias)

All outcomes

Blinding of outcome assessment (detection Unclear risk bias)

All outcomes

Incomplete outcome data (attrition bias) Low risk All outcomes
Double-blind. Subjects took, by inhalation, active medication (tiotropium in lactose) or placebo (lactose) once each morning from identically appearing capsules

No information

The intention-to-treat principle of including all randomized patients was used in all efficacy analyses. Patients who had missing baseline data, or $<2$ weeks of data for certain end points, were excluded from the 1 yr comparisons for those end points. When patients discontinued due to worsening of disease ( $5 \%$ of patients), missing data were imputed using the least favourable data observed prior to discontinuation. In all other cases, missing data following patient withdrawal were imputed by carrying the last observation forward. In order to assess the impact of imputation, data were also analysed based on patients who completed the 
Casaburi 2002 (Continued)

study to 12 months alone. This sensitivity analysis showed that the results were consistent with those obtained after imputation of missing data

Selective reporting (reporting bias) Unclear risk

We could not locate a prospectively registered protocol to check all outcomes were reported

\section{Chan 2007}

Methods

Design: randomized, double-blind, parallel-group study

Duration: 48 weeks

Location: 101 centres in Canada involving 72 specialists and 29 general practitioners

Participants

Popoulation: 913 participants were randomised to tiotropium (608) and placebo (305)

Baseline characteristics

Mean age (years): tio 66.8, pbo 66.9

$\%$ Male: tio 59, pbo 61

$\% \mathrm{FEV}_{1}$ predicted: tio 39.4 , pbo 39.3

Pack years (mean): tio 50.2, pbo 51.0

Inclusion criteria: Male and female outpatients aged 40 years or older, with a clinical diagnosis of COPD (FEV1 65\% predicted or less and FEV1/forced vital capacity [FVC] $70 \%$ or less) were considered for inclusion in the present study. Participants were required to have a smoking history of 10 pack-years or greater.

The inclusion criteria relating to 'exacerbation history' initially required that patients had experienced one or more exacerbations within the past year (requiring treatment with antibiotics and/or oral steroids), but not within the six weeks before entering the study. However, due to slower than expected enrolment, this criterion was amended to include patients with fewer exacerbations (one exacerbation in the past two years)

Exclusion criteria: history of asthma, allergic rhinitis or atopy; a recent lower respiratory tract infection or any exacerbation (within the previous six weeks); a recent history of myocardial infarction (within the previous six months) or cardiac arrhythmia requiring drug therapy; and oral corticosteroid use at unstable doses during the six weeks before entering the study or at a stable dose exceeding the equivalent of $10 \mathrm{mg}$ prednisone daily. In addition, those patients with a significant disease other than COPD that would put the patient at risk because of participation in the study, or patients with a disease that may have influenced the results of the study, were not enrolled

Interventions

\section{Tiotropium 18 bid (LAMA)}

2. Placbeo (PBO)

Inhaler device: dry powder Handihaler

Allowed co-medications: During the treatment period, patients were permitted oral corticosteroids (at a stable dose of $10 \mathrm{mg}$ or less of prednisone daily or equivalent), stable doses of inhaled corticosteroids, theophylline preparations, mucolytic preparations (not containing bronchodilators), LABAs and, for acute symptom relief, as-needed salbutamol metered-dose inhaler. Patients were not allowed to use inhaled anticholinergics (other than the study drug) or oral beta2-agonists during the treatment period. To treat 
COPD exacerbations during the trial, the investigators were permitted to administer any additional medication deemed necessary

Outcomes Lung function (FEV1, FEV6 and forced vital capacity), symptoms, health-related quality of life (St George's Respiratory Questionnaire) and exacerbations

Notes $\quad$ Funding: Boehringer Ingelheim Canada Ltd and Pfizer Canada

Identifier(s): 205.259

\section{Risk of bias}

\begin{tabular}{|c|c|c|}
\hline Bias & Authors' judgement & Support for judgement \\
\hline $\begin{array}{l}\text { Random sequence generation (selection } \\
\text { bias) }\end{array}$ & Low risk & $\begin{array}{l}\text { Patients were randomly assigned to receive } \\
\text { either tiotropium } 18 \text { once daily or placebo } \\
\text { for } 48 \text { weeks (in a ratio of } 2: 1 \text { ) [industry } \\
\text { funded] }\end{array}$ \\
\hline Allocation concealment (selection bias) & Unclear risk & Not described \\
\hline $\begin{array}{l}\text { Blinding of participants and personnel } \\
\text { (performance bias) } \\
\text { All outcomes }\end{array}$ & Low risk & $\begin{array}{l}\text { Double-blind, both medications delivered } \\
\text { via the Handihaler }\end{array}$ \\
\hline $\begin{array}{l}\text { Blinding of outcome assessment (detection } \\
\text { bias) } \\
\text { All outcomes }\end{array}$ & Unclear risk & Not described \\
\hline
\end{tabular}

Incomplete outcome data (attrition bias) Low risk

All outcomes analyses were applied to the full analysis set (FAS) patient population with the last observation carried forward method, except when patients discontinued because of worsening COPD, when the least favourable data before discontinuation were carried forward. The FAS population included all patients who were randomly assigned, took at least one dose of study medication, and had a valid baseline measurement and an additional measurement after at least one week of multiple dosing. $24 \%$ dropout overall, fairly even between groups

All outcomes stated in the prospectively registered protocol were reported in full 
Methods

Participants
Design: randomized, double-blind, placebo-controlled trial

Duration: 2 years

Location: 61 sites in 11 different countries

Population: 519 participants were randomised to tiotropium (260) and placebo (259) Baseline characteristics - given for the whole population, not per group

Mean age (years): 64.6

$\%$ Male: 77.3

$\% \mathrm{FEV}_{1}$ predicted (pre-BD): 38.2

Pack years (mean): 51.7

Inclusion criteria: men and women, aged 40-80 years, with a clinical diagnosis of $\mathrm{COPD}$, ratio of FEV1/FVC $<70 \%$ and a smoking history greater than 10 pack-years

Exclusion criteria: Patients with pulmonary disease other than COPD, including asthma, clinically significant bronchiectasis, interstitial lung disease, pleural disease, and previous history of thoracic surgery, such as lung resection or lung volume reduction surgery, were excluded. Patients requiring supplemental oxygen at rest or during exercise to prevent desaturation $(<85 \%)$ were also excluded. Patients with disorders that could impact their ability to participate in exercise testing, such as obesity (body mass index $>30 \mathrm{~kg} / \mathrm{m} 2$ ), and cardiovascular or musculoskeletal disease were excluded

\begin{tabular}{|c|c|c|}
\hline Interventions & \multicolumn{2}{|c|}{$\begin{array}{l}\text { 1. Tiotropium } 18 \text { bid (LAMA) } \\
\text { 2. Placebo (PBO) } \\
\text { Inhaler device: Spiriva HandiHaler } \\
\text { Allowed co-medications: Patients were allowed to continue taking other prescribed } \\
\text { medications, including long-acting } \beta \text {-sympathomimetic bronchodilators and inhaled } \\
\text { corticosteroids, with the same timing and dosage throughout the study }\end{array}$} \\
\hline Outcomes & \multicolumn{2}{|c|}{ exercise endurance measures, FEV1, SGRQ } \\
\hline Notes & \multicolumn{2}{|c|}{$\begin{array}{l}\text { Funding: Boehringer Ingelheim } \\
\text { Identifier(s): NCT00525512 }\end{array}$} \\
\hline \multicolumn{3}{|l|}{ Risk of bias } \\
\hline Bias & Authors' judgement & Support for judgement \\
\hline $\begin{array}{l}\text { Random sequence generation (selection } \\
\text { bias) }\end{array}$ & Low risk & $\begin{array}{l}\text { Randomised, methods unclear but indus- } \\
\text { try funded }\end{array}$ \\
\hline Allocation concealment (selection bias) & Unclear risk & Not described \\
\hline $\begin{array}{l}\text { Blinding of participants and personnel } \\
\text { (performance bias) } \\
\text { All outcomes }\end{array}$ & Low risk & Double blind \\
\hline
\end{tabular}

Blinding of outcome assessment (detection Unclear risk

Not described

All outcomes 


\begin{tabular}{|c|c|c|}
\hline $\begin{array}{l}\text { Incomplete outcome data (attrition bias) } \\
\text { All outcomes }\end{array}$ & High risk & $\begin{array}{l}\text { Overall dropout } 31.2 \% \text {, higher in the } \\
\text { placebo group }(37 \%) \text {. }\end{array}$ \\
\hline Selective reporting (reporting bias) & Low risk & $\begin{array}{l}\text { The published paper did not report out- } \\
\text { comes for the full multi-centre study, just } \\
\text { the feasibility phase. Full results posted on } \\
\text { cinicaltrials.gov were not found until after } \\
\text { the analysis had been conducted }\end{array}$ \\
\hline
\end{tabular}

\section{Dahl 2010}

Methods

Design: randomised double-blind double-dummy parallel-group study

Duration: 12 months (+ 2 weeks run-in period)

Location: Denmark, UK, Germany, Russia, USA (unclear how many centres)

Participants

Population: 1732 participants were randomised to formoterol (435), two doses of indacaterol (437 and 428) and placebo (432)

\section{Baseline characteristics}

Mean age (years): form 64, ind300 64, ind600 63, pbo 63

$\%$ Male: form 80.2, ind300 80.3, ind600 76.9, pbo 81.5

$\% \mathrm{FEV}_{1}$ predicted: form 52.5 , ind300 51.5, ind600 50.8, pbo 52.0

Pack-years: form 40, ind300 40, ind600 40, pbo 43

Inclusion criteria: males and females aged 40 and older; clinical diagnosis of moderate to severe COPD; history of at least 20 pack-years

Exclusion criteria: history of asthma; current respiratory tract infection or hospitalisation for COPD exacerbation within the previous 6 weeks

1. Formoterol 12 bid (LABA)

2. Indacaterol $300 \mathrm{qd}(\mathrm{LABA})$

3. Indacaterol $600 \mathrm{qd}(\mathrm{LABA})$

4. Placebo (PBO)

Inhaler device: dry powder turbuhaler and single dose dry powder inhaler

Allowed co-medications: Fixed-dose combinations of inhaled corticosteroids (ICS) plus LABA were replaced by monotherapy ICS at an equivalent dose and regimen plus salbutamol as needed. Participants receiving ICS monotherapy continued treatment at a stable dose throughout the study. Oral corticosteroids were not allowed, or a change in ICS was noted during the previous month

Outcomes

St George's Respiratory Questionnaire (SGRQ), COPD exacerbations, trough FEV 1 and PEF, dyspnoea (baseline and transition scores), diary card data, 6-minute walk test, ECG, vital signs and haematology

Notes

Funding: Novartis

Identifier(s): NCT00393458

Risk of bias 
Dahl 2010 (Continued)

\begin{tabular}{|c|c|c|}
\hline Bias & Authors' judgement & Support for judgement \\
\hline $\begin{array}{l}\text { Random sequence generation (selection } \\
\text { bias) }\end{array}$ & Low risk & $\begin{array}{l}\text { Randomised to treatment (1:1:1:1) with } \\
\text { stratification for smoking status (current/ } \\
\text { ex-smoker) using an automated interactive } \\
\text { system }\end{array}$ \\
\hline Allocation concealment (selection bias) & Low risk & $\begin{array}{l}\text { Using an automated interactive system } \\
\text { [concealment assumed by automatisation] }\end{array}$ \\
\hline $\begin{array}{l}\text { Blinding of participants and personnel } \\
\text { (performance bias) } \\
\text { All outcomes }\end{array}$ & Low risk & Double-blind double-dummy trial \\
\hline $\begin{array}{l}\text { Blinding of outcome assessment (detection } \\
\text { bias) } \\
\text { All outcomes }\end{array}$ & Low risk & $\begin{array}{l}\text { Protocol state double blind for sub- } \\
\text { ject, caregiver, investigator and outcomes } \\
\text { assessor http://www.clinicaltrials.gov/ct2/ } \\
\text { show/NCT00393458 }\end{array}$ \\
\hline $\begin{array}{l}\text { Incomplete outcome data (attrition bias) } \\
\text { All outcomes }\end{array}$ & High risk & $\begin{array}{l}\text { Efficacy results are presented for the mod- } \\
\text { ified intention-to-treat (ITT) population } \\
\text { including all randomised patients who re- } \\
\text { ceived at least one dose of study drug but } \\
\text { excluding patients from six sites owing to } \\
\text { non-conformance with good clinical prac- } \\
\text { tice. Withdrawal relatively high in both } \\
\text { groups (formoterol, 25.7; placebo } 31.7 \text { ) }\end{array}$ \\
\hline Selective reporting (reporting bias) & Low risk & $\begin{array}{l}\text { All stated and expected outcomes reported } \\
\text { in detail [exacerbation rates only presented } \\
\text { without imputation] }\end{array}$ \\
\hline
\end{tabular}

Dal Negro 2003

Methods

Participants
Design: Randomised, double-blind, parallel group, pilot study

Duration: 12 months (+ 2 week run-in)

Location: single centre in Italy

Population: 18 participants were randomised to salmeterol (6), salmeterol/fluticasone combination (6), and placebo (6)

\section{Baseline characteristics}

Mean age (years): ranged from 50 to 78 across groups, means not reported

$\%$ Male: salm 100, flut/salm 83.3, pbo 83.3

$\% \mathrm{FEV}_{1}$ predicted: salm 48.0, flut/salm 50.0, pbo 50.0

Pack-years: salm 43.1, flut/salm 40.1, pbo 42.7

Inclusion criteria: Basal FEV1 < 80\% predicted normal value, but $>800 \mathrm{ml}$; FEV1/FVC ratio $<70 \%$ predicted; a FEV1 change of $<12 \%$ as a percent of the predicted normal value following salbutamol $400 \mathrm{mg}$; regular treatment with oral theophylline $200 \mathrm{mg}$ 
Dal Negro 2003 (Continued)

bid and short acting b2-adrenergics prn for a period of at least 6 month; current or ex smokers with a smoking history of at least 10 pack-years

Exclusion criteria: Current evidence of asthma or other pulmonary diseases; regular treatment with ICS; unstable respiratory disease requiring oral/parenteral corticosteroids within 4 weeks prior to the beginning of the study; changes in COPD medication in the last 4 weeks before entering the run-in period; upper or lower respiratory tract infection within 4 weeks before the screening visit; unstable angina or unstable arrhythmias; recent myocardial infarction or hearth failure; insulin-dependent diabetes mellitus; neuropsychiatric disorders; concurrent use of medications that affected COPD (e.g. beta-blockers) or interacted with methylxanthine products such as macrolides or fluoroquinolones; known or suspected hypersensitivity to ICS, b2-agonist or lactose; evidence of alcohol abuse

Interventions

1. Salmeterol 50 bid (LABA)

2. Salmeterol/fluticasone $50 / 250$ bid (LABA/ICS)

2. Placebo (PBO)

Inhaler device: Diskus

Allowed co-medications: Theophylline and salbutamol as required

Outcomes

Exacerbations per year, FEV1, morning PEF, daily symptom scores, use of rescue medication and adverse events

Notes

Funding: Unclear

Identifier(s): unknown

\section{Risk of bias}

Bias

Random sequence generation (selection Unclear risk bias)
Authors' judgement

(

.


Dal Negro 2003 (Continued)

Selective reporting (reporting bias) High risk

Several key outcomes not reported (mortality, adverse events). Difficulty contacting authors

Doherty 2012

Methods

Design: randomised, double-blind, placebo-controlled trial

Duration: 6 months (+ 2 weeks run-in period)

Location: 164 centres in North, Central and South America, Europe, Africa and Asia

Participants

Population: 1196 participants were randomised to formoterol (243), mometasone (253) , formoterol combination therapy at two doses (225 and 239), and placebo (236)

Baseline characteristics

Age (mean years): form 59.7, mom 60.5, form $/ \mathrm{mom} 400$ 59.2, form/mom200 60.1, pbo, 58.8

\% Male: form 74.9, mom 77.9, form/mom 400 74.7, form/mom 20073.2 , pbo, 75.4

$\% \mathrm{FEV}_{1}$ predicted: form 38.2, mom 40.2, form/mom400 38.1, form/mom200 38.7, pbo, 38.0

Pack-years (mean): form 45.9, mom 41.1, form/mom400 54.8, form/mom200 40.3, pbo, 43.5

Inclusion criteria: males and females aged 40 and older; $\mathrm{FEV}_{1} / \mathrm{FVC}<70 \%$; PFEV $25 \%$ to $60 \%$; COPD symptoms for at least 24 months; history of at least 10 pack-years

Exclusion criteria: current diagnosis of asthma; marked bronchodilator reversibility; recent COPD exacerbation; history of lung cancer/surgery; other significant medical illness

Interventions

1. Formoterol 10 bid (LABA)

2. Mometasone 400 bid (ICS)

3. Formoterol/mometasone $10 / 400$ bid (LABA/ICS)

4. Formoterol/mometasone $10 / 200$ bid (LABA/ICS)

5. Placebo (PBO)

Inhaler device: metered dose

Allowed co-medications: open-label, short-acting beta2-agonist (SABA)/short-acting anticholinergic combination was allowed. All long-acting COPD treatments (LABA, inhaled corticosteroids, LABA/ICS FDC or long-acting anticholinergics) were disallowed

Outcomes

St George's Respiratory Questionnaire (including number reaching a minimally clinically important difference), COPD exacerbations, $\mathrm{FEV}_{1}$ area under the curve from 0 to 12 hours post-dose, trough $\mathrm{FEV}_{1}$ (not for LABA placebo comparison), diary card data

Notes

Funding: Merck \& Co

Identifier(s): NCT00383721

\section{Risk of bias}

Bias

Authors' judgement

Support for judgement

Long-acting inhaled therapy (beta-agonists, anticholinergics and steroids) for COPD: a network meta-analysis (Review) 
Doherty 2012 (Continued)

\begin{tabular}{|c|c|c|}
\hline $\begin{array}{l}\text { Random sequence generation (selection } \\
\text { bias) }\end{array}$ & Low risk & $\begin{array}{l}\text { Subjects were randomized in a } 1: 1: 1: 1: 1 \mathrm{ra}- \\
\text { tio [industry sponsored] }\end{array}$ \\
\hline Allocation concealment (selection bias) & Unclear risk & $\begin{array}{l}\text { Subjects who discontinued early were not } \\
\text { replaced [no other details given] }\end{array}$ \\
\hline $\begin{array}{l}\text { Blinding of participants and personnel } \\
\text { (performance bias) } \\
\text { All outcomes }\end{array}$ & Low risk & $\begin{array}{l}\text { Double-blind, double-dummy. Protocol } \\
\text { states subjects and investigators were blind }\end{array}$ \\
\hline $\begin{array}{l}\text { Blinding of outcome assessment (detection } \\
\text { bias) } \\
\text { All outcomes }\end{array}$ & Unclear risk & $\begin{array}{l}\text { Protocol and paper do not provide details } \\
\text { about blinding of outcome assessors }\end{array}$ \\
\hline $\begin{array}{l}\text { Incomplete outcome data (attrition bias) } \\
\text { All outcomes }\end{array}$ & Low risk & $\begin{array}{l}\text { Withdrawal rates were quite different (for- } \\
\text { moterol } 20.6 \% \text {; placebo } 28.4 \% \text { ) but effi- } \\
\text { cacy analyses and safety summaries were } \\
\text { based on the intent-to-treat principle for all } \\
\text { randomized subjects }\end{array}$ \\
\hline Selective reporting (reporting bias) & High risk & $\begin{array}{l}\text { Quality of life [primary outcome] was not } \\
\text { reported in a way that could be analysed for } \\
\text { the comparison in question. All other stated } \\
\text { and expected outcomes were reported and } \\
\text { analysed }\end{array}$ \\
\hline
\end{tabular}

\section{Donohue 2010 [INHANCE]}

\begin{tabular}{|c|c|}
\hline Methods & $\begin{array}{l}\text { Design: This study was performed in two stages in an adaptive seamless design. In stage } \\
1 \text {, patients were randomized to receive indacaterol } 75,150,300 \text {, or } 600 \mathrm{mg} \text { once daily, } \\
\text { formoterol } 12 \mathrm{mg} \text { twice daily, or placebo, all double-blind, or open-label tiotropium } 18 \\
\text { mg once daily. } \\
\text { An independent committee used predefined efficacy criteria to select two indacaterol } \\
\text { doses based on } 2 \text {-week efficacy and safety data. As reported elsewhere, the two indacaterol } \\
\text { doses selected were } 150 \text { and } 300 \mathrm{mg}(18) \text {. In stage } 2 \text {, the four treatment groups were the } \\
\text { two selected doses of indacaterol, tiotropium, and placebo. Treatment continued to } 26 \\
\text { weeks, with additional patients recruited and randomized } \\
\text { Duration: } 26 \text { weeks (+ } 2 \text { week run-in) } \\
\text { Location: } 345 \text { centres in } 12 \text { countries }\end{array}$ \\
\hline Participants & $\begin{array}{l}\text { Population: } 1683 \text { participants were randomised to indacaterol at two doses ( } 416 \text { and } \\
\text { 416), open-label tiotropium (415), and placebo ( } 418 \text { ) } \\
\text { Baseline characteristics } \\
\text { Age (mean years): ind } 15063.4 \text {, ind } 30063.3 \text {, tio } 64.0 \text {, pbo } 63.6 \\
\% \mathrm{Male}_{\text {ind } 150} 62.3 \text {, ind } 30063.2 \text {, tio } 64.8 \text {, pbo } 61.0 \\
\% \mathrm{FEV}_{1} \text { predicted: ind150 56.1, ind } 30056.3 \text {, tio } 53.9 \text {, pbo } 56.1 \\
\text { Pack-years (mean): ind } 15048.3 \text {, ind } 30050.8 \text {, tio } 50.0 \text {, pbo } 49.7 \\
\text { Inclusion criteria: Male and female adults aged } \geq 40 \text { years, who have signed an In- }\end{array}$ \\
\hline
\end{tabular}

Long-acting inhaled therapy (beta-agonists, anticholinergics and steroids) for COPD: a network meta-analysis (Review) 


\section{Donohue 2010 [INHANCE] (Continued)}

formed Consent Form prior to initiation of any study-related procedure. Co-operative outpatients with a diagnosis of COPD (moderate to severe as classified by the Global Initiative for Chronic Obstructive Pulmonary Disease (GOLD) Guidelines, 2005) and smoking history of at least 20 pack yearsPost-bronchodilator FEV1 $<80 \%$ and $\geq 30 \%$ of the predicted normal value. Post-bronchodilator FEV1/FVC $<70 \%$ (Post refers to within $30 \mathrm{~min}$ of inhalation of $400 \mu \mathrm{g}$ of salbutamol)

Exclusion criteria: lactating females; hospitalised for a COPD exacerbation in the 6 weeks prior to Visit 1 or during the run-in period; requiring long term oxygen therapy (> $15 \mathrm{~h}$ a day); respiratory tract infection 6 weeks prior to $\mathrm{V} 1$; concomitant pulmonary disease, pulmonary tuberculosis, or clinically significant bronchiectasis; history of asthma; Type I or uncontrolled Type II diabetes; contraindications for tiotropium; clinically relevant laboratory abnormalities or a clinically significant abnormality; active cancer or a history of cancer with less than 5 years disease free survival time; history of long QT syndrome or whose QTc interval is prolonged; hypersensitivity to any of the study drugs or drugs with similar chemical structures; treatment with the investigational drug (with further criteria); live attenuated vaccinations within 30 days prior to visit 1 , or during run-in period; known history of non compliance to medication; unable to satisfactorily use a dry powder inhaler device or perform spirometry measurements

Interventions
1. Indacaterol $150 \mathrm{qd}$ (LABA)
2. Indacaterol $300 \mathrm{qd}$ (LABA)
3. Tiotropium $18 \mathrm{qd}$ (LAMA) - open-label
4. Placebo (PBO)
Inhaler device: 1,2 , and 4 via single-dose dry powder inhaler, open-label tiotropium
via HandiHaler
Allowed co-medications: Patients could continue inhaled corticosteroid (ICS)
monotherapy if stable for 1 month before screening; dose and regimen were to remain
stable throughout the study. Before the start of the run-in period, treatment with an-
ticholinergic bronchodilators or with $\beta 2$-agonists was discontinued with appropriate
washout, and patients receiving fixed-combination $\beta 2$-agonist/ICS were switched to ICS
monotherapy at an equivalent dose. All patients were supplied with albuterol for use as
needed

The primary efficacy outcome was trough FEV1 at 12 weeks. Additional analyses (not adjusted for multiplicity) included transition dyspnoea index (TDI), health status (St George's Respiratory Questionnaire [SGRQ]), and exacerbations. Serum potassium, blood glucose, and QTc interval were measured

\section{Risk of bias}

Random sequence generation (selection Low risk bias)
Randomization was performed using an automated interactive voice response system, and was stratified by smoking status (current or ex-smoker) 


\section{Donohue 2010 [INHANCE] (Continued)}

\begin{tabular}{|c|c|c|}
\hline Allocation concealment (selection bias) & Low risk & Interactive voice response system \\
\hline $\begin{array}{l}\text { Blinding of participants and personnel } \\
\text { (performance bias) } \\
\text { All outcomes }\end{array}$ & High risk & $\begin{array}{l}\text { Blinding procedures were sound, but } \\
\text { tiotropium was delivered open label which } \\
\text { introduced bias for these comparisons } \\
\text { On completion of stage 1, the independent } \\
\text { dose selection committee had access to un- } \\
\text { blinded data. The only information com- } \\
\text { municated with the sponsor and investiga- } \\
\text { tors was the two selected indacaterol doses, } \\
\text { and personnel involved in the continuing } \\
\text { clinical study remained blinded for the re- } \\
\text { mainder of the study. } \\
\text { The blinding of indacaterol and placebo } \\
\text { continued until the study database was } \\
\text { locked at the end of stage } 2\end{array}$ \\
\hline $\begin{array}{l}\text { Blinding of outcome assessment (detection } \\
\text { bias) } \\
\text { All outcomes }\end{array}$ & Low risk & $\begin{array}{l}\text { Blinding procedures were sound, but } \\
\text { tiotropium was delivered open label which } \\
\text { introduced bias for these comparisons. } \\
\text { Double Blind (Subject, Caregiver, Inves- } \\
\text { tigator, Outcomes Assessor) [clinicaltrials. } \\
\text { gov] }\end{array}$ \\
\hline $\begin{array}{l}\text { Incomplete outcome data (attrition bias) } \\
\text { All outcomes }\end{array}$ & Low risk & $\begin{array}{l}\text { Efficacy was evaluated for the intention-to- } \\
\text { treat population, comprising all random- } \\
\text { ized patients who received at least one dose } \\
\text { of study } \\
\text { drug. Dropout was variable and generally } \\
\text { high across groups (ranging from } 18 \text { to } \\
31 \%) .98 .9 \% \text { were included in the analysis }\end{array}$ \\
\hline Selective reporting (reporting bias) & Low risk & $\begin{array}{l}\text { Study was prospectively registered, and all } \\
\text { results were available from the published } \\
\text { reports and clinicaltrials.gov }\end{array}$ \\
\hline
\end{tabular}

\section{Dusser 2006}

$\begin{array}{ll}\text { Methods } & \text { Design: parallel group, double-blind, randomized, placebo-controlled study } \\ \text { Duration: } 48 \text { weeks }(+3 \text { week screening visit }) & \text { Location: } 177 \text { centres in France }\end{array}$

Participants

Population: 1010 participants were randomised to tiotropium (500) and placebo (510) Baseline characteristics

Age (mean years): tio 64.5, pbo 65.0

$\%$ Male: tio 89 , pbo 87

$\% \mathrm{FEV}_{1}$ predicted: tio 48.2 , pbo 47.6

Pack-years (mean): not reported 
Dusser 2006 (Continued)

Inclusion criteria: Male and female patients aged $>40$ yrs old with a clinical diagnosis of COPD (pre-bronchodilator FEV1 30-65\% predicted and FEV1/slow vital capacity (SVC) $<70 \%$ pred) were eligible for inclusion in the study. Participants were also required to have a smoking history of $>10$ pack-yrs and one or more exacerbations in the last year (as reported in the patient's medical file), but not within the 6 weeks prior to entering the

\section{study.}

Exclusion criteria: history of asthma, allergic rhinitis or atopy; a recent lower respiratory tract infection or any exacerbation (within the previous 6 weeks); regular use of daytime oxygen therapy; oral corticosteroid use at unstable doses 6 weeks prior to entering the study or at a dose exceeding the equivalent of $10 \mathrm{mg}$ prednisone daily. In addition, those patients with a significant disease other than COPD that would put the patient at risk because of participation in the study, or a disease that would influence the results of the study, were not enrolled

Interventions

1. Tiotropium 18 qd (LAMA)

2. Placebo (PBO

Inhaler device: HandiHaler

Allowed co-medications: Patients were permitted short-acting b2-agonists, as needed, for acute symptom relief. Concomitant use of inhaled corticosteroids (ICS) and oral steroids (at a dose of ,10 mg prednisone daily or equivalent) was allowed if the dosage was stable for $>6$ weeks before study entry. To treat COPD exacerbations during the trial, the investigators were permitted to administer any additional medication deemed necessary (excluding anticholinergics and long-acting b2-agonists). During the treatment period, patients were not allowed to use oral or inhaled long-acting b2-agonists, inhaled anticholinergics (other than the study drug) or theophylline

Outcomes

Primary endpoint was morning PEFR. Secondary endpoints were incidence, severity and duration of exacerbations, use of rescue medications, number of lost working days, number of days of hospitalisations, number of short courses of steroids/antibiotics, spirometric parameters at clinic visits, viral characterisation of severe exacerbations

Notes

Funding: Boehringer Ingelheim

Identifier(s): 205.214

\section{Risk of bias}

\section{Bias}

Random sequence generation (selection Low risk bias)

\begin{tabular}{l|l}
\hline Allocation concealment (selection bias) & Unclear risk \\
\hline $\begin{array}{l}\text { Blinding of participants and personnel } \\
\text { (performance bias) }\end{array}$ & Low risk \\
All outcomes &
\end{tabular}

\section{Support for judgement}

Randomised 1:1, methods not described but industry funded

Not described

Double-blind, treatment and placebo were both delivered via the HandiHaler 
Dusser 2006 (Continued)

\begin{tabular}{|c|c|c|}
\hline $\begin{array}{l}\text { Blinding of outcome assessment (detection } \\
\text { bias) } \\
\text { All outcomes }\end{array}$ & Unclear risk & Not described \\
\hline $\begin{array}{l}\text { Incomplete outcome data (attrition bias) } \\
\text { All outcomes }\end{array}$ & Low risk & $\begin{array}{l}\text { More patients in the tiotropium group } \\
\text { completed the trial than those in the } \\
\text { placebo group ( } 76.6 \% \text { versus } 71.2 \% \text { ). An } \\
\text { intent-to-treat (ITT), last-observation-car- } \\
\text { ried forward (LOCF) method was used } \\
\text { for spirometric end-point analyses, except } \\
\text { when patients discontinued due to worsen- } \\
\text { ing COPD, when the least favourable data } \\
\text { prior to discontinuation were carried for- } \\
\text { ward. All randomised patients with baseline } \\
\text { and post-treatment data who took at least } \\
\text { one capsule of study drug were included in } \\
\text { the primary data set }\end{array}$ \\
\hline Selective reporting (reporting bias) & Low risk & $\begin{array}{l}\text { Data were available for the outcomes stated } \\
\text { in the industry protocol }\end{array}$ \\
\hline
\end{tabular}

Fang 2008

Methods

Design: randomised, parallel-group, controlled study

Duration: 12 months (+ 2 week run-in)

Location: outpatients and inpatients of The First Affiliated Hospital of Kunming Medical Collage, China

Participants

Population: 126 participants were included in the per protocol analysis: tiotropium (32) , salmeterol/fluticasone combination therapy (32), and two other arms that were not relevant to this review (salmeterol/fluticasone combination plus tiotropium, 33; and a blank control group, 29). Actual numbers randomised are unclear

Baseline characteristics

Age (mean years): tio 63, salm/flut 62

$\%$ Male: tio 70 . salm/flut 77.5

$\% \mathrm{FEV}_{1}$ predicted: not reported

Pack-years (mean): not reported

Inclusion criteria: $\mathrm{FEV}_{1}$ is $25 \%$ to $70 \%$ predicted pre-bronchodilator; $\mathrm{FEV}_{1} / \mathrm{FVC}<$ $70 \% ; \mathrm{FEV}_{1}$ increased by $<15 \%$ predicted post-bronchodilator $(400 \mu \mathrm{g}$ salbutamol).

Exclusion criteria: diseases other than COPD; need long-term oxygen therapy; currently receiving system hormone therapy

Interventions

1. Tiotropium 18 qd (LAMA)

2. Salmeterol/fluticasone $50 / 250$ bid (LABA/ICS)

Inhaler device: unclear

Allowed co-medications: unclear, other than rescue medication

Long-acting inhaled therapy (beta-agonists, anticholinergics and steroids) for COPD: a network meta-analysis (Review) 
Fang 2008 (Continued)

Outcomes

FVC, $\mathrm{FEV}_{1}$, PEF, worsening (judged by counting the use of hormone or antibiotics amount; St. George's Respiratory Questionnaire (SGRQ); adverse events

$\begin{array}{ll}\text { Notes } & \text { Funding: unknown } \\ & \text { Identifier(s): none }\end{array}$

Risk of bias

\begin{tabular}{|c|c|c|}
\hline Bias & Authors' judgement & Support for judgement \\
\hline $\begin{array}{l}\text { Random sequence generation (selection } \\
\text { bias) }\end{array}$ & Low risk & Random number table was used \\
\hline Allocation concealment (selection bias) & Unclear risk & Not described \\
\hline $\begin{array}{l}\text { Blinding of participants and personnel } \\
\text { (performance bias) } \\
\text { All outcomes }\end{array}$ & High risk & $\begin{array}{l}\text { Blinding not mentioned, treatment group } \\
\text { translated as 'blank' therefore assumed not } \\
\text { blinded }\end{array}$ \\
\hline $\begin{array}{l}\text { Blinding of outcome assessment (detection } \\
\text { bias) } \\
\text { All outcomes }\end{array}$ & Unclear risk & Not described \\
\hline $\begin{array}{l}\text { Incomplete outcome data (attrition bias) } \\
\text { All outcomes }\end{array}$ & High risk & $\begin{array}{l}\text { Intention-to-treat analysis }(\mathrm{n}=161) \text { and } \\
\text { per-protocol analysis }(\mathrm{n}=126 \text {, age } 45-71 \\
\text { years) were performed. The abstract refers } \\
\text { to the per-protocol analysis (representing } \\
78 \% \text { of the ITT, and presumably less of the } \\
\text { total randomised population) }\end{array}$ \\
\hline Selective reporting (reporting bias) & Unclear risk & $\begin{array}{l}\text { Could not locate protocol to check out- } \\
\text { come reporting }\end{array}$ \\
\hline
\end{tabular}

Ferguson 2008

Methods

Design: Randomized, double-blind, parallel-group study

Duration: 12 months (+ 4 week run-in)

Location: 94 research sites in the United States and Canada

Participants

Population: 782 people were randomised to salmeterol (388) and fluticasone/salmeterol combination (394)

Baseline characteristics

Age (mean years): salm 65.0, flut/salm 64.9

$\%$ Male: salm 52, flut/salm 58

$\% \mathrm{FEV}_{1}$ predicted: salm 32.8, flut/salm 32.8

Pack-years (mean): salm 54.4, flut/salm 58.5

Inclusion criteria: 40 years of age or older with a diagnosis of COPD a cigarette smoking history of greater than or equal to 10 pack-years, a pre-albuterol FEV1/FVC of 0.70 or 
less, a FEV 1 of $50 \%$ of predicted normal or less and a history of 1 or more exacerbations of COPD in the year prior to the study that required treatment with oral corticosteroids, antibiotics, or hospitalisation.

Exclusion criteria: diagnosis of asthma, a significant lung disease other than COPD, a clinically significant and uncontrolled medical disorder including but not limited to cardiovascular, endocrine or metabolic, neurological, psychiatric, hepatic, renal, gastric, and neuromuscular diseases, or had a COPD exacerbation that was not resolved at screening

\begin{tabular}{l|l} 
Interventions & $\begin{array}{l}\text { 1. Salmeterol } 50 \text { bid (LABA) } \\
\text { 2. Salmeterol/fluticasone 50/250 bid (LABA/ICS) } \\
\text { Inhaler device: Diskus dry powder } \\
\text { Allowed co-medications: As-needed albuterol } \\
\text { study. The use of concurrent inhaled long-acting b } \\
\text { ticholinergic), ipratropium/albuterol combination } \\
\text { corticosteroids, and theophylline preparations wer } \\
\text { riod. Oral corticosteroids and antibiotics were allowe } \\
\text { exacerbations }\end{array}$ \\
\hline Outcomes & $\begin{array}{l}\text { COPD exacerbations, pre-dose FEV1, diary recor } \\
\text { due to COPD, and use of supplemental albutero }\end{array}$ \\
\hline Notes & $\begin{array}{l}\text { Funding: GlaxoSmithKline } \\
\text { Identifier(s): NCT00144911, GSK SCO40043 }\end{array}$
\end{tabular}

Risk of bias

Bias

Authors' judgement

Support for judgement

Random sequence generation (selection Low risk

Centre based randomisation schedule bias)

\begin{tabular}{lll}
\hline Allocation concealment (selection bias) & Unclear risk & Not described \\
\hline $\begin{array}{l}\text { Blinding of participants and personnel } \\
\text { (performance bias) } \\
\text { All outcomes }\end{array}$ & Low risk & $\begin{array}{l}\text { Described as double-blind [presumed par- } \\
\text { ticipants and personnel/investigators] }\end{array}$ \\
\hline
\end{tabular}

\begin{tabular}{l|l|l}
\hline $\begin{array}{l}\text { Blinding of outcome assessment (detection } \\
\text { bias) } \\
\text { All outcomes }\end{array}$ & Unclear risk & Not described \\
\hline $\begin{array}{l}\text { Incomplete outcome data (attrition bias) } \\
\text { All outcomes }\end{array}$ & High risk & $\begin{array}{l}\text { Dropout high and fairly even (30\% vs. } \\
38 \%) \text { Method of imputation only de- } \\
\text { scribed for the primary outcome ('End- } \\
\text { point was defined as the last scheduled mea- } \\
\text { surement of pre-dose AM FEV1 during the } \\
52 \text {-week treatment period') }\end{array}$
\end{tabular}


Ferguson 2008 (Continued)

Selective reporting (reporting bias) Low risk

Checked GSK documents - all stated and expected outcomes are reported

FLTA3025

Methods

Design: randomised, double-blind, parallel-group, comparative trial

Duration: 6 months (+ 2 week run-in)

Location: 55 centres in the United States

Participants

Population: 640 people were randomised to two doses of fluticasone (216 and 218), and placebo (206)

Baseline characteristics

Age (mean years): flut 250 65.2, flut500 63.3, placebo 64.8

\% Male: flut250 72.2, flut500 66.1, placebo 68.0

$\% \mathrm{FEV}_{1}$ predicted: not reported

Pack-years (mean): not reported

Inclusion criteria: Male or female subjects were eligible if they: were diagnosed with COPD; were at least 40 years of age; had a current or prior history of at least 20 packyears of cigarette smoking; had a history of cough productive of sputum on most days for at least 3 months of the year, for at least 2 years, that was not attributable to another disease process; had a baseline FEV1 $<65 \%$ of predicted normal but $>0.70 \mathrm{~L}$ or FEV1 $\leq 0.70 \mathrm{~L}$ and $>40 \%$ of predicted normal and FEV1/forced vital capacity (FVC) ratio of $<0.70$; had a score of $\geq 2$ on the Modified Medical Research Council (MMRC) Dyspnea Scale at screening and a score of $\geq 4$ on the CBSQ at randomisation, and had not received systemic corticosteroids or high-dose inhaled corticosteroid therapy for at least 6 months prior to screening

Exclusion criteria: Current diagnosis of asthma, concurrent participation in a pulmonary rehabilitation program, a respiratory disease other than COPD or other significant concurrent disease, an abnormal and clinically significant ECG at screening, and the occurrence of a moderate or severe COPD exacerbation during the run-in period

Interventions

Population:

1. Fluticasone 250 bid (ICS)

2. Fluticasone 500 bid (ICS)

3. Placebo (PBO)

Inhaler device: Diskus dry powder

Allowed co-medications: Concurrent use of the following respiratory medications was not allowed: beta-agonists (other than salbutamol), cromolyns, corticosteroids (oral, inhaled, and intranasal), anti-leukotrienes, and ipratropium. Concurrent use of theophylline was allowed. Use of antibiotics for the treatment of up to three COPD exacerbations was allowed

Outcomes

Morning pre-dose FEV1, Chronic Bronchitis Symptoms Questionnaire (CBSQ), Transition Dyspnoea Index (TDI, exacerbations of COPD, subject-recorded daily morning PEF rate, supplemental salbutamol use, night-time awakenings and quality of life (CDRQ) 
FLTA3025 (Continued)

\begin{tabular}{|c|c|c|}
\hline Notes & $\begin{array}{l}\text { Funding: GlaxoSmithKline } \\
\text { Identifier(s): GSK FLTA3025 }\end{array}$ & \\
\hline \multicolumn{3}{|l|}{ Risk of bias } \\
\hline Bias & Authors' judgement & Support for judgement \\
\hline $\begin{array}{l}\text { Random sequence generation (selection } \\
\text { bias) }\end{array}$ & Low risk & $\begin{array}{l}\text { Randomised trial [GSK funded, likely to } \\
\text { be computerised randomisation schedule] }\end{array}$ \\
\hline Allocation concealment (selection bias) & Unclear risk & Not described \\
\hline $\begin{array}{l}\text { Blinding of participants and personnel } \\
\text { (performance bias) } \\
\text { All outcomes }\end{array}$ & Low risk & $\begin{array}{l}\text { Double-blinded trial [presumed partici- } \\
\text { pant and personnel/investigator] }\end{array}$ \\
\hline $\begin{array}{l}\text { Blinding of outcome assessment (detection } \\
\text { bias) } \\
\text { All outcomes }\end{array}$ & Unclear risk & Not described \\
\hline $\begin{array}{l}\text { Incomplete outcome data (attrition bias) } \\
\text { All outcomes }\end{array}$ & Low risk & $\begin{array}{l}\text { Dropout high but even across groups. The } \\
\text { Intent-to-Treat (ITT) population consisted } \\
\text { of all randomized subjects who received at } \\
\text { least } 1 \text { dose of study medication. The ITT } \\
\text { population was the primary population for } \\
\text { all efficacy and safety analyses }\end{array}$ \\
\hline Selective reporting (reporting bias) & Low risk & $\begin{array}{l}\text { All outcomes were reported in the results } \\
\text { summary }\end{array}$ \\
\hline
\end{tabular}

Gelb 2012

Methods

Design: randomised, double-blind, dose-comparison study

Duration: 52 weeks (run-in unclear)

Location: unclear number of centres

Participants

Population: 605 participants were randomised to two doses of aclidinium bromide (310 and 290)

Baseline characteristics

Age (mean years): not reported

$\%$ Male: not reported

$\% \mathrm{FEV}_{1}$ predicted: acl200 47.5, acl400 45.5

Pack-years (mean): not reported

Inclusion criteria: unclear, abstracts only

Exclusion criteria: unclear, abstracts only 
Gelb 2012 (Continued)

\begin{tabular}{|c|c|c|}
\hline Interventions & \multicolumn{2}{|c|}{$\begin{array}{l}\text { 1. Aclidinium } 200 \text { bid (LAMA) } \\
\text { 2. Aclidinium } 400 \text { bid (LAMA) } \\
\text { Inhaler device: unclear } \\
\text { Allowed co-medications: unclear }\end{array}$} \\
\hline Outcomes & \multicolumn{2}{|c|}{$\begin{array}{l}\text { The primary endpoint was change from baseline to Week } 52 \text { in trough FEV1. Other } \\
\text { efficacy parameters included change from baseline to Week } 52 \text { in peak FEV1, trough } \\
\text { and peak FEV1 by study visit, normalized FEV1AUC0-3, and change from baseline to } \\
\text { Week } 52 \text { in SGRQ and EuroQol scores }\end{array}$} \\
\hline Notes & \multicolumn{2}{|c|}{$\begin{array}{l}\text { Funding: Forest and Almirall } \\
\text { Identifier(s): unknown }\end{array}$} \\
\hline \multicolumn{3}{|l|}{ Risk of bias } \\
\hline Bias & Authors' judgement & Support for judgement \\
\hline $\begin{array}{l}\text { Random sequence generation (selection } \\
\text { bias) }\end{array}$ & Low risk & $\begin{array}{l}\text { Patients were randomized (1:1) to receive } \\
\text { aclidinium } 200 \mu \mathrm{g} \text { or } 400 \mu \mathrm{g} \text { BID in a } \\
\text { double-blind manner }\end{array}$ \\
\hline Allocation concealment (selection bias) & Unclear risk & Not described \\
\hline $\begin{array}{l}\text { Blinding of participants and personnel } \\
\text { (performance bias) } \\
\text { All outcomes }\end{array}$ & Low risk & $\begin{array}{l}\text { Treatments were delivered in a double- } \\
\text { blind manner }\end{array}$ \\
\hline $\begin{array}{l}\text { Blinding of outcome assessment (detection } \\
\text { bias) } \\
\text { All outcomes }\end{array}$ & Unclear risk & Not described \\
\hline $\begin{array}{l}\text { Incomplete outcome data (attrition bias) } \\
\text { All outcomes }\end{array}$ & Unclear risk & $\begin{array}{l}\text { Not enough information in abstracts to } \\
\text { make a judgement }\end{array}$ \\
\hline Selective reporting (reporting bias) & High risk & $\begin{array}{l}\text { Minimal information available. Full trial } \\
\text { report could not be located }\end{array}$ \\
\hline
\end{tabular}

\section{GLOW1 2011}

Methods

Design: double-blind, placebo-controlled study

Duration: 26 weeks (+ 7 day pre-screening period and 14 day run-in)

Location: 97 centres in 11 countries

Participants

Population: 822 participants were randomised to glycopyrronium (552) and placebo (270)

\section{Baseline characteristics}

Age (mean years): gly 63.8, pbo 64.0

$\%$ Male: gly 82.5 , pbo 80.5 


\% FEV 1 predicted: gly 54.8, pbo 54.3
Pack-years (mean): gly 44.9, pbo 44.6
Inclusion criteria: Patients with COPD with a smoking history of $>10$ pack-years, post-
bronchodilator forced expiratory volume in 1 second (FEV1) $<80 \%$ and . $30 \%$ predicted
normal and FEV1/forced vital capacity $<0.70$
Exclusion criteria: lower respiratory tract infection within 6 weeks, concomitant pul-
monary disease, history of asthma, lung cancer or long QT syndrome or QTc $>450$ ms
(males) or $>470$ (females), symptomatic prostatic hyperplasia, bladder-neck obstruc-
tion, moderate/ severe renal impairment, urinary retention, narrow angle glaucoma and
history of alpha-1 antitrypsin deficiency. Patients were also excluded if they were partic-
ipating in a supervised pulmonary rehabilitation programme, had contraindications for
tiotropium or ipratropium or had experienced adverse reactions to inhaled anticholin-
ergics

Interventions

1. Glycopyrronium bromide 50 qd (LAMA)

2. Placebo (PBO)

Inhaler device: low-resistance single-dose dry-powder inhaler (Breezhaler)

Allowed co-medications: inhaled/intranasal corticosteroids and $\mathrm{H} 1$ antagonists were permitted in patients stabilized on them prior to study entry. Patients were required to cease taking long-acting bronchodilator therapy before beginning the run-in period

Outcomes

The primary outcome measure was trough FEV1 at Week 12 . Secondary outcome measures included breathlessness on the transition dyspnoea index (TDI) and health-related quality of life (HRQoL) according to the St. George's Respiratory Questionnaire (SGRQ) at Week 26, time to first moderate or severe COPD exacerbation and mean daily rescue medication use over 26 weeks

$\begin{array}{ll}\text { Notes } & \text { Funding: Novartis } \\ & \text { Identifier(s): NCT01005901 }\end{array}$

Risk of bias

\begin{tabular}{lll}
\hline Bias & Authors' judgement & Support for judgement \\
\hline $\begin{array}{l}\text { Random sequence generation (selection } \\
\text { bias) }\end{array}$ & Low risk & $\begin{array}{l}\text { randomized in a 2:1 ratio [sequence gen- } \\
\text { eration not described, but industry funded } \\
\text { so presumed electronic] }\end{array}$ \\
\hline $\begin{array}{l}\text { Allocation concealment (selection bias) } \\
\begin{array}{l}\text { Blinding of participants and personnel } \\
\text { (performance bias) } \\
\text { All outcomes }\end{array}\end{array}$ & Low risk & Not described \\
\hline
\end{tabular}

Blinding of outcome assessment (detection Low risk bias)

All outcomes
Double Blind (Subject, Caregiver, Investigator, Outcomes Assessor) [clinicaltrials. gov] 


\begin{tabular}{|l|l|l|l|l}
\hline $\begin{array}{l}\text { Incomplete outcome data (attrition bias) } \\
\text { All outcomes }\end{array}$ & Low risk & $\begin{array}{l}\text { Dropout was relatively even and around } \\
20 \% \text { in both groups. Efficacy was based on } \\
\text { centralized spirometry and assessed in the } \\
\text { full analysis set (FAS), which included all } \\
\text { randomized patients who received at least } \\
\text { one dose of study drug; patients were anal- } \\
\text { ysed according to the }\end{array}$ \\
treatment to which they were randomized. \\
The last observation of pre-dose trough \\
FEV1 was carried forward (LOCF) for \\
missing values
\end{tabular}

\section{GLOW2 2012}

Methods
Design: Multi-centre, double-blind, placebo-controlled with open-label tiotropium arm, parallel group study

Duration: 52 weeks ( +7 day pre-screening period and 14 day run-in

Location: 139 centres in 16 countries

Participants

Population: 1066 participants were randomised to glycopyrronium (529), open-label tiotropium (268), and placebo (269)

\section{Baseline characteristics}

Age (mean years): gly 63.5, tio 63.9, pbo 63.6

\% Male: gly 64.6, tio 62.9, pbo 64.6

$\% \mathrm{FEV}_{1}$ predicted: gly 55.7 , tio 56.0 , pbo 56.4

Pack-years (mean): gly 49.0, tio 50.2, pbo 48.0

Inclusion criteria: Patients with COPD with a smoking history of $>10$ pack-years, postbronchodilator forced expiratory volume in 1 second (FEV1) $<80 \%$ and . 30\% predicted normal and FEV1/forced vital capacity $<0.70$

Exclusion criteria: lower respiratory tract infection within 6 weeks, concomitant pulmonary disease, history of asthma, lung cancer or long QT syndrome or QTc > $450 \mathrm{~ms}$ (males) or $>470$ (females), symptomatic prostatic hyperplasia, bladder-neck obstruction, moderate/ severe renal impairment, urinary retention, narrow angle glaucoma and history of alpha-1 antitrypsin deficiency. Patients were also excluded if they were participating in a supervised pulmonary rehabilitation programme, had contraindications for tiotropium or ipratropium or had experienced adverse reactions to inhaled anticholinergics

Interventions

1. Glycopyrronium 50 qd (LAMA)

2. Tiotropium 18 qd (LAMA) - open-label

3. Placebo (PBO)

Inhaler device: Glycopyrronium and placebo were delivered via theBreezhaler, Tiotropium was delivered open-label via the HandiHaler

Allowed co-medications: In addition to the study treatment, concomitant medications 
GLOW2 2012 (Continued)

(inhaled or intranasal corticosteroids and $\mathrm{H} 1$ antagonists) were permitted in patients who had been stabilised on a recommended and constant dose prior to study entry. Patients were provided with a salbutamol/albuterol inhaler to be used as rescue medication during the study

Outcomes

The primary efficacy variable was trough FEV1 following 12 weeks of treatment. Secondary variables included dyspnoea measured using the TDI at week 26 and health status according to the total score on SGRQ at week 52, time to first moderate or severe COPD exacerbation and mean daily rescue medication use over

52 weeks

$\begin{array}{ll}\text { Notes } & \text { Funding: Novartis } \\ & \text { Identifier(s): NCT00929110 }\end{array}$

Risk of bias

\begin{tabular}{|c|c|c|}
\hline Bias & Authors' judgement & Support for judgement \\
\hline
\end{tabular}

Random sequence generation (selection Low risk bias)

Patients were randomised 2:1:1 ratio [sequence generation not described, but industry funded so presumed electronic]

\begin{tabular}{|c|c|c|}
\hline Allocation concealment (selection bias) & Unclear risk & Not described \\
\hline $\begin{array}{l}\text { Blinding of participants and personnel } \\
\text { (performance bias) } \\
\text { All outcomes }\end{array}$ & High risk & $\begin{array}{l}\text { Blinding procedures were sound, but } \\
\text { tiotropium was delivered open label which } \\
\text { introduced bias for these comparisons }\end{array}$ \\
\hline $\begin{array}{l}\text { Blinding of outcome assessment (detection } \\
\text { bias) } \\
\text { All outcomes }\end{array}$ & High risk & $\begin{array}{l}\text { Blinding procedures were sound, but } \\
\text { tiotropium was delivered open label which } \\
\text { introduced bias for these comparisons }\end{array}$ \\
\hline $\begin{array}{l}\text { Incomplete outcome data (attrition bias) } \\
\text { All outcomes }\end{array}$ & Low risk & $\begin{array}{l}\text { A higher percentage of patients in the } \\
\text { placebo group discontinued }(28.3 \%) \text {, com- } \\
\text { pared with the patients in NVA237 ( } 22 \text {. } \\
3 \% \text { ) and tiotropium groups }(23.1 \%) \text {. Ef- } \\
\text { ficacy was assessed in the full analysis set } \\
\text { (FAS) which included all randomised pa- } \\
\text { tients who received at least one dose of the } \\
\text { study drug; patients in the FAS were anal- } \\
\text { ysed according to the treatment to which } \\
\text { they were randomised }\end{array}$ \\
\hline Selective reporting (reporting bias) & Low risk & $\begin{array}{l}\text { Full results were available from the pub- } \\
\text { lished report and on clinicaltrials.gov in ac- } \\
\text { cordance with the protocol }\end{array}$ \\
\hline
\end{tabular}

Long-acting inhaled therapy (beta-agonists, anticholinergics and steroids) for COPD: a network meta-analysis (Review) 
Methods

Participants
Design: randomised, double-blind, placebo-controlled, parallel-group trial

Duration: 6 months (+ 2 weeks run-in period)

Location: 75 centres in the USA, one in Puerto Rico

\begin{tabular}{|c|c|}
\hline 1 alticipants & $\begin{array}{l}\text { Baseline characteristics } \\
\text { Age (mean years): salm } 64.2 \text {, flut } 63.3 \text {, salm/flut } 63.4 \text {, pbo } 64.8 \\
\% \text { Male: salm } 57.6 \text {, flut } 66.1 \text {, salm/flut } 60.7 \text {, pbo } 68.1 \\
\% \mathrm{FEV}_{1} \text { predicted: salm } 42 \text {, flut } 42 \text {, salm/flut } 41 \text {, pbo } 42 \\
\text { Pack-years (mean): salm } 57 \text {, flut } 60 \text {, salm/flut } 53 \text {, pbo } 56 \\
\text { Inclusion criteria: males and females aged } 40 \text { and older; clinical diagnosis of COPD; } \\
\text { history of at least } 20 \text { pack-years and cough productive of sputum on most days for at } \\
\text { least } 3 \text { months of the year for at least } 2 \text { years; } \mathrm{FEV}_{1} / \mathrm{FVC} \text { ratio }<70 \% \text { and baseline } \mathrm{FEV}_{1} \\
<65 \% \text { predicted but }>0.70 \mathrm{~L} \\
\text { Exclusion criteria: current diagnosis of asthma; abnormal clinically significant ECG; } \\
\text { moderate or severe exacerbation during the run-in period; any significant medical dis- } \\
\text { order }\end{array}$ \\
\hline Interventions & $\begin{array}{l}\text { 1. Salmeterol } 50 \text { bid (LABA) } \\
\text { 2. Fluticasone } 250 \text { bid (ICS) } \\
\text { 3. Salmeterol/fluticasone } 50 / 250 \text { bid (LABA/ICS) } \\
\text { 4. Placebo (PBO) } \\
\text { Inhaler device: Diskus dry powder } \\
\text { Allowed co-medications: Stable regimens of theophylline were allowed (no change in } \\
\text { dose for } 1 \text { month before screening) [only } 11 \% \text { were taking these medications]. Disallowed } \\
\text { medications included oral corticosteroids within the past } 6 \text { weeks and long-term oxygen } \\
\text { therapy, and participants discontinued the use of corticosteroids and bronchodilators }\end{array}$ \\
\hline
\end{tabular}

Outcomes

Chronic Respiratory Disease Questionnaire (CRQ), COPD exacerbations, morning predose and 2-hour post-dose $\mathrm{FEV}_{1}$, morning peak expiratory flow (PEF), dyspnoea (as assessed by the transition dyspnoea index [TDI])
Funding: GlaxoSmithKline

Identifier(s): GSK SFCA3007

\section{Risk of bias}

\begin{tabular}{|c|c|c|}
\hline Bias & Authors' judgement & Support for judgement \\
\hline $\begin{array}{l}\text { Random sequence generation (selection } \\
\text { bias) }\end{array}$ & Low risk & $\begin{array}{l}\text { Randomization was stratified by reversibil- } \\
\text { ity (defined as a } 12 \% \text { and } 200 \mathrm{~mL} \text { increase } \\
\text { in FEV1 from baseline following the ad- } \\
\text { ministration of } 400 \mathrm{~g} \text { albuterol) and inves- } \\
\text { tigative site [sequence generation not de- } \\
\text { scribed but study was industry sponsored] }\end{array}$ \\
\hline
\end{tabular}

Allocation concealment (selection bias) Unclear risk

No details provided 
Hanania 2003 (Continued)

Blinding of participants and personnel Low risk (performance bias)

All outcomes

Blinding of outcome assessment (detection Low risk bias)

All outcomes

Incomplete outcome data (attrition bias) Low risk All outcomes

Selective reporting (reporting bias)

Low risk
Described as double blind [presumed subject and investigator]

Reported outcomes not subject to detection bias [exacerbations, all-cause mortality, adverse events and withdrawal]

Withdrawal high and even between groups (formoterol $31.7 \%$, placebo $31.9 \%$ ). In order to account for patient withdrawals, endpoint was used as the primary time point and was defined as the last on-treatment post baseline assessment excluding any data from the discontinuation visit

All expected and stated outcomes were reported [KK check CDRQ]

Kardos 2007

Methods

Design: Randomized, double-blind, parallel-group study

Duration: 10 months (+ 4 week run-in)

Location: 95 respiratory centres in Germany

Participants

Population: 994 participants were randomised to salmeterol (487) and salmeterol/fluticasone combination (507)

\section{Baseline characteristics}

Age (mean years): salm 64.0, salm/flut 63.8

$\%$ Male: salm 77.6, salm/flut 74.0

$\% \mathrm{FEV}_{1}$ predicted: salm 40.3, salm/flut 40.4

Pack-years (mean): salm 37.0, salm/flut 36.8

Inclusion criteria: Outpatients with post-bronchodilator FEV1 < 50\% predicted., FEV1/FVC of $70 \%$ predicted or less, age of $40 \mathrm{yr}$ or more, smoking history of 10 packyears or more, and a documented history of two or more moderate to severe exacerbations in the last year before the study.

Exclusion criteria: Patients with COPD exacerbations, hospital admissions, or change in COPD therapy during the $4 \mathrm{wk}$ before Visit 1 or during the 4 -wk run-in period were excluded. Patients with asthma, significant lung diseases other than COPD, and need for long-term oxygen therapy or chronic systemic steroid use were also excluded

Interventions

1. Salmeterol 50 bid (LABA)

2. Salmeterol/fluticasone $50 / 500$ bid (LABA/ICS)

Inhaler device: Diskus dry powder

Allowed co-medications: Inhaled salbutamol was used as reliever medication, and regular treatment with short-acting bronchodilators, antioxidants/mucolytics, short-acting oral beta 2 agonists, and theophylline was permitted 
Kardos 2007 (Continued)

Outcomes

Number of exacerbations, pre-bronchodilator PEF, post-bronchodilator FEV1, SGRQ, symptoms and breathlessness, diary card data

Notes Funding: GlaxoSmithKline

Identifier(s): unknown

Risk of bias

\begin{tabular}{|c|c|c|}
\hline Bias & Authors' judgement & Support for judgement \\
\hline $\begin{array}{l}\text { Random sequence generation (selection } \\
\text { bias) }\end{array}$ & Low risk & $\begin{array}{l}\text { Consecutive numbers were assigned to pa- } \\
\text { tients that determined the blinded treat- } \\
\text { ment based on a centrally generated list } \\
\text { with blocks of six }\end{array}$ \\
\hline Allocation concealment (selection bias) & Low risk & Randomisation list was centrally generated \\
\hline $\begin{array}{l}\text { Blinding of participants and personnel } \\
\text { (performance bias) } \\
\text { All outcomes }\end{array}$ & Low risk & $\begin{array}{l}\text { Described as double-blind treatment [pre- } \\
\text { sumed participants and personnel/investi- } \\
\text { gators] }\end{array}$ \\
\hline $\begin{array}{l}\text { Blinding of outcome assessment (detection } \\
\text { bias) } \\
\text { All outcomes }\end{array}$ & Unclear risk & Not described \\
\hline $\begin{array}{l}\text { Incomplete outcome data (attrition bias) } \\
\text { All outcomes }\end{array}$ & Low risk & $\begin{array}{l}\text { Similar withdrawal rates in each group. } \\
\text { ITT included } 99.6 \% \text { of the randomised } \\
\text { population ( } 4 \text { patients were excluded due } \\
\text { to a randomisation error) }\end{array}$ \\
\hline Selective reporting (reporting bias) & Unclear risk & $\begin{array}{l}\text { Unable to locate prospective trial registra- } \\
\text { tion to check that all outcomes were re- } \\
\text { ported. Author contacted who forwarded } \\
\text { request to GSK - no data were provided in } \\
\text { time for publication }\end{array}$ \\
\hline
\end{tabular}

Kornmann 2011

Methods

Design: randomised, double-blind, placebo-controlled trial

Duration: 6 months (+ 2 weeks run-in period)

Location: 142 centres in 15 countries

Participants

Participants: 1002 participants were randomised to salmeterol (334), indacaterol (333)

, and placebo (335)

Baseline characteristics

Age (mean years): salm 63, ind 63, pbo 64

$\%$ Male: salm 75, ind 72, pbo 77

$\% \mathrm{FEV}_{1}$ predicted: salm 53, ind 54, pbo 53

Long-acting inhaled therapy (beta-agonists, anticholinergics and steroids) for COPD: a network meta-analysis (Review) 
Pack-years (mean): salm 40, ind 40, pbo 41

Inclusion criteria: Males and females aged 40 and older; diagnosis of moderate to severe COPD; history of at least 20 pack-years; $<80 \%$ and $>30 \%$ predicted $\mathrm{FEV}_{1} ; \mathrm{FEV}_{1}$ / $\mathrm{FVC}<0.70$

Exclusion criteria: history of asthma; hospitalisation for COPD exacerbation in the 6 weeks before Visit 1 or during run-in; requiring oxygen therapy; respiratory tract infection within 6 weeks before Visit 1 and during the run-in period; concomitant pulmonary disease; history of long QTc syndrome or QTc interval > $450 \mathrm{~ms}$ for males and > 470 $\mathrm{ms}$ for females; clinically significant condition

Interventions
$\begin{aligned} & \text { 1. Salmeterol } 50 \text { bid (LABA) } \\ & \text { 2. Indacaterol } 150 \mathrm{qd} \text { (LABA) } \\ & \text { 3. Placebo (PBO) } \\ & \text { Inhaler device: dry powder (indacaterol in a single-dose version taken in the morning) } \\ & \text { Allowed co-medications: Concomitant medication with inhaled corticosteroids was } \\ & \text { allowed if stable for } 1 \text { month before screening and remained stable throughout the study; } \\ & \text { salbutamol was provided for relief. Participants previously taking fixed combinations of } \\ & \text { ICS and LABA were switched to equivalent ICS monotherapy }\end{aligned}$

Outcomes

St George's Respiratory Questionnaire (including proportion meeting minimal clinically important difference), trough $\mathrm{FEV}_{1}$, transition dyspnoea index, morning and evening PEF, diary card data, vital signs and ECGs

$\begin{array}{ll}\text { Notes } & \text { Funding: Novartis } \\ & \text { Identifier(s): NCT00567996 }\end{array}$

Risk of bias

\begin{tabular}{|c|c|c|}
\hline Bias & Authors' judgement & Support for judgement \\
\hline $\begin{array}{l}\text { Random sequence generation (selection } \\
\text { bias) }\end{array}$ & Low risk & $\begin{array}{l}\text { Patients were randomly allocated to treat- } \\
\text { ment in a 1:1:1 ratio (with stratification for } \\
\text { smoking status) using an automated system }\end{array}$ \\
\hline
\end{tabular}

Allocation concealment (selection bias) Low risk

Blinding of participants and personnel Low risk (performance bias)

All outcomes

Blinding of outcome assessment (detection Low risk bias)

All outcomes
Using an automated system [concealment assumed by automatisation]

Subject, investigator, outcomes assessor all blind [from protocol]. Blinding was maintained from randomisation until database lock unless any patient emergencies arose

Subject, investigator, outcomes assessor all blind [from protocol]. Blinding was maintained from randomisation until database lock unless any patient emergencies arose 
Kornmann 2011 (Continued)

\begin{tabular}{|c|c|c|}
\hline $\begin{array}{l}\text { Incomplete outcome data (attrition bias) } \\
\text { All outcomes }\end{array}$ & Low risk & $\begin{array}{l}\text { Withdrawal somewhat higher in placebo } \\
\text { group (salmeterol } 15 \% \text {; placebo } 20.1 \% \text { ). } \\
\text { Efficacy data were analysed for the inten- } \\
\text { tion-to-treat (ITT) population, compris- } \\
\text { ing all randomised patients who received at } \\
\text { least one dose of the study drug. The pop- } \\
\text { ulation for the safety analysis comprised all } \\
\text { patients who received at least one dose of } \\
\text { the study drug }\end{array}$ \\
\hline
\end{tabular}

Selective reporting (reporting bias) High risk

FEV1 data only given in graphical form. No exacerbation data provided

Lapperre 2009

Methods

Design: double-blind, parallel, 4-group, placebo-controlled, randomised design

Duration: 2.5 years

Location: 2 centres in the Netherlands

Participants

Population: 114 participants were randomised to fluticasone (26), salmeterol/fluticasone combination therapy (28), placebo (29), and one other arm that was not relevant to this review (fluticasone for 6 months followed by placebo for 24 months, 31)

Baseline characteristics

Age (mean years): flut 62, salm/flut 62, pbo 59

$\%$ Male: flut 88.5 , salm/flut 88 , pbo 83.3

$\% \mathrm{FEV}_{1}$ predicted (pre-BD): flut 57, salm/flut 55, pbo 54

Pack-years (median): flut 44, salm/flut 47, pbo 42

Inclusion criteria: aged 45 to 75 years, were current or former smokers, had smoked for 10 or more pack-years, and had lung function levels compatible with Global Initiative for Chronic Obstructive Lung Disease (GOLD) stages II and III.

Disease (GOLD) stages II and III

Exclusion criteria: asthma and receipt of ICS within 6 months before random assignment

Interventions

1. Fluticasone 500 bid (ICS)

2. Salmeterol/fluticasone $50 / 500$ bid (LABA/ICS)

3. Placebo (PBO)

Inhaler device: Diskus dry powder

Allowed co-medications: patients could continue taking short-acting bronchodilators

Outcomes

Cell counts in bronchial biopsies and sputum (primary outcome); methacholine responsiveness at baseline, 6, and 30 months; and clinical outcomes every 3 months

Notes

Funding: Netherlands Organization for Scientific Research, Netherlands Asthma Foundation, GlaxoSmithKline of The Netherlands, University Medical Center Groningen, and Leiden University Medical Center

Identifier(s): NCT00158847

\section{Risk of bias}

Long-acting inhaled therapy (beta-agonists, anticholinergics and steroids) for COPD: a network meta-analysis (Review)

Copyright () 2014 The Cochrane Collaboration. Published by John Wiley \& Sons, Ltd. 
Lapperre 2009 (Continued)

\begin{tabular}{|c|c|c|}
\hline Bias & Authors' judgement & Support for judgement \\
\hline $\begin{array}{l}\text { Random sequence generation (selection } \\
\text { bias) }\end{array}$ & Low risk & $\begin{array}{l}\text { At entry, an independent randomisation } \\
\text { centre provided patient and medication } \\
\text { numbers by using a minimization pro- } \\
\text { cedure that balanced treatment groups } \\
\text { for centre, sex, smoking status, FEV1/ } \\
\text { IVC } 60 \% \text {, and methacholine PC } 20 \text { (the } \\
\text { provocative concentration of methacholine } \\
\text { that causes a } 20 \% \text { decrease in FEV1) } 2 \mathrm{mg} / \\
\mathrm{mL} \text { ) }\end{array}$ \\
\hline Allocation concealment (selection bias) & Low risk & $\begin{array}{l}\text { An independent randomisation centre pro- } \\
\text { vided patient and medication numbers }\end{array}$ \\
\hline $\begin{array}{l}\text { Blinding of participants and personnel } \\
\text { (performance bias) } \\
\text { All outcomes }\end{array}$ & Low risk & $\begin{array}{l}\text { Study medications were individually num- } \\
\text { bered, and we used Diskus dry-pow- } \\
\text { der inhalers (GlaxoSmithKline, Zeist, The } \\
\text { Netherlands) with } 60 \text { doses per inhaler; all } \\
\text { active treatment medication and placebo } \\
\text { were identical in appearance }\end{array}$ \\
\hline $\begin{array}{l}\text { Blinding of outcome assessment (detection } \\
\text { bias) } \\
\text { All outcomes }\end{array}$ & Unclear risk & Not described \\
\hline $\begin{array}{l}\text { Incomplete outcome data (attrition bias) } \\
\text { All outcomes }\end{array}$ & High risk & $\begin{array}{l}\text { The withdrawal rates were very high com- } \\
\text { pared to the number of events for the dif- } \\
\text { ferent outcomes. Per-protocol analysis used }\end{array}$ \\
\hline Selective reporting (reporting bias) & Low risk & $\begin{array}{l}\text { Data not available from the published re- } \\
\text { port for several outcomes but authors pro- } \\
\text { vided data upon request }\end{array}$ \\
\hline
\end{tabular}

Laptseva 2002

Methods

Design: Randomised, double-blind, parallel-group study

Duration: 6 months

Location: unclear

Participants

Population: 49 people were randomised to budesonide (25) and placebo (24)

Baseline characteristics

None reported - abstract only

Inclusion criteria: Patients aged between 40 and 65. FEV1 40-60\% of predicted normal,

FEV1/VC $<55 \%$, bronchodilator reversibility of $<15 \%$

Exclusion criteria: none reported 
Laptseva 2002 (Continued)

\begin{tabular}{|c|c|c|}
\hline Interventions & \multicolumn{2}{|c|}{$\begin{array}{l}\text { 1. Budesonide } 400 \text { bid (ICS) } \\
\text { 2. Placebo (PBO) } \\
\text { Inhaler device: not reported } \\
\text { Allowed co-medications: All the patients received anticholinergic drug and methylxan- } \\
\text { thine or short-acting B2-agent }\end{array}$} \\
\hline Outcomes & \multicolumn{2}{|c|}{ Number and severity of exacerbations, FEV1, FVC, diary card symptoms, PEFR } \\
\hline Notes & \multicolumn{2}{|l|}{$\begin{array}{l}\text { Funding: unclear } \\
\text { Identifier(s): unknown }\end{array}$} \\
\hline \multicolumn{3}{|l|}{ Risk of bias } \\
\hline Bias & Authors' judgement & Support for judgement \\
\hline $\begin{array}{l}\text { Random sequence generation (selection } \\
\text { bias) }\end{array}$ & Unclear risk & Randomised, not described \\
\hline Allocation concealment (selection bias) & Unclear risk & Not described \\
\hline $\begin{array}{l}\text { Blinding of participants and personnel } \\
\text { (performance bias) } \\
\text { All outcomes }\end{array}$ & Low risk & $\begin{array}{l}\text { Described as double blind [presumed par- } \\
\text { ticipants and personnel/investigators] }\end{array}$ \\
\hline $\begin{array}{l}\text { Blinding of outcome assessment (detection } \\
\text { bias) } \\
\text { All outcomes }\end{array}$ & Unclear risk & Not described \\
\hline $\begin{array}{l}\text { Incomplete outcome data (attrition bias) } \\
\text { All outcomes }\end{array}$ & Unclear risk & No details provided \\
\hline Selective reporting (reporting bias) & High risk & $\begin{array}{l}\text { Only abstract available. Outcomes could } \\
\text { not be used. Could not find contact infor- } \\
\text { mation for authors }\end{array}$ \\
\hline
\end{tabular}

Mahler 2002

Methods

Design: randomised, double-blind, placebo-controlled, parallel-group, multi-centre trial Duration: 6 months (+ 2 weeks run-in period)

Location: 65 centres in the United States

Participants

Population: 674 participants were randomised to salmeterol (160), fluticasone (168), salmeterol/fluticasone combination (165), and placebo (181)

Baseline characteristics

Age (mean years): salm 63.5, flut 64.4, salm/flut 61.9, pbo 64.0

\% Male: salm 64.4, flut 61.3, salm/flut 62.4, pbo 75.1

$\% \mathrm{FEV}_{1}$ predicted: salm 40, flut 41, salm/flut 41, pbo 41

Pack-years (mean): salm 52.5, flut 54, salm/flut 55, pbo 60

Long-acting inhaled therapy (beta-agonists, anticholinergics and steroids) for COPD: a network meta-analysis (Review) 
Inclusion criteria: males and females aged 40 and older; history of at least 20 packyears; diagnosis of COPD; $\mathrm{FEV}_{1}<65 \%$ of predicted but $>0.70 \mathrm{~L}, \mathrm{FEV}_{1} / \mathrm{FVC}$ ratio < $70 \%$; daily cough productive of sputum for 3 months of the year for 2 consecutive years and dyspnoea

Exclusion criteria: current diagnosis of asthma; abnormal clinically significant ECG; moderate or severe exacerbation during the run-in period; any significant medical disorder

2. Fluticasone 500 bid (ICS)

3. Salmeterol/fluticasone $50 / 500$ bid (LABA/ICS)

4. Placebo (PBO)

Inhaler device: Diskus dry powder

Allowed co-medications: Albuterol was allowed as needed, as were stable regimens of theophylline. Disallowed medications included oral corticosteroid use in the past 6 weeks, long-term oxygen therapy, corticosteroids and all bronchodilators

Outcomes

Chronic Respiratory Disease Questionnaire, COPD exacerbations, AM pre-dose and 2hour post-dose $\mathrm{FEV}_{1}$, serial $\mathrm{FEV}_{1}$ over 12 hours, morning (AM) peak expiratory flow rate (PEFR), Chronic Bronchitis Symptoms Questionnaire (CBSQ), diary card data

Notes

Funding: GlaxoSmithKline

Identifier(s): GSK SFCA3006

Risk of bias

\begin{tabular}{l|l|l}
\hline Bias & Authors' judgement & Support for judgement \\
\hline $\begin{array}{l}\text { Random sequence generation (selection } \\
\text { bias) }\end{array}$ & Low risk & $\begin{array}{l}\text { Randomisation was stratified by reversibil- } \\
\text { ity and investigative site to ensure a bal- } \\
\text { ance between treatment groups at each site } \\
\text { and in terms of the number of reversible } \\
\text { patients [no other details, industry spon- } \\
\text { sored] }\end{array}$ \\
\hline \begin{tabular}{l} 
Allocation concealment (selection bias) \\
\hline $\begin{array}{l}\text { Blinding of participants and personnel } \\
\text { (performance bias) } \\
\text { All outcomes }\end{array}$
\end{tabular} & Low risk & No details provided \\
\hline
\end{tabular}

Blinding of outcome assessment (detection Low risk bias)

All outcomes
No details provided but outcomes not subject to detection bias
Incomplete outcome data (attrition bias) High risk All outcomes
Withdrawal high and uneven between groups (salmeterol 28\%, placebo 38\%). Analyses based on the intent-to-treat (ITT) population consisted of all randomized 
Mahler 2002 (Continued)

subjects who had taken at least one dose of double-blind study drug

Selective reporting (reporting bias) Low risk

All stated and expected outcomes were reported except FEV1 (secondary outcome)

Mahmud 2007

\begin{tabular}{|c|c|c|}
\hline Methods & \multicolumn{2}{|c|}{$\begin{array}{l}\text { Design: Randomised, parallel-group study (blinding unclear) } \\
\text { Duration: } 6 \text { months } \\
\text { Location: National Institute of Diseases of Chest and Hospital, Bangladesh }\end{array}$} \\
\hline Participants & \multicolumn{2}{|c|}{$\begin{array}{l}\text { Population: } 100 \text { participants were randomised to salmeterol and tiotropium (unclear } \\
\text { how many per group) } \\
\text { Baseline characteristics - minimal information } \\
\text { Age (mean years): not reported } \\
\% \text { Male: } 91 \text { both groups merged } \\
\% \mathrm{FEV}_{1} \text { predicted: not reported } \\
\text { Pack-years (mean): not reported } \\
\text { Inclusion criteria: patients with moderately severe COPD (definition not given) } \\
\text { Exclusion criteria: not described }\end{array}$} \\
\hline Interventions & \multicolumn{2}{|c|}{$\begin{array}{l}\text { 1. Salmeterol } 50 \text { bid (LABA) } \\
\text { 2. Tiotropium } 18 \mathrm{qd} \text { (LAMA) } \\
\text { Inhaler device: not described } \\
\text { Allowed co-medications: Both groups received beclomethasone } 500 \mu \mathrm{g} \text { twice daily }+ \\
\text { methylxanthines }\end{array}$} \\
\hline Outcomes & \multicolumn{2}{|c|}{$\begin{array}{l}\text { FEV1, health related quality of life (HRQoL), base line dyspnoea index and frequency } \\
\text { of COPD exacerbation. Patients were allowed to use salbutamol as per need basis }\end{array}$} \\
\hline Notes & \multicolumn{2}{|l|}{$\begin{array}{l}\text { Funding: unclear } \\
\text { Identifier(s): unknown }\end{array}$} \\
\hline \multicolumn{3}{|l|}{ Risk of bias } \\
\hline Bias & Authors' judgement & Support for judgement \\
\hline $\begin{array}{l}\text { Random sequence generation (selection } \\
\text { bias) }\end{array}$ & Unclear risk & Described as randomised, no details \\
\hline Allocation concealment (selection bias) & Unclear risk & Not described \\
\hline $\begin{array}{l}\text { Blinding of participants and personnel } \\
\text { (performance bias) }\end{array}$ & Unclear risk & $\begin{array}{l}\text { Not described as double blind - no descrip- } \\
\text { tion of procedures }\end{array}$ \\
\hline
\end{tabular}

All outcomes 
Mahmud 2007 (Continued)

\begin{tabular}{lll}
$\begin{array}{l}\text { Blinding of outcome assessment (detection } \\
\text { bias) } \\
\text { All outcomes }\end{array}$ & Unclear risk & $\begin{array}{l}\text { Not described as double blind - no descrip- } \\
\text { tion of procedures }\end{array}$ \\
\hline $\begin{array}{l}\text { Incomplete outcome data (attrition bias) } \\
\text { All outcomes }\end{array}$ & Unclear risk & $\begin{array}{l}90 / 100 \text { ultimately completed the study- } 43 \\
\text { in group A and 47 in group B }\end{array}$ \\
\hline Selective reporting (reporting bias) & High risk & Abstract only \\
\hline
\end{tabular}

Niewoehner 2005

\begin{tabular}{|c|c|}
\hline Methods & $\begin{array}{l}\text { Design: Randomised, double-blind, parallel-group study } \\
\text { Duration: } 6 \text { months } \\
\text { Location: } 26 \text { Veteran Affairs medical centres in the United States }\end{array}$ \\
\hline Participants & $\begin{array}{l}\text { Population: } 1829 \text { participants were randomised to tiotropium (914) and placebo (915) } \\
\text { Baseline characteristics } \\
\text { Age (mean years): tio } 67.6 \text {, pbo } 68.1 \\
\% \text { Male: tio 98, pbo } 99 \\
\% \mathrm{FEV}_{1} \text { predicted: tio } 35.6 \text {, pbo } 35.6 \\
\text { Pack-years (mean): tio } 67.4 \text {, pbo } 69.4 \\
\text { Inclusion criteria: age of } 40 \text { years or older, a cigarette smoking history of } 10 \text { pack-years } \\
\text { or more, a clinical diagnosis of COPD, and an FEV1 of } 60 \% \text { predicted or less and } 70 \% \\
\text { or less of the FVC. } \\
\text { Exclusion criteria: clinical diagnosis of asthma, a myocardial infarction within the pre- } \\
\text { vious } 6 \text { months, a serious cardiac arrhythmia or hospitalizations for heart failure within } \\
\text { the previous year, known moderate to severe renal impairment, moderate to severe symp- } \\
\text { tomatic prostatic hypertrophy or bladder-neck obstruction, narrow-angle glaucoma, cur- } \\
\text { rent radiation or chemotherapy for a malignant condition, or inability to give informed } \\
\text { consent. We also excluded patients who took systemic corticosteroids at unstable doses, } \\
\text { or in regular daily doses of } 20 \text { mg or more of prednisone (or equivalent), or who had not } \\
\text { fully recovered from an exacerbation for at least } 30 \text { days before the first study visit }\end{array}$ \\
\hline
\end{tabular}

Interventions

1. Tiotropium 18 qd (LAMA)

2. Placebo (PBO)

Inhaler device: Dry powder HandiHaler

Allowed co-medications: Patients otherwise received usual care, except for other anticholinergic bronchodilators. They continued taking all other respiratory medications (including inhaled corticosteroids and long-acting -agonists), and primary providers were allowed to prescribe additional medications according to medical need. Primary providers also prescribed antibiotics and systemic steroid prescriptions for exacerbations without restrictions

Outcomes

The co-primary end points were the percentage of patients with a COPD exacerbation and the percentage of patients with a COPD-related hospitalisation

Notes

Funding: Boehringer Ingelheim and Pfizer

Identifier(s): unknown

Long-acting inhaled therapy (beta-agonists, anticholinergics and steroids) for COPD: a network meta-analysis (Review)

Copyright () 2014 The Cochrane Collaboration. Published by John Wiley \& Sons, Ltd. 
Niewoehner 2005 (Continued)

\section{Risk of bias}

\begin{tabular}{|c|c|c|}
\hline Bias & Authors' judgement & Support for judgement \\
\hline $\begin{array}{l}\text { Random sequence generation (selection } \\
\text { bias) }\end{array}$ & Low risk & $\begin{array}{l}\text { We allocated eligible patients in equal num- } \\
\text { bers to receive tiotropium or placebo ac- } \\
\text { cording to a centrally generated blocked } \\
\text { randomisation list. We generated a single } \\
\text { randomisation and assigned blocks to cen- } \\
\text { tres }\end{array}$ \\
\hline Allocation concealment (selection bias) & Unclear risk & Not described \\
\hline $\begin{array}{l}\text { Blinding of participants and personnel } \\
\text { (performance bias) } \\
\text { All outcomes }\end{array}$ & Low risk & $\begin{array}{l}\text { Blinding of supplies was performed at } \\
\text { Boehringer Ingelheim before distribution } \\
\text { to investigational sites. The double-blind } \\
\text { remained in place until all patients were } \\
\text { clinically complete or until a serious adverse } \\
\text { event required unblinding }\end{array}$ \\
\hline $\begin{array}{l}\text { Blinding of outcome assessment (detection } \\
\text { bias) } \\
\text { All outcomes }\end{array}$ & Unclear risk & $\begin{array}{l}\text { Unclear who performed the assessment and } \\
\text { whether they were blind }\end{array}$ \\
\hline $\begin{array}{l}\text { Incomplete outcome data (attrition bias) } \\
\text { All outcomes }\end{array}$ & Low risk & $\begin{array}{l}\text { Dropout higher in placebo but less than } \\
15 \% \text { in both groups. 'We analyzed the data } \\
\text { by using a modified intention-to-treat prin- } \\
\text { ciple. Therefore, we included all available } \\
\text { data for the patients with any follow-up } \\
\text { contact who took at least } 1 \text { capsule of study } \\
\text { drug in the analysis. We handled missing } \\
\text { data by using longitudinal data analysis } \\
\text { methods (spirometry), analysis of observed } \\
\text { data only (number of events), or analysis } \\
\text { methods for censored data (time-to-event } \\
\text { data).' }\end{array}$ \\
\hline Selective reporting (reporting bias) & Unclear risk & $\begin{array}{l}\text { Study protocol could not be located to con- } \\
\text { firm that all pre-defined outcomes were re- } \\
\text { ported }\end{array}$ \\
\hline
\end{tabular}

\section{Ohar 2013}

Design: randomised, parallel-group study
Duration: 6 months
Location: unclear


Ohar 2013 (Continued)

\begin{tabular}{|c|c|c|}
\hline Participants & \multicolumn{2}{|c|}{$\begin{array}{l}\text { Population: } 639 \text { participants were included in the analysis for salmeterol }(325) \text { and } \\
\text { salmeterol/fluticasone combination therapy }(314) \text {, but it is unclear from the abstract } \\
\text { how many were randomised } \\
\text { Baseline characteristics } \\
\text { Not described, abstract only } \\
\text { Inclusion criteria: }>40 \text { years of age and a historical FEV1/FVC }<0.7 \text {, recent event (within } \\
14 \text { days of randomisation) of: }<10 \text {-day hospitalisation for an acute COPD exacerbation, } \\
\text { or exacerbation requiring treatment with oral corticosteroids (OCS) or OCS+antibiotics } \\
\text { in an ER, or during a physician's office visit. If the index event was office-based, a six- } \\
\text { month history of hospitalizations attributed to AECOPD was also required. } \\
\text { Exclusion criteria: not described }\end{array}$} \\
\hline Interventions & \multicolumn{2}{|c|}{$\begin{array}{l}\text { 1. Salmeterol } 50 \text { bid (LABA) } \\
\text { 2. Salmeterol/fluticasone } 50 / 250 \text { bid (LABA/ICS) } \\
\text { Inhaler device: Diskus dry powder } \\
\text { Allowed co-medications: not described }\end{array}$} \\
\hline Outcomes & \multicolumn{2}{|c|}{ Pre-dose FEV1, exacerbation outcomes } \\
\hline Notes & \multicolumn{2}{|l|}{$\begin{array}{l}\text { Funding: unclear } \\
\text { Identifier(s): unknown }\end{array}$} \\
\hline \multicolumn{3}{|l|}{ Risk of bias } \\
\hline Bias & Authors' judgement & Support for judgement \\
\hline $\begin{array}{l}\text { Random sequence generation (selection } \\
\text { bias) }\end{array}$ & Unclear risk & Randomised, no details \\
\hline Allocation concealment (selection bias) & Unclear risk & Not described \\
\hline $\begin{array}{l}\text { Blinding of participants and personnel } \\
\text { (performance bias) } \\
\text { All outcomes }\end{array}$ & Unclear risk & $\begin{array}{l}\text { Not described, but both treatments were } \\
\text { delivered via the Diskus dry powder inhaler }\end{array}$ \\
\hline $\begin{array}{l}\text { Blinding of outcome assessment (detection } \\
\text { bias) } \\
\text { All outcomes }\end{array}$ & Unclear risk & Not described \\
\hline $\begin{array}{l}\text { Incomplete outcome data (attrition bias) } \\
\text { All outcomes }\end{array}$ & Unclear risk & $\begin{array}{l}\text { Unclear how many were randomised and } \\
\text { if/how data were imputed for dropouts }\end{array}$ \\
\hline Selective reporting (reporting bias) & High risk & Only abstract available \\
\hline
\end{tabular}


Methods

Participants
Design: Randomised, double-blinded and placebo-controlled design

Duration: 6 months

Location: single centre in Turkey

Population: 26 people were randomised to budesonide (13) and placebo (13) Baseline characteristics

Age (mean years): bud 64.9, placebo 65.9

$\%$ Male: bud 84.6, placebo 53.8

$\% \mathrm{FEV}_{1}$ predicted: bud 61.1, placebo 57.3

Pack-years (mean): bud 45.6, placebo 44.4

Inclusion criteria: FEV1/FVCo70\% and FEV1450\% the predicted value, (2) reversibility with inhaled-b2-agonists ( $400 \mathrm{mg}$ salbutamol) of less than $200 \mathrm{ml}$ or less than $12 \%$ of predicted FEV1, (3) stable COPD defined as no acute exacerbation within the preceding 3 months, (4) no history of systemic disease or other pulmonary disease, (5) no therapy with inhaled or systemic corticosteroids within 3 months prior to entry into the study and (6) no history of asthma or atopy

Exclusion criteria: No additional information

\begin{tabular}{|c|c|c|}
\hline Interventions & \multicolumn{2}{|c|}{$\begin{array}{l}\text { 1. Budesonide } 400 \text { bid (ICS) } \\
\text { 2. Placebo (PBO) } \\
\text { Inhaler device: dry powder } \\
\text { Allowed co-medications: All of the patients were on therapy with inhaled salbutamol } \\
\text { and ipratropium bromide. In nine patients, sustained-released theophyline was also being } \\
\text { given }\end{array}$} \\
\hline Outcomes & \multicolumn{2}{|c|}{ FVC, FEV1, diary card data } \\
\hline Notes & \multicolumn{2}{|l|}{$\begin{array}{l}\text { Funding: unclear } \\
\text { Identifier(s): unknown }\end{array}$} \\
\hline \multicolumn{3}{|l|}{ Risk of bias } \\
\hline Bias & Authors' judgement & Support for judgement \\
\hline $\begin{array}{l}\text { Random sequence generation (selection } \\
\text { bias) }\end{array}$ & Low risk & $\begin{array}{l}\text { Patients were randomised by a computer } \\
\text { generated, blinded randomisation list }\end{array}$ \\
\hline Allocation concealment (selection bias) & Low risk & 'Blinded' randomisation list \\
\hline $\begin{array}{l}\text { Blinding of participants and personnel } \\
\text { (performance bias) } \\
\text { All outcomes }\end{array}$ & Low risk & $\begin{array}{l}\text { Described as double blind [presumed pa- } \\
\text { tients and personnel/investigators] }\end{array}$ \\
\hline $\begin{array}{l}\text { Blinding of outcome assessment (detection } \\
\text { bias) } \\
\text { All outcomes }\end{array}$ & Unclear risk & $\begin{array}{l}\text { The cells were counted by our pathologist } \\
\text { who was also blinded. Not clear for other } \\
\text { outcomes }\end{array}$ \\
\hline $\begin{array}{l}\text { Incomplete outcome data (attrition bias) } \\
\text { All outcomes }\end{array}$ & Unclear risk & $\begin{array}{l}\text { 'The results presented are an analysis of } \\
22 \text { subjects ( } 12 \text { budesonide-treated subjects }\end{array}$ \\
\hline
\end{tabular}

Long-acting inhaled therapy (beta-agonists, anticholinergics and steroids) for COPD: a network meta-analysis (Review) 


\begin{tabular}{|c|c|c|}
\hline & & $\begin{array}{l}\text { and } 10 \text { placebo-treated subjects) who com- } \\
\text { pleted the study'. Both dropout rates were } \\
\text { low but uneven between groups (two were } \\
\text { excluded from the placebo group and one } \\
\text { from the budesonide group. One extra, pre- } \\
\text { sumed to have been randomised to placebo } \\
\text { [assuming equal group size at randomisa- } \\
\text { tion] was excluded for failure to take the } \\
\text { medication consistently) }\end{array}$ \\
\hline Selective reporting (reporting bias) & High risk & $\begin{array}{l}\text { Key expected outcomes missing (mortality, } \\
\text { serious adverse events). No reply from au- } \\
\text { thors by time of publication }\end{array}$ \\
\hline
\end{tabular}

\section{Paggiaro 1998}

Methods

Participants
Design: Multicentre, randomised, placebo-controlled trial

Duration: 6 months (+ 2 week run-in)

Location: 13 European countries, New Zealand and South Africa

Population: 281 participants were randomised to fluticasone (142) and placebo (139) Baseline characteristics

Age (mean years): flut 62, placebo 64

$\%$ Male: flut 70 , placebo 78

$\% \mathrm{FEV}_{1}$ predicted: flut 59, placebo 55

Pack-years (mean): not reported

Inclusion criteria: Current or ex-smokers, 50-75 years with a history of smoking equivalent to at least 10 pack-years and chronic bronchitis (a cough with excess sputum production for at least 3 months in at least 2 consecutive years without any other pathology) . Patients also had to have a history of at least one exacerbation each year for the previous 3 years that required a visit to their doctor or hospital, a high expectation, according to the investigator, of experiencing an exacerbation during the 6-month treatment period, a regular productive cough, a predicted FEV1 of 35-90\%, a ratio of FEV1 to forced vital capacity of $70 \%$ or less, and reversibility in FEV1 of less than $15 \%$ after inhalation of $400 \mu \mathrm{g}$ or $800 \mu \mathrm{g}$ salbutamol via a metered-dose inhaler or Diskhaler

Exclusion criteria: Patients with abnormal chest radiographs or who had received oral or depot steroids, inhaled steroids of more than $500 \mu \mathrm{g}$ daily, antibiotic therapy, had been admitted to hospital in the 4 weeks before the study, or who were currently taking fluticasone propionate were excluded

Interventions
1. Fluticasone 500 bid (ICS)

2. Placebo (PBO)

Inhaler device: Metered-dose inhalers, with a spacer if desired

Allowed co-medications: Patients could take short-acting 2-agonists for the relief of symptoms as required throughout the study. Other COPD medications, such as anticholinergics and xanthine derivatives, could be continued throughout the study without dose changes 


\section{Paggiaro 1998 (Continued)}

COPD exacerbations, FEV1, morning PEF, FVC, 6-minute walk test, Borg score, diary
card symptom scores, daily sputum volume, total adverse events, serum cortisol concen-
tration

Notes

Funding: Unclear ('code was held by the sponsor company's statisticians')

Identifier(s): unknown

\section{Risk of bias}

\begin{tabular}{|c|c|c|}
\hline Bias & Authors' judgement & Support for judgement \\
\hline $\begin{array}{l}\text { Random sequence generation (selection } \\
\text { bias) }\end{array}$ & Low risk & $\begin{array}{l}\text { Random numbers were computer gener- } \\
\text { ated on PACT (version } 2.7 \text { ) }\end{array}$ \\
\hline Allocation concealment (selection bias) & Low risk & $\begin{array}{l}\text { Each investigator was given a set of four } \\
\text { or more sealed envelopes containing the as- } \\
\text { signment codes, from which they assigned } \\
\text { treatment, starting with the lowest number }\end{array}$ \\
\hline $\begin{array}{l}\text { Blinding of participants and personnel } \\
\text { (performance bias) } \\
\text { All outcomes }\end{array}$ & Low risk & $\begin{array}{l}\text { Described as double-blind [presumed pa- } \\
\text { tient and personnel/investigator] }\end{array}$ \\
\hline $\begin{array}{l}\text { Blinding of outcome assessment (detection } \\
\text { bias) } \\
\text { All outcomes }\end{array}$ & Unclear risk & Not described \\
\hline $\begin{array}{l}\text { Incomplete outcome data (attrition bias) } \\
\text { All outcomes }\end{array}$ & High risk & $\begin{array}{l}\text { 'We did analysis by intention to treat of } \\
\text { all patients who took at least one dose of } \\
\text { study medication'. 'Only available data was } \\
\text { analysed'. Dropout uneven }\end{array}$ \\
\hline Selective reporting (reporting bias) & High risk & $\begin{array}{l}\text { Key expected outcomes not reported (mor- } \\
\text { tality and serious adverse events). No reply } \\
\text { from authors by time of publication }\end{array}$ \\
\hline
\end{tabular}

Pauwels 1999

Methods

Participants
Design: Parallel-group, double-blind, placebo-controlled, randomised, multicenter study

Duration: 3 years (+ 3 month smoking cessation run-in)

Location: 39 study centres in 9 European countries

Population: 1277 participants were randomised to budesonide (634) and placebo (643) Baseline characteristics

Age (mean years): bud 52.5, pbo 52.4

$\%$ Male: bud 73.5 , pbo 72.2

$\% \mathrm{FEV}_{1}$ predicted: bud 76.8 , pbo 76.9 
Pauwels 1999 (Continued)

Pack-years (mean): bud 39.4, pbo 39.2

Inclusion criteria: Persons 30 to 65 years of age were eligible if they were currently smoking at least five cigarettes per day and had smoked cigarettes for at least 10 years or had a smoking history of at least 5 pack-years. The FEV1 after the use of a bronchodilator had to be between 50 percent and 100 percent of the predicted normal value, and the ratio of pre-bronchodilator FEV 1 to slow vital capacity had to be less than 70 percent. The increase in FEV1 after the inhalation of $1 \mathrm{mg}$ of terbutaline from a dry-powder inhaler had to be less than 10 percent of the predicted normal value. The change in FEV1 between the end of the first three-month period of the run-in phase and the end of the second had to be less than 15 percent.

Exclusion criteria: Subjects with a history of asthma, allergic rhinitis, or allergic eczema and those who had used oral glucocorticoids for more than four weeks during the preceding six months were excluded. The use of inhaled glucocorticoids other than the study medication, beta-blockers, cromones, or long-acting inhaled b2-adrenergic agonists was not allowed

\begin{tabular}{|c|c|c|}
\hline Interventions & \multicolumn{2}{|c|}{$\begin{array}{l}\text { 1. Budesonide } 400 \text { bid (ICS) } \\
\text { 2. Placebo (PBO) } \\
\text { Inhaler device: } 1 \text {, Pulmicort; } 2 \text {, dry powder turbuhaler } \\
\text { Allowed co-medications: The use of inhaled glucocorticoids other than the study med- } \\
\text { ication, beta-blockers, cromones, or long-acting inhaled beta2-adrenergic agonists was } \\
\text { not allowed }\end{array}$} \\
\hline Outcomes & \multicolumn{2}{|c|}{$\begin{array}{l}\text { Change in post-dose FEV1, serious adverse events, mortality, glucocorticoid-related side } \\
\text { effects, bone density }\end{array}$} \\
\hline Notes & \multicolumn{2}{|c|}{$\begin{array}{l}\text { Funding: Funded by a grant from Astra Draco, Lund, Sweden } \\
\text { Identifier(s): unknown }\end{array}$} \\
\hline \multicolumn{3}{|l|}{ Risk of bias } \\
\hline Bias & Authors' judgement & Support for judgement \\
\hline $\begin{array}{l}\text { Random sequence generation (selection } \\
\text { bias) }\end{array}$ & Low risk & $\begin{array}{l}\text { 'Randomly assigned'. No specific details } \\
\text { given but industry sponsored }\end{array}$ \\
\hline Allocation concealment (selection bias) & Unclear risk & Not described \\
\hline $\begin{array}{l}\text { Blinding of participants and personnel } \\
\text { (performance bias) } \\
\text { All outcomes }\end{array}$ & Low risk & $\begin{array}{l}\text { Described as double-blind [presumed par- } \\
\text { ticipant and personnel/investigator] }\end{array}$ \\
\hline $\begin{array}{l}\text { Blinding of outcome assessment (detection } \\
\text { bias) } \\
\text { All outcomes }\end{array}$ & Low risk & $\begin{array}{l}\text { Central evaluator who was unaware of the } \\
\text { treatment received and were analyzed ac- } \\
\text { cording to a standardized computerized } \\
\text { protocol }\end{array}$ \\
\hline
\end{tabular}

Long-acting inhaled therapy (beta-agonists, anticholinergics and steroids) for COPD: a network meta-analysis (Review) 
Pauwels 1999 (Continued)

\begin{tabular}{l|l|l}
\hline $\begin{array}{l}\text { Incomplete outcome data (attrition bias) } \\
\text { All outcomes }\end{array}$ & Low risk & $\begin{array}{l}\text { Data on the randomised subjects were anal- } \\
\text { ysed on an intention-to-treat basis. With- } \\
\text { drawal rates under } 30 \% \text { and even in both } \\
\text { groups }\end{array}$ \\
\hline Selective reporting (reporting bias) & High risk & $\begin{array}{l}\text { Several missing outcomes. Could not locate } \\
\text { protocol to check that all prospectively reg- } \\
\text { istered outcomes were reported. Contacted } \\
\text { second author, no reply by time of publi- } \\
\text { cation }\end{array}$ \\
\hline
\end{tabular}

Powrie 2007

Methods

Design: single-centre, double-blind, randomised, placebo-controlled trial

Duration: 12 months (+ 2 week run-in)

Location: London Chest Hospital, UK

Participants

Population: 142 participants were randomised to tiotropium (69) and placebo (73) Baseline characteristics

Age (mean years): tio 66.3, pbo 66.4

$\%$ Male: tio 69.6, pbo 56.2

$\% \mathrm{FEV}_{1}$ predicted: tio 50.9 , pbo 49.2

Pack-years (mean): tio 54.6, pbo 55.7

Inclusion criteria: Patients aged $>40$ yrs with a diagnosis of COPD (FEV1 ,80\% of the predicted value and FEV1/FVC ,70\%) and a minimum 10-pack-yr smoking history were recruited from primary care or the outpatients department of the London Chest Hospital

(London, UK).

Exclusion criteria: patients with a history of asthma or atopy were excluded, as were those on long-term oxygen therapy or with another clinically significant disease

Interventions

1. Tiotropium 18 qd (LAMA)

2. Placebo (PBO)

Inhaler device: HandiHaler

Allowed co-medications: Anticholinergics other than the study drug were not permitted during the course of the study. Otherwise, patients remained on their usual medication

Outcomes

Sputum and serum cytokines were assayed by ELISA and exacerbation frequency calculated using a symptom-based diary

Notes

Funding: Boehringer-Ingelheim

Identifier(s): NCT00405236

Risk of bias

Bias

Authors' judgement

Support for judgement

Long-acting inhaled therapy (beta-agonists, anticholinergics and steroids) for COPD: a network meta-analysis (Review) 
Powrie 2007 (Continued)

\begin{tabular}{l|l|l}
$\begin{array}{l}\text { Random sequence generation (selection } \\
\text { bias) }\end{array}$ & Low risk & $\begin{array}{l}\text { Randomised [not described but industry } \\
\text { funded so presumed to be electronic] }\end{array}$ \\
\hline Allocation concealment (selection bias) & Unclear risk & Not described \\
\hline
\end{tabular}

Blinding of participants and personnel Low risk (performance bias)

All outcomes

Described as double-blind. Tiotropium and placebo were both given via the HandiHaler device

Blinding of outcome assessment (detection Unclear risk

Not described

bias)

All outcomes

Incomplete outcome data (attrition bias) Low risk

All outcomes

Dropout was high but even between groups after 1 year (tio $30.5 \%$, placebo $28.8 \%$ ) . Analyses were carried out using the full analysis data set (all

randomised treated patients with efficacy data). All randomised patients received at least one dose of the study treatment

Selective reporting (reporting bias) Low risk

The study was prospectively registered. No results are posted on clinicaltrials.gov but the trial publication reports the stated outcomes

Renkema 1996

Methods

Design: Parallel, double-blind, randomised, placebo-controlled study

Duration: 2 years (+ 3 month run-in)

Location: single centre in the Netherlands

Participants

Population: 39 participants were randomised to budesonide (21) and placebo (18) Baseline characteristics

Age (mean years): bud 56, pbo 54

$\%$ Male: bud 100 , pbo 100

$\% \mathrm{FEV}_{1}$ predicted: bud 67, placebo 60

Pack-years (mean): not reported

Inclusion criteria: Clinical diagnosis of COPD based on history (persistent dyspnoea, mainly on exertion, without sudden attacks of dyspnoea); FEV1 less than $80 \%$ of the predicted value; residual volume (RV) greater than $100 \%$ of the predicted value; specific compliance expressed as a percentage of the predicted value greater than $100 \%$ after bronchodilation; when, however, air trapping (calculated as thoracic gas volume measured by body plethysmography minus functional residual capacity measured with an indicator gas) was greater than $1.5 \mathrm{~L}$ Csp was allowed to be less than $100 \%$ of predicted; no signs of allergy (negative skin test results, total serum $\mathrm{IgE}<200 \mathrm{IU} / \mathrm{mL}$, eosinophils in peripheral blood $<250 \times 103 / \mathrm{mL}$ ); and stable phase of the disease.

Exclusion criteria: Excluded were patients older than 70 years at entry, patients receiving

Long-acting inhaled therapy (beta-agonists, anticholinergics and steroids) for COPD: a network meta-analysis (Review)

Copyright (c) 2014 The Cochrane Collaboration. Published by John Wiley \& Sons, Ltd. 
continuous corticosteroid therapy, and patients with severe concomitant disease, likely to interfere with the purpose of the study. All patients had ai-antitrypsin serum levels within the normal range. All patients were smokers or ex-smokers. Smoking history was expressed as cigarette years

\begin{tabular}{ll} 
Interventions & $\begin{array}{l}\text { 1. Budesonide } 800 \text { bid (ICS) plus placebo tablet once daily } \\
\text { 2. Placebo (PBO) plus placebo tablet once daily } \\
\text { Inhaler device: metered-dose through a 750-ml spacer } \\
\text { Allowed co-medications: Throughout the study, patients were maintained on regimens } \\
\text { of their usual bronchodilator medication, consisting of anticholinergics. beta-agonists, } \\
\text { theophylline, or a combination of these drugs }\end{array}$ \\
\hline Outcomes & FEV1, compliance, symptom scores, fasting morning plasma cortisol levels \\
\hline Notes & Funding: Grants from the Netherlands Asthma Foundation, ASTRA BV Holland, and \\
AB DRACO Sweden. \\
Identifier(s): unknown
\end{tabular}

Risk of bias

\begin{tabular}{|c|c|c|}
\hline Bias & Authors' judgement & Support for judgement \\
\hline $\begin{array}{l}\text { Random sequence generation (selection } \\
\text { bias) }\end{array}$ & Low risk & $\begin{array}{l}\text { By computerized randomisation, stratified } \\
\text { for smoking }\end{array}$ \\
\hline Allocation concealment (selection bias) & Low risk & Allocated blindly \\
\hline $\begin{array}{l}\text { Blinding of participants and personnel } \\
\text { (performance bias) } \\
\text { All outcomes }\end{array}$ & Low risk & $\begin{array}{l}\text { Double-blind [presumed patients and per- } \\
\text { sonnel/investigators] }\end{array}$ \\
\hline $\begin{array}{l}\text { Blinding of outcome assessment (detection } \\
\text { bias) } \\
\text { All outcomes }\end{array}$ & Unclear risk & Not described \\
\hline $\begin{array}{l}\text { Incomplete outcome data (attrition bias) } \\
\text { All outcomes }\end{array}$ & High risk & $\begin{array}{l}\text { Uneven withdrawal rates, no description of } \\
\text { imputation to account for dropout }\end{array}$ \\
\hline Selective reporting (reporting bias) & High risk & $\begin{array}{l}\text { Key expected outcomes not reported (mor- } \\
\text { tality and adverse events). No reply from } \\
\text { authors by time of publication }\end{array}$ \\
\hline
\end{tabular}


Methods

Participants
Design: randomised, double-blind, double-dummy, parallel-group, active- and placebocontrolled, multi-centre study

Duration: 12 months (+ 2 weeks run-in period)

Location: 237 sites in the USA, Europe and Mexico

Population: 1964 participants were randomised to formoterol (495), formoterol/budesonide at two doses (494 and 494), and placebo (481)

Baseline characteristics

Age (mean years): form 62.9, form/bud320 63.2, form/bud160 63.6, pbo 62.9

\% Male: form 65.3, form/bud320 62.3, form/bud160 62.8, pbo 65.3

$\% \mathrm{FEV}_{1}$ predicted: form 39.3, form/bud320 38.6, form/bud160 39.6, pbo 40.8

Pack-years (median): form 40, form/bud320 40, form/bud160 40, pbo 40

Inclusion criteria: Males and females aged 40 and older; moderate to severe COPD for $2+$ years; history of at least 10 pack-years

Exclusion criteria: history of asthma or seasonal rhinitis before age 40; significant/ unstable cardiovascular disorder; significant respiratory tract disorder other than COPD; homozygous alpha $a_{1}$-antitrypsin deficiency or other clinically significant co-morbidities precluding participation

Interventions

1. Formoterol 12 bid (LABA)

2. Formoterol/budesonide $9 / 320$ (LABA/ICS)

3. Formoterol/budesonide $9 / 160$ (LABA/ICS)

4. Placebo (PBO)

Inhaler device: dry powder

Allowed co-medications: Salbutamol was allowed as relief medication. Previous inhaled corticosteroids were discontinued, and disallowed medication included long-acting anticholinergics; inhaled LABAs or SABAs (other than salbutamol); oral beta-adrenoreceptor agonists; ephedrine; leukotriene receptor agonists; xanthine derivatives except for shortterm use

Outcomes

St George's Respiratory Questionnaire (SGRQ), COPD exacerbations, pre-dose FEV , $_{1}$ one hour post-dose $\mathrm{FEV}_{1}$, morning and evening PEF

Funding: AstraZeneca

Identifier(s): NCT00206167

Risk of bias

Bias Authors' judgement

Support for judgement

Random sequence generation (selection Low risk bias)

Allocation concealment (selection bias) Low risk

Designed to conform with the Declaration of Helsinki, and was consistent with the International Conference on Harmonisation and Good Clinical Practice and applicable regulatory requirements

Designed to conform with the Declaration of Helsinki, and was consistent with the International Conference on Harmonisation 
Rennard 2009 (Continued)

and Good Clinical Practice and applicable regulatory requirements

Blinding of participants and personnel Low risk (performance bias)

All outcomes
To maintain blinding, patients received both a pressurized metered-dose inhaler (pMDI) and a dry powder inhaler(DPI) containing either active treatment or double-dummy placebo (PL) as appropriate

Included outcomes unlikely to be affected by detection bias
Blinding of outcome assessment (detection Low risk bias)

All outcomes
Incomplete outcome data (attrition bias) High risk All outcomes
Withdrawal even but high in both groups [formoterol $31.7 \%$, placebo $36.4 \%$ ). The efficacy analysis set (i.e. intent-to-treat population) included all randomized patients who received at least one dose of randomized study medication and contributed sufficient data for at least one co-primary or secondary efficacy endpoint to be calculated during the randomized treatment period. The safety analysis population included all randomized patients who received at least one dose of randomized study medication and from whom any post-randomisation data were available

Serial spirometry was only reported for a subset. Exacerbations not reported in a way that could be included in meta-analysis

Rossi 2002

Methods

Design: multi-centre, randomised, parallel-group, placebo-controlled study

Duration: 12 months (+ 10 to 21 days run-in period)

Location: 81 centres worldwide

Participants

Population: 645 participants were randomised to formoterol at two different doses (211 and 214), and placebo (220)

\section{Baseline characteristics}

Age (mean years): form 12 63, form 24 62, pbo 63

$\%$ Male: form 12 87.2, form 2483.2 , pbo 79.5

$\% \mathrm{FEV}_{1}$ predicted: not reported

Pack-years (mean): not reported

Inclusion criteria: males and females aged 40 and older; diagnosis of COPD; history of at least 10 pack-years; $\mathrm{FEV}_{1}<70 \%$ predicted; $\mathrm{FEV}_{1} / \mathrm{FVC}$ ration $<0.89$

Exclusion criteria: history of asthma; respiratory tract infection in the past month; need for long-term oxygen therapy 
Rossi 2002 (Continued)

\begin{tabular}{|c|c|c|}
\hline Interventions & \multicolumn{2}{|c|}{$\begin{array}{l}\text { 1. Formoterol } 12 \text { bid (LABA) } \\
\text { 2. Formoterol } 24 \text { bid (LABA) } \\
\text { 3. Placebo (PBO) } \\
\text { Inhaler device: dry powder } \\
\text { Allowed co-medications: Stable participants receiving inhaled corticosteroid treatment } \\
\text { were instructed to remain on that treatment throughout the study; Salbutamol (up to } 8 \\
\text { puffs/d) was allowed as the rescue medication. Short courses of antibiotics, oral corticos- } \\
\text { teroids and/or oxygen were permitted in case of exacerbation or respiratory infection up } \\
\text { to two times during the study. All other bronchodilating medications were discontinued }\end{array}$} \\
\hline Outcomes & \multicolumn{2}{|c|}{$\begin{array}{l}\text { St George's Respiratory Questionnaire (SGRQ), COPD exacerbations, standardised } \\
\text { AUC for FVC, absolute } \mathrm{FEV}_{1} \text { values at all time points, predose } \mathrm{FEV}_{1} \text {, morning PEF, } \\
\text { daily total symptom score, vital signs, ECG }\end{array}$} \\
\hline Notes & \multicolumn{2}{|l|}{$\begin{array}{l}\text { Funding: Novartis } \\
\text { Identifier(s): unknown }\end{array}$} \\
\hline \multicolumn{3}{|l|}{ Risk of bias } \\
\hline Bias & Authors' judgement & Support for judgement \\
\hline $\begin{array}{l}\text { Random sequence generation (selection } \\
\text { bias) }\end{array}$ & Low risk & $\begin{array}{l}\text { Randomized, parallel-group study [no spe- } \\
\text { cific details, industry sponsored] }\end{array}$ \\
\hline Allocation concealment (selection bias) & Unclear risk & No details provided \\
\hline $\begin{array}{l}\text { Blinding of participants and personnel } \\
\text { (performance bias) } \\
\text { All outcomes }\end{array}$ & Low risk & $\begin{array}{l}\text { F12, F24, and PL were administered in a } \\
\text { double-blind manner }\end{array}$ \\
\hline $\begin{array}{l}\text { Blinding of outcome assessment (detection } \\
\text { bias) } \\
\text { All outcomes }\end{array}$ & Low risk & $\begin{array}{l}\text { No details provided but outcomes included } \\
\text { in meta-analysis unlikely to be subject to } \\
\text { detection bias }\end{array}$ \\
\hline $\begin{array}{l}\text { Incomplete outcome data (attrition bias) } \\
\text { All outcomes }\end{array}$ & Low risk & $\begin{array}{l}\text { Withdrawal rates were relatively similar } \\
\text { across the three groups (formoterol } 1224 \text {. } \\
6 \% \text {, formoterol } 2418.7 \% \text {, placebo } 26.8 \% \text { ) } \\
\text {.The statistical analysis was carried out ac- } \\
\text { cording to the intent-to-treat principle }\end{array}$ \\
\hline Selective reporting (reporting bias) & Low risk & $\begin{array}{l}\text { All outcomes stated and expected were re- } \\
\text { ported in detail (except FEV1 [secondary] } \\
\text { as AUC outcome) }\end{array}$ \\
\hline
\end{tabular}


Methods

Participants
Design: randomised, double blind, double dummy, placebo-controlled phase IV trial

Duration: 3 years (preceded by an optional smoking cessation stage, 3 month washout period and 14 day pre-treatment phase)

Location: 44 general practices in the Netherlands

Population: 190 participants were randomised to fluticasone (94) and placebo (96) Baseline characteristics

Age (mean years): flut 58.4, pbo 59.6

$\%$ Male: flut 73, pbo 68

$\% \mathrm{FEV}_{1}$ predicted: flut 63.2, pbo 65.7

Pack-years (mean): flut 30.2, pbo 26.5

Inclusion criteria: Age 35-75 years; current or former smoker; chronic dyspnoea, sputum production and cough for at least three consecutive months per year during the previous two years; post-bronchodilator forced expiratory volume in one second (FEV1) $<90 \%$ of the predicted value, and/or post-bronchodilator FEV1/FVC (forced vital capacity) of the predicted value $<88 \%$ for men and $<89 \%$ for women.

Exclusion criteria: Post-bronchodilator FEV1 $<40 \%$ of predicted and/or a history of asthma, allergic rhinitis, or allergic eczema

Interventions

1. Fluticasone 500 bid (ICS)

2. Placebo (PBO)

Inhaler device: Diskus dry powder inhaler. Unclear from trial report whether the placebo was administered to match the fluticasone inhaler or the other active treatment which was delivered as effervescent tablets dissolved in a glass of tap

Allowed co-medications: not reported

Outcomes

Rate of exacerbations and quality life as measured with the interviewer-administered version of the Chronic Respiratory Questionnaire (CRQ)

Notes

Funding: Dutch Council for Health Insurances, with complementary funding by the Netherlands Asthma Foundation (authors had received various GSK and other pharmaceutical research grants)

Identifier(s): unknown

\section{Risk of bias}

Bias

Authors' judgement

Support for judgement

Random sequence generation (selection Low risk bias)

\begin{tabular}{l|l|l} 
Allocation concealment (selection bias) & Unclear risk & Not described \\
\hline $\begin{array}{l}\text { Blinding of participants and personnel } \\
\text { (performance bias) }\end{array}$ & Low risk & $\begin{array}{l}\text { Neither investigators nor patients were } \\
\text { aware of the group assignment. Placebo de- } \\
\text { All outcomes }\end{array}$
\end{tabular}

Long-acting inhaled therapy (beta-agonists, anticholinergics and steroids) for COPD: a network meta-analysis (Review)
An independent statistician generated a randomisation list based on a block size of three for treatment allocation to balance the three treatment arms by study centre scribed as 'matching' 
Schermer 2009 (Continued)

Blinding of outcome assessment (detection Low risk

bias)

All outcomes
Neither investigators nor patients were aware of the group assignment [presuming the investigators were those doing the outcome assessments]
Incomplete outcome data (attrition bias) High risk All outcomes
Dropout was high in both groups. The primary analyses were done on an intentionto-treat basis. Additional per protocol analyses were done on patients with a trial medication compliance rate $>80 \%$. Unclear how data were imputed or who was included in the ITT population

Selective reporting (reporting bias) High risk
All outcomes stated in the protocol were reported but some key expected outcomes were missing (serious adverse events and pneumonia). No reply from author by time of publication

\section{SCO100470}

Methods

Participants
Design: multi-centre, randomised, double-blind, double dummy, parallel group design Duration: 6 months (+ run-in of unclear duration)

Location: Conducted at 135 centres in 20 countries

Population: 1050 people were randomised to fluticasone (532) and fluticasone/salmeterol combination (518)

Baseline characteristics

Age (mean years): salm 63.7, flut/salm 63.5

$\%$ Male: salm 77.3, flut/salm 78.4

$\% \mathrm{FEV}_{1}$ predicted: not reported

Pack-years (mean): not reported

Inclusion criteria: Male or female, aged 40-80 years with an established history of GOLD stage II COPD; poor reversibility of airflow obstruction (defined as $\leq 10 \%$ increase in FEV1 as a percentage of the normal predicted value); a minimum score of $\geq$ 2 on the Modified Medical Research Council Dyspnoea Scale, and a smoking history of at least 10 pack years. In addition, subjects had to achieve a composite symptom score of $\geq 120$ (out of 400 maximum score, measured using visual analogue scales) on at least 4 of the last 7 days of the run-in period, and to have a Baseline Dyspnoea Index (BDI) score of $\leq 7$ units at Visit 2

Exclusion criteria: Subjects would be excluded if they had asthma or atopic disease, had a lung disease likely to confound the drug response other than COPD, had a recent exacerbation (within 4 weeks or screening or during run-in); were receiving long-term oxygen therapy or pulmonary rehabilitation or had taken tiotropium bromide, inhaled corticosteroids or anti-leukotriene medication within 14 days of visit 1 


\begin{tabular}{|c|c|c|}
\hline Interventions & \multicolumn{2}{|c|}{$\begin{array}{l}\text { 1. Salmeterol } 50 \text { bid (LABA) } \\
\text { 2. Salmeterol/fluticasone } 50 / 250 \text { bid (LABA/ICS) } \\
\text { Inhaler device: Diskus accuhaler } \\
\text { Allowed co-medications: Not reported }\end{array}$} \\
\hline Outcomes & \multicolumn{2}{|c|}{$\begin{array}{l}\text { Transitional Dyspnoea Index (TDI), change from baseline in trough FEV1, change from } \\
\text { baseline in trough FVC and FVC/FEV1 ratio, TDI focal score, change from baseline } \\
\text { in post-dose FEV1, FVC and FVC/FEV1 ratio, change from baseline in mean morning } \\
\text { PEF, change from baseline in St George's Respiratory Questionnaire }\end{array}$} \\
\hline Notes & \multicolumn{2}{|c|}{$\begin{array}{l}\text { Funding: GlaxoSmithKline } \\
\text { Identifier(s): GSK SCO100470 }\end{array}$} \\
\hline \multicolumn{3}{|l|}{ Risk of bias } \\
\hline Bias & Authors' judgement & Support for judgement \\
\hline $\begin{array}{l}\text { Random sequence generation (selection } \\
\text { bias) }\end{array}$ & Low risk & $\begin{array}{l}\text { Described as randomised [assumed to ad- } \\
\text { here to usual GSK methodology] }\end{array}$ \\
\hline Allocation concealment (selection bias) & Unclear risk & Not described \\
\hline $\begin{array}{l}\text { Blinding of participants and personnel } \\
\text { (performance bias) } \\
\text { All outcomes }\end{array}$ & Low risk & $\begin{array}{l}\text { Described as double-blind [presumed par- } \\
\text { ticipants and personnel/investigators] }\end{array}$ \\
\hline $\begin{array}{l}\text { Blinding of outcome assessment (detection } \\
\text { bias) } \\
\text { All outcomes }\end{array}$ & Unclear risk & $\begin{array}{l}\text { Not described - only results summary avail- } \\
\text { able }\end{array}$ \\
\hline $\begin{array}{l}\text { Incomplete outcome data (attrition bias) } \\
\text { All outcomes }\end{array}$ & Low risk & $\begin{array}{l}\text { Dropout low and even between groups } \\
\text { (11.4\% vs. } 13.9 \%) \text {. The ITT (Intent to } \\
\text { treat) Population (all subjects randomised } \\
\text { and confirmed as having received at least } \\
\text { one dose of double-blind study medica- } \\
\text { tion) was the primary population for analy- } \\
\text { sis of all efficacy and health outcomes vari- } \\
\text { ables; the Safety Population (identical to } \\
\text { the ITT Population) was used for analysis } \\
\text { of all safety variables }\end{array}$ \\
\hline Selective reporting (reporting bias) & Low risk & $\begin{array}{l}\text { All stated outcomes were reported and no } \\
\text { expected outcomes were missing }\end{array}$ \\
\hline
\end{tabular}


Duration: 12 months (+ 2 week run-in)

Location: 49 centres in Italy and 7 in Poland

Participants

Population: 387 participants were randomised to fluticasone (131), fluticasone/salmeterol combination (131), and placebo (125)

\section{Baseline characteristics}

Age (mean years): flut 64.6, flut/salm 63.9, pbo 65.7

$\%$ Male: flut 83.2, flut/salm 84.0, pbo 80.0

$\% \mathrm{FEV}_{1}$ predicted: not reported

Pack-years (mean): not reported

Inclusion criteria: Male or female subjects aged > 40 years with an established clinical history of COPD; subjects who demonstrated at Visit 1 a pre-bronchodilator baseline FEV1/VC $<88 \%$ for men and $<89 \%$ for women of predicted normal values and FEV1 $\leq 70 \%$ of predicted normal value, but $>800 \mathrm{~mL}$; subjects who demonstrated at Visit 1 , poor reversibility of airflow obstruction, defined as an increase of FEV1 $<10 \%$ of the normal predicted FEV1 value (or $<200 \mathrm{ml}$ from baseline), 30 minutes after inhalation of $400 \mu \mathrm{g}$ salbutamol via MDI; . current or ex-smokers with a smoking history of at least 10 pack-years

Exclusion criteria: As above

Interventions
$\begin{aligned} & \text { 1. Fluticasone } 500 \text { bid (ICS) } \\ & \text { 2. Salmeterol/fluticasone } 50 / 500 \text { bid (LABA/ICS) } \\ & \text { 3. Placebo (PBO) } \\ & \text { Inhaler device: metered dose } \\ & \text { Allowed co-medications: not reported }\end{aligned}$

Outcomes

COPD exacerbations, clinic FEV1, VC, FEV1/VC, daily record card symptoms, PEFR, distance walked in the six minute walk test (SWT), perceived breathlessness before and after SWT, quality of life (SGRQ), use of relief medication, adverse events, SAEs on therapy

\section{Notes}

Funding: GlaxoSmithKline

Identifier(s): GSK SCO30002

\section{Risk of bias}

\begin{tabular}{l|l} 
Bias Authors' judgement $\quad$ Support for judgement
\end{tabular}

Random sequence generation (selection Low risk bias)

Randomised to treatment. No details given but assumed to adhere to GSK methodology

\begin{tabular}{llll}
\hline Allocation concealment (selection bias) & Unclear risk & Not described \\
\hline $\begin{array}{l}\text { Blinding of participants and personnel } \\
\text { (performance bias) }\end{array}$ & Low risk & $\begin{array}{l}\text { Described as double-blind [presumed par- } \\
\text { ticipants and personnel/investigators] }\end{array}$
\end{tabular}

All outcomes

Long-acting inhaled therapy (beta-agonists, anticholinergics and steroids) for COPD: a network meta-analysis (Review)

Copyright $₫ 2014$ The Cochrane Collaboration. Published by John Wiley \& Sons, Ltd. 


\begin{tabular}{l|l|l}
$\begin{array}{l}\text { Blinding of outcome assessment (detection } \\
\text { bias) } \\
\text { All outcomes }\end{array}$ & Unclear risk & Not described \\
\hline $\begin{array}{l}\text { Incomplete outcome data (attrition bias) } \\
\text { All outcomes }\end{array}$ & Low risk & $\begin{array}{l}\text { Dropout high at } 26 \% \text { and } 32 \% \text { for ICS } \\
\text { and placebo respectively but even. The Sa- } \\
\text { fety population/Intent-to-treat (ITT) pop- } \\
\text { ulation consisted of all randomised patients } \\
\text { who took study medication (all of those } \\
\text { randomised) }\end{array}$ \\
\hline Selective reporting (reporting bias) & Low risk & $\begin{array}{l}\text { All outcomes stated in the GSK summary } \\
\text { were reported in detail }\end{array}$ \\
\hline
\end{tabular}

\section{SCO40041}

Methods

Design: Randomized, double-blind parallel group trial

Duration: 3 years

Location: 31 centres in the United States

Participants

Population: 186 people were randomised to salmeterol (94) and fluticasone/salmeterol combination (92)

\section{Baseline characteristics}

Age (mean years): salm 65.9, flut/salm 65.4

\% Male: salm 62.8, flut/salm 59.8

$\% \mathrm{FEV}_{1}$ predicted: not reported

Pack-years (mean): not reported

Inclusion criteria: Male/female subjects with an established clinical history of COPD

(including a history of exacerbations), a baseline (pre-bronchodilator) FEV $1<70 \%$ of the predicted normal value, a baseline (pre-bronchodilator) FEV1 / FVC ratio 70\%, have at least one evaluable native hip and have a smoking history of $\geq 10$ pack-years.

Exclusion criteria: No information

$\begin{array}{ll}\text { Interventions } & \text { 1. Salmeterol } 50 \text { bid (LABA) } \\ \text { 2. Salmeterol/fluticasone 50/250 bid (LABA/ICS) } \\ \text { Inhaler device: Diskus } \\ \text { Allowed co-medications: no information }\end{array}$

Outcomes

Change in bone mineral density at the lumbar spine and hip, adverse events, serious adverse events, fatal SAEs

Notes

Funding: GlaxoSmithKline

Identifier(s): GSK SCO40041

\section{Risk of bias}

Bias

Authors' judgement

Support for judgement 


\begin{tabular}{l|l|l}
\hline $\begin{array}{l}\text { Random sequence generation (selection } \\
\text { bias) }\end{array}$ & Low risk & $\begin{array}{l}\text { Randomised to treatment [no specific in- } \\
\text { formation but assumed to adhere to GSK } \\
\text { methods] }\end{array}$ \\
\hline $\begin{array}{l}\text { Allocation concealment (selection bias) } \\
\begin{array}{l}\text { Blinding of participants and personnel } \\
\text { (performance bias) } \\
\text { All outcomes }\end{array}\end{array}$ & Low risk & Not described \\
\hline $\begin{array}{l}\text { Blinding of outcome assessment (detection } \\
\text { bias) } \\
\text { All outcomes }\end{array}$ & Unclear risk & $\begin{array}{l}\text { Double-blind [presumed participant and } \\
\text { personnel/investigator] }\end{array}$ \\
\hline $\begin{array}{l}\text { Incomplete outcome data (attrition bias) } \\
\text { All outcomes }\end{array}$ & High risk & Not described \\
\hline \begin{tabular}{l} 
Selective reporting (reporting bias) \\
\hline
\end{tabular} & Low risk & $\begin{array}{l}\text { Withdrawal very high in both groups (39 } \\
\text { and 41\%) }\end{array}$ \\
\hline
\end{tabular}

\section{Senderovitz 1999}

\section{Methods}

Participants
Design: Placebo-controlled, randomised, double-blind multi-centre trial Duration: 6 months (+ 2 week prednisolone run-in)

Location: 5 centres in Denmark

Pudesonide (14) and placebo (12) groups
Baseline characteristics
Age (mean years): bud 58.5 , pbo 62.5
$\%$ Male: bud 57, pbo 50
$\% \mathrm{FEV}_{1}$ predicted: not reported
Pack-years (mean): not reported
Inclusion criteria: Outpatients aged $18-75$ years with stable COPD were included.
FEV1, forced vital capacity (FVC) $<0.7$, a post-bronchodilator FEVl $<70 \%$ of predicted,
FEVl $>40 \%$ of predicted and an increase in FEVl $<15 \%$ after inhalation of O-5 mg
terbutaline
Exclusion criteria: Clinical evidence of asthma (e.g. pollen season related symptoms,
exercise-induced symptoms only and significantly elevated levels of eosinophils and IgE)
, a history of atopy (hay fever and/or atopic dermatitis), treatment with inhaled corti-
costeroids within the last 6 months, treatment with oral corticosteroids, cromoglycate
or nedocromil within the last 4 weeks, other systemic disease making compliance and
participation in the study difficult, pregnancy and breast feeding, and an increase in FEV,
$>30 \%$ of baseline after 2 weeks of prednisolone treatment

Interventions
1. Budesonide 400 bid (ICS)

2. Placebo (PBO)

Inhaler device: Spirocort Turbuhaler 
Senderovitz 1999 (Continued)

Allowed co-medications: not reported

\begin{tabular}{ll}
\hline Outcomes & FEV1, exacerbations, adverse events and symptom scores \\
\hline Notes & $\begin{array}{l}\text { Funding: not reported } \\
\text { Identifier(s): unknown }\end{array}$ \\
\hline
\end{tabular}

Risk of bias

\begin{tabular}{|c|c|c|}
\hline Bias & Authors' judgement & Support for judgement \\
\hline $\begin{array}{l}\text { Random sequence generation (selection } \\
\text { bias) }\end{array}$ & Unclear risk & $\begin{array}{l}\text { Reversible patients with } 15 \%<\text { AFEVl }< \\
30 \% \text { of baseline and irreversible patients } \\
\text { with AFEV, }<15 \% \text { were separately ran- } \\
\text { domized }\end{array}$ \\
\hline Allocation concealment (selection bias) & Unclear risk & Not described \\
\hline $\begin{array}{l}\text { Blinding of participants and personnel } \\
\text { (performance bias) } \\
\text { All outcomes }\end{array}$ & Low risk & $\begin{array}{l}\text { Described as double-blind [presumed par- } \\
\text { ticipants and personnel/investigators] }\end{array}$ \\
\hline $\begin{array}{l}\text { Blinding of outcome assessment (detection } \\
\text { bias) } \\
\text { All outcomes }\end{array}$ & Unclear risk & Not described \\
\hline $\begin{array}{l}\text { Incomplete outcome data (attrition bias) } \\
\text { All outcomes }\end{array}$ & Unclear risk & $\begin{array}{l}26 \text { out of } 37 \text { were evaluable ( } 12 \text { in placebo } \\
\text { group, } 14 \text { in active group - } 30 \% \text { dropout } \\
\text { overall). Number randomised and number } \\
\text { of dropouts not provided for each group. } \\
\text { ITT not adopted }\end{array}$ \\
\hline Selective reporting (reporting bias) & High risk & $\begin{array}{l}\text { Several key expected outcomes not re- } \\
\text { ported (mortality, adverse events, with- } \\
\text { drawal per group). Author contacted but } \\
\text { not able to provide data }\end{array}$ \\
\hline
\end{tabular}

Shaker 2009

Methods

Design: Randomised, double-blinded, placebo-controlled, parallel-group, single-centre study

Duration: 2 to 4 years (+ 2 week prednisolone run-in)

Location: single centre in Denmark

Participants

Population: 254 participants were randomised to budesonide (127) and placebo (127) Baseline characteristics

Age (mean years): bud 63.6, pbo 63.6

$\%$ Male: bud 62.2, pbo 54.3 
Shaker 2009 (Continued)

$\% \mathrm{FEV}_{1}$ predicted: bud 51, placebo 53

Pack-years (mean): bud 56, pbo 56

Inclusion criteria: Patients aged 50-80 years were eligible if they were current smokers with a clinical diagnosis of COPD for not less than 2 years. All patients should have a significant smoking history of at least 10 cigarettes per day during the last 6 months and a previous history of at least 20 pack-years. Ex-smokers were excluded. Baseline lung function criteria were: FEV1 between $35 \%$ and $70 \%$ of predicted (pre-bronchodilator) , and FEV1/forced vital capacity (FEV1/FVC) $\leq 60 \%$

Exclusion criteria: Reversibility of $\geq 12 \%$ and $200 \mathrm{~mL}$ in FEV1 from baseline values, 15 minutes after inhalation of $1 \mathrm{mg}$ terbutaline or $\geq 15 \%$ and $300 \mathrm{~mL}$ after 2 weeks on oral prednisolone $(25 \mathrm{mg}$ ) was an exclusion criterion. Patients were also excluded if they: had any severe concomitant disease; had an exacerbation within 30 days prior to the first visit; received oral steroids for more than 4 weeks within 6 months of the first visit; or were on long-term oxygen therapy

Interventions

1. Budesonide 400 bid (ICS)

2. Placebo (PBO)

Inhaler device: Pulmicort Turbuhaler

Allowed co-medications: Bronchodilators, mucolytics, and short courses of oral corticosteroids (maximum 3 courses of 4 -week duration per year) and antibiotics were allowed during the study

Outcomes

15th percentile density (PD15), change over time in the relative area of emphysema at a threshold of -910 Hounsfield units (RA-910), FEV1, diffusion capacity (DLCO), and number of exacerbations

$\begin{array}{ll}\text { Notes } & \text { Funding: AstraZeneca } \\ & \text { Identifier(s): unknown }\end{array}$

\section{Risk of bias}

Bias

Random sequence generation (selection Low risk bias)

\section{Authors' judgement}

\section{Support for judgement}

Patients were allocated into either group in a proportion of $1: 1$ by block randomisation using a random sequence generated by a computer program at AstraZeneca

Not described

Double-blind. To maintain blinding all Turbuhalers were of identical appearance
Blinding of participants and personnel Low risk (performance bias)

All outcomes
Not described

Blinding of outcome assessment (detection Unclear risk bias)

All outcomes 
Shaker 2009 (Continued)

\begin{tabular}{l|ll}
$\begin{array}{l}\text { Incomplete outcome data (attrition bias) } \\
\text { All outcomes }\end{array}$ & High risk & $\begin{array}{l}\text { High proportion of dropouts in both } \\
\text { groups }(43 \% \text { intervention and } 49 \% \\
\text { placebo) }\end{array}$ \\
\hline Selective reporting (reporting bias) & Low risk & $\begin{array}{l}\text { Couldn't locate protocol to check that all } \\
\text { prospectively registered outcomes were re- } \\
\text { ported but authors provided all relevant } \\
\text { outcomes upon request }\end{array}$ \\
\hline
\end{tabular}

Sharafkhaneh 2012

Methods

Design: Randomised, double-blind, double-dummy, parallel-group, multi-centre study Duration: 12 months (+ 2 week run-in)

Location: 180 study sites in the United States, Central and South America, and South Africa

Participants

Population: 1219 participants were randomised to formoterol (404) and two doses of formoterol/budesonide combination (407 and 408)

Baseline characteristics

Age (mean years): form 62.5 ,form/bud320 63.8, form/bud160 62.8

\% Male: form 56.8 ,form/bud320 64.4, form/bud160 64.7

$\% \mathrm{FEV}_{1}$ predicted: form 37.5, form/bud320 37.9, form/bud160 37.6

Pack-years (mean): form 43, form/bud320 46, form/bud160 44

Inclusion criteria: Patients were current smokers or ex-smokers with a smoking history of 10 pack-years, aged 40 years, with a clinical diagnosis of COPD with symptoms for $>2$ years. Patients were required to have a history of 1 COPD exacerbation requiring treatment with a course of systemic corticosteroids, antibiotics, or both, within 12 months before screening (visit 1) and documented use of an inhaled short-acting bronchodilator as rescue medication. At screening, a pre-bronchodilator FEV1 of $50 \%$ of predicted normal and a pre-bronchodilator FEV1/FVC of $<70 \%$ also were required.

Exclusion criteria: Exclusion criteria included current, previous (within past 60 days) , or planned enrolment in a COPD pulmonary rehabilitation program, treatment with oral corticosteroids, and incidence of a COPD exacerbation or any other significant medical diagnosis between the screening and randomisation visits

Interventions

1. Formoterol 9 BID (LABA)

2. Formoterol/budesonide $9 / 320$ BID (LABA/ICS)

3. Formoterol/budesonide 9/160 BID (LABA/ICS)

Inhaler device: 1 , dry powder; 2 and 3 pressurised metered dose

Allowed co-medications: Aalbuterol pMDI $90 \mathrm{mg} 2$ inhalations) was provided for asneeded use during screening and run-in, and throughout the study

Outcomes

COPD exacerbations, FEV1, FVC, morning and evening PEF, diary card symptoms, rescue medication use, BODE index, exercise capacity, health-related quality of life (SGRQ), adverse events

Notes

Funding: AstraZeneca

Identifier(s): NCT00419744, AZ D589CC00003

Long-acting inhaled therapy (beta-agonists, anticholinergics and steroids) for COPD: a network meta-analysis (Review) 
Sharafkhaneh 2012 (Continued)

\section{Risk of bias}

\begin{tabular}{|c|c|c|}
\hline Bias & Authors' judgement & Support for judgement \\
\hline $\begin{array}{l}\text { Random sequence generation (selection } \\
\text { bias) }\end{array}$ & Low risk & $\begin{array}{l}\text { Assignments were made sequentially by in- } \\
\text { teractive voice response system following } \\
\text { a computer generated allocation schedule } \\
\text { produced in advance }\end{array}$ \\
\hline Allocation concealment (selection bias) & Low risk & $\begin{array}{l}\text { Assignments were made sequentially by in- } \\
\text { teractive voice response system following } \\
\text { a computer generated allocation schedule } \\
\text { produced in advance }\end{array}$ \\
\hline
\end{tabular}

Blinding of participants and personnel Low risk (performance bias)

All outcomes

To maintain patient and investigator blinding, all active treatments were provided in blinded treatment kits. Patients in the budesonide/formoterol pMDI groups received a placebo DPI and those in the formoterol DPI group received a placebo pMDI

Blinding of outcome assessment (detection Unclear risk

Not described bias)

All outcomes

Incomplete outcome data (attrition bias) High risk All outcomes

The withdrawal rates were relatively even but high, especially compared to the low event rates for the outcomes of interest

Selective reporting (reporting bias) Low risk

All outcomes stated in the protocol were reported in detail

\section{SLMF4010}

Methods

Design: multi-centre, randomised, parallel-group, placebo-controlled, double-blind study

Duration: 6 months (run-in not defined)

Location: 9 centres in France

Participants

Population: 34 participants were randomised to salmeterol (17) and placebo (17)

Baseline characteristics

Age (mean years): salm 62.9, pbo 64.6

$\%$ Male: salm 94.1, pbo 82.4

$\% \mathrm{FEV}_{1}$ predicted: not reported

Pack-years (mean): not reported

Inclusion criteria: males and females aged 40 and older; history of at least 20 packyears; diagnosis of COPD; $\mathrm{FEV}_{1}>60 \%$ of theoretical value, $\mathrm{FEV}_{1} / \mathrm{TLC}$ ratio $>75 \%$ 
in absolute value and $>85 \%$ of theoretical value, $\mathrm{FEV}_{1}$ reversibility $>12 \%$ and $>200$ $\mathrm{mL} 20$ minutes after $400 \mu \mathrm{g}$ of salbutamol

Exclusion criteria: history of asthma or allergy including non-respiratory signs (bronchial cancer, thoracic surgery, etc.); severe cardiovascular disease; exacerbation and/ or other acute respiratory disease within 4 weeks before enrolment

\begin{tabular}{l|l} 
Interventions & $\begin{array}{l}\text { 1. Salmeterol } 50 \text { bid (LABA) } \\
\text { 2. Placbeo (PBO) } \\
\text { Inhaler device: dry powder } \\
\text { Allowed co-medications: Disal } \\
\text { inhaled or systemic corticoster } \\
\text { rolment }\end{array}$ \\
\hline Outcomes & $\begin{array}{l}\text { St George's Respiratory Questio } \\
\text { stay, variations in IC, FRC, FE } \\
\text { salbutamol), exercise capacity, }\end{array}$ \\
\hline Notes & Funding: GlaxoSmithKline \\
Identifier(s): GSK SLMF4010
\end{tabular}

Risk of bias

Bias

Authors' judgement

Support for judgement

Random sequence generation (selection Low risk bias)

Randomised and stratified on tobacco status [no other details, industry sponsored]

\begin{tabular}{l|ll}
\hline Allocation concealment (selection bias) & Unclear risk & No details provided \\
\hline $\begin{array}{l}\text { Blinding of participants and personnel } \\
\text { (performance bias) }\end{array}$ & Low risk & $\begin{array}{l}\text { Double-blind (presumed subject and inves- } \\
\text { tigator) }\end{array}$ \\
\hline
\end{tabular}

Blinding of outcome assessment (detection Low risk bias)

All outcomes
No details provided. Included outcomes unlikely to be subject to detection bias
Incomplete outcome data (attrition bias) High risk

All outcomes
Withdrawal very high in both groups [ 41 . $2 \%$ each]. The ITT population included all randomised subjects having received at least one dose of study medication and for whom the assessment data for at least one assessment criterion was available and was analysed based on treatment allocated. Safety population consisted of all randomised subjects having received at least one dose of study medication and was analysed based on treatment really received 
SLMF4010 (Continued)

Selective reporting (reporting bias) High risk

Quality of life [primary outcome] and trough FEV1 [secondary] were not reported in a way that could be included in meta-analysis. All other outcomes reported and included

SPARK 2013

Methods

Design: randomised, double-blind, parallel-group study

Duration: 64 weeks

Location: 345 study locations

Participants

Population: 2224 participants were randomised to open-label tiotropium (742), glycopyrronium (741), and a combination therapy not relevant to this review (741)

Baseline characteristics

Age (mean years): gly 63.1, tio 63.6

$\%$ Male: gly 73.2 , tio 75.0

$\% \mathrm{FEV}_{1}$ predicted: not reported

Pack-years (mean): not reported

Inclusion criteria: Male or female adults aged $\geq 40$ years, who had signed an informed consent form prior to initiation of any study-related procedure; severe to very severe Chronic Obstructive Pulmonary Disease COPD (Stage III or IV) according to the Global Initiative for Chronic Obstructive Lung Disease (GOLD) Guidelines 2008; current or ex-smokers with a smoking history of at least 10 pack years (Ten pack-years were defined as 20 cigarettes a day for 10 years, or 10 cigarettes a day for 20 years); postbronchodilator Forced Expiratory Volume in one second ( FEV1) $<50 \%$ of the predicted normal value, and post-bronchodilator FEV1/ Forced Vital Capacity (FVC) $<0.70$ at Visit 2; documented history of at least 1 COPD exacerbation in the previous 12 months that required treatment with systemic glucocorticosteroids and/or antibiotics

Exclusion criteria: Pregnant women or nursing mothers; women of child-bearing potential; requiring long term oxygen therapy; COPD exacerbation that required treatment with antibiotics, systemic steroids (oral or intravenous) or hospitalisation in the 6 weeks prior to visit 1 ; respiratory tract infection within 4 weeks prior to visit 1 ; concomitant pulmonary disease; lung lobectomy, or lung volume reduction or lung transplantation; clinically relevant laboratory abnormality or a clinically significant condition; history of asthma, allergic rhinitis, eczema or alphal antitrypsin deficiency; contraindication for study drugs

Interventions

1. Glycopyrronium 50 qd (LAMA)

2. Tiotropium 18 qd (LAMA) - open-label

Inhaler device: Glycopyrronium was delivered via a Novartis single-dose dry powder inhaler, and tiotropium was delivered open-label via the HandiHaler

Allowed co-medications: Salbutamol could be taken as needed throughout the study;

Outcomes

The primary outcome was rate of moderate/severe COPD exacerbations. Secondary outcomes included pre-dose FEV1 and FVC, rescue medication use, and the St George's Respiratory Questionnaire

Long-acting inhaled therapy (beta-agonists, anticholinergics and steroids) for COPD: a network meta-analysis (Review)

Copyright @ 2014 The Cochrane Collaboration. Published by John Wiley \& Sons, Ltd. 
SPARK 2013 (Continued)

\begin{tabular}{|c|c|c|}
\hline Notes & $\begin{array}{l}\text { Funding: Novartis } \\
\text { Identifier(s): NCT01120691 }\end{array}$ & \\
\hline \multicolumn{3}{|l|}{ Risk of bias } \\
\hline Bias & Authors' judgement & Support for judgement \\
\hline $\begin{array}{l}\text { Random sequence generation (selection } \\
\text { bias) }\end{array}$ & Low risk & $\begin{array}{l}\text { Randomised, not defined but industry } \\
\text { funded }\end{array}$ \\
\hline Allocation concealment (selection bias) & Unclear risk & Not described \\
\hline $\begin{array}{l}\text { Blinding of participants and personnel } \\
\text { (performance bias) } \\
\text { All outcomes }\end{array}$ & High risk & $\begin{array}{l}\text { Blinding procedures were sound, but } \\
\text { tiotropium was delivered open label which } \\
\text { introduced bias for these comparisons. } \\
\text { Double Blind (Subject, Caregiver, Investi- } \\
\text { gator, Outcomes Assessor) }\end{array}$ \\
\hline $\begin{array}{l}\text { Blinding of outcome assessment (detection } \\
\text { bias) } \\
\text { All outcomes }\end{array}$ & High risk & $\begin{array}{l}\text { Blinding procedures were sound, but } \\
\text { tiotropium was delivered open label which } \\
\text { introduced bias for these comparisons. } \\
\text { Double Blind (Subject, Caregiver, Investi- } \\
\text { gator, Outcomes Assessor) }\end{array}$ \\
\hline $\begin{array}{l}\text { Incomplete outcome data (attrition bias) } \\
\text { All outcomes }\end{array}$ & Low risk & $\begin{array}{l}\text { The full analysis set included over } 99 \% \text { of } \\
\text { the randomised population. } 25 \% \text { dropped } \\
\text { out overall, and dropout was relatively even } \\
\text { across groups ( } 24 \text { and } 27 \% \text { ) }\end{array}$ \\
\hline Selective reporting (reporting bias) & Low risk & $\begin{array}{l}\text { Outcomes were fully reported on clinical- } \\
\text { trials.gov }\end{array}$ \\
\hline
\end{tabular}

\section{Szafranski 2003}

\begin{tabular}{|c|c|}
\hline Methods & $\begin{array}{l}\text { Design: randomised, double-blind, placebo-controlled, parallel-group, multi-centre } \\
\text { study } \\
\text { Duration: } 12 \text { months }(+2 \text { weeks run-in period) } \\
\text { Location: } 89 \text { centres from } 11 \text { countries }\end{array}$ \\
\hline Participants & 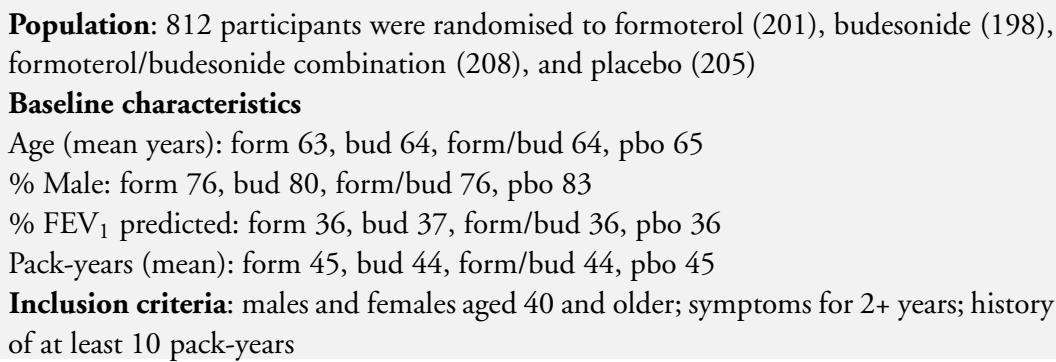 \\
\hline
\end{tabular}


Exclusion criteria: history of asthma or seasonal rhinitis before 40 years of age; relevant cardiovascular disorders; use of beta-blockers; current respiratory tract disorders other than COPD or any other significant diseases or disorders; requiring regular use of oxygen therapy; exacerbation during run-in

\begin{tabular}{|c|c|c|}
\hline Interventions & \multicolumn{2}{|c|}{$\begin{array}{l}\text { 1. Formoterol } 12 \text { bid (LABA) } \\
\text { 2. Budesonide } 400 \text { bid (ICS) } \\
\text { 3. Formoterol/budesonide } 9 / 320 \text { bid (LABA/ICS) } \\
\text { 4. Placebo (PBO) } \\
\text { Inhaler device: Dry powder turbuhaler } \\
\text { Allowed co-medications: terbutaline }(0.5 \mathrm{mg}) \text { as reliever. Disallowed medication in- } \\
\text { cluded parenteral steroids, oral steroids, antibiotics and nebulised treatment from } 4 \text { weeks } \\
\text { before; inhaled steroids from } 2 \text { weeks before; inhaled long-acting beta } \text {-agonists from } \\
48 \text { hours before; inhaled short-acting beta } 2 \text {-agonists from } 6 \text { hours before; other bron- } \\
\text { chodilators from } 6 \text { to } 48 \text { hours before }\end{array}$} \\
\hline Outcomes & \multicolumn{2}{|c|}{$\begin{array}{l}\text { St George's Respiratory Questionnaire (SGRQ), COPD exacerbations, } \mathrm{FEV}_{1} \text {, vital ca- } \\
\text { pacity, morning and evening PEF, diary card data }\end{array}$} \\
\hline Notes & \multicolumn{2}{|c|}{$\begin{array}{l}\text { Funding: AstraZeneca } \\
\text { Identifier(s): AZ SD-039-CR-0629 }\end{array}$} \\
\hline \multicolumn{3}{|l|}{ Risk of bias } \\
\hline Bias & Authors' judgement & Support for judgement \\
\hline $\begin{array}{l}\text { Random sequence generation (selection } \\
\text { bias) }\end{array}$ & Low risk & $\begin{array}{l}\text { A total of } 812 \text { patients were randomised } \\
\text { [no other details, industry sponsored] }\end{array}$ \\
\hline Allocation concealment (selection bias) & Unclear risk & No details provided \\
\hline $\begin{array}{l}\text { Blinding of participants and personnel } \\
\text { (performance bias) } \\
\text { All outcomes }\end{array}$ & Low risk & $\begin{array}{l}\text { Double-blind [presumed subject and inves- } \\
\text { tigator] }\end{array}$ \\
\hline $\begin{array}{l}\text { Blinding of outcome assessment (detection } \\
\text { bias) } \\
\text { All outcomes }\end{array}$ & Low risk & $\begin{array}{l}\text { No details provided. Inlcuded outcomes } \\
\text { unlikely to be affected by detection bias }\end{array}$ \\
\hline $\begin{array}{l}\text { Incomplete outcome data (attrition bias) } \\
\text { All outcomes }\end{array}$ & High risk & $\begin{array}{l}\text { Withdrawal high and uneven between } \\
\text { groups (formoterol } 31.8 \% \text {, placebo } 43 . \\
9 \% \text { ). An intention-to-treat analysis was } \\
\text { used }\end{array}$ \\
\hline Selective reporting (reporting bias) & High risk & $\begin{array}{l}\text { Quality of life [primary] stated as outcome } \\
\text { but not reported in enough detail to in- } \\
\text { clude in meta-analysis }\end{array}$ \\
\hline
\end{tabular}


Design: randomised, double-blind, double-dummy, placebo-controlled, parallel-group, multicenter study

Duration: 6 months (+ 2 weeks run-in period)

Location: 194 centres in the USA, Czech Republic, the Netherlands, Poland and South Africa

Participants

Interventions
Population: 1704 participants were randomised to formoterol (284), budesonide (275) , three doses of formoterol/budesonide combination (281, 277 and 287, one of which was not included in the review as they were delivered in separate inhalers), and placebo (300)

\section{Baseline characteristics}

Age (mean years): form 63.5, bud 63.4, form/bud160 63.6, 1form/bud320 63.1, pbo 63.2

\% Male: form 65.5, bud 67.6, form/bud160 64.4, 1 form/bud320 67.9, pbo 69

$\% \mathrm{FEV}_{1}$ predicted: form 39.6, bud 39.7, form/bud160 39.9, 1 form/bud320 39.1, pbo 41.3

Pack-years (median): form 40, bud 41, form/bud160 40, 1 form/bud320 40, pbo 40

Inclusion criteria: male and female current or former smokers; history of at least 10 pack-years; clinical diagnosis of COPD; 40+ years; symptoms for longer than 2 years; at least one exacerbation treated with oral corticosteroids and/or antibacterials within 1 to 12 months before screening

Exclusion criteria: history of asthma or seasonal rhinitis before age 40; significant/ unstable cardiovascular disorder; significant respiratory tract disorder other than COPD; homozygous alpha ${ }_{1}$-antitrypsin deficiency or other clinically significant co-morbidities precluding participation
1. Formoterol 12 bid (LABA)
2. Budesonide 320 bid (ICS)
3. Formoterol/budesonide $9 / 160$ bid in one inhaler (LABA/ICS)
4. Formoterol/budesonide $9 / 320$ bid in one inhaler (LABA/ICS)
5. Placebo (PBO)

Inhaler device: dry powder

Allowed co-medications: Allowed medications were ephedrine-free antitussives and mucolytics; nasal corticosteroids; stable-dose non-nebulised ipratropium; cardioselective beta-adrenoceptor antagonists; salbutamol as rescue; oral steroids, xanthines, inhaled beta-agonists and ipratropium as medication for exacerbations. Medications disallowed during the study period were long-acting anticholinergics; inhaled LABAs or SABAs (other than salbutamol); oral beta-adrenoreceptor agonists; ephedrine; leukotriene receptor agonists and xanthine derivatives except for short-term use

Outcomes

St George's Respiratory Questionnaire (SGRQ) including number of people reaching threshold for minimal clinically important difference from baseline (4 units), COPD exacerbations per patient year, pre-dose $\mathrm{fFEV}_{1}$ and 1-hour post-dose $\mathrm{FEV}_{1}$, dyspnoea, morning and evening PEF

Notes

Funding: AstraZeneca

Identifier(s): NCT00206154, AZ D5899C00002 
Tashkin 2008 [SHINE]

\begin{tabular}{|c|c|c|}
\hline Bias & Authors' judgement & Support for judgement \\
\hline $\begin{array}{l}\text { Random sequence generation (selection } \\
\text { bias) }\end{array}$ & Low risk & $\begin{array}{l}\text { Eligable patients were randomized in bal- } \\
\text { anced blocks according to a computer-gen- } \\
\text { erated randomisation scheme at each site }\end{array}$ \\
\hline Allocation concealment (selection bias) & Unclear risk & No information provided \\
\hline $\begin{array}{l}\text { Blinding of participants and personnel } \\
\text { (performance bias) } \\
\text { All outcomes }\end{array}$ & Low risk & $\begin{array}{l}\text { To maintain blinding, patients received } \\
\text { both a pressurized metered-dose inhaler } \\
\text { (pMDI) and a dry powder inhaler (DPI) } \\
\text { containing either active treatment or } \\
\text { placebo (PL), or combinations of active } \\
\text { treatment and placebo, as appropriate }\end{array}$ \\
\hline
\end{tabular}

Blinding of outcome assessment (detection Low risk bias)

All outcomes

Incomplete outcome data (attrition bias) Low risk All outcomes

Selective reporting (reporting bias)

Low risk
ECG results were evaluated by a cardiologist in a blinded fashion through an independent ECG service provider

Withdrawal rates were similar $(21.5 \%$ formoterol, $25.7 \%$ placebo) and 'the efficacy analysis set included all randomised patients who received at least one dose of study medication and contributed sufficient data for at least one co-primary or secondary efficacy endpoint'

All stated outcomes were reported in full and included in the quantitative synthesis

\section{Tashkin 2008a [UPLIFT]}

$\begin{array}{ll}\text { Methods } & \text { Design: randomised, double-blind, parallel-group trial } \\ \text { Duration: } 4 \text { years } \\ \text { Location: } 487 \text { investigational centres in } 37 \text { countries }\end{array}$

Participants

Population: 5933 participants were randomised to tiotropium (2987) and placebo (3006)

\section{Baseline characteristics}

Age (mean years): tio 64.5, pbo 64.5

$\%$ Male: tio 75.4 , pbo 73.9

$\% \mathrm{FEV}_{1}$ predicted: tio 39.5 , pbo 39.3

Pack-years (mean): tio 49.0, pbo 48.4

Inclusion criteria: diagnosis of COPD, an age of 40 years or more, a smoking history of at least 10 pack-years, a post-bronchodilator FEV1 of $70 \%$ or less of the predicted value, and an FEV1 of $70 \%$ or less of the FVC (after supervised administration of 80 $\mu \mathrm{g}$ of ipratropium, followed by $400 \mu \mathrm{g}$ of albuterol 60 minutes later). 
Tashkin 2008a [UPLIFT] (Continued)

Exclusion criteria: history of asthma, a COPD exacerbation or respiratory infection within 4 weeks before screening, a history of pulmonary resection, use of supplemental oxygen for more than 12 hours per day, and the presence of a coexisting illness that could preclude participation in the study or interfere with the study results

\begin{tabular}{ll} 
Interventions & $\begin{array}{l}\text { 1. Tiotropium } 18 \text { qd (LAMA) } \\
\text { 2. Placebo (PBO) } \\
\text { Inhaler device: HandiHaler } \\
\text { Allowed co-medications: All respiratory medications, except other inhaled anticholin- } \\
\text { ergic drugs, were permitted during the trial }\end{array}$ \\
\hline Outcomes & $\begin{array}{l}\text { The two co-primary end points were the yearly rate of decline in the mean FEV1 be- } \\
\text { fore the use of a study drug and short-acting bronchodilators in the morning (pre- } \\
\text { bronchodilator) and after the use of a study drug (post-bronchodilator) from day } 30 \\
\text { (steady state) until completion of double-blind treatment. Secondary outcome measures } \\
\text { included the rate of decline in the mean forced vital capacity (FVC) and slow vital ca- } \\
\text { pacity (SVC); health-related quality of life, as measured by the total score on St. George's } \\
\text { Respiratory Questionnaire (SGRQ) and exacerbations }\end{array}$ \\
\hline
\end{tabular}

Notes

Funding: Boehringer Ingelheim

Identifier(s): NCT00144339

\section{Risk of bias}

\begin{tabular}{|c|c|c|}
\hline Bias & Authors' judgement & Support for judgement \\
\hline $\begin{array}{l}\text { Random sequence generation (selection } \\
\text { bias) }\end{array}$ & Low risk & $\begin{array}{l}\text { Eligible patients were randomly assigned } \\
\text { in a } 1: 1 \text { ratio to receive either tiotropium } \\
\text { or placebo with the use of centralized ran- } \\
\text { domisation in blocks of four, stratified ac- } \\
\text { cording to site }\end{array}$ \\
\hline Allocation concealment (selection bias) & Low risk & $\begin{array}{l}\text { Centralised randomisation implies that it } \\
\text { was concealed }\end{array}$ \\
\hline $\begin{array}{l}\text { Blinding of participants and personnel } \\
\text { (performance bias) } \\
\text { All outcomes }\end{array}$ & Low risk & $\begin{array}{l}\text { Refers to 'double-blind treatment period'. } \\
\text { Placebo was delivered via a matching in- } \\
\text { haler }\end{array}$ \\
\hline $\begin{array}{l}\text { Blinding of outcome assessment (detection } \\
\text { bias) } \\
\text { All outcomes }\end{array}$ & Unclear risk & Not described \\
\hline
\end{tabular}

Incomplete outcome data (attrition bias) Unclear risk All outcomes
Total dropout over 4 years was high $(37 \%$ and $45 \%$ for tio and placebo respectively) , but dropout was balanced. Around 83\% were included in the final analyses across both groups. Given the length of the study, it is difficult to assess the effect of missing 
Tashkin 2008a [UPLIFT] (Continued)

data on the results

Selective reporting (reporting bias) Low risk

Study results are posted in full on clinicaltrials.gov, and well reported in numerous publications

Tashkin 2012

Methods

Design: randomised, double-blind, placebo-controlled trial

Duration: 6 months (+ 2 weeks run-in period)

Location: 131 centres located in South America, Asia, Africa, Europe and North America

Participants

Population: 1055 participants were randomised to formoterol (209), mometasone (210)

, two doses of formoterol/mometasone combination (217 and 207), and placebo (212)

Baseline characteristics

Age (mean years): form 59.6, mom 59.8, form/mom400 59.7, form/mom200 60.9, pbo

58.8

$\%$ Male: form 72.7, mom 78.1, form/mom400 78.8, form/mom200 77.8, pbo 80.2

$\% \mathrm{FEV}_{1}$ predicted: not reported

Pack-years (mean): form 40.3, mom 40.0, form/mom400 39.7, form/mom200 41.7, pbo 40.3

Inclusion criteria: males and females aged 40 and older; history of at least 10 packyears; moderate to severe COPD for at least 2 years; predicted $\mathrm{FEV}_{1}$ between $25 \%$ and $60 \%$ normal

Exclusion criteria: exacerbation in the four weeks before randomisation; significant medical illness; diagnosis of asthma, lung cancer or alpha ${ }_{1}$-antitrypsin deficiency, lobectomy, pneumonectomy, lung volume reduction surgery or ocular problems

Interventions

1. Formoterol 10 bid (LABA)

2. Mometasone 400 bid (ICS)

3. Formoterol/mometasone $10 / 400$ bid (LABA/ICS)

4. Formoterol/mometasone $10 / 200 \mathrm{bid}$ (LABA/ICS)

5. Placebo (PBO)

Inhaler device: metered dose

Allowed co-medications: Participants were given open-label, short-acting beta 2 -agonist (SABA)/short-acting anticholinergic fixed-dose combination to use as relief medication throughout the study. All long-acting COPD treatments (LABA, ICS, LABA/ICS FDC or long-acting anticholinergics), supplemental oxygen and beta-blocking agents were not allowed during the study period

Outcomes

St George's Respiratory Questionnaire (SQRQ), reported as both final scores and the number of people experiencing a MCID (improvement or worsening by 4 units), COPD exacerbations, serial $\mathrm{FEV}_{1}$ post-dose, standardised $\mathrm{FEV}_{1}$ area under the curve, systemic and ocular effects

Notes

Funding: Merck \& Co/Schering-Plough

Identifier(s): NCT00383435

Long-acting inhaled therapy (beta-agonists, anticholinergics and steroids) for COPD: a network meta-analysis (Review)

Copyright () 2014 The Cochrane Collaboration. Published by John Wiley \& Sons, Ltd. 
Tashkin 2012 (Continued)

\section{Risk of bias}

\begin{tabular}{|c|c|c|}
\hline Bias & Authors' judgement & Support for judgement \\
\hline $\begin{array}{l}\text { Random sequence generation (selection } \\
\text { bias) }\end{array}$ & Low risk & $\begin{array}{l}\text { The sponsor's statistician produced a com- } \\
\text { puter-generated randomisation schedule } \\
\text { with treatment codes in blocks using SAS. } \\
\text { Randomisation was stratified according to } \\
\text { the subject's smoking status at the time of } \\
\text { randomisation }\end{array}$ \\
\hline Allocation concealment (selection bias) & Low risk & $\begin{array}{l}\text { Randomized treatment assignment was } \\
\text { provided to the investigative site by means } \\
\text { of an interactive voice response system at } \\
\text { the time subjects were randomized }\end{array}$ \\
\hline $\begin{array}{l}\text { Blinding of participants and personnel } \\
\text { (performance bias) } \\
\text { All outcomes }\end{array}$ & Low risk & $\begin{array}{l}\text { Protocol describes the study masking as } \\
\text { double-blind (subject, investigator) }\end{array}$ \\
\hline $\begin{array}{l}\text { Blinding of outcome assessment (detection } \\
\text { bias) } \\
\text { All outcomes }\end{array}$ & Low risk & $\begin{array}{l}\text { Protocol describes the study masking as } \\
\text { double-blind (subject, investigator) }\end{array}$ \\
\hline $\begin{array}{l}\text { Incomplete outcome data (attrition bias) } \\
\text { All outcomes }\end{array}$ & Unclear risk & $\begin{array}{l}\text { Withdrawal rates } 17.7 \% \text { in formoterol and } \\
25 \% \text { in the placebo group, unclear methods } \\
\text { of imputation for some outcomes }\end{array}$ \\
\hline Selective reporting (reporting bias) & High risk & $\begin{array}{l}\text { Can't extract FEV1 (table 3), other out- } \\
\text { comes poorly reported for the comparison } \\
\text { used in this review }\end{array}$ \\
\hline
\end{tabular}

To 2011

Methods

Design: randomised, parallel-group, open-label study

Duration: 12 months

Location: Japan

Participants

Population: 186 participants were randomised to salmeterol (61) and indacaterol (125) Baseline characteristics - for whole population only

Age (mean years): 69.1

$\%$ Male: not reported

$\% \mathrm{FEV}_{1}$ predicted: 53

Pack-years (mean): not reported

Inclusion criteria: patients with moderate-to-severe COPD (post-bronchodilator FEV1/FVC $<70 \%$ and FEV1 $>30 \%$ to $<80 \%$ predicted) and smoking history of at least 20 pack-years

Exclusion criteria: not reported, abstract only 


\begin{tabular}{|c|c|c|}
\hline Interventions & \multicolumn{2}{|l|}{$\begin{array}{l}\text { 1. Salmeterol } 50 \text { bid (LABA) } \\
\text { 2. Indacaterol } 300 \mathrm{qd} \text { (LABA) } \\
\text { Inhaler device: unclear } \\
\text { Allowed co-medications: not described }\end{array}$} \\
\hline Outcomes & \multicolumn{2}{|l|}{ trough FEV1, TDI and safety assessments } \\
\hline Notes & \multicolumn{2}{|l|}{$\begin{array}{l}\text { Funding: Novartis } \\
\text { Identifier(s): unknown }\end{array}$} \\
\hline \multicolumn{3}{|l|}{ Risk of bias } \\
\hline Bias & Authors' judgement & Support for judgement \\
\hline $\begin{array}{l}\text { Random sequence generation (selection } \\
\text { bias) }\end{array}$ & Unclear risk & $\begin{array}{l}\text { Patients meeting inclusion criteria were } \\
\text { randomised in the ratio } 2: 1 \text { to indacaterol } \\
\text { and salmeterol (methods not described) }\end{array}$ \\
\hline Allocation concealment (selection bias) & Unclear risk & no details \\
\hline $\begin{array}{l}\text { Blinding of participants and personnel } \\
\text { (performance bias) } \\
\text { All outcomes }\end{array}$ & High risk & $\begin{array}{l}\text { Both treatments were administered open- } \\
\text { label }\end{array}$ \\
\hline $\begin{array}{l}\text { Blinding of outcome assessment (detection } \\
\text { bias) } \\
\text { All outcomes }\end{array}$ & High risk & $\begin{array}{l}\text { Both treatments were administered open- } \\
\text { label }\end{array}$ \\
\hline $\begin{array}{l}\text { Incomplete outcome data (attrition bias) } \\
\text { All outcomes }\end{array}$ & Unclear risk & Unclear, abstract only \\
\hline Selective reporting (reporting bias) & High risk & $\begin{array}{l}\text { Data could not be included in meta-analy- } \\
\text { sis, only abstract available }\end{array}$ \\
\hline
\end{tabular}

\section{Tonnel 2008 [TIPHON]}

Methods

Participants
Design: randomised, double-blind, multi-centre study

Duration: 9 months (+ 2 week run-in)

Location: 123 centres in France

Population: 554 participants were randomised to tiotropium (266) and placebo (288) Baseline characteristics

Age (mean years): tio 64.9, pbo 63.5

$\%$ Male: tio 86.8 , pbo 85.4

$\% \mathrm{FEV}_{1}$ predicted: tio 47.5 , pbo 46.2

Pack-years (mean): tio 44.4, pbo 43.0

Inclusion criteria: male and female outpatients ages $>40$ years with a clinical diagnosis of COPD (pre- and post-bronchodilator FEV1 $20-70 \%$ predicted and FEV1/SVC <70\%) 
Tonnel 2008 [TIPHON] (Continued)

corresponding to mild, moderate, or severe COPD according to 1995 ATS criteria, and a smoking history of $>10$ pack-years were eligible for inclusion.

Exclusion criteria: history of asthma, allergic rhinitis, or atopy; regular use of daytime oxygen therapy; a recent respiratory tract infection (within the previous 6 week); a recent history of myocardial infarction (within the previous 6 months); cardiac arrhythmia requiring drug therapy (within the previous year); or hospitalisation for either heart failure or pulmonary edema (within the previous 3 years)

Interventions

1. Tiotropium 18 qd (LAMA)

2. Placebo (PBO)

Inhaler device: HandiHaler

Allowed co-medications: Patients were permitted to use salbutamol as needed. Concomitant use of theophylline preparations, mucolytics, inhaled corticosteroids, and oral steroids at a dose of $<10 \mathrm{mg}$ prednisone daily or equivalent, was allowed if the dosage was stabilized for $>6$ weeks before study entry. During the treatment period, patients were not allowed to use beta blockers, antileukotrienes, oral or inhaled long-acting beta2agonists, short-acting anticholinergics, or any other investigational drug

Outcomes

The primary efficacy endpoint was proportion of patients achieving a reduction of at least 4 units in the SGRQ total score at the end of the study. Secondary endpoints included FEV1, FVC, inspiratory capacity, SVC, FIV1, exacerbations and adverse events

Notes Funding: Boehringer Ingelheim, France

Identifier(s): 205.256

Risk of bias

\begin{tabular}{|c|c|c|}
\hline Bias & Authors' judgement & Support for judgement \\
\hline
\end{tabular}

Random sequence generation (selection Low risk bias)

Patients were assigned using a computergenerated randomisation schedule, with no stratification (block size of 4)

\begin{tabular}{|c|c|c|}
\hline Allocation concealment (selection bias) & Unclear risk & Not described \\
\hline $\begin{array}{l}\text { Blinding of participants and personnel } \\
\text { (performance bias) } \\
\text { All outcomes }\end{array}$ & Low risk & $\begin{array}{l}\text { Double-blind, tiotropium and placebo } \\
\text { were delivered via the same type of inhaler }\end{array}$ \\
\hline $\begin{array}{l}\text { Blinding of outcome assessment (detection } \\
\text { bias) } \\
\text { All outcomes }\end{array}$ & Unclear risk & Unlcear who performed the assessments \\
\hline $\begin{array}{l}\text { Incomplete outcome data (attrition bias) } \\
\text { All outcomes }\end{array}$ & Low risk & $\begin{array}{l}\text { Efficacy was measured in the full anal- } \\
\text { ysis population, which included all ran- } \\
\text { domised patients who received study med- } \\
\text { ication and had baseline and at least } 1 \\
\text { valid post-treatment measurement. Miss- } \\
\text { ing SGRQ component or total scores were }\end{array}$ \\
\hline
\end{tabular}

Long-acting inhaled therapy (beta-agonists, anticholinergics and steroids) for COPD: a network meta-analysis (Review) 
Tonnel 2008 [TIPHON] (Continued)

imputed using the last observation carried forward. Dropout was higher in the placebo group (25.7 vs $14.7 \%)$

Selective reporting (reporting bias) Low risk

Outcomes were well reported in accordance with the manufacturer protocol

Trooster 2011

Methods

Design: randomized, double-blind, placebo-controlled, multi-national study

Duration: 24 weeks

Location: 62 centres in 10 countries

Participants

Population: 457 participants were randomised to tiotropium (238) and placebo (219) Baseline characteristics

Age (mean years): tio 61.2, pbo 62.3

$\%$ Male: tio 69.7, pbo 67.1

$\% \mathrm{FEV}_{1}$ predicted: not reported

Pack-years (mean): not reported

Inclusion criteria: moderate COPD (post-bronchodilator forced expiratory volume in 1 second [FEV1] 50-80\% predicted; GOLD Stage II) who have not previously been treated with maintenance therapy, i.e. who have only been treated with short-acting b2agonists on an as-needed basis in the 6 months prior to study enrolment and who have symptomatic shortness of breath.

Exclusion criteria: (1) were treated with maintenance respiratory medications within the 6 months prior to screening; (2) had an upper respiratory tract infection or COPD exacerbation in the 6 weeks prior to the screening visit or during the screening visit prior to Visit 3; (3) had non-pulmonary disease that would limit physical activity (e.g. arthritis, amputation); (4) had a history of asthma, cystic fibrosis, pulmonary fibrosis, bronchiectasis, pulmonary resection or other significant respiratory disorders other than COPD; (5) had significant diseases other than COPD which, in the opinion of the investigator, may influence the results of the study or the patient's ability to participate; (6) contraindication to exercise testing; (7) had prior participation (within 2 years) of either cardiac or pulmonary rehabilitation

Interventions $\quad$ 1.Tiotropium 18 qd (LAMA)

2. Placebo (PBO

Inhaler device: HandiHaler

Allowed co-medications: as-needed albuterol. There was no restrictions for medications prescribed for treatment of exacerbations as long as they are used for fewer than 2 cumulative weeks

Outcomes

The primary endpoint is lung function improvement as captured by the area under the curve (AUC) of FEV1 versus time (FEV1AUC 0-3h). Physical activity is assessed during the week prior to each study visit, using a validated activity monitor as a secondary endpoint. Additional secondary objectives include the effect of tiotropium treatment on other lung function variables, patient and physician global evaluations, worker productivity as assessed by the Work Productivity and Activity Impairment questionnaire, and the use of rescue medication. Information on COPD exacerbations is collected through

Long-acting inhaled therapy (beta-agonists, anticholinergics and steroids) for COPD: a network meta-analysis (Review)

Copyright @ 2014 The Cochrane Collaboration. Published by John Wiley \& Sons, Ltd. 
Trooster 2011 (Continued)

serious adverse event monitoring

\begin{tabular}{l|ll}
\hline Notes & $\begin{array}{l}\text { Funding: Boehringer Ingelheim/Pfizer } \\
\text { Identifier(s): NCT00523991 and 205.365, A4471008 }\end{array}$ \\
\hline Risk of bias & Authors' judgement & Support for judgement \\
\hline Bias & Low risk & $\begin{array}{l}\text { Randomized in a ratio of 1:1 [industry } \\
\text { funded] }\end{array}$ \\
\hline $\begin{array}{l}\text { Random sequence generation (selection } \\
\text { bias) }\end{array}$ & Unclear risk & Not described \\
\hline $\begin{array}{l}\text { Allocation concealment (selection bias) } \\
\text { Blinding of participants and personnel } \\
\text { (performance bias) } \\
\text { All outcomes }\end{array}$ & Low risk & $\begin{array}{l}\text { Double-blind treatment phase. Placebo } \\
\text { was delivered in an identical inhaler }\end{array}$ \\
\hline $\begin{array}{l}\text { Blinding of outcome assessment (detection } \\
\text { bias) } \\
\text { All outcomes }\end{array}$ & Unclear risk & Not described \\
\hline
\end{tabular}

Incomplete outcome data (attrition bias) Low risk All outcomes

Full Analysis Set (FAS): All subjects who were randomized, received at least 1 dose of the study drug, and had baseline and at least 1 post-baseline data measurement available for the primary efficacy variable. All efficacy analyses, except analyses for physical activity endpoints, were performed using the FAS population $(95 \%$ of those randomised). $89 \%$ and $90 \%$ completed the study

Selective reporting (reporting bias) Low risk

Results were well reported in the publication and posted on clinicaltrials.gov

\section{Verhoeven 2002}

Methods

Participants
Design: Randomised, double-blind, placebo-controlled study

Duration: 6 months (+ 2 week run-in)

Location: single centre in the Netherlands

Population: 23 participants were randomised to fluticasone (10) and placebo (13) Baseline characteristics

Age (mean years): flut 54, pbo 56

$\%$ Male: flut 80 , pbo 84.6

$\% \mathrm{FEV}_{1}$ predicted: flut 66 , pbo 61

Pack-years (mean): flut 25, pbo 26 
Inclusion criteria: Chronic productive cough, FEV1 $<70 \%$ of predicted normal value, FEV1 reversibility of $<10 \%$ predicted after $750 \mathrm{mg}$ terbutaline administered by metered dose inhalation, negative serological examination (Phadiatop test), and negative skin prick tests for standard inhaled allergens).22 Patients with an FEV1/inspiratory vital capacity (IVC) ratio of $<0.70$ were also included, provided their total lung capacity (TLC) was greater than the predicted value +1.64 SD. Reference values were obtained from ECGS standards.23 Participants had to be current and persistent smokers aged 4070 years.

Exclusion criteria: History of asthma characterised by attacks of dyspnoea, chest tightness or wheezing, respiratory tract infection in the 4 weeks preceding the first visit, or were suffering from serious or unstable concomitant disease

Interventions
2. Placebo (PBO)
Inhaler device: Diskhaler
Allowed co-medications: Eligible patients using anti-inflammatory treatment including
non-steroidal anti-inflammatory drugs were asked to refrain from oral prescriptions for
at least 3 months and from inhaled corticosteroids, sodium cromoglycate, or nedocromil
sodium for at least 6 weeks before the start of the study. Long acting b2 agonists, xanthine
derivatives, and antihistamine drugs also had to be stopped at least 6 weeks before the
start of the study

Outcomes

Use of secondary medication, compliance, FEV1, PC20, FEV1/FVC, cortisol levels and inflammatory markers

Notes

Funding: GlaxoWellcome

Identifier(s): FLIL44/FMS40060

\section{Risk of bias}

\begin{tabular}{l|l|l} 
Bias & Authors' judgement & Support for judgement \\
\hline $\begin{array}{l}\text { Random sequence generation (selection } \\
\text { bias) }\end{array}$ & Low risk & $\begin{array}{l}\text { Randomly allocated [no details, but indus- } \\
\text { try funded] }\end{array}$ \\
\hline $\begin{array}{l}\text { Allocation concealment (selection bias) } \\
\text { Blinding of participants and personnel } \\
\text { (performance bias) } \\
\text { All outcomes }\end{array}$ & Low risk & Not described \\
\hline $\begin{array}{l}\text { Blinding of outcome assessment (detection } \\
\text { bias) } \\
\text { All outcomes }\end{array}$ & Unclear risk & $\begin{array}{l}\text { Described as double-blind [presumed par- } \\
\text { ticipants and personnel/investigators] }\end{array}$ \\
\hline
\end{tabular}

Incomplete outcome data (attrition bias) Low risk

No dropouts in either group

All outcomes 
Verhoeven 2002 (Continued)

Selective reporting (reporting bias) Low risk

Adverse event data not adequately reported but information supplied by the author

Vestbo 1999

Methods

Design: Double-blind, parallel-group, randomised clinical trial nested in a continuing epidemiological study, the Copenhagen City Heart Study (CCHS)

Duration: 3 years

Location: single centre in Denmark

Participants

Population: 290 people were randomised to budesonide (145) and placebo (145)

Baseline characteristics

Age (mean years): bud 59, pbo 59.1

$\%$ Male: bud 85 , pbo 90

$\% \mathrm{FEV}_{1}$ predicted: bud 86.2, pbo 86.9

Pack-years (mean): not reported

Inclusion criteria: CCHS participant; age 30-70 years; FEV1/vital capacity ratio 0.7 or less; FEV1 reversibility after inhalation of $1.0 \mathrm{mg}$ terbutaline from Turbuhaler (Bricanyl, Lund, Sweden) of less than $15 \%$ of pre-bronchodilator FEV1; FEV1 reversibility after 10 days of treatment with oral prednisolone $37.5 \mathrm{mg}$ daily of less than $15 \%$ of prebronchodilator FEV1; and informed consent. Pack-years or other measures of cigarette smoking were not part of inclusion criteria.

Exclusion criteria: Long-term treatment (more than two episodes of more than 4 weeks) with oral or inhaled steroids within 6 months of study entry. Other exclusion criteria were pregnancy or lactation, intention to become pregnant, other serious systemic disease that could influence the results of this study (investigators' judgment), chronic alcohol or drug use, and participation in other clinical studies of COPD within 1 month of inclusion

Interventions

1. Budesonide $800 \mu \mathrm{g}$ am and $400 \mu \mathrm{g} \mathrm{pm}$ [first six months]; $400 \mu \mathrm{g}$ twice daily [following 30 months] (ICS)

2. Placebo (PBO)

Inhaler device: Turbuhaler

Allowed co-medications: Continuous use of inhaled corticosteroids other than study medication was not allowed. Oral, inhaled, or parenteral steroids could be used during exacerbations for up to three periods of 4 weeks each year. Treatment with beta- 2 agonists of all kinds, theophylline, disodium cromoglycate, and mucolytics was allowed but kept constant. Concomitant use of beta-blockers was not allowed during the study

Outcomes

FEV1, VC, FVC, respiratory symptoms, exacerbations, chronic mucus hyper-secretion, adverse events

$\begin{array}{ll}\text { Notes } & \text { Funding: AstraZeneca } \\ & \text { Identifier(s): unknown }\end{array}$

Risk of bias

Bias

Authors' judgement

Support for judgement

Long-acting inhaled therapy (beta-agonists, anticholinergics and steroids) for COPD: a network meta-analysis (Review)

Copyright () 2014 The Cochrane Collaboration. Published by John Wiley \& Sons, Ltd. 
Vestbo 1999 (Continued)

\begin{tabular}{|c|c|c|}
\hline $\begin{array}{l}\text { Random sequence generation (selection } \\
\text { bias) }\end{array}$ & Low risk & $\begin{array}{l}\text { Randomisation was masked and the ran- } \\
\text { domisation sequence generated by com- } \\
\text { puter at Astra. Study numbers were allo- } \\
\text { cated in a consecutive order }\end{array}$ \\
\hline Allocation concealment (selection bias) & Low risk & $\begin{array}{l}\text { The randomisation code was held by Astra } \\
\text { and was not available to the researchers un- } \\
\text { til the study had been completed }\end{array}$ \\
\hline $\begin{array}{l}\text { Blinding of participants and personnel } \\
\text { (performance bias) } \\
\text { All outcomes }\end{array}$ & Low risk & $\begin{array}{l}\text { Double-blind. All study inhalers (budes- } \\
\text { onide and placebo) had the same appear- } \\
\text { ance }\end{array}$ \\
\hline $\begin{array}{l}\text { Blinding of outcome assessment (detection } \\
\text { bias) } \\
\text { All outcomes }\end{array}$ & Unclear risk & Not described \\
\hline $\begin{array}{l}\text { Incomplete outcome data (attrition bias) } \\
\text { All outcomes }\end{array}$ & High risk & $\begin{array}{l}\text { Dropout higher in placebo group ( } 35 \% \text { vs } \\
25 \% \text { in budesonide group). ITT used }\end{array}$ \\
\hline Selective reporting (reporting bias) & Unclear risk & $\begin{array}{l}\text { All stated outcomes reported but unable to } \\
\text { check against trial registration. Difficulty } \\
\text { contacting authors }\end{array}$ \\
\hline
\end{tabular}

\section{Vogelmeier 2008}

Methods

Design: randomised, partially blinded, placebo-controlled trial

Duration: 6 months (+ 2 weeks run-in)

Location: outpatient and specialist clinics at 86 centres in 8 countries

Participants

Population: 640 participants were randomised to formoterol (210), tiotropium (221), and placebo (209)

\section{Baseline characteristics}

Age (mean years): form 61.8, tio 63.4, pbo 62.5

$\%$ Male: form 75.7, tio 79.2, pbo 77.5

$\% \mathrm{FEV}_{1}$ predicted: form 51.6, tio 51.6, pbo 51.1

Pack-years (mean): form 35.4, tio 38.6, pbo 40.1

Inclusion criteria: males and females aged 40 and older; history of at least 10 packyears; $\mathrm{FEV}_{1}<70 \%$ predicted normal; $\mathrm{FEV}_{1} / \mathrm{FVC}<70 \%$

Exclusion criteria: respiratory tract infection or hospitalised for an acute exacerbation within the month before screening; clinically significant condition other than COPD such as ischaemic heart disease

Interventions

1. Formoterol 10 bid (LABA)

2. Tiotropium 18 qd (LAMA) - open-label

3. Placebo (PBO)

Inhaler device: Multi-dose dry powder inhaler - tiotropium open label

Allowed co-medications: salbutamol as rescue (but not in the 8 hours before a study 
visit); inhaled corticosteroids (ICS) were allowed at a stable daily dose. Any participants receiving fixed combinations of ICS and beta 2 -agonists were switched to receive the same dose of ICS and on-demand salbutamol

Outcomes

St George's Respiratory Questionnaire (SGRQ), COPD exacerbations, FEV 1 and FEV measured at 5 minutes, 2 hours and 3 hours post-dose, PEF, 6-minute walk test, haematology, blood chemistry, ECG, diary card data

\begin{tabular}{l|l} 
Notes & Funding: Novartis \\
& Identifier(s): NCT00134979
\end{tabular}

\section{Risk of bias}

\begin{tabular}{|c|c|c|}
\hline Bias & Authors' judgement & Support for judgement \\
\hline $\begin{array}{l}\text { Random sequence generation (selection } \\
\text { bias) }\end{array}$ & Low risk & $\begin{array}{l}\text { Randomization was not stratified [no other } \\
\text { information given but assumed to follow } \\
\text { convention Novartis sequence generation } \\
\text { methods] }\end{array}$ \\
\hline Allocation concealment (selection bias) & Unclear risk & No information provided \\
\hline $\begin{array}{l}\text { Blinding of participants and personnel } \\
\text { (performance bias) } \\
\text { All outcomes }\end{array}$ & High risk & Tiotropium was delivered open-label \\
\hline $\begin{array}{l}\text { Blinding of outcome assessment (detection } \\
\text { bias) } \\
\text { All outcomes }\end{array}$ & High risk & Tiotropium was delivered open-label \\
\hline $\begin{array}{l}\text { Incomplete outcome data (attrition bias) } \\
\text { All outcomes }\end{array}$ & Unclear risk & $\begin{array}{l}\text { The intent-to-treat (ITT) population con- } \\
\text { sisted of all randomized patients who re- } \\
\text { ceived at least one dose of study medica- } \\
\text { tion. This population was used for efficacy } \\
\text { and safety analyses }\end{array}$ \\
\hline Selective reporting (reporting bias) & High risk & $\begin{array}{l}\text { FEV1 and SGRQ outcomes only provided } \\
\text { in graphical form with inexact P-value }\end{array}$ \\
\hline
\end{tabular}

\section{Vogelmeier 2011 [POET]}

Methods

Participants
Design: randomized, double-blind, double-dummy, parallel-group trial

Duration: 1 year (+ 2 week run-in)

Location: 725 centres in 25 countries

Population: 7376 participants were randomised to tiotropium (3707) and salmeterol (3669)

\section{Baseline characteristics}


Age (mean years): salm 62.8, tio 62.9

$\%$ Male: salm 74.9, tio 74.4

$\% \mathrm{FEV}_{1}$ predicted: salm 49.4, tio 49.2

Pack-years (mean): salm 37.8, tio 38.8

Inclusion criteria: at least 40 years of age and had a smoking history of 10 pack-years or more, a diagnosis of COPD, a forced expiratory volume in 1 second (FEV1) after bronchodilation of $<70 \%$ of the predicted value, a ratio of FEV1 to forced vital capacity (FVC) of $<70 \%$, and a documented history of at least one exacerbation leading to treatment with systemic glucocorticoids or antibiotics or hospitalisation within the previous year

Exclusion criteria: significant disease other than COPD; diagnosis of asthma; life-threatening pulmonary obstruction, or a history of CF; active TB; narrow angle glaucoma; myocardial infarction or hospital admission for heart failure within the year prior to visit 1; cardiac arrhythmia requiring medical or surgical treatment; severe CV disorders; hypersensitivity to components of study drugs; respiratory infection or exacerbation in the 4 weeks prior to visit 1

Interventions
2. Salmeterol 50 bid (LABA) - plus HandiHaler placebo
Inhaler device: HandiHaler and pressurised metered dose inhaler (pMDI)
Allowed co-medications: Patients were allowed to continue their usual medications for
COPD, except for anticholinergic drugs and long-acting $\beta 2$-agonists, during the double-
blind treatment phase

Outcomes

time to first exacerbation (primary); Secondary and safety end points included time-toevent end points, number-of-event end points, serious adverse events, and death

Notes

Funding: Boehringer Ingelheim and Pfizer

Identifier(s): NCT00563381

\section{Risk of bias}

Bias

Random sequence generation (selection Low risk bias)
Authors' judgement

\section{Support for judgement}

A randomisation list was generated by the sponsor using a validated system involving a pseudo-random number generator. Patients were randomized in a 1:1 ratio in blocks of four, with equal allocation of treatment within each block per country site

\begin{tabular}{l|l|l}
\hline $\begin{array}{l}\text { Allocation concealment (selection bias) } \\
\text { Low risk }\end{array}$ & $\begin{array}{l}\text { Patients were randomized to treatment via } \\
\text { an Interactive Voice Response System (Per- } \\
\text { ceptive Informatics Inc., Berlin, Germany) }\end{array}$ \\
\hline $\begin{array}{l}\text { Blinding of participants and personnel } \\
\text { (performance bias) } \\
\text { All outcomes }\end{array}$ & Low risk & $\begin{array}{l}\text { Blinding was maintained by allocation of } \\
\text { a dummy placebo MDI to those random- } \\
\text { ized to the tiotropium arm and a dummy }\end{array}$
\end{tabular}

Long-acting inhaled therapy (beta-agonists, anticholinergics and steroids) for COPD: a network meta-analysis (Review)

Copyright () 2014 The Cochrane Collaboration. Published by John Wiley \& Sons, Ltd. 
Vogelmeier 2011 [POET] (Continued)

placebo HandiHaler to those in the salmeterol arm. Tiotropium and placebo capsules were identical in size and colour and were therefore indistinguishable

Blinding of outcome assessment (detection Low risk bias)

All outcomes

Incomplete outcome data (attrition bias) Low risk All outcomes
A committee assessing cause of death was blind to treatment group. Authors judged that other outcomes were blind also

The efficacy and safety analyses included all the patients who underwent randomisation and who received at least one dose of the study medication. Fewer patients in the tiotropium group than in the salmeterol group withdrew from the study prematurely: 585 patients $(15.8 \%)$ vs. 648 patients $(17.7 \%)$ but both were judged to be low over a year and considering imputation of missing values

Outcomes were well reported in the publications and on clinicaltrials.gov

Wedzicha 2008 [INSPIRE]

Methods

Design: multicenter, randomized, double-blind, double-dummy controlled trial

Duration: 2 years ( +2 week run-in)

Location: 179 centres from 20 countries

Participants

Population: 1323 participants were randomised to tiotropium (665) and salmeterol/ fluticasone combination (658)

\section{Baseline characteristics}

Age (mean years): tio 65, SFC 64

$\%$ Male: tio 84 , SFC 81

$\% \mathrm{FEV}_{1}$ predicted: tio 39.4 , SFC 39.1

Pack-years (mean): tio 39.5, SFC 41.3

Inclusion criteria: aged 40 to 80 years, with a smoking history of 10 or more packyears, a clinical history of COPD exacerbations, a post-bronchodilator FEV1 of less than $50 \%$ predicted, reversibility to $400 \mathrm{mg}$ salbutamol $10 \%$ or less of predicted FEV1, and a score of 2 or more on the Modified Medical Research Council dyspnoea scale.

Exclusion criteria: any respiratory disorder other than COPD or who required daily long-term oxygen therapy $(>12 \mathrm{~h} / \mathrm{d})$

Interventions

1. Tiotropium 18 qd (LAMA) - plus Diskus/Accuhaler placebo

2. Salmeterol/fluticasone 50/500 (LABA/ICS) - plus HandiHaler placebo

Inhaler device: Diskus/Accuhaler and Handihaler

Allowed co-medications: After randomisation, in addition to study medication, patients were allowed short-acting inhaled beta-agonists for relief therapy and standardized short courses of oral systemic corticosteroids and/or antibiotics where indicated for treatment 
Wedzicha 2008 [INSPIRE] (Continued)

of COPD exacerbations

\begin{tabular}{l|l} 
Outcomes & $\begin{array}{l}\text { Primary endpoint was health care utilization exacerbation rate. Other endpoints included } \\
\text { health status measured by St. George's Respiratory Questionnaire (SGRQ), mortality, } \\
\text { adverse events, and study withdrawal }\end{array}$ \\
\hline Notes & $\begin{array}{l}\text { Funding: GlaxoSmithKline } \\
\text { Identifier(s): NCT00361959 }\end{array}$ \\
\hline
\end{tabular}

Risk of bias

\begin{tabular}{|c|c|c|}
\hline Bias & Authors' judgement & Support for judgement \\
\hline $\begin{array}{l}\text { Random sequence generation (selection } \\
\text { bias) }\end{array}$ & Low risk & $\begin{array}{l}\text { Patients were randomized using a pre- } \\
\text { defined, computer-generated, central ran- } \\
\text { domisation list. Treatment allocation was } \\
\text { stratified by centre and smoking status on } \\
\text { a } 1: 1 \text { basis, in line with current guidelines. } \\
\text { The block size used was four }\end{array}$ \\
\hline Allocation concealment (selection bias) & Low risk & $\begin{array}{l}\text { telephone-based interactive voice response } \\
\text { system }\end{array}$ \\
\hline $\begin{array}{l}\text { Blinding of participants and personnel } \\
\text { (performance bias) } \\
\text { All outcomes }\end{array}$ & Low risk & Double-blind, double-dummy \\
\hline $\begin{array}{l}\text { Blinding of outcome assessment (detection } \\
\text { bias) } \\
\text { All outcomes }\end{array}$ & Unclear risk & Not described \\
\hline $\begin{array}{l}\text { Incomplete outcome data (attrition bias) } \\
\text { All outcomes }\end{array}$ & Low risk & $\begin{array}{l}1,323 \text { were randomized and comprised } \\
\text { the intent-to-treat population. Withdrawal } \\
\text { was high in both groups but balanced after } \\
\text { two years ( } 35.3 \text { and } 42 \% \text { ) }\end{array}$ \\
\hline Selective reporting (reporting bias) & Low risk & $\begin{array}{l}\text { Outcomes were well reported in the pub- } \\
\text { lications, and matched the study protocol } \\
\text { (although results have not been posted on } \\
\text { clinicaltrials.gov) }\end{array}$ \\
\hline
\end{tabular}

Zheng 2006

Methods

Design: multi-centre, randomised, double-blind, parallel group study

Duration: 24 weeks (+ 2 week run-in)

Location: 12 centres in China 


\begin{tabular}{|c|c|c|}
\hline Participants & \multicolumn{2}{|c|}{$\begin{array}{l}\text { Population: } 448 \text { participants were randomised to salmeterol/fluticasone combination } \\
\text { (297) and placebo (148) } \\
\text { Baseline characteristics } \\
\text { Age (mean years): SFC 66.0, pbo } 66.6 \\
\% \text { Male: SFC 90.6, pbo } 86.5 \\
\% \text { FEV }_{1} \text { predicted: not reported } \\
\text { Pack-years (mean): not reported } \\
\text { Inclusion criteria: Male and female subjects (aged } 40-79 \text { years) with a diagnosis of } \\
\text { COPD as per GOLD criteria; poor reversibility of airflow obstruction which was defined } \\
\text { as an increase of less than } 10 \% \text { of the normal predicted FEV1 value, } 30 \text { minutes to } 2 \\
\text { hours after inhalation of } 400 \text { mcg salbutamol via MDI and spacerGFEV1/FVC ratio } \\
\text { (Postbronchodilator) } 70 \% \text {. } \\
\text { Exclusion criteria: diagnosis of asthma and other respiratory disease such as lung cancer, } \\
\text { sarcoidosis, active tuberculosis, primary or severe subsequent lung fibrosis and bronchiec- } \\
\text { tasis, and serious, uncontrolled other system disorders; required long-term oxygen ther- } \\
\text { apy (LTOT); had received inhaled corticosteroids at a dose of }>1000 \text { ug/day (BDP or } \\
\text { BUD) or }>500 \text { ug/day (FP) or had received systemic corticosteroids in the last } 4 \text { weeks } \\
\text { before entry to the run-in period. After the run-in, at randomisation. Subjects who had } \\
\text { received systemic corticosteroids, had changes in COPD medication, received antibiotic } \\
\text { therapy or had been hospitalised for COPD exacerbation were not randomized }\end{array}$} \\
\hline Interventions & \multicolumn{2}{|c|}{$\begin{array}{l}\text { 1. Salmeterol/fluticasone } 50 / 500 \text { bid (LABA/ICS) } \\
\text { 2. Placebo (PBO) } \\
\text { Inhaler device: Accuhaler } \\
\text { Allowed co-medications: Ventolin was permitted to be used as rescue medication on a } \\
\text { required basis and sputum reduction medication could also be taken in the treatment } \\
\text { period at unchanged doses }\end{array}$} \\
\hline Outcomes & \multicolumn{2}{|c|}{$\begin{array}{l}\text { Pre-bronchodilator FEV1; St. George's Respiratory Questionnaire (SGRQ); use of relief } \\
\text { bronchodilator and night time awakenings from Daily Record Cards; post-bronchodila- } \\
\text { tor FEV1; COPD exacerbation (CE) }\end{array}$} \\
\hline Notes & \multicolumn{2}{|c|}{$\begin{array}{l}\text { Funding: GlaxoSmithKline } \\
\text { Identifier(s): SCO100540 }\end{array}$} \\
\hline \multicolumn{3}{|l|}{ Risk of bias } \\
\hline Bias & Authors' judgement & Support for judgement \\
\hline $\begin{array}{l}\text { Random sequence generation (selection } \\
\text { bias) }\end{array}$ & Low risk & $\begin{array}{l}\text { randomised, according to a } 2: 1 \text { ratio [GSK } \\
\text { sponsored] }\end{array}$ \\
\hline Allocation concealment (selection bias) & Unclear risk & not described \\
\hline $\begin{array}{l}\text { Blinding of participants and personnel } \\
\text { (performance bias) } \\
\text { All outcomes }\end{array}$ & Low risk & SFC or matching placebo \\
\hline
\end{tabular}




\begin{tabular}{l|l|l}
\hline $\begin{array}{l}\text { Blinding of outcome assessment (detection } \\
\text { bias) } \\
\text { All outcomes }\end{array}$ & Unclear risk & Unclear who performed the assessments \\
\hline $\begin{array}{l}\text { Incomplete outcome data (attrition bias) } \\
\text { All outcomes }\end{array}$ & Low risk & $\begin{array}{l}\text { The final pre-bronchodilator FEV1 after } \\
\text { treatment period was analysed using the } \\
\text { Last Observation Carried Forward (LOCF) } \\
\text { method. For SGRQ, LOCF was also used } \\
\text { for data of subjects who were withdrawn }\end{array}$ \\
\hline Selective reporting (reporting bias) & Low risk & $\begin{array}{l}\text { Outcomes were well reported in the man- } \\
\text { ufacturer document }\end{array}$ \\
\hline
\end{tabular}

\section{Zhong 2012}

Methods

Participants
Design: multi-centre, randomised, parallel-group, double-blind, double-dummy design Duration: 6 months (+ 2 week run-in)

Location: 12 centres in China

\begin{tabular}{|c|c|}
\hline & $\begin{array}{l}\text { budesonide combination therapy }(156) \\
\text { Baseline characteristics } \\
\text { Age (mean years): bud } 64.7 \text {, form/bud } 65.7 \\
\% \mathrm{Male}_{\text {bud }} 92.1 \text {, form/bud } 98.1 \\
\% \mathrm{FEV} \text { predicted (pre-BD): bud } 32.9 \text {, form/bud } 32.4 \\
\text { Pack-years (mean): not reported } \\
\text { Inclusion criteria: male or female outpatients > } 40 \text { years of age with a diagnosis of } \\
\text { COPD; pre-bronchodilator FEV } 1<50 \% \text { of predicted normal value; FEV1/FVC }<70 \% \text {; } \\
\text { at least } 1 \text { COPD exacerbation during } 2-12 \text { months prior to the study; a smoking history } \\
\text { of }>10 \text { pack-years. } \\
\text { Exclusion criteria: history of asthma; seasonal allergic rhinitis with onset before } 40 \text { years } \\
\text { of age; a COPD exacerbation within } 4 \text { weeks of study entry or during the run-in; post } \\
\text { BD FEV1 }>80 \% \text { of the predicted normal value at baseline; any other serious diseases } \\
\text { or disorders that were considered to influence the study results or increase the risk of } \\
\text { participation in the study }\end{array}$ \\
\hline Interventions & $\begin{array}{l}\text { 1. Budesonide } 400 \text { bid (ICS) } \\
\text { 2. Formoterol/budesonide } 360 / 9 \text { (LABA/ICS) } \\
\text { Inhaler device: Turbuhaler } \\
\text { Allowed co-medications: terbutaline was used as reliever during the run-in period and } \\
\text { throughout the study. No other bronchodilator was permitted to be used during the } \\
\text { study period }\end{array}$ \\
\hline Outcomes & Lung function, daily symptoms, reliever use, and health related quality of life (SGRQ) \\
\hline Notes & $\begin{array}{l}\text { Funding: AstraZeneca } \\
\text { Identifier(s): NCT00421122 }\end{array}$ \\
\hline
\end{tabular}


Zhong 2012 (Continued)

\begin{tabular}{|c|c|c|}
\hline Bias & Authors' judgement & Support for judgement \\
\hline $\begin{array}{l}\text { Random sequence generation (selection } \\
\text { bias) }\end{array}$ & Low risk & $\begin{array}{l}\text { The randomisation schedule was generated } \\
\text { using a computer program at AstraZeneca, } \\
\text { Sweden. Patients were randomised in equal } \\
\text { proportion to either treatment }\end{array}$ \\
\hline Allocation concealment (selection bias) & Unclear risk & Not described \\
\hline $\begin{array}{l}\text { Blinding of participants and personnel } \\
\text { (performance bias) } \\
\text { All outcomes }\end{array}$ & Low risk & $\begin{array}{l}\text { Double-blind, double-dummy. Treatment } \\
\text { codes were not broken for the planned anal- } \\
\text { yses of data until all decisions had been } \\
\text { made and documented }\end{array}$ \\
\hline $\begin{array}{l}\text { Blinding of outcome assessment (detection } \\
\text { bias) } \\
\text { All outcomes }\end{array}$ & Unclear risk & Unclear who performed the assessments \\
\hline $\begin{array}{l}\text { Incomplete outcome data (attrition bias) } \\
\text { All outcomes }\end{array}$ & Low risk & $\begin{array}{l}\text { The full analysis set (FAS) included all ran- } \\
\text { domised subjects after eliminating those } \\
\text { who did not have any post-randomisation } \\
\text { efficacy data ( } \mathrm{n}=16,5.2 \%) \text {. Dropout was } \\
\text { somewhat unbalanced ( } 15 \text { and } 23 \% \text { ) but } \\
\text { considered acceptable given the imputation }\end{array}$ \\
\hline Selective reporting (reporting bias) & Low risk & $\begin{array}{l}\text { Outcomes were well reported in accordance } \\
\text { with the online protocol, although no re- } \\
\text { sults have been posted on clinicaltrials.gov }\end{array}$ \\
\hline
\end{tabular}

Characteristics of excluded studies [ordered by study ID]

\begin{tabular}{l|l}
\hline Study & Reason for exclusion \\
\hline Aalbers 2002 & 12 weeks [LABA-COP] \\
\hline ACCORD II 2012 & Extension phase, initial randomised treatment period too short \\
\hline Ambrosino 2008 & Given alongside pulmonary rehabilitation \\
\hline Auffarth 1991 & 8 weeks. Crossover [STER-COP] \\
\hline Barnes 2006 & 13 weeks [CCB-COP]
\end{tabular}


(Continued)

\begin{tabular}{|c|c|}
\hline Beeh 2006 & 12 weeks [TIO6-COP] \\
\hline Bogdan 2011 & 12 weeks [LABA-COP] \\
\hline Bourbeau 2007 & 12 weeks [STER-COP] \\
\hline Briggs 2005 & 12 weeks [TIO5-COP] \\
\hline Brightling 2005 & Crossover [STER-COP] \\
\hline Burl 2011 & 12 weeks [TIO5-COP] \\
\hline Cazzola 2007 & 12 weeks [TIO2-COP] \\
\hline Choudhury 2005 & Discontinuation study, ICS \\
\hline Covelli 2005 & 12 weeks [TIO6-COP] \\
\hline Culpitt 1999 & 4 weeks, crossover [STER-COP] \\
\hline Dahl 2001 & 12 weeks [LABA-COP] \\
\hline Dahl 2013 [BEACON] & 4 weeks \\
\hline Dawber 2005 & 3 weeks [TIO1-COP] \\
\hline Derenne 1995 & Very high dose, beclomethasone \\
\hline Dransfield 2013 & vilanterol, fluticasone furoate \\
\hline FCO30002 & 12 weeks [STER-COP] \\
\hline Ferreira 2001 & 2 weeks, crossover [STER-COP] \\
\hline Ferreira 2003 & crossover [STER-COP] \\
\hline Freeman 2007 & 12 weeks [TIO6-COP] \\
\hline Fukuchi 2013 & 12 weeks [PICS-COP] \\
\hline Guenette 2011 & 2 weeks, crossover [STER-COP] \\
\hline Hanrahan 2008 & 12 weeks [LABA-COP] \\
\hline Hattotuwa 2002 & 12 weeks [STER-COP] \\
\hline Johansson 2008 & Johansson 2008 [TIO6-COP] \\
\hline
\end{tabular}


(Continued)

\begin{tabular}{|c|c|}
\hline John 2005 & crossover [STER-COP] \\
\hline Kerstjens 1992 & beclomethasone, ipratropium \\
\hline Kerwin 2013 & vilanterol, fluticasone furoate \\
\hline Llewellyn-Jones 1996 & 8 weeks [STER-COP] \\
\hline Loppow 2001 & 4 weeks, crossover [STER-COP] \\
\hline Lung Health Study 2000 & triamcinolone \\
\hline Magnussen 2008 & 12 weeks [TIO6-COP] \\
\hline Mahler 1999 & 12 weeks [LABA-COP] \\
\hline Mahler 2010 & 12 weeks [TIO6-COP] \\
\hline Mahler 2010a & 12 weeks [TIO6-COP] \\
\hline Martinez 2013 & vilanterol, fluticasone furoate \\
\hline Mirici 2001 & 12 weeks [STER-COP] \\
\hline Moita 2008 & 12 weeks [TIO6-COP] \\
\hline NCT00144326 & 12 weeks [TIO6-COP] \\
\hline Nelson 2007 & 12 weeks [LABA-COP] \\
\hline Nishimura 1999 & 4 weeks, crossover [STER-COP] \\
\hline O’Donnell 2006 & 8 weeks [CCB-COP/CCB3-COP] \\
\hline Rennard 2001 & 12 weeks [LABA-COP] \\
\hline Robertson 1986 & 2 weeks, crossover [STER-COP] \\
\hline Rutgers 1998 & 6 weeks [STER-COP] \\
\hline SCO40034 & 12 weeks [TIO1-COP] \\
\hline Sin 2004 & 8/16 weeks [STER-COP] \\
\hline $\operatorname{Sin} 2008$ & 4 weeks [STER-COP] \\
\hline Sun 2007 & 12 weeks [TIO6-COP] \\
\hline
\end{tabular}


(Continued)

\begin{tabular}{|c|c|}
\hline Tashkin 2009 & 12 weeks [TIO3-COP] \\
\hline Thompson 1992 & 6 weeks [STER-COP] \\
\hline Thompson 2002 & 12 weeks, crossover [STER-COP] \\
\hline van der Valk 2002 & discontinuation study, ICS \\
\hline van Grunsven 2003 & 12 weeks [STER-COP] \\
\hline Verkinde 2006 & 12 weeks [TIO6-COP] \\
\hline Voshaar 2008 & 12 weeks [TIO6-COP] \\
\hline Wadbo 2002 & 12 weeks [LABA-COP] \\
\hline Watkins 2002 & 12 weeks [LABA-COP] \\
\hline Weiner 1995 & 6 weeks, crossover [STER-COP] \\
\hline Weiner 1999 & 6 weeks, crossover [STER-COP] \\
\hline Weir 1990 & 2 weeks, crossover [STER-COP] \\
\hline Weir 1999 & beclomethasone \\
\hline Welte 2009 & 12 weeks [TIO2-COP] \\
\hline Wempe 1992 & 3 weeks, crossover [STER-COP] \\
\hline Wouters 2005 & discontinuation study, ICS \\
\hline Yang 2012 & invalid control, symptomatic treatment \\
\hline Yildiz 2004 & 12 weeks [STER-COP] \\
\hline
\end{tabular}

\section{Characteristics of ongoing studies [ordered by study ID]}

\section{INSTEAD}

\begin{tabular}{ll} 
Trial name or title & $\begin{array}{l}\text { Comparison of Indacaterol } 150 \mu \mathrm{g} \text { Once Daily (o.d.) With Salmeterol/Fluticasone Propionate } 50 \mu \mathrm{g} / 500 \\
\mu \mathrm{g} \text { Twice Daily (b.i.d.) (INSTEAD) }\end{array}$ \\
\hline Methods & $\begin{array}{l}\text { Allocation: randomly assigned } \\
\text { Endpoint classification: safety/efficacy study } \\
\text { Intervention model: parallel assignment } \\
\text { Masking: double-blind (participant, caregiver, investigator, outcomes assessor) }\end{array}$
\end{tabular}




\section{INSTEAD (Continued)}

\begin{tabular}{ll}
\hline Participants & Patients with moderate COPD (stage II) \\
\hline Interventions & $\begin{array}{l}\text { Indacaterol } 150 \mathrm{qd} \\
\text { Salmeterol/fluticasone } 50 / 500 \mathrm{bid}\end{array}$ \\
\hline Outcomes & $\begin{array}{l}\text { Primary: trough FEV } 1 . \text { Secondary: other lung function measures, transition dyspnoea index, exacerbations, } \\
\text { SGRQ, adverse events, diary card data }\end{array}$ \\
\hline Starting date & March 2012 (first received on clinicaltrials.gov) \\
\hline Contact information & Novartis Pharmaceuticals: +41613241111 \\
\hline Notes & $\begin{array}{l}\text { Funding: Novartis } \\
\text { Identifiers: CQAB149B2401, 2011-003732-31 }\end{array}$ \\
\hline
\end{tabular}

\section{Vestbo 2013}

\begin{tabular}{l|l}
\hline Trial name or title & Study to Understand Mortality and Morbidity in COPD (SUMMIT) \\
\hline Methods & Multicentre, randomised, double-blind, parallel-group, placebo-controlled trial \\
\hline Participants & 16,000 patients with moderate COPD \\
\hline Interventions & $\begin{array}{l}\text { Once-daily treatment with fluticasone furoate/vilanterol (100/25 mg), fluticasone furoate (100 mg), vilanterol } \\
(25 \mathrm{mg}) \text { or matched placebo }\end{array}$ \\
\hline Outcomes & Mortality is the primary endpoint \\
\hline Starting date & Recruitment commenced in March 2011 and is expected to conclude in late 2013 \\
\hline Contact information & $\begin{array}{l}\text { E-mail: jvestbo@dadlnet.dk; J. Vestbo, Dept of Respiratory Medicine J, Odense University Hospital, Sdr } \\
\text { Ringvej } 29,5000 \text { Odense C, Denmark }\end{array}$ \\
\hline Notes & - \\
\hline
\end{tabular}




\section{DATA AND ANALYSES}

This review has no analyses.

\section{A D D I TIONAL TABLES}

Table 1. All included studies-summary characteristics

\begin{tabular}{|c|c|c|c|c|c|c|c|}
\hline Study ID & Weeks & $\underset{a}{\text { Arms included }}$ & $\mathbf{N}$ & Age $^{b}$ & $\%$ male & $\%$ pred $\mathbf{F E V}_{1 b}$ & Pack-years ${ }^{b}$ \\
\hline $\begin{array}{l}\text { Abrahams } \\
2013\end{array}$ & 24 & $\begin{array}{l}\text { tiotropium, } \\
\text { placebo }\end{array}$ & 856 & 64.2 & 64.9 & 43.3 & 46.9 \\
\hline $\begin{array}{l}\text { ACCLAIM } \\
2009\end{array}$ & 52 & $\begin{array}{l}\text { aclidinium, } \\
\text { placebo }\end{array}$ & 843 & 62.4 & 78.6 & 53.9 & 39.9 \\
\hline $\begin{array}{l}\text { ACCLAIM II } \\
2009\end{array}$ & 52 & $\begin{array}{l}\text { aclidinium, } \\
\text { placebo }\end{array}$ & 804 & 65.1 & 63.0 & 50.3 & 57.9 \\
\hline Anzueto 2009 & 52 & $\begin{array}{l}\text { salmeterol, sal- } \\
\text { meterol/ } \\
\text { fluticasone }\end{array}$ & 797 & 65.4 & 54 & 34.0 & 57.2 \\
\hline $\begin{array}{l}\text { ATTAIN } \\
2011\end{array}$ & 24 & $\begin{array}{l}\text { aclidinium (2), } \\
\text { placebo }\end{array}$ & 828 & 62.4 & 67.4 & 52.5 & 40.2 \\
\hline $\begin{array}{l}\text { Bateman } \\
2010 a\end{array}$ & 48 & $\begin{array}{l}\text { tiotropium, } \\
\text { placebo }\end{array}$ & 3991 & 64.8 & 77.6 & 39.9 & 46 \\
\hline $\begin{array}{l}\text { Bateman } \\
\text { 2010b }\end{array}$ & 48 & $\begin{array}{l}\text { tiotropium (2), } \\
\text { placebo }\end{array}$ & 1990 & 65.0 & 74.2 & 37.7 & $\mathrm{nr}$ \\
\hline $\begin{array}{l}\text { Bateman } 2013 \\
\text { [SHINE] }\end{array}$ & 26 & $\begin{array}{l}\text { indacaterol, } \\
\text { tiotropium, } \\
\text { glycopyrro- } \\
\text { nium, placebo }\end{array}$ & 1667 & 64.0 & 74.9 & 55.0 & $\mathrm{nr}$ \\
\hline $\begin{array}{l}\text { Bourbeau } \\
1998\end{array}$ & 26 & $\begin{array}{l}\text { budesonide, } \\
\text { placebo }\end{array}$ & 79 & 66 & 78.6 & 36.5 & 51 \\
\hline Brusasco 2003 & 26 & $\begin{array}{l}\text { salmeterol, } \\
\text { tiotropium, } \\
\text { placebo }\end{array}$ & 1207 & 64.2 & 76.3 & 38.5 & 43.8 \\
\hline $\begin{array}{l}\text { Burge } 2000 \\
\text { [ISOLDE] }\end{array}$ & 156 & $\begin{array}{l}\text { fluticasone, } \\
\text { placebo }\end{array}$ & 751 & 63.8 & 74.6 & 50.2 & 44 \\
\hline
\end{tabular}


Table 1. All included studies-summary characteristics (Continued)

\begin{tabular}{|c|c|c|c|c|c|c|c|}
\hline $\begin{array}{l}\text { Calverley } \\
2003 a\end{array}$ & 52 & $\begin{array}{l}\text { for- } \\
\text { moterol, budes- } \\
\text { onide, for- } \\
\text { moterol/budes- } \\
\text { onide, placebo }\end{array}$ & 1122 & 64 & 76 & 36 & 39 \\
\hline $\begin{array}{l}\text { Calverley } \\
2003 \\
\text { [TRISTAN] }\end{array}$ & 52 & $\begin{array}{l}\text { salmeterol, flu- } \\
\text { ticasone, salme- } \\
\text { terol/fluticas- } \\
\text { one, placebo }\end{array}$ & 1466 & 63.2 & 72.5 & 44.7 & 42.3 \\
\hline $\begin{array}{l}\text { Calverley } \\
2003 b\end{array}$ & 52 & $\begin{array}{l}\text { mometasone, } \\
\text { placebo }\end{array}$ & 631 & $\mathrm{nr}$ & $\mathrm{nr}$ & 47 & $\mathrm{nr}$ \\
\hline $\begin{array}{l}\text { Calverley } \\
2007 \\
{[\text { TORCH] }}\end{array}$ & 156 & $\begin{array}{l}\text { salmeterol, flu- } \\
\text { ticasone, salme- } \\
\text { terol/fluticas- } \\
\text { one, placebo }\end{array}$ & 6185 & 65.0 & 75.8 & 44.0 & 48.5 \\
\hline $\begin{array}{l}\text { Calverley } \\
2008\end{array}$ & 52 & $\begin{array}{l}\text { mometasone } \\
(2), \text { placebo }\end{array}$ & 911 & 65.1 & 68.3 & 42.3 & $\mathrm{nr}$ \\
\hline $\begin{array}{l}\text { Calverley } \\
2010\end{array}$ & 48 & $\begin{array}{l}\text { formoterol, for- } \\
\text { moterol/ } \\
\text { budesonide }\end{array}$ & 718 & 63.9 & 81.3 & 42.4 & 38.8 \\
\hline $\begin{array}{l}\text { Campbell } \\
2005\end{array}$ & 26 & $\begin{array}{l}\text { formoterol, } \\
\text { placebo }\end{array}$ & 432 & 55 & 67 & 53.6 & 37 \\
\hline $\begin{array}{l}\text { Casaburi } \\
2002\end{array}$ & 52 & $\begin{array}{l}\text { tiotropium, } \\
\text { placebo }\end{array}$ & 921 & 65 & 65.0 & 38.7 & 61.4 \\
\hline Chan 2007 & 48 & $\begin{array}{l}\text { tiotropium, } \\
\text { placebo }\end{array}$ & 913 & 66.8 & 59.7 & 39.4 & 50.6 \\
\hline Cooper 2010 & 104 & $\begin{array}{l}\text { tiotropium, } \\
\text { placebo }\end{array}$ & 519 & 64.6 & 77.3 & 38.2 & 51.7 \\
\hline Dahl 2010 & 52 & $\begin{array}{l}\text { formoterol, } \\
\text { placebo }\end{array}$ & 867 & 63.5 & 31.9 & 51.7 & 40.8 \\
\hline $\begin{array}{l}\text { Dal Negro } \\
2003\end{array}$ & 52 & $\begin{array}{l}\text { salmeterol, sal- } \\
\text { meterol/flutica- } \\
\text { sone, placebo }\end{array}$ & 18 & $\mathrm{nr}$ & 83.3 & 50.0 & 41.4 \\
\hline Doherty 2012 & 26 & $\begin{array}{l}\text { formoterol, } \\
\text { mometasone, } \\
\text { formoterol/ }\end{array}$ & 1196 & 59.7 & 75.2 & 38.6 & 45.1 \\
\hline
\end{tabular}


Table 1. All included studies-summary characteristics (Continued)

\begin{tabular}{|c|c|c|c|c|c|c|c|}
\hline & & $\begin{array}{l}\text { mometasone } \\
(2) \text {, placebo }\end{array}$ & & & & & \\
\hline $\begin{array}{l}\text { Donohue } \\
2010 \\
\text { [INHANCE] }\end{array}$ & 26 & $\begin{array}{l}\text { indacaterol (2), } \\
\text { tiotropium, } \\
\text { placebo }\end{array}$ & 1683 & 63.6 & 62.8 & 55.6 & 49.7 \\
\hline Dusser 2006 & 48 & $\begin{array}{l}\text { tiotropium, } \\
\text { placebo }\end{array}$ & 1010 & 64.7 & 88 & 47.9 & $\mathrm{nr}$ \\
\hline Fang 2008 & 52 & $\begin{array}{l}\text { tiotropium, sal- } \\
\text { meterol/ } \\
\text { fluticasone }\end{array}$ & 126 & 62.5 & 73.8 & $\mathrm{nr}$ & $\mathrm{nr}$ \\
\hline $\begin{array}{l}\text { Ferguson } \\
2008\end{array}$ & 52 & $\begin{array}{l}\text { salmeterol, sal- } \\
\text { meterol/ } \\
\text { fluticasone }\end{array}$ & 782 & 64.9 & 55 & 32.8 & 56.5 \\
\hline FLTA3025 & 26 & $\begin{array}{l}\text { fluticasone (2), } \\
\text { placebo }\end{array}$ & 640 & 64.4 & 68.8 & $\mathrm{nr}$ & $\mathrm{nr}$ \\
\hline Gelb 2012 & 52 & aclidinium (2) & 605 & $\mathrm{nr}$ & $\mathrm{nr}$ & 46.5 & $\mathrm{nr}$ \\
\hline $\begin{array}{l}\text { GLOW1 } \\
2011\end{array}$ & 26 & $\begin{array}{l}\text { glycopyrro- } \\
\text { nium, placebo }\end{array}$ & 822 & 63.9 & 81.8 & 54.6 & 44.8 \\
\hline $\begin{array}{l}\text { GLOW2 } \\
2012\end{array}$ & 52 & $\begin{array}{l}\text { glycopyrro- } \\
\text { nium, } \\
\text { tiotropium, } \\
\text { placebo }\end{array}$ & 1066 & 63.6 & 64.2 & 56.0 & 49.1 \\
\hline Hanania 2003 & 26 & $\begin{array}{l}\text { salmeterol, flu- } \\
\text { ticasone, salme- } \\
\text { terol/fluticas- } \\
\text { one, placebo }\end{array}$ & 723 & 63.9 & 63.1 & 42 & 56.5 \\
\hline Kardos 2007 & 43 & $\begin{array}{l}\text { salmeterol, sal- } \\
\text { meterol/ } \\
\text { fluticasone }\end{array}$ & 994 & 63.9 & 75.8 & 40.4 & 36.9 \\
\hline $\begin{array}{l}\text { Kornmann } \\
2011\end{array}$ & 26 & $\begin{array}{l}\text { salmeterol, } \\
\text { placebo }\end{array}$ & 339 & 63.3 & 74.7 & 53.3 & 40.3 \\
\hline Lapperre 2009 & 130 & $\begin{array}{l}\text { fluticasone (2) } \\
\text {, salmeterol/flu- } \\
\text { ticasone, } \\
\text { placebo }\end{array}$ & 114 & 61 & 86.6 & 55.3 & 44.3 \\
\hline
\end{tabular}


Table 1. All included studies-summary characteristics (Continued)

\begin{tabular}{|c|c|c|c|c|c|c|c|}
\hline Laptseva 2002 & 26 & $\begin{array}{l}\text { budesonide, } \\
\text { placebo }\end{array}$ & 49 & $\mathrm{nr}$ & $\mathrm{nr}$ & $\mathrm{nr}$ & $\mathrm{nr}$ \\
\hline Mahler 2002 & 26 & $\begin{array}{l}\text { salmeterol, flu- } \\
\text { ticasone, salme- } \\
\text { terol/fluticas- } \\
\text { one, placebo }\end{array}$ & 674 & 63.5 & 65.8 & 41 & 40.8 \\
\hline $\begin{array}{l}\text { Mahmud } \\
2007\end{array}$ & 26 & $\begin{array}{l}\text { salmeterol, } \\
\text { tiotropium }\end{array}$ & 90 & $\mathrm{nr}$ & 91 & $\mathrm{nr}$ & $\mathrm{nr}$ \\
\hline $\begin{array}{l}\text { Niewoehner } \\
2005\end{array}$ & 26 & $\begin{array}{l}\text { tiotropium, } \\
\text { placebo }\end{array}$ & 1829 & 67.9 & 98.5 & 35.6 & 68.4 \\
\hline Ohar 2013 & 26 & $\begin{array}{l}\text { salmeterol, sal- } \\
\text { meterol/ } \\
\text { fluticasone }\end{array}$ & 639 & $\mathrm{nr}$ & $\mathrm{nr}$ & $\mathrm{nr}$ & $\mathrm{nr}$ \\
\hline Ozol 2005 & 26 & $\begin{array}{l}\text { budesonide, } \\
\text { placebo }\end{array}$ & 26 & 65.4 & 69.2 & 59.2 & 45.0 \\
\hline Paggiaro 1998 & 26 & $\begin{array}{l}\text { fluticasone, } \\
\text { placebo }\end{array}$ & 281 & 63 & 74 & 57 & $\mathrm{nr}$ \\
\hline Pauwels 1999 & 156 & $\begin{array}{l}\text { budesonide, } \\
\text { placebo }\end{array}$ & 1277 & 52.5 & 72.9 & 76.9 & 39.3 \\
\hline Powrie 2007 & 52 & $\begin{array}{l}\text { tiotropium, } \\
\text { placebo }\end{array}$ & 142 & 66.4 & 62.9 & 50.0 & 55.2 \\
\hline $\begin{array}{l}\text { Renkema } \\
1996\end{array}$ & 104 & $\begin{array}{l}\text { budesonide, } \\
\text { placebo }\end{array}$ & 39 & 55 & 100 & 63.5 & $\mathrm{nr}$ \\
\hline Rennard 2009 & 52 & $\begin{array}{l}\text { for- } \\
\text { moterol, budes- } \\
\text { onide, for- } \\
\text { moterol/budes- } \\
\text { onide, placebo }\end{array}$ & 1964 & 63.2 & 63.9 & 39.6 & 40 (med) \\
\hline Rossi 2002 & 52 & $\begin{array}{l}\text { formoterol (2), } \\
\text { placebo }\end{array}$ & 645 & 62.7 & 83.3 & $\mathrm{nr}$ & $\mathrm{nr}$ \\
\hline $\begin{array}{l}\text { Schermer } \\
2009\end{array}$ & 156 & $\begin{array}{l}\text { fluticasone, } \\
\text { placebo }\end{array}$ & 190 & 59.0 & 70.5 & 64.5 & 28.3 \\
\hline SCO100470 & 26 & $\begin{array}{l}\text { salmeterol, sal- } \\
\text { meterol/ } \\
\text { fluticasone }\end{array}$ & 1050 & 63.6 & 77.8 & $\mathrm{nr}$ & $\mathrm{nr}$ \\
\hline
\end{tabular}


Table 1. All included studies-summary characteristics (Continued)

\begin{tabular}{|c|c|c|c|c|c|c|c|}
\hline SCO30002 & 52 & $\begin{array}{l}\text { salmeterol/flu- } \\
\text { ticasone, fluti- } \\
\text { casone, placebo }\end{array}$ & 387 & 64.8 & 82 & $\mathrm{nr}$ & $\mathrm{nr}$ \\
\hline SCO40041 & 156 & $\begin{array}{l}\text { salmeterol, sal- } \\
\text { meterol/ } \\
\text { fluticasone }\end{array}$ & 186 & 65.7 & 61.3 & $\mathrm{nr}$ & $\mathrm{nr}$ \\
\hline $\begin{array}{l}\text { Senderovitz } \\
1999\end{array}$ & 26 & $\begin{array}{l}\text { budesonide, } \\
\text { placebo }\end{array}$ & 26 & 60.5 & 53.5 & $\mathrm{nr}$ & $\mathrm{nr}$ \\
\hline Shaker 2009 & $104+$ & $\begin{array}{l}\text { budesonide, } \\
\text { placebo }\end{array}$ & 254 & 63.6 & 58.3 & 52 & 56 \\
\hline $\begin{array}{l}\text { Sharafkhaneh } \\
2012\end{array}$ & 52 & $\begin{array}{l}\text { formoterol, } \\
\text { budesonide/ } \\
\text { formoterol (2) }\end{array}$ & 1219 & 63.0 & 62.0 & 37.7 & 44.3 \\
\hline SLMF4010 & 26 & $\begin{array}{l}\text { salmeterol, } \\
\text { placebo }\end{array}$ & 34 & 63.8 & 88.3 & $\mathrm{nr}$ & $\mathrm{nr}$ \\
\hline SPARK 2013 & 64 & $\begin{array}{l}\text { tiotropium } \\
(\mathrm{OL}) \text {, glycopy- } \\
\text { rronium }\end{array}$ & 1483 & 63.4 & 74.1 & $\mathrm{nr}$ & $\mathrm{nr}$ \\
\hline $\begin{array}{l}\text { Szafranski } \\
2003\end{array}$ & 52 & $\begin{array}{l}\text { for- } \\
\text { moterol, budes- } \\
\text { onide, for- } \\
\text { moterol/budes- } \\
\text { onide, placebo }\end{array}$ & 812 & 64 & 78.8 & 36.2 & 44.5 \\
\hline $\begin{array}{l}\text { Tashkin } 2008 \\
\text { [SHINE] }\end{array}$ & 26 & $\begin{array}{l}\text { formoterol, } \\
\text { budesonide, } \\
\text { formoterol/ } \\
\text { budesonide (3), } \\
\text { placebo }\end{array}$ & 1704 & 63.4 & 66.9 & 39.9 & 40 (med) \\
\hline $\begin{array}{l}\text { Tashkin } \\
\text { 2008a } \\
\text { [UPLIFT] }\end{array}$ & 208 & $\begin{array}{l}\text { tiotropium, } \\
\text { placebo }\end{array}$ & 5993 & 64.5 & 74.7 & 39.4 & 48.7 \\
\hline Tashkin 2012 & 26 & $\begin{array}{l}\text { formoterol, } \\
\text { mometasone, } \\
\text { formoterol/ } \\
\text { mometasone } \\
\text { (2), placebo }\end{array}$ & 1055 & 59.8 & 77.5 & $\mathrm{nr}$ & 40.4 \\
\hline
\end{tabular}


Table 1. All included studies-summary characteristics (Continued)

\begin{tabular}{|c|c|c|c|c|c|c|c|}
\hline To 2011 & 52 & $\begin{array}{l}\text { salmeterol, in- } \\
\text { dacaterol }\end{array}$ & 186 & 69.1 & $\mathrm{nr}$ & 53 & $\mathrm{nr}$ \\
\hline $\begin{array}{l}\text { Tonnel } 2008 \\
\text { [TIPHON] }\end{array}$ & 39 & $\begin{array}{l}\text { tiotropium, } \\
\text { placebo }\end{array}$ & 554 & 64.2 & 86.1 & 46.9 & 43.7 \\
\hline Trooster 2011 & 24 & $\begin{array}{l}\text { tiotropium, } \\
\text { placebo }\end{array}$ & 457 & 61.8 & 68.4 & $\mathrm{nr}$ & $\mathrm{nr}$ \\
\hline $\begin{array}{l}\text { Verhoeven } \\
2002\end{array}$ & 26 & $\begin{array}{l}\text { fluticasone, } \\
\text { placebo }\end{array}$ & 23 & 55 & 82.3 & 63.5 & 25.5 \\
\hline Vestbo 1999 & 156 & $\begin{array}{l}\text { budesonide, } \\
\text { placebo }\end{array}$ & 290 & 59.1 & 87.5 & 86.6 & $\mathrm{nr}$ \\
\hline $\begin{array}{l}\text { Vogelmeier } \\
2008\end{array}$ & 26 & $\begin{array}{l}\text { formoterol, } \\
\text { tiotropium, } \\
\text { placebo }\end{array}$ & 640 & 62.6 & 77.5 & 51.4 & 38.0 \\
\hline $\begin{array}{l}\text { Vogelmeier } \\
2011 \text { [POET] }\end{array}$ & 52 & $\begin{array}{l}\text { salmeterol, } \\
\text { tiotropium }\end{array}$ & 7384 & 62.9 & 74.7 & 49.3 & 38.3 \\
\hline $\begin{array}{l}\text { Wedzicha } \\
2008 \\
\text { [INSPIRE] }\end{array}$ & 104 & $\begin{array}{l}\text { tiotropium, sal- } \\
\text { meterol/ } \\
\text { fluticasone }\end{array}$ & 1323 & 64.5 & 82.5 & 39.3 & 40.4 \\
\hline Zheng 2006 & 24 & $\begin{array}{l}\text { salmeterol/ } \\
\text { fluticasone, } \\
\text { placebo }\end{array}$ & 448 & 66.3 & 88.6 & $\mathrm{nr}$ & $\mathrm{nr}$ \\
\hline Zhong 2012 & 24 & $\begin{array}{l}\text { budesonide, } \\
\text { formoterol/ } \\
\text { budesonide }\end{array}$ & 308 & 65.2 & 95.1 & 32.7 & $\mathrm{nr}$ \\
\hline
\end{tabular}

${ }^{a}$ Numbers in parentheses indicate multiple doses of the same treatment.

${ }^{b}$ Age, $\%$ predicted $\mathrm{FEV}_{1}$ and pack-years smoked are reported as means unless otherwise stated.

bid = twice daily.

$\mathrm{FEV}_{1}$ = forced expiratory volume in one second.

ICS $=$ inhaled corticosteroid.

LABA = long-acting beta 2 -agonist.

LABA/ICS = long-acting beta 2 -agonist/inhaled corticosteroid combination therapy.

LAMA = long-acting muscarinic antagonist.

$\mathrm{nr}=$ not reported.

$\mathrm{PBO}=$ placebo inhaler.

qd = once daily. 
Table 2. SGRQ network composition and transitivity assessment ${ }^{a}$

\begin{tabular}{|c|c|c|c|c|c|c|}
\hline Comparison & Comparisons & $\mathbf{N}$ & Age $^{b}$ & $\%$ male & $\% \mathbf{F E V}_{1 c}$ & Packs $^{d}$ \\
\hline LABA vs placebo & 16 & 13,808 & 62.9 & 74.7 & 46.2 & 42.5 \\
\hline $\begin{array}{l}\text { LAMA } \quad \text { vs } \\
\text { placebo }\end{array}$ & 15 & 22,406 & 64.2 & 71.3 & 47.1 & 47.5 \\
\hline ICS vs placebo & 10 & 8153 & 63.4 & 74.9 & 41.7 & 42.7 \\
\hline $\begin{array}{l}\text { LABA/ICS vs } \\
\text { placebo }\end{array}$ & 10 & 9097 & 63.1 & 75.3 & 39.7 & 42.4 \\
\hline LABA vs LAMA & 2 & 2680 & 63.7 & 69.5 & 55.2 & 49.7 \\
\hline LABA vs ICS & 7 & 6226 & 62.7 & 73.8 & 40.0 & 42.7 \\
\hline $\begin{array}{l}\text { LABA vs LABA/ } \\
\text { ICS }\end{array}$ & 13 & 12,505 & 63.1 & 71.0 & 38.8 & 43.9 \\
\hline LAMA vs ICS & 0 & - & - & - & - & - \\
\hline $\begin{array}{ll}\text { LAMA } & \text { vs } \\
\text { LABA/ICS }\end{array}$ & 1 & 1323 & 64.5 & 82.5 & 39.3 & 40.4 \\
\hline $\begin{array}{l}\text { ICS vs LABA/ } \\
\text { ICS }\end{array}$ & 10 & 8721 & 62.9 & 75.3 & 38.8 & 42.9 \\
\hline \multicolumn{7}{|c|}{$\begin{array}{l}{ }^{a} \text { Summary population data are for all study comparisons excluding those made in the } 29 \text { studies that could not be included in either } \\
\text { the six-month or the } 12 \text {-month SGRQ network. }\end{array}$} \\
\hline \multicolumn{7}{|c|}{${ }^{b}$ Age $=$ mean years. } \\
\hline \multicolumn{7}{|c|}{${ }^{c} \% \mathrm{FEV}_{1}=$ mean percentage predicted $\mathrm{FEV}_{1}}$. \\
\hline \multicolumn{7}{|c|}{${ }^{d}$ Packs $=$ mean pack-years. } \\
\hline \multicolumn{7}{|c|}{$\mathrm{FEV}_{1}=$ forced expiratory volume in one second. } \\
\hline \multicolumn{7}{|c|}{ ICS = inhaled corticosteroid. } \\
\hline \multicolumn{7}{|c|}{ LABA = long-acting beta 2 -agonist } \\
\hline \multicolumn{7}{|c|}{ LABA/ICS = long-acting beta 2 -agonist/inhaled corticosteroid combination therapy. } \\
\hline \multicolumn{7}{|c|}{ LAMA = long-acting muscarinic antagonist. } \\
\hline SGRQ = St Georg & '’s Respiratory Q & lestionnai & & & & \\
\hline
\end{tabular}

Table 3. FEV $_{1}$ network composition and transitivity assessment ${ }^{a}$

\begin{tabular}{llllllll}
\hline Comparison & Comparisons & $\mathbf{N}$ & Age $^{b}$ & \% male & \%FEV $_{1 c}$ & Packs $^{d}$ \\
\hline LABA vs Placebo & 13 & 8680 & 63.3 & 73.2 & 47.7 & 43.9 \\
\hline $\begin{array}{l}\text { LAMA } \\
\begin{array}{l}\text { Placebo } \\
\text { vs }\end{array}\end{array}$ & 16 & 23,111 & 64.3 & 72.2 & 47.6 & 48.9 \\
\hline
\end{tabular}


Table 3. FEV $_{1}$ network composition and transitivity assessment ${ }^{a} \quad$ (Continued)

\begin{tabular}{|c|c|c|c|c|c|c|}
\hline ICS vs Placebo & 12 & 4574 & 63.6 & 71.9 & 46.2 & 45.2 \\
\hline $\begin{array}{l}\text { LABA/ICS vs } \\
\text { Placebo }\end{array}$ & 9 & 4978 & 63.9 & 73.5 & 41.6 & 44.4 \\
\hline LABA vs LAMA & 2 & 2680 & 63.7 & 69.5 & 55.2 & 49.7 \\
\hline LABA vs ICS & 5 & 2506 & 63.6 & 67.1 & 40.6 & 46.7 \\
\hline $\begin{array}{l}\text { LABA vs LABA/ } \\
\text { ICS }\end{array}$ & 12 & 8005 & 63.7 & 68.8 & 39.9 & 45.8 \\
\hline LAMA vs ICS & 0 & - & - & - & - & - \\
\hline $\begin{array}{l}\text { LAMA } \\
\text { LABA/ICS }\end{array}$ & 0 & - & - & - & - & - \\
\hline $\begin{array}{l}\text { ICS vs LABA/ } \\
\text { ICS }\end{array}$ & 8 & 4560 & 63.6 & 71.7 & 39.0 & 45.5 \\
\hline
\end{tabular}

${ }^{a}$ Summary population data are for all study comparisons excluding those made in the 23 studies that could not be included in either the six-month or the 12-month $\mathrm{FEV}_{1}$ network; all doses are given in micrograms.

${ }^{b}$ Age $=$ mean years.

$c_{\%} \mathrm{FEV}_{1}=$ mean percentage predicted $\mathrm{FEV}_{1}$.

${ }^{d}$ Packs $=$ mean pack-years .

FEV1 = forced expiratory volume in one second.

ICS $=$ inhaled corticosteroid.

LABA = long-acting beta 2 -agonist.

LABA/ICS = long-acting beta 2 -agonist/inhaled corticosteroid combination therapy.

LAMA = long-acting muscarinic antagonist.

Table 4. Distribution of studies by individual treatment node

\begin{tabular}{|c|c|c|}
\hline Class & Treatment node mcg & Studies \\
\hline \multirow[t]{5}{*}{ LABA } & Formoterol 12 bid & $\begin{array}{l}\text { Calverley 2003a; Calverley } 2003 \text { [TRISTAN]; Calverley 2010; } \\
\text { Campbell 2005; Dahl 2010; Doherty 2012; Rennard 2009; Rossi 2002; } \\
\text { Sharafkhaneh 2012; Szafranski 2003; Tashkin } 2008 \text { [SHINE]; Tashkin 2012; } \\
\text { Vogelmeier 2008 }{ }^{a}\end{array}$ \\
\hline & Formoterol 24 bid & Rossi 2002 \\
\hline & Indacaterol $300 \mathrm{qd}$ & Dahl 2010; Donohue 2010 [INHANCE] \\
\hline & Indacaterol $600 \mathrm{qd}$ & Dahl 2010 \\
\hline & Indacaterol $150 \mathrm{qd}$ & Bateman 2013 [SHINE]; Donohue 2010 [INHANCE] \\
\hline
\end{tabular}


Table 4. Distribution of studies by individual treatment node (Continued)

\begin{tabular}{|c|c|c|}
\hline & Salmeterol 50 bid & $\begin{array}{l}\text { Anzueto 2009; Brusasco 2003; Dal Negro 2003 }{ }^{a} \text {; Calverley } 2007 \text { [TORCH]; } \\
\text { Ferguson 2008; Hanania 2003 }{ }^{a} \text {; Kardos 2007; Kornmann 2011; Mahler 2002 } \\
\text { Mahmud 2007 }{ }^{a} \text {; Ohar 2013 } \\
\text { Vogelmeier } 2011 \text { [POET] }^{a}\end{array}$ \\
\hline \multirow[t]{7}{*}{ LAMA } & Tiotropium 5 qd & Abrahams 2013; Bateman 2010a; Bateman 2010b \\
\hline & Tiotropium $10 \mathrm{qd}$ & Bateman 2010b \\
\hline & Tiotropium $18 \mathrm{qd}$ & 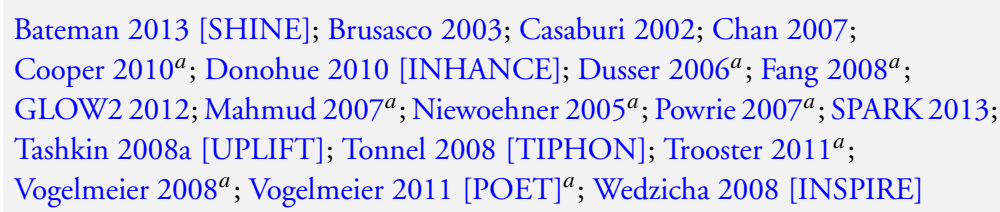 \\
\hline & Aclidinium bromide $200 \mathrm{qd}$ & ACCLAIM 2009; ACCLAIM II 2009 \\
\hline & Aclidinium bromide 200 bid & ATTAIN 2011; GLOW1 2011 \\
\hline & Aclidinium bromide 400 bid & ATTAIN 2011; Gelb 2012 \\
\hline & Glycopyrronium bromide $50 \mathrm{qd}$ & Bateman 2013 [SHINE]; GLOW1 2011; GLOW2 2012; SPARK 2013 \\
\hline \multirow[t]{5}{*}{ ICS } & Budesonide $320-400$ bid & $\begin{array}{l}\text { Calverley 2003a; Laptseva } 2002^{a} \text {; Ozol 2005 }{ }^{a} \text {; Pauwels } 1999^{a} \text {; } \\
\text { Senderovitz 1999 }{ }^{a} \text {; Shaker 2009 } \text {; Szafranski 2003; Tashkin } 2008 \text { [SHINE]; } \\
\text { Zhong } 2012\end{array}$ \\
\hline & Budesonide $750-1000$ bid & Bourbeau 1998; Renkema 1996 ; Vestbo 1999 \\
\hline & Fluticasone 250 bid & FLTA3025; Hanania 2003 \\
\hline & Fluticasone 500 bid & $\begin{array}{l}\text { Burge } 2000 \text { [ISOLDE]; Calverley } 2003 \text { [TRISTAN]; Calverley } 2007 \text { [TORCH]; } \\
\text { FLTA3025; Lapperre 2009 } \text {; Mahler 2002; Paggiaro 1998; Schermer 2009; } \\
\text { SCO30002 }^{a} \text {; Verhoeven } 2002^{a}\end{array}$ \\
\hline & Mometasone 400 bid or $800 \mathrm{qd}$ & Calverley 2003b; Calverley 2008; Doherty 2012; Tashkin 2012 \\
\hline \multirow[t]{5}{*}{ LABA/ICS } & Formoterol/bud $12 / 160 \mathrm{bid}$ & Rennard 2009; Sharafkhaneh 2012; Tashkin 2008 [SHINE]; Zhong 2012 \\
\hline & Formoterol/bud $12 / 320$ bid & $\begin{array}{l}\text { Calverley 2003a; Calverley 2010; Rennard 2009; Sharafkhaneh 2012; } \\
\text { Szafranski 2003; Tashkin } 2008 \text { [SHINE] }\end{array}$ \\
\hline & Formoterol/mom 12/200 bid & Doherty 2012; Tashkin 2012 \\
\hline & Formoterol/mom $12 / 400$ bid & Doherty 2012; Tashkin 2012 \\
\hline & Salmeterol/flut 50/250 bid & Anzueto 2009; Dal Negro 2003; Fang 2008 ${ }^{a}$; Hanania 2003; Ohar 2013 \\
\hline
\end{tabular}


Table 4. Distribution of studies by individual treatment node (Continued)

\begin{tabular}{|c|c|c|}
\hline & Salmeterol/flut 50/500 bid & 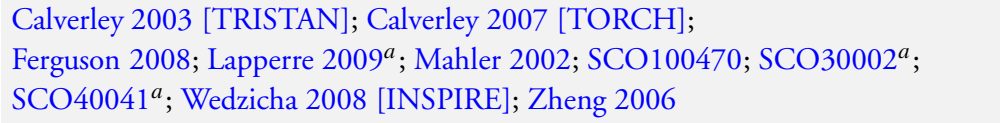 \\
\hline PBO & Placebo inhaler & 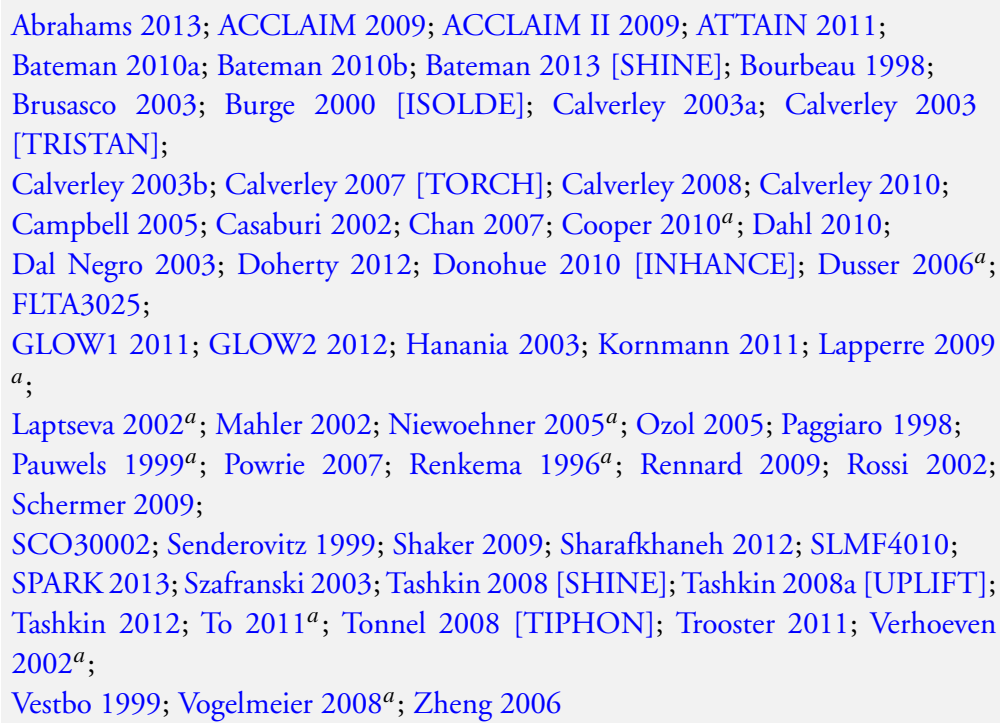 \\
\hline
\end{tabular}

${ }^{a}$ Studies not contributing data to either outcome.

bid = twice daily.

ICS $=$ inhaled corticosteroid.

LABA = long-acting beta 2 -agonist.

LABA/ICS = long-acting beta 2 -agonist/inhaled corticosteroid combination therapy.

LAMA = long-acting muscarinic antagonist.

$\mathrm{PBO}=$ placebo inhaler.

$\mathrm{qd}=$ once daily.

Table 5. Sensitivity analysis-blinding

\begin{tabular}{lll}
\hline Study ID & Arm removed & Analyses affected \\
\hline Bateman 2013 [SHINE] & Tiotropium $18 \mathrm{mcg}$ & SGRQ6m, FEV6m \\
\hline Donohue 2010 [INHANCE] & Tiotropium $18 \mathrm{mcg}$ & SGRQ6m, FEV6m \\
\hline GLOW2 2012 & Tiotropium $18 \mathrm{mcg}$ & SGRQ6m, FEV6m, SGRQ12m, FEV12m \\
\hline SPARK 2013 & Whole study (2 arms) & SGRQ6m, FEV6m, SGRQ12m, FEV12m \\
\hline Vogelmeier 2008 & Tiotropium $18 \mathrm{mcg}$ & Did not appear in analyses \\
\hline
\end{tabular}

$\mathrm{FEV}=$ forced expiratory volume in one second 
SGRQ = St George's Respiratory Questionnaire

$6 \mathrm{~m}=$ six month analysis

$12 \mathrm{~m}=12$ month analysis

Table 6. SGRQ class effects versus placebo (six months) ${ }^{a}$

\begin{tabular}{|c|c|c|c|c|c|c|c|c|}
\hline \multirow[b]{2}{*}{ Class } & \multicolumn{2}{|c|}{$\begin{array}{l}\text { Effect vs placebo } \\
\text { Class NWMA }\end{array}$} & \multicolumn{2}{|c|}{$\begin{array}{l}\text { Effect vs placebo } \\
\text { Sensitivity analysis }\end{array}$} & \multicolumn{4}{|l|}{ Rank } \\
\hline & Median & $95 \%$ CrI & Median & $95 \% \mathrm{CrI}$ & Mean & Median & 95\% CrI & $\operatorname{Pr}$ (best) \\
\hline LABA/ICS & -3.89 & $\begin{array}{l}(-4.70 \text { to }-2 . \\
97)\end{array}$ & -3.89 & $\begin{array}{l}(-4.66 \text { to }-3 \text {. } \\
05)\end{array}$ & 1.0 & 1 & (1 to 2$)$ & 0.96 \\
\hline LAMA & -2.63 & $\begin{array}{l}(-3.53 \text { to }-1 . \\
97)\end{array}$ & -2.78 & $\begin{array}{l}(-3.58 \text { to }-2 \text {. } \\
13)\end{array}$ & 2.4 & 2 & (1 to 4$)$ & 0.03 \\
\hline LABA & -2.29 & $\begin{array}{l}(-3.18 \text { to }-1 . \\
53)\end{array}$ & -2.09 & $\begin{array}{l}(-2.93 \text { to }-1 . \\
36)\end{array}$ & 3.1 & 3 & (2 to 4$)$ & 0.01 \\
\hline ICS & -2.00 & $\begin{array}{l}(-3.06 \text { to }-0 . \\
87)\end{array}$ & -1.96 & $\begin{array}{l}(-2.99 \text { to }-0 . \\
91)\end{array}$ & 3.5 & 4 & (2 to 4$)$ & 0.00 \\
\hline
\end{tabular}

${ }^{a}$ For effects versus placebo, smaller values indicate larger benefits of the active treatment; all doses are given in micrograms.

$\mathrm{Crl}=$ credible interval.

SGRQ = St George's Respiratory Questionnaire.

ICS $=$ inhaled corticosteroid.

LABA = long-acting beta 2 -agonist.

LABA/ICS = long-acting beta 2 -agonist/inhaled corticosteroid.

LAMA = long-acting antimuscarinic antagonist.

NWMA = network meta-analysis.

$\operatorname{Pr}=$ probability.

Table 7. SGRQ individual treatment effects versus placebo (six months) ${ }^{a}$

\begin{tabular}{|c|c|c|c|c|c|c|c|c|c|}
\hline \multicolumn{2}{|c|}{$\begin{array}{l}\text { Rank (from class } \\
\text { NWMA) }\end{array}$} & \multicolumn{2}{|c|}{$\begin{array}{l}\text { Effect vs placebo } \\
\text { Class NWMA }\end{array}$} & \multicolumn{2}{|c|}{$\begin{array}{l}\text { Effect vs placebo } \\
\text { NWMA no class }\end{array}$} & \multicolumn{4}{|c|}{ Rank (from class NWMA) } \\
\hline Class & $\begin{array}{l}\text { Treatment } \\
\text { (num- } \\
\text { ber daily } \\
\text { doses) }\end{array}$ & Median & $95 \% \mathrm{CrI}$ & Median & $95 \% \mathrm{CrI}$ & Mean & Median & $95 \% \mathrm{CrI}$ & $\operatorname{Pr}$ (best) \\
\hline \multirow[t]{2}{*}{ LABA } & $\begin{array}{l}\text { Form } 12 \\
\text { (2) }\end{array}$ & -1.84 & $\begin{array}{l}(-2.60 \text { to }- \\
0.94)\end{array}$ & -1.20 & $\begin{array}{l}(-2.10 \text { to }- \\
0.30)\end{array}$ & 14.9 & 15 & (10 to 17$)$ & 0.00 \\
\hline & $\begin{array}{l}\text { Ind } 300 \\
\text { (1) }\end{array}$ & -2.38 & $\begin{array}{l}(-3.63 \text { to }- \\
1.44)\end{array}$ & -3.10 & $\begin{array}{l}(-4.86 \text { to }- \\
1.36)\end{array}$ & 11.3 & 12 & (5 to 17 ) & 0.00 \\
\hline
\end{tabular}


Table 7. SGRQ individual treatment effects versus placebo (six months) ${ }^{a} \quad$ (Continued) $^{-}$

\begin{tabular}{|c|c|c|c|c|c|c|c|c|c|}
\hline & $\begin{array}{l}\text { Ind } 150 \\
\text { (1) }\end{array}$ & -2.75 & $\begin{array}{l}(-3.95 \text { to }- \\
1.85)\end{array}$ & -3.67 & $\begin{array}{l}(-4.76 \text { to }- \\
2.58)\end{array}$ & 8.7 & 8 & (3 to 16$)$ & 0.01 \\
\hline & $\begin{array}{l}\text { Salm } 50 \\
\text { (2) }\end{array}$ & -2.20 & $\begin{array}{l}(-2.98 \text { to }- \\
1.43)\end{array}$ & -2.27 & $\begin{array}{l}(-3.27 \text { to }- \\
1.27)\end{array}$ & 12.9 & 13 & (7 to 17 ) & 0.00 \\
\hline \multirow[t]{5}{*}{ LAMA } & Tio 5 (1) & -2.50 & $\begin{array}{l}(-3.16 \text { to }- \\
1.86)\end{array}$ & -2.42 & $\begin{array}{l}(-3.20 \text { to }- \\
1.63)\end{array}$ & 10.5 & 10 & (6 to 16$)$ & 0.00 \\
\hline & Tio 18 (1) & -2.53 & $\begin{array}{l}(-3.12 \text { to }- \\
1.97)\end{array}$ & -2.66 & $\begin{array}{l}(-3.33 \text { to }- \\
1.99)\end{array}$ & 10.3 & 10 & (6 to 15$)$ & 0.00 \\
\hline & Acl 200 (2) & -2.66 & $\begin{array}{l}(-4.04 \text { to }- \\
1.70)\end{array}$ & -3.79 & $\begin{array}{l}(-6.14 \text { to }- \\
1.45)\end{array}$ & 9.1 & 9 & ( 2 to 16$)$ & 0.01 \\
\hline & Acl 400 (2) & -2.81 & $\begin{array}{l}(-4.40 \text { to }- \\
1.90)\end{array}$ & -4.59 & $\begin{array}{l}(-6.94 \text { to }- \\
2.23)\end{array}$ & 7.9 & 7 & (1 to 15$)$ & 0.03 \\
\hline & Gly 50 (1) & -2.63 & $\begin{array}{l}(-3.42 \text { to }- \\
1.94)\end{array}$ & -2.83 & $\begin{array}{l}(-3.74 \text { to }- \\
1.91)\end{array}$ & 9.5 & 9 & (5 to 15$)$ & 0.00 \\
\hline \multirow[t]{3}{*}{ ICS } & $\begin{array}{l}\text { Bud } 400 \\
\text { (2) }\end{array}$ & -1.76 & $\begin{array}{l}(-2.82 \text { to }- \\
0.55)\end{array}$ & -0.97 & $\begin{array}{l}(-2.32 \text { to } 0 . \\
38)\end{array}$ & 14.9 & 16 & (7 to 17 ) & 0.00 \\
\hline & $\begin{array}{l}\text { Flut } 500 \\
\text { (2) }\end{array}$ & -1.95 & $\begin{array}{l}(-3.07 \text { to }- \\
0.74)\end{array}$ & -1.71 & $\begin{array}{l}(-3.40 \text { to }- \\
0.01)\end{array}$ & 13.9 & 15 & (6 to 17 ) & 0.00 \\
\hline & $\begin{array}{l}\text { Mom } 400 \\
\text { (2) }\end{array}$ & -2.28 & $\begin{array}{l}(-3.51 \text { to }- \\
1.19)\end{array}$ & -2.77 & $\begin{array}{l}(-4.47 \text { to }- \\
1.09)\end{array}$ & 11.9 & 13 & (5 to 17 ) & 0.00 \\
\hline \multirow[t]{5}{*}{ LABA/ICS } & $\begin{array}{l}\text { Form-bud } \\
12 / 160(2)\end{array}$ & -4.04 & $\begin{array}{l}(-4.91 \text { to }- \\
3.15)\end{array}$ & -3.85 & $\begin{array}{l}(-4.99 \text { to }- \\
2.70)\end{array}$ & 2.6 & 2 & (1 to 6$)$ & 0.29 \\
\hline & $\begin{array}{l}\text { Form-bud } \\
12 / 320(2)\end{array}$ & -3.80 & $\begin{array}{l}(-4.63 \text { to }- \\
2.84)\end{array}$ & -3.31 & $\begin{array}{l}(-4.39 \text { to }- \\
2.22)\end{array}$ & 3.9 & 4 & (1 to 9$)$ & 0.10 \\
\hline & $\begin{array}{l}\text { Form- } \\
\text { mom 12/ } \\
200(2)\end{array}$ & -3.85 & $\begin{array}{l}(-4.82 \text { to }- \\
2.66)\end{array}$ & -3.45 & $\begin{array}{l}(-5.17 \text { to }- \\
1.74)\end{array}$ & 3.7 & 4 & (1 to 10$)$ & 0.15 \\
\hline & $\begin{array}{l}\text { Form- } \\
\text { mom 12/ } \\
400(2)\end{array}$ & -3.75 & $\begin{array}{l}(-4.72 \text { to }- \\
2.48)\end{array}$ & -3.09 & $\begin{array}{l}(-4.81 \text { to }- \\
1.37)\end{array}$ & 4.3 & 4 & (1 to 11 ) & 0.10 \\
\hline & $\begin{array}{l}\text { Salm-flut } \\
50 / 500(2)\end{array}$ & -4.05 & $\begin{array}{l}(-4.97 \text { to }- \\
3.18)\end{array}$ & -4.36 & $\begin{array}{l}(-5.60 \text { to }- \\
3.12)\end{array}$ & 2.6 & 2 & (1 to 6$)$ & 0.31 \\
\hline
\end{tabular}

${ }^{a}$ For effects versus placebo, smaller values indicate larger benefits of the active treatment; all doses are given in micrograms. $\mathrm{Crl}=$ credible interval. 
SGRQ = St George's Respiratory Questionnaire.

ICS = inhaled corticosteroid.

LABA = long-acting beta 2 -agonist.

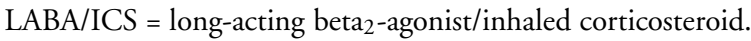

LAMA = long-acting antimuscarinic antagonist.

NWMA = network meta-analysis.

$\operatorname{Pr}=$ probability.

Table 8. FEV $_{1}$ class effects versus placebo (six months) ${ }^{a}$

\begin{tabular}{|c|c|c|c|c|c|c|c|c|}
\hline \multirow[b]{2}{*}{ Class } & \multicolumn{2}{|c|}{$\begin{array}{l}\text { Effect vs placebo } \\
\text { Class NWMA }\end{array}$} & \multicolumn{2}{|c|}{$\begin{array}{l}\text { Effect vs placebo } \\
\text { Sensitivity analysis }\end{array}$} & \multicolumn{4}{|l|}{ Rank } \\
\hline & Median & $95 \%$ CrI & Median & $95 \%$ CrI & Mean & Median & $95 \% \mathrm{CrI}$ & $\operatorname{Pr}$ (best) \\
\hline LABA/ICS & 133.30 & $\begin{array}{l}(100.60 \text { to } \\
164.00)\end{array}$ & 132.80 & $\begin{array}{ll}(98.93 & \text { to } \\
165.60) & \end{array}$ & 1.1 & 1 & (1 to 2$)$ & 0.9 \\
\hline LAMA & 103.50 & $\begin{array}{l}(81.78,124 . \\
90)\end{array}$ & 103.60 & $\begin{array}{ll}(79.01 & \text { to } \\
126.60) & \end{array}$ & 2.4 & 2 & (1 to 3 ) & 0.1 \\
\hline LABA & 99.44 & $\begin{array}{l}(71.98,127 . \\
80)\end{array}$ & 99.86 & $\begin{array}{l}(70.41 \\
130.50)\end{array}$ to & 2.6 & 3 & (1 to 4$)$ & 0.0 \\
\hline ICS & 65.36 & $\begin{array}{l}(33.06,96 . \\
91)\end{array}$ & 65.52 & $\begin{array}{l}(31.23 \\
97.16)\end{array} \quad$ to & 3.9 & 4 & (3 to 4$)$ & 0.0 \\
\hline
\end{tabular}

${ }^{a}$ For effects versus placebo, smaller values indicate larger benefits of the active treatment; all doses are given in micrograms.

$\mathrm{Crl}=$ credible interval.

$\mathrm{FEV}_{1}$ = forced expiratory volume in one second.

ICS $=$ inhaled corticosteroid.

LABA = long-acting beta 2 -agonist.

LABA/ICS = long-acting beta 2 -agonist/inhaled corticosteroid.

LAMA = long-acting antimuscarinic antagonist.

NWMA = network meta-analysis.

$\operatorname{Pr}=$ probability.

Table 9. FEV $_{1}$ individual treatment effects versus placebo (six months) ${ }^{a}$

\begin{tabular}{|c|c|c|c|c|c|c|c|c|c|}
\hline \multirow[b]{2}{*}{ Class } & \multirow[b]{2}{*}{$\begin{array}{l}\text { Treatment } \\
\text { (num- } \\
\text { ber daily } \\
\text { doses) }\end{array}$} & \multicolumn{2}{|c|}{$\begin{array}{l}\text { Effect vs placebo } \\
\text { Class NWMA }\end{array}$} & \multicolumn{2}{|c|}{$\begin{array}{l}\text { Effect vs placebo } \\
\text { NWMA no class }\end{array}$} & \multicolumn{4}{|c|}{ Rank (from class NWMA) } \\
\hline & & Median & $95 \% \mathrm{CrI}$ & Median & $95 \% \mathrm{CrI}$ & Mean & Median & $95 \% \mathrm{CrI}$ & $\operatorname{Pr}$ (best) \\
\hline LABA & $\begin{array}{l}\text { Form } 12 \\
\text { (2) }\end{array}$ & 94.88 & $\begin{array}{l}(60.70 \text { to } \\
122.80)\end{array}$ & 53.92 & $\begin{array}{l}(13.00 \text { to } \\
94.07)\end{array}$ & 12.0 & 13 & (5 to 18$)$ & 0.00 \\
\hline
\end{tabular}

Long-acting inhaled therapy (beta-agonists, anticholinergics and steroids) for COPD: a network meta-analysis (Review) 
Table 9. FEV $_{1}$ individual treatment effects versus placebo (six months) ${ }^{a} \quad$ (Continued) $^{-}$

\begin{tabular}{|c|c|c|c|c|c|c|c|c|c|}
\hline & $\begin{array}{l}\text { Ind } 300 \\
\text { (1) }\end{array}$ & 103.30 & $\begin{array}{l}(71.95 \text { to } \\
150.10)\end{array}$ & 137.90 & $\begin{array}{l}(63.69 \text { to } \\
209.90)\end{array}$ & 9.5 & 10 & (2 to 16 ) & 0.02 \\
\hline & $\begin{array}{l}\text { Ind } 150 \\
\text { (1) }\end{array}$ & 99.53 & $\begin{array}{l}(72.32 \text { to } \\
127.20)\end{array}$ & 100.70 & $\begin{array}{l}(65.74 \text { to } \\
133.80)\end{array}$ & 10.8 & 12 & (4 to 16$)$ & 0.00 \\
\hline & $\begin{array}{l}\text { Salm } 50 \\
\text { (2) }\end{array}$ & 101.00 & $\begin{array}{l}(73.39 \text { to } \\
130.70)\end{array}$ & 114.70 & $\begin{array}{l}(75.96 \text { to } \\
149.30)\end{array}$ & 10.3 & 11 & (4 to 16$)$ & 0.00 \\
\hline \multirow[t]{7}{*}{ LAMA } & Tio 5 (1) & 105.40 & $\begin{array}{l}(81.87 \text { to } \\
131.80)\end{array}$ & 110.50 & $\begin{array}{l}(73.82 \text { to } \\
145.40)\end{array}$ & 8.9 & 9 & (3 to 15$)$ & 0.01 \\
\hline & Tio 10 (1) & 106.40 & $\begin{array}{l}(79.80 \text { to } \\
142.00)\end{array}$ & 121.00 & $\begin{array}{l}(62.88 \text { to } \\
175.20)\end{array}$ & 8.6 & 8 & (2 to 15$)$ & 0.02 \\
\hline & Tio 18 (1) & 105.20 & $\begin{array}{l}(85.54 \text { to } \\
125.50)\end{array}$ & 107.00 & $\begin{array}{l}(82.93 \text { to } \\
129.50)\end{array}$ & 9.0 & 9 & (4 to 15$)$ & 0.00 \\
\hline & $\operatorname{Acl} 200$ (1) & 98.83 & $\begin{array}{l}(59.06 \text { to } \\
123.20)\end{array}$ & 59.31 & $\begin{array}{l}(9.47 \quad \text { to } \\
107.90)\end{array}$ & 11.3 & 11 & (5 to 18 ) & 0.00 \\
\hline & $\operatorname{Acl} 200$ (2) & 100.60 & $\begin{array}{l}(65.20 \text { to } \\
127.10)\end{array}$ & 74.82 & $\begin{array}{l}(11.81 \text { to } \\
134.20)\end{array}$ & 10.7 & 11 & (4 to 17 ) & 0.00 \\
\hline & Acl 400 (2) & 107.30 & $\begin{array}{l}(80.93 \text { to } \\
143.50)\end{array}$ & 108.80 & $\begin{array}{l}(45.06 \text { to } \\
168.30)\end{array}$ & 8.2 & 8 & (2 to 15$)$ & 0.02 \\
\hline & Gly 50 (1) & 103.60 & $\begin{array}{l}(79.83 \text { to } \\
127.50)\end{array}$ & 101.50 & $\begin{array}{l}(67.86 \text { to } \\
133.40)\end{array}$ & 9.5 & 10 & (3 to 15$)$ & 0.00 \\
\hline \multirow[t]{4}{*}{ ICS } & $\begin{array}{l}\text { Bud } 400 \\
\text { (2) }\end{array}$ & 61.89 & $\begin{array}{l}(23.86 \text { to } \\
94.06)\end{array}$ & 14.59 & $\begin{array}{l}(-29.22 \text { to } \\
58.25)\end{array}$ & 17.6 & 18 & (14 to 19$)$ & 0.00 \\
\hline & $\begin{array}{l}\text { Bud } 750+ \\
\text { (2) }\end{array}$ & 63.10 & $\begin{array}{l}(14.75 \text { to } \\
99.65)\end{array}$ & -2.26 & $\begin{array}{l}(-95.77 \text { to } \\
91.34)\end{array}$ & 17.3 & 18 & (12 to 19$)$ & 0.00 \\
\hline & $\begin{array}{l}\text { Flut } 250 \\
\text { (2) }\end{array}$ & 66.78 & $\begin{array}{l}(34.19 \text { to } \\
101.10)\end{array}$ & 76.18 & $\begin{array}{l}(29.36 \text { to } \\
122.30)\end{array}$ & 16.9 & 17 & (11 to 19 ) & 0.00 \\
\hline & $\begin{array}{l}\text { Flut } 500 \\
\text { (2) }\end{array}$ & 72.16 & $\begin{array}{l}(40.20 \text { to } \\
109.80)\end{array}$ & 97.04 & $\begin{array}{l}(54.90 \text { to } \\
138.40)\end{array}$ & 15.9 & 16 & (8 to 19$)$ & 0.00 \\
\hline \multirow[t]{2}{*}{ LABA/ICS } & $\begin{array}{l}\text { Form-bud } \\
12 / 160(2)\end{array}$ & 131.10 & $\begin{array}{l}(91.65 \text { to } \\
164.00)\end{array}$ & 80.84 & $\begin{array}{l}(26.99 \text { to } \\
132.70)\end{array}$ & 3.9 & 3 & (1 to 13 ) & 0.16 \\
\hline & $\begin{array}{l}\text { Form-bud } \\
12 / 320(2)\end{array}$ & 127.30 & $\begin{array}{l}(85.14 \text { to } \\
159.50)\end{array}$ & 72.77 & $\begin{array}{l}(28.75 \text { to } \\
116.70)\end{array}$ & 4.7 & 4 & (1 to 14$)$ & 0.11 \\
\hline
\end{tabular}


Table 9. FEV $_{1}$ individual treatment effects versus placebo (six months) ${ }^{a} \quad$ (Continued) $^{-}$

\begin{tabular}{|c|c|c|c|c|c|c|c|c|}
\hline $\begin{array}{l}\text { Salm-flut } \\
50 / 250(2)\end{array}$ & 139.70 & $\begin{array}{l}(106.20 \text { to } \\
182.90)\end{array}$ & 173.00 & $\begin{array}{l}(116.20 \text { to } \\
226.40)\end{array}$ & 2.4 & 2 & (1 to 8$)$ & 0.39 \\
\hline $\begin{array}{l}\text { Salm-flut } \\
50 / 500(2)\end{array}$ & 137.10 & $\begin{array}{l}(104.40 \text { to } \\
172.10)\end{array}$ & 152.40 & $\begin{array}{l}(104.10 \text { to } \\
197.80)\end{array}$ & 2.8 & 2 & $(1$ to 9$)$ & 0.26 \\
\hline
\end{tabular}

${ }^{a}$ For effects versus placebo, bigger values indicate larger benefits of the active treatment; all doses are given in micrograms.

$\mathrm{Crl}=$ credible interval.

$\mathrm{FEV}_{1}=$ forced expiratory volume in one second.

ICS = inhaled corticosteroid.

LABA = long-acting beta 2 -agonist.

LABA/ICS = long-acting beta 2 -agonist/inhaled corticosteroid.

LAMA = long-acting antimuscarinic antagonist.

NWMA = network meta-analysis.

$\operatorname{Pr}=$ probability.

\section{A P P E N D I C E S}

\section{Appendix I. The Cochrane Library search strategy}

\#1 MeSH descriptor: [Pulmonary Disease, Chronic Obstructive] explode all trees

\#2 MeSH descriptor: [Lung Diseases, Obstructive] this term only

\#3 COPD:ti

\#4 (obstruct*) near/3 (pulmonary or lung* or airway* or airflow* or bronch* or respirat*):ti

\#5 \#1 or \#2 or \#3 or \#4

\#6 indacaterol

\#7 salmeterol

\#8 *formoterol

\#9 long* near (beta* near agonist*)

\#10 budesonide

\#11 fluticasone

\#12 mometasone

\#13 inhal* near (corticosteroid* or steroid*)

\#14 tiotropium

$\# 15$ aclidinium

\#16 Glycopyrronium

\#17 long* near muscarinic*

\#18 umeclidinium

\#19 vilanterol

\#20 (LABA or LAMA or ICS):ti,ab

\#21 $\{$ or \#6-\#20\}

\#22 \#5 and \#21 


\section{Appendix 2. Sources and search methods for the Cochrane Airways Group Specialised Register (CAGR)}

\section{Electronic searches: core databases}

\begin{tabular}{ll}
\hline Database & Frequency of search \\
\hline CENTRAL (The Cochrane Library) & Monthly \\
\hline MEDLINE (Ovid) & Weekly \\
\hline EMBASE (Ovid) & Weekly \\
\hline PsycINFO (Ovid) & Monthly \\
\hline CINAHL (EBSCO) & Monthly \\
\hline AMED (EBSCO) & Monthly \\
\hline
\end{tabular}

Handsearches: core respiratory conference abstracts

\begin{tabular}{l|l}
\hline Conference & Years searched \\
\hline American Academy of Allergy, Asthma and Immunology (AAAAI) & 2001 onwards \\
\hline American Thoracic Society (ATS) & 2001 onwards \\
\hline Asia Pacific Society of Respirology (APSR) & 2004 onwards \\
\hline British Thoracic Society Winter Meeting (BTS) & 2000 onwards \\
\hline Chest Meeting & 2003 onwards \\
\hline European Respiratory Society (ERS) & $1992,1994,2000$ onwards \\
\hline International Primary Care Respiratory Group Congress (IPCRG) & 2002 onwards \\
\hline Thoracic Society of Australia and New Zealand (TSANZ) & 1999 onwards \\
\hline
\end{tabular}

\section{MEDLINE search strategy used to identify trials for the CAGR}




\section{COPD search}

1. Lung Diseases, Obstructive/

2. exp Pulmonary Disease, Chronic Obstructive/

3. emphysema $\$$.mp.

4. (chronic $\$$ adj3 bronchiti\$).mp.

5. (obstruct $\$$ adj3 (pulmonary or lung $\$$ or airway $\$$ or airflow $\$$ or bronch $\$$ or respirat $\$$ )).mp.

6. COPD.mp.

7. COAD.mp.

8. COBD.mp.

9. AECB.mp.

10. or/1-9

\section{Filter to identify RCTs}

1. exp "clinical trial [publication type]"/

2. (randomised or randomised).ab,ti.

3. placebo.ab,ti.

4. dt.fs.

5. randomly.ab,ti.

6. trial.ab,ti.

7. groups.ab,ti.

8. or/1-7

9. Animals/

10. Humans/

11. 9 not (9 and 10)

12. 8 not 11

The MEDLINE strategy and the RCT filter are adapted to identify trials in other electronic databases

\section{Appendix 3. Search to retrieve relevant trials from the CAGR}

\#1 MeSH DESCRIPTOR Pulmonary Disease, Chronic Obstructive Explode All

\#2 MeSH DESCRIPTOR Bronchitis, Chronic

\#3 (obstruct*) near3 (pulmonary or lung* or airway* or airflow* or bronch* or respirat*)

\#4 COPD:MISC1

\#5 (COPD OR COAD OR COBD):TI,AB,KW

\#6 \#1 OR \#2 OR \#3 OR \#4 OR \#5

$\# 7$ indacaterol or QAB149

\#8 salmeterol

\#9 * formoterol

\#10 long* near (beta* near agonist*)

\#11 budesonide

\#12 fluticasone

\#13 mometasone

\#14 inhal* near (corticosteroid* or steroid*)

\#15 tiotropium

\#16 aclidinium or LAS34273

\#17 Glycopyrronium or NVA237

\#18 long* near muscarinic*

\#19 umeclidinium or GSK573719

\#20 vilanterol or GW642444

\#21 (LABA or LAMA or ICS):TI,AB

$\# 22 \# 7$ or \#8 or \#9 or \#10 or \#11 or \#12 or \#13 or \#14 or \#15 or \#16 or \#17 or \#18 or \#19 or \#20 or \#21

$\# 23 \# 6$ and \#22

Long-acting inhaled therapy (beta-agonists, anticholinergics and steroids) for COPD: a network meta-analysis (Review)

Copyright (c) 2014 The Cochrane Collaboration. Published by John Wiley \& Sons, Ltd. 
[Note: in search line \#4, MISC1 refers to the field in which the record has been coded for condition, in this case, COPD]

\section{Appendix 4. SGRQ class effects versus placebo (12 months) ${ }^{a}$}

\begin{tabular}{|c|c|c|c|c|c|c|c|c|}
\hline \multirow[b]{2}{*}{ Class } & \multicolumn{2}{|c|}{$\begin{array}{l}\text { Effect vs placebo } \\
\text { Class NWMA }\end{array}$} & \multicolumn{2}{|c|}{$\begin{array}{l}\text { Effect vs placebo } \\
\text { Sensitivity analysis }\end{array}$} & \multicolumn{4}{|l|}{ Rank } \\
\hline & Median & $95 \% \mathrm{CrI}$ & Median & $95 \% \mathrm{CrI}$ & Mean & Median & $95 \% \mathrm{CrI}$ & $\operatorname{Pr}$ (best) \\
\hline LABA/ICS & -3.60 & $\begin{array}{l}(-4.63 \text { to }-2 . \\
34)\end{array}$ & -3.53 & $\begin{array}{l}(-4.69 \text { to }-2 \text {. } \\
15)\end{array}$ & 1.2 & 1 & (1 to 3 ) & 0.86 \\
\hline LAMA & -2.50 & $\begin{array}{l}(-3.30 \text { to }-1 \\
68)\end{array}$ & -2.56 & $\begin{array}{l}(-3.49 \text { to }-1 \text {. } \\
69)\end{array}$ & 2.9 & 3 & (1 to 4 ) & 0.04 \\
\hline LABA & -2.55 & $\begin{array}{l}(-3.68 \text { to }-1 \text {. } \\
70)\end{array}$ & -2.61 & $\begin{array}{l}(-3.82 \text { to }-1 . \\
68)\end{array}$ & 2.8 & 3 & (1 to 4$)$ & 0.07 \\
\hline ICS & -2.34 & $\begin{array}{l}(-3.45 \text { to }-1 \text {. } \\
27)\end{array}$ & -2.34 & $\begin{array}{l}(-3.58 \text { to }-1 \text {. } \\
16)\end{array}$ & 3.2 & 3 & (1 to 4$)$ & 0.03 \\
\hline
\end{tabular}

${ }^{a}$ For effects versus placebo, smaller values indicate larger benefits of the active treatment

$\mathrm{Crl}=$ credible interval.

SGRQ = St George's Respiratory Questionnaire.

ICS $=$ inhaled corticosteroid.

LABA = long-acting beta 2 -agonist.

LABA/ICS = long-acting beta 2 -agonist/inhaled corticosteroid.

LAMA = long-acting antimuscarinic antagonist.

NWMA = network meta-analysis.

$\operatorname{Pr}=$ probability.

Appendix 5. SGRQ individual treatment effects versus placebo ( 2 months) ${ }^{a}$

\begin{tabular}{|c|c|c|c|c|c|c|c|}
\hline \multirow[b]{2}{*}{ Class } & \multirow[b]{2}{*}{ Treatment } & \multicolumn{2}{|c|}{$\begin{array}{l}\text { Effect vs placebo } \\
\text { Class NWMA }\end{array}$} & \multicolumn{4}{|l|}{ Rank } \\
\hline & & Median & $95 \% \mathrm{CrI}$ & Mean & Median & $95 \%$ CrI & $\operatorname{Pr}$ (best) \\
\hline \multirow[t]{2}{*}{ LABA } & Form $12(2)$ & -2.51 & $\begin{array}{l}(-3.39 \text { to }-1 . \\
73)\end{array}$ & 10.7 & 11 & (4 to 17 ) & 0.00 \\
\hline & Form 24 (2) & -2.71 & $\begin{array}{l}(-4.43 \text { to }-1 . \\
60)\end{array}$ & 8.8 & 8 & (1 to 18$)$ & 0.05 \\
\hline
\end{tabular}




\begin{tabular}{|c|c|c|c|c|c|c|c|}
\hline & Ind $300(1)$ & -2.85 & $\begin{array}{l}(-4.44 \text { to }-1 \\
77)\end{array}$ & 7.8 & 7 & (1 to 17 ) & 0.06 \\
\hline & Ind 6000 & -2.81 & $\begin{array}{l}(-4.38 \text { to }-1 \text {. } \\
74)\end{array}$ & 8.1 & 7 & (1 to 17 ) & 0.05 \\
\hline & Salm 50 (2) & -1.81 & $\begin{array}{l}(-2.62 \text { to }-0 . \\
92)\end{array}$ & 16.0 & 17 & (9 to 18 ) & 0.00 \\
\hline \multirow[t]{7}{*}{ LAMA } & Tio 5 (1) & -2.77 & $\begin{array}{l}(-3.50 \text { to }-2 \text {. } \\
08)\end{array}$ & 8.1 & 8 & (3 to 15$)$ & 0.00 \\
\hline & Tio 10 (1) & -2.83 & $\begin{array}{l}(-4.04 \text { to }-1 \text {. } \\
92)\end{array}$ & 7.6 & 7 & (1 to 16$)$ & 0.03 \\
\hline & Tio 18 (1) & -2.15 & $\begin{array}{l}(-2.88 \text { to }-1 \text {. } \\
33)\end{array}$ & 13.6 & 14 & (6 to 18$)$ & 0.00 \\
\hline & Acl 200 (1) & -2.33 & $\begin{array}{l}(-3.28 \text { to }-1 \text {. } \\
16)\end{array}$ & 12.0 & 12 & (4 to 18 ) & 0.00 \\
\hline & Acl 200 (2) & -2.52 & $\begin{array}{l}(-3.94 \text { to }-1 . \\
08)\end{array}$ & 10.3 & 10 & (2 to 18 ) & 0.02 \\
\hline & Acl 400 (2) & -2.49 & $\begin{array}{l}(-3.89 \text { to }-1 \text {. } \\
04)\end{array}$ & 10.5 & 11 & ( 2 to 18$)$ & 0.02 \\
\hline & Gly 50 (1) & -2.42 & $\begin{array}{l}(-3.31 \text { to }-1 \text {. } \\
40)\end{array}$ & 11.2 & 11 & ( 4 to 18 ) & 0.00 \\
\hline \multirow[t]{3}{*}{ ICS } & Bud 400 (2) & -2.33 & $\begin{array}{l}(-3.48 \text { to }-1 \text {. } \\
21)\end{array}$ & 12.0 & 12 & ( 4 to 18 ) & 0.00 \\
\hline & Flut 500 (2) & -2.16 & $\begin{array}{l}(-2.89 \text { to }-1 . \\
41)\end{array}$ & 13.5 & 14 & (6 to 18$)$ & 0.00 \\
\hline & Mom 400 (2) & -2.51 & $\begin{array}{l}(-3.97 \text { to }-1 . \\
31)\end{array}$ & 10.4 & 11 & (2 to 18 ) & 0.02 \\
\hline \multirow[t]{3}{*}{ LABA/ICS } & $\begin{array}{l}\text { Form-bud 12/ } \\
160(2)\end{array}$ & -3.45 & $\begin{array}{l}(-4.75 \text { to }-1 . \\
62)\end{array}$ & 4.9 & 3 & (1 to 16$)$ & 0.19 \\
\hline & $\begin{array}{l}\text { Form-bud 12/ } \\
320(2)\end{array}$ & -3.74 & $\begin{array}{l}(-4.80 \text { to }-2 . \\
70)\end{array}$ & 2.6 & 2 & (1 to 8$)$ & 0.35 \\
\hline & $\begin{array}{l}\text { Salm-flut 50/ } \\
500(2)\end{array}$ & -3.58 & $\begin{array}{l}(-4.29 \text { to }-2 . \\
85)\end{array}$ & 3.1 & 3 & (1 to 8$)$ & 0.21 \\
\hline
\end{tabular}


${ }^{a}$ For effects versus placebo, smaller values indicate larger benefits of the active treatment. All doses are in micrograms

$\mathrm{Crl}=$ credible interval.

SGRQ = St George's Respiratory Questionnaire.

ICS = inhaled corticosteroid.

LABA = long-acting beta 2 -agonist.

LABA/ICS = long-acting beta 2 -agonist/inhaled corticosteroid.

LAMA = long-acting antimuscarinic antagonist.

NWMA = network meta-analysis.

$\operatorname{Pr}=$ probability.

Appendix 6. FEV 1 class effects versus placebo ( 12 months $)^{a}$

\begin{tabular}{|c|c|c|c|c|c|c|c|c|}
\hline \multirow[b]{2}{*}{ Class } & \multicolumn{2}{|c|}{$\begin{array}{l}\text { Effect vs placebo } \\
\text { Class NWMA }\end{array}$} & \multicolumn{2}{|c|}{$\begin{array}{l}\text { Effect vs placebo } \\
\text { Sensitivity analysis }\end{array}$} & \multicolumn{4}{|l|}{ Rank } \\
\hline & Median & $95 \% \mathrm{CrI}$ & Median & $95 \%$ CrI & Mean & Median & $95 \%$ CrI & $\operatorname{Pr}$ (best) \\
\hline LABA/ICS & 100.80 & $\begin{array}{l}(55.50 \quad \text { to } \\
140.10)\end{array}$ & 100.00 & $\begin{array}{l}(53.77 \text { to } \\
141.50)\end{array}$ & 1.7 & 1 & (1 to 3 ) & 0.5 \\
\hline LAMA & 92.64 & $\begin{array}{l}(56.23 \text { to } \\
129.60)\end{array}$ & 94.23 & $\begin{array}{ll}(56.08 & \text { to } \\
134.30) & \end{array}$ & 2.0 & 2 & (1 to 3 ) & 0.3 \\
\hline LABA & 87.05 & $\begin{array}{ll}(47.28 & \text { to } \\
130.50) & \end{array}$ & 86.88 & $\begin{array}{ll}(46.12 & \text { to } \\
132.00) & \end{array}$ & 2.3 & 2 & (1 to 3 ) & 0.2 \\
\hline ICS & 28.36 & $\begin{array}{l}(-11.93 \text { to } \\
65.70)\end{array}$ & 28.00 & $\begin{array}{l}(-13.34 \quad \text { to } \\
66.90)\end{array}$ & 4.1 & 4 & (4 to 5$)$ & 0.0 \\
\hline $\begin{array}{l}{ }^{a} \text { For effects } \\
\text { Crl = credib } \\
\mathrm{FEV}_{1}=\text { forc } \\
\mathrm{ICS}=\text { inhal } \\
\mathrm{LABA}=\text { lon } \\
\mathrm{LABA} / \mathrm{ICS} \\
\mathrm{LAMA}=\mathrm{lo} \\
\mathrm{NWMA}=\mathrm{r} \\
\mathrm{Pr}=\text { probab }\end{array}$ & $\begin{array}{l}\text { ersus plac } \\
\text { interval. } \\
\mathrm{d} \text { expirato } \\
\text { d corticost } \\
\text {-acting be } \\
\text { long-actir } \\
\text { g-acting at } \\
\text { twork me } \\
\text { ity. }\end{array}$ & $\begin{array}{l}\text { smaller values } \\
\text { lume in one } s \\
\text { gonist. } \\
\mathrm{ta}_{2} \text {-agonist/in } \\
\text { uscarinic antag } \\
\text { alysis. }\end{array}$ & $\begin{array}{l}\text { ndicate lar } \\
\text { cond. } \\
\text { aled corti } \\
\text { onist. }\end{array}$ & enefits of the & ctive tre & tment & & \\
\hline
\end{tabular}


Appendix 7. FEV 1 individual treatment effects versus placebo ( 12 months $)^{a}$

\begin{tabular}{|c|c|c|c|c|c|c|c|}
\hline \multirow[b]{2}{*}{ Class } & \multirow[b]{2}{*}{ Treatment } & \multicolumn{2}{|c|}{$\begin{array}{l}\text { Effect vs placebo } \\
\text { Class NWMA }\end{array}$} & \multicolumn{4}{|l|}{ Rank } \\
\hline & & Median & 95\% CrI & Mean & Median & 95\% CrI & Pr (best) \\
\hline \multirow[t]{4}{*}{ LABA } & Form $12(2)$ & 69.96 & $\begin{array}{l}(33.27 \text { to } 105 . \\
40)\end{array}$ & 12.2 & 13 & (6 to 16$)$ & 0.00 \\
\hline & Ind 300 (1) & 102.20 & $\begin{array}{l}(52.85 \text { to } 169 . \\
30)\end{array}$ & 6.2 & 6 & (1 to 14$)$ & 0.15 \\
\hline & Ind $600(1)$ & 99.22 & $\begin{array}{l}(51.43 \text { to } 162 . \\
50)\end{array}$ & 6.7 & 6 & (1 to 14 ) & 0.10 \\
\hline & Salm 50 (2) & 78.73 & $\begin{array}{l}(36.65 \text { to } 118 . \\
20)\end{array}$ & 10.6 & 11 & (4 to 15$)$ & 0.00 \\
\hline \multirow[t]{6}{*}{ LAMA } & Tio 5 (1) & 96.90 & $\begin{array}{l}(59.78 \text { to } 136 . \\
30)\end{array}$ & 7.0 & 7 & (1 to 14$)$ & 0.04 \\
\hline & Tio 10 (1) & 103.00 & $\begin{array}{l}(61.53 \text { to } 157 . \\
10)\end{array}$ & 5.8 & 5 & (1 to 13 ) & 0.13 \\
\hline & Tio 18 (1) & 82.37 & $\begin{array}{l}(50.63 \text { to } 114 . \\
10)\end{array}$ & 9.9 & 10 & (3 to 15$)$ & 0.01 \\
\hline & Acl 200 (2) & 87.55 & $\begin{array}{l}(28.91 \text { to } 138 . \\
30)\end{array}$ & 8.9 & 9 & (1 to 16$)$ & 0.03 \\
\hline & Acl 400 (2) & 97.26 & $\begin{array}{l}(48.15 \text { to } 159 . \\
00)\end{array}$ & 6.8 & 6 & (1 to 14$)$ & 0.10 \\
\hline & Gly 50 (1) & 91.43 & $\begin{array}{l}(51.93 \text { to } 130 . \\
90)\end{array}$ & 8.0 & 8 & (1 to 14 ) & 0.03 \\
\hline \multirow[t]{4}{*}{ ICS } & Bud 400 (2) & 25.02 & $\begin{array}{l}(-23.30 \text { to } 66 . \\
78)\end{array}$ & 16.7 & 17 & (13 to 19 ) & 0.00 \\
\hline & Bud 750+ (2) & 24.02 & $\begin{array}{l}(-31.55 \text { to } 68 . \\
90)\end{array}$ & 16.8 & 17 & (13 to 19$)$ & 0.00 \\
\hline & Flut $500(2)$ & 27.04 & $\begin{array}{l}(-9.27 \text { to } 61 . \\
93)\end{array}$ & 16.5 & 17 & (14 to 19$)$ & 0.00 \\
\hline & Mom 400 (2) & 38.89 & $\begin{array}{l}(-3.13 \text { to } 87 . \\
00)\end{array}$ & 15.2 & 15 & (9 to 18 ) & 0.00 \\
\hline
\end{tabular}




\begin{tabular}{|c|c|c|c|c|c|c|c|}
\hline \multirow[t]{4}{*}{ LABA/ICS } & $\begin{array}{l}\text { Form-bud 12/ } \\
160(2)\end{array}$ & 99.60 & $\begin{array}{l}(56.01 \text { to } 139 . \\
80)\end{array}$ & 6.4 & 6 & (1 to 14 ) & 0.07 \\
\hline & $\begin{array}{l}\text { Form-bud 12/ } \\
320(2)\end{array}$ & 105.00 & $\begin{array}{l}(66.88 \text { to } 141 . \\
80)\end{array}$ & 5.3 & 5 & (1 to 12 ) & 0.11 \\
\hline & $\begin{array}{l}\text { Salm-flut } 50 / \\
250(2)\end{array}$ & 102.10 & $\begin{array}{l}(35.97 \text { to } 158 . \\
80)\end{array}$ & 6.3 & 5 & (1 to 15 ) & 0.14 \\
\hline & $\begin{array}{l}\text { Salm-flut 50/ } \\
500(2)\end{array}$ & 100.50 & $\begin{array}{l}(59.29 \text { to } 138 . \\
70)\end{array}$ & 6.2 & 6 & (1 to 13 ) & 0.08 \\
\hline
\end{tabular}

${ }^{a}$ For effects versus placebo, smaller values indicate larger benefits of the active treatment. All doses are in micrograms $\mathrm{Crl}=$ credible interval.

$\mathrm{FEV}_{1}$ = forced expiratory volume in one second.

ICS = inhaled corticosteroid.

LABA = long-acting beta 2 -agonist.

LABA/ICS = long-acting beta 2 -agonist/inhaled corticosteroid.

LAMA = long-acting antimuscarinic antagonist.

NWMA = network meta-analysis.

$\operatorname{Pr}=$ probability.

\section{CONTRIBUTIONSOFAUTHORS}

Kayleigh Kew extracted data, assessed trials for methodological quality and otherwise constructed the review. Sofia Dias conducted the network meta-analyses and constructed figures. Chris Cates assisted with statistical issues and clinical interpretation of the results. All authors contributed to the writing of the review.

\section{DECLARATIONSOF INTEREST}

None known.

\section{SOURCES OF SUPPORT}

\section{Internal sources}

- No sources of support supplied 


\section{External sources}

- Kayleigh Kew, UK.

NIHR, Programme grant funding

- Christopher Cates, UK.

NIHR, Programme grant funding

\section{DIFFERENCES BETWEEN PROTOCOLANDREVIEW}

We did not perform a formal cost-effectiveness analysis and instead presented a summary in the discussion. We did not systematically contact trial authors to ask for additional data or risk of bias, and two review authors did not independently extract data. So as not to delay publication, data and risk of bias were cross-checked in studies with extraction in previous reviews by one review author (KMK), and discrepancies were resolved by a second review author (CJC). The objective "How does combining different pharmacological treatments affect the long-term efficacy?" was not addressed and so was removed.

\section{INDEX TERMS}

\section{Medical Subject Headings (MeSH)}

Adrenal Cortex Hormones [therapeutic use]; Adrenergic beta-2 Receptor Agonists [therapeutic use]; Cholinergic Antagonists [therapeutic use]; DNA-Binding Proteins; Delayed-Action Preparations [administration \& dosage]; Muscarinic Antagonists [therapeutic use]; Nuclear Proteins; Pulmonary Disease, Chronic Obstructive [*drug therapy]; Randomized Controlled Trials as Topic

\section{MeSH check words}

Female; Humans; Male; Middle Aged 